Portland State University

PDXScholar

$12-7-2021$

\title{
Parenting and Children's Academic Coping as a Dynamic System: Feedforward, Feedback, and Mediators of Changes Across the School Year
}

Kristen Elizabeth Raine

Portland State University

Follow this and additional works at: https://pdxscholar.library.pdx.edu/open_access_etds

Part of the Developmental Psychology Commons

Let us know how access to this document benefits you.

\section{Recommended Citation}

Raine, Kristen Elizabeth, "Parenting and Children's Academic Coping as a Dynamic System: Feedforward, Feedback, and Mediators of Changes Across the School Year" (2021). Dissertations and Theses. Paper 5846.

https://doi.org/10.15760/etd. 7717

This Thesis is brought to you for free and open access. It has been accepted for inclusion in Dissertations and Theses by an authorized administrator of PDXScholar. Please contact us if we can make this document more accessible: pdxscholar@pdx.edu. 
Parenting and Children's Academic Coping as a Dynamic System:

Feedforward, Feedback, and Mediators of Changes Across the School Year

by

Kristen Elizabeth Raine

A thesis submitted in partial fulfillment of the requirements for the degree of

Master of Science

in

Psychology

Thesis Committee:

Ellen A. Skinner, Chair

Thomas A. Kindermann

Andrew J. Mashburn

Portland State University

2021 
(C) 2021 Kristen Raine 


\title{
PARENTING AND ACADEMIC COPING
}

\begin{abstract}
Using a motivational framework based in self-determination theory (Deci \& Ryan, 1985; Skinner \& Wellborn, 1997), the present study investigated the dynamic system between parenting and children's coping, defined as the ways they handle the everyday difficulties they encounter in school, using a sample of 1,020 students in grades three through six drawn from a larger cohort-sequential study. Three overarching research questions were examined using multiple regression that concerned 1) feedforward effects from parents' initial provision of motivational support (i.e., involvement, structure, and autonomy support) to changes in children's academic coping across the school year, 2) feedback effects from children's initial coping to changes in the same parenting dimensions across the same timeframe, and 3) children's self-system processes of relatedness, competence, and autonomy, and corresponding catastrophizing appraisals as possible mediators of the connection between parenting and changes in coping.
\end{abstract}

Results examining feedforward effects from parenting dimensions to changes in children's coping partially supported study hypotheses, with involvement, structure, and autonomy support uniquely predicting changes in multiple individual ways of coping, but not changes in coping profiles. Theorized feedback effects were more fully supported with both adaptive and maladaptive profiles predicting increases in all three parental dimensions, and multiple individual adaptive and maladaptive ways predicting changes in structure and autonomy support, while changes in involvement were uniquely predicted only by projection. For mediational analyses, parental dimensions and individual ways of 


\section{PARENTING AND ACADEMIC COPING}

coping were only retained for further analyses if they had significant findings for feedforward effects. Of these, results indicated that most self-system processes and catastrophizing appraisals partially mediated the connection between parenting and changes in children's coping across the school year. Exceptions were seen for autonomy and catastrophizing of competence and autonomy, which did not mediate involvement and confusion, respectively, but were instead independent contributors to changes in these ways of coping. Altogether, study findings highlight the important role parents play in fostering constructive coping and buffering against maladaptive coping, and explicate mechanisms underlying these feedforward effects. But even further, they provide preliminary evidence for a conceptualization of the connection between parenting and children's academic coping as a dynamic system with two active social partners that mutually influence each other. Strengths and limitations, as well as implications for future study and practice are discussed. 


\section{PARENTING AND ACADEMIC COPING}

\section{Acknowledgements}

It is with the deepest gratitude that I would like to thank my mentor and thesis chair, Dr. Ellen Skinner, for her consistent and unfailing support, guidance, and kindness during the process of developing, thinking, and writing about this project. Her enthusiasm and genuine care enabled me to persevere and remain resilient during a global pandemic and made a weekly zoom meeting something to look to forward to. I would also like to thank my committee members, Dr. Thomas Kindermann and Dr. Andrew Mashburn for always having sensible and thoughtful advice and keeping me to a "thesis-sized" thesis.

My parents and sister have also played an essential role in the completion of this document and deserve many thanks for providing perspective, love, and support, watching children so I could write for at least an hour at a time, and reminding me to take a deep breath. And finally, I would like to thank my husband, Cody, and my children, Welly and Lily, for putting up with me while I hid out in the attic writing, and always being willing to talk things over, whether about regression results or the adventures of bunny and kitty. 


\section{PARENTING AND ACADEMIC COPING}

\section{Table of Contents}

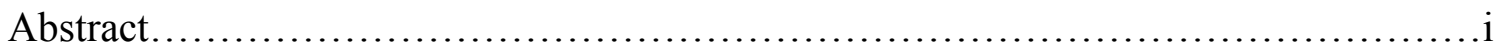

Acknowledgements.............................................................

List of Tables.............................................................................

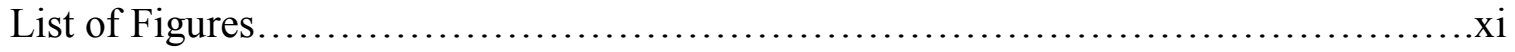

Chapter I. Problem Statement.....................................................

Parenting and Academic Coping ...........................................

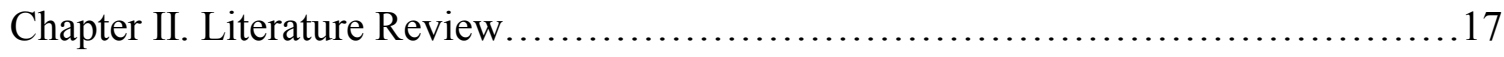

Academic Coping Outcomes..............................................17

Transition to Middle School...............................................22

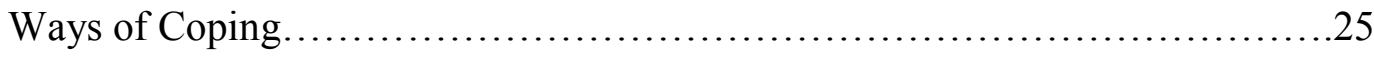

Self-determination Theory as a Conceptual Framework for Academic Coping...31

Parenting and the Development of Academic Coping............................39

Effects of Children's Academic Coping on Parenting...........................52

Children's Self-system Processes as Mediators of Parenting and Academic

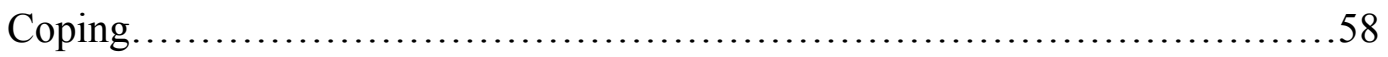

Summary Critique of Research Examining Parenting Effects on Academic

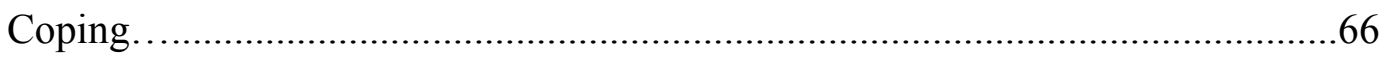

Chapter III. Purpose of Study ...............................................67

Contributions of the Present Study .......................................67

Research Questions and Hypotheses...................................... 83

Chapter IV. Method ........................................................... 91 


\section{PARENTING AND ACADEMIC COPING}

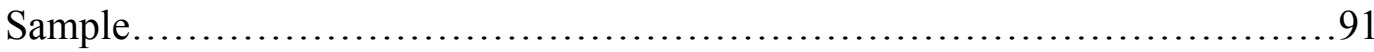

Design and Procedure................................................ 91

Measures.................................................................. 91

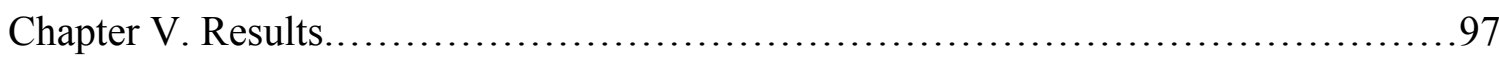

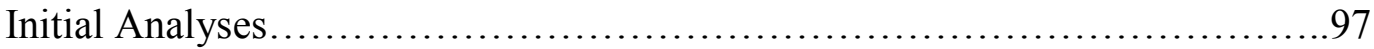

Descriptive Analyses and Measurement Properties...........................98

Research Question 1....................................................111

Research Question 2.......................................................131

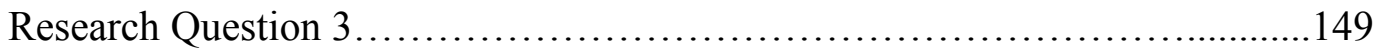

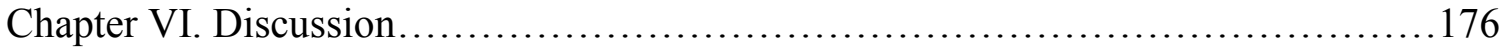

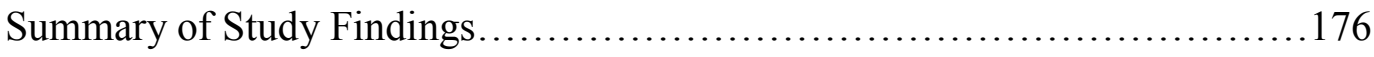

Strengths and Limitations.................................................... 191

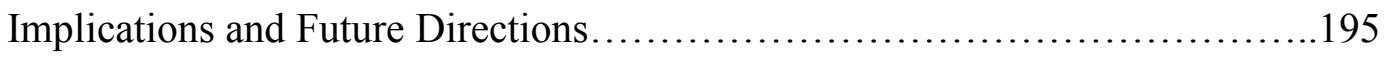

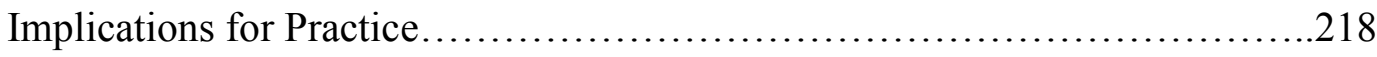

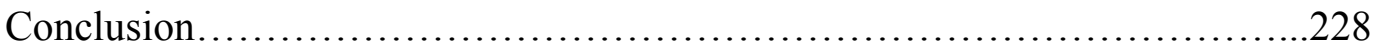

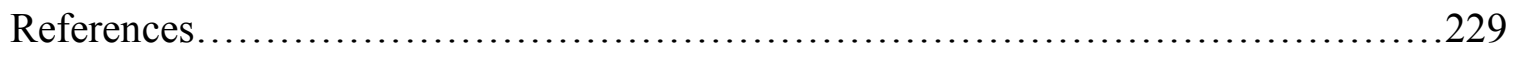

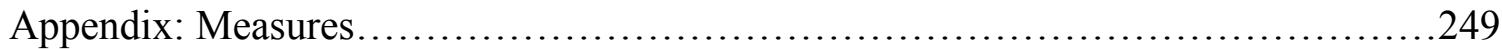




\section{PARENTING AND ACADEMIC COPING}

\section{List of Tables}

Table 2.1. Ways of Coping in the Academic Domain..................................38

Table 2.2. Studies of Parenting and Academic Coping in Children and Youth...........41

Table 2.3. Significant Pearson Correlation Coefficients of Studies on Involvement and

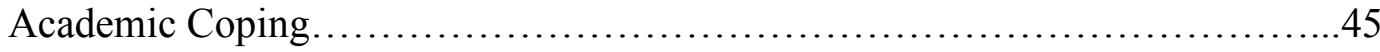

Table 2.4 Significant Pearson Correlation Coefficients of Studies on Structure and

Academic Coping. 47

Table 2.5. Significant Pearson Correlation Coefficients of Studies on Autonomy Support and Academic Coping.

Table 2.6. Mediational Studies of Parenting and Academic Coping.....................61

Table 5.1. Summary of Descriptive Statistics....................................... 102

Table 5.2. Concurrent Correlations between Ways of Academic Coping in the Fall and in the Spring 104

Table 5.3. Concurrent Correlations between Parent Motivational Supports in the Fall and in the Spring .105

Table 5.4. Concurrent Correlations between Children's Self-system Processes and

Catastrophizing in the Fall and in the Spring. 106

Table 5.5 Concurrent Correlations between Parenting and Academic Coping Variables in the Fall and in the Spring 107

Table 5.6. Concurrent Correlations between Parenting, Self-system, and Catastrophizing Variables in the Fall and in the Spring..... 108 


\section{PARENTING AND ACADEMIC COPING}

Table 5.7. Concurrent Correlations between Academic Coping Allocation Scores, Selfsystem, and Catastrophizing Variables in the Fall and in the Spring.............109

Table 5.8. Correlations between Fall Parenting and Spring Academic Coping

Variables

Table 5.9. Regression Analyses Predicting Changes in Adaptive Coping Profiles from Individual Parenting Variables in Fall

Table 5.10. Regression Analyses Predicting Individual Adaptive Ways of Coping in Spring from Parental Motivational Supports in Fall while Controlling for Same

Way of Coping in Fall

Table 5.11. Regression Analyses Predicting Individual Adaptive Ways of Coping in Spring from Parental Motivational Supports in Fall.

Table 5.12. Regression Analyses Predicting Changes in Individual Adaptive Ways of Coping in Spring from Individual Parental Motivational Supports in Fall.......121

Table 5.13. Regression Analyses Predicting Changes in Maladaptive Coping Profiles in the Spring from Individual Parenting Variables in the Fall. 124

Table 5.14. Regression Analyses Predicting Changes in Individual Maladaptive Ways of Coping in Spring from Parental Motivational Supports in Fall. 126

Table 5.15. Regression Analyses Predicting Individual Maladaptive Ways of Coping in Spring from Parental Motivational Supports in Fall. 128

Table 5.16. Regression Analyses Predicting Changes in Individual Maladaptive Ways of Coping in the Spring from Individual Parenting Variables in the Fall 130 


\section{PARENTING AND ACADEMIC COPING}

Table 5.17. Correlations between Fall Academic Coping and Spring Parenting

Variables

Table 5.18. Regression Analyses Predicting Parental Motivational Supports from

Adaptive Coping.

Table 5.19. Regression Analyses Predicting Parental Motivational Supports from Individual Adaptive Ways of Coping controlling for Fall Motivational Support Variable

Table 5.20. Regression Analyses Predicting Parental Motivational Supports in Spring from Individual Adaptive Ways of Coping in Fall

Table 5.21. Regression Analyses Predicting Changes in Parental Motivational Supports from Fall to Spring from each Individual Adaptive Way of Coping in Fall......139

Table 5.22. Regression Analyses Predicting Changes in Parental Motivational Supports from Fall to Spring from Maladaptive Coping Profiles in Fall

Table 5.23. Regression Analyses Predicting Parental Motivational Supports in Spring from Individual Maladaptive Ways of Coping in Fall Controlling for Individual

Fall Motivational Support

Table 5.24. Regression Analyses Predicting Parental Motivational Supports in Spring from Individual Maladaptive Ways of Coping in Fall

Table 5.25. Regression Analyses Predicting Changes in Parental Motivational Supports from Fall to Spring from each Individual Maladaptive Way of Coping in Fall..148

Table 5.26. Correlations between Parenting in the Fall, Self-systems in the Spring, and

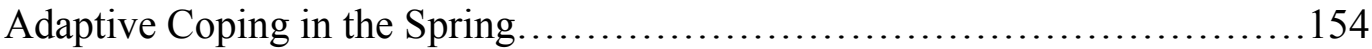




\section{PARENTING AND ACADEMIC COPING}

Table 5.27. Children's Self-system Processes in Spring as Mediators of the Effects of Involvement in the Fall on Changes in Strategizing from Fall to Spring.........156

Table 5.28. Children's Self-system Processes in Spring as Mediators of the Effects of Structure in the Fall on Changes in Help-seeking from Fall to Spring...........158

Table 5.29. Children's Self-system Processes in Spring as Mediators of the Effects of Involvement in the Fall on Changes in Comfort-seeking from Fall to Spring...160

Table 5.30. Children's Self-system Processes in Spring as Mediators of the Effects of Involvement in the Fall on Changes in Commitment from Fall to Spring........162

Table 5.31. Correlations between Parenting in the Fall, Catastrophizing in the Spring, and

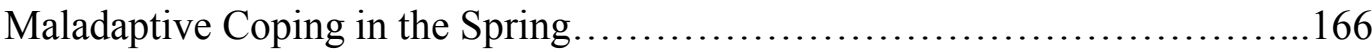

Table 5.32. Children's Catastrophizing Appraisals in Spring as Mediators of the Effects of Involvement and Structure in the Fall on Changes in Confusion from Fall to

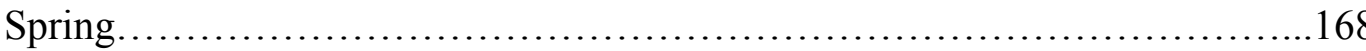

Table 5.33. Children's Catastrophizing Appraisals in Spring as Mediators of the Effects of Involvement in the Fall on Changes in Concealment from Fall to Spring.....170

Table 5.34. Children's Catastrophizing Appraisals in Spring as Mediators of the Effects of Structure in the Fall on Changes in Self-pity from Fall to Spring..............172

Table 5.35. Children's Catastrophizing Appraisals in Spring as Mediators of the Effects of Involvement in the Fall on Changes in Projection from Fall to Spring 174

Table 6.1. Summary of Study Findings for Research Question 1: Effects of Initial Parenting Dimensions on Changes in Academic Coping..... 180 


\section{PARENTING AND ACADEMIC COPING}

Table 6.2. Summary of Findings for Research Question 2: Feedback Effects from

Children's Academic Coping to Changes in Parental Motivational Supports....183 


\section{PARENTING AND ACADEMIC COPING}

\section{List of Figures}

Figure 1.1. A Motivational Model of Academic Coping................................4

Figure 2.1. A Self-determination Theory Based Model of Children's Academic

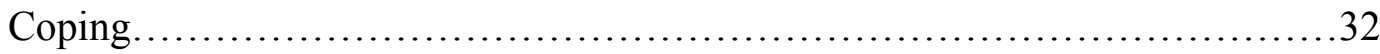

Figure 3.1. The Dynamic Relationship between Parenting and Children's Adaptive and

Maladaptive Coping........................................................ 68

Figure 3.2. Hypothesized Relationship Between Parental Provisions and Adaptive

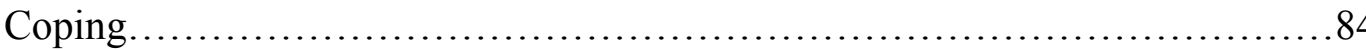

Figure 3.3. Hypothesized Relationship Between Parental Motivational Supports and

Maladaptive Coping Profiles and Individual Ways...............................85

Figure 3.4. Feedback Effects from Children's Adaptive Coping to Parental Motivational

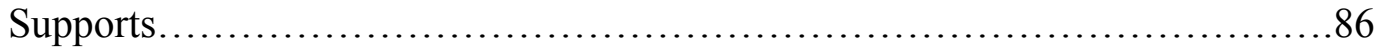

Figure 3.5. Feedback Effects from Children's Maladaptive Coping to Parent's Offering of

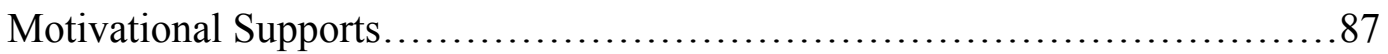

Figure 3.6. Children's Self-system Processes as Mediators of Parents' Motivational

Supports and Children's Academic Coping .....................................89

Figure 3.7. Children's Catastrophizing Appraisals as Mediators of Parental Motivational

Supports and Maladaptive Academic Coping................................99

Figure 5.1. Regression Coefficients for all Fall Parenting Motivational Supports Predicting Spring Adaptive Coping While Controlling for Fall Adaptive Coping. 


\section{PARENTING AND ACADEMIC COPING}

Figure 5.2. Unique Effects from Parent Motivational Supports in Fall to Adaptive Coping in Spring 114

Figure 5.3. Parenting Support Variables in the Fall Predicting Spring Maladaptive Coping While Controlling for Fall Maladaptive Coping.

Figure 5.4. Parental Provision of Motivational Support in the Fall Predicting Maladaptive Coping in the Spring......................................................... 124

Figure 5.5. Children's Self-system Processes and Catastrophizing Appraisals as Mediators of Parental Motivational Supports and Academic Coping 152

Figure 6.1. Summary of Findings for Research Question 3a: Children's Self-system Processes Tested Individually as Mediators of Parental Motivational Supports and Adaptive Coping. 188

Figure 6.2. Summary of Findings for Research Question 3b: Children's Catastrophizing Appraisals Tested Individually as Mediators of Parental Motivational Supports and Maladaptive Coping 189 


\section{PARENTING AND ACADEMIC COPING}

\section{Chapter I. Problem Statement}

As part of their everyday school experience, students are confronted with challenging and demanding tasks. In response to these challenges, children engage in academic coping, defined here as the patterns of action (including goal-directed behaviors and emotions) students use on the ground to deal with the problems, difficulties, and obstacles they encounter daily in their schoolwork. The extent to which students cope constructively can make a material difference to their academic functioning and development over time. Previous research has shown that children who use adaptive coping strategies experience a host of positive outcomes, including greater engagement, persistence, re-engagement, learning and deeper processing when learning, feelings of effectiveness, and overall life satisfaction (Skinner \& Saxton, 2019). Through adaptive coping processes, children also learn how to handle future stressors more constructively, leading not only to the wide range of positive outcomes mentioned above, but also to the increased use of more productive coping strategies when dealing with academic challenges in the future.

The development of effective strategies for dealing with academic challenges and demands may be especially important during late elementary and early middle school, as students approach and deal with the transition to middle school. This transition has proven normatively stressful for many students, based in part on the dramatic differences between elementary and middle school environments (Eccles \& Roeser, 2009). These changes, including larger class sizes, impersonal schools, higher levels of competition and social comparison, less interesting schoolwork, and more coercive teaching, coincide 


\section{PARENTING AND ACADEMIC COPING}

with a developmental period that requires more autonomy, belongingness, and feelings of mastery (Eccles \& Roeser, 2009; Wigfield et al., 2015). Because this misalignment between the needs of adolescents and the resources schools provide may result in higher levels of stress, the ability to cope with academic challenges and setbacks may take on an especially important role during this transition.

Although there is broad consensus in the field regarding the importance of coping, there is little agreement among researchers about what constitutes adaptive and maladaptive ways of coping. Disagreement about the core categories of coping can be seen in the measures of academic coping used in the field today. Currently there are 22 measures of academic coping that assess differing and partially overlapping categories of coping. Ways of coping included on these scales diverge in both their definitions and labels: Some assess the same category of coping but use different labels, some use the same labels to refer to different kinds of coping. In fact, of these 22 measures, no two include the same set of categories of coping.

To some extent, confusion about adaptive and maladaptive ways of coping stems from the "double-edged" nature of particular strategies, which may not clearly be "good" or "bad," but instead potentially have both positive and negative effects. For example, help-seeking is classified as an adaptive way of coping because it allows children to access effective strategies from knowledgeable adults or peers, but it may also allow the child to avoid taking responsibility for the task and instead "delegate" it to the other person. Similarly, rumination is a maladaptive strategy because it is associated with ongoing anxiety and distress. However, it also includes high levels of involuntary 


\section{PARENTING AND ACADEMIC COPING}

engagement, which can make it appear, at least to onlookers, like a positive coping strategy. The cloudiness surrounding conceptions of academic coping may also be due to its emergence out of research on coping more generally, which focuses largely on individual differences in how adults deal with traumatic major life events (e.g., health crises, criminal victimization, bereavement) and the function of coping in warding off harm and reestablishing equilibrium. It is not clear whether this model of coping is useful in conceptualizing the kinds of everyday coping enacted by children in academic settings, where demands are normative, and the function of coping is to foster learning and promote healthy development.

To focus our understanding of coping on children's experiences in their day-today lives within the academic domain, I have applied a motivational and developmental framework based in self-determination theory (SDT; see Figure 1, Deci \& Ryan, 1985; Skinner \& Wellborn, 1994, 1997). This framework suggests that children's coping is rooted in three fundamental psychological needs-- for relatedness, competence, and autonomy; and is triggered in response to threats to those needs (sometimes marked by catastrophizing appraisals) and shaped by self-appraisals (conceptions about themselves and the world around them). From this perspective, children's coping efforts are built upon the social interactions they experience over time and these interactions can support or hinder the subsequent development of their coping capacities.

Expanding upon this idea, the motivational framework identifies a set of productive coping strategies children can use, such as strategizing, help-seeking, comfortseeking, self-encouragement, and commitment, that are considered adaptive precisely 


\section{PARENTING AND ACADEMIC COPING}

because they help students access effective strategies and replenish emotional and motivational resources they can then redeploy to reengage more constructively with academic demands. It also identifies maladaptive ways that children can cope, such as escape, confusion, concealment, self-pity, rumination, and projection. These ways of coping are considered unproductive because they can contribute to higher subsequent levels of school-related stress, psychological distress, and giving up when faced with difficulty, as well as undermine engagement, re-engagement, and persistence. They also foster negative views of school, schoolwork, and the child's own ability, as well as push away other individuals that might offer help, such as parents, teachers, and peers.

Figure 1.1

A Motivational Model of Academic Coping

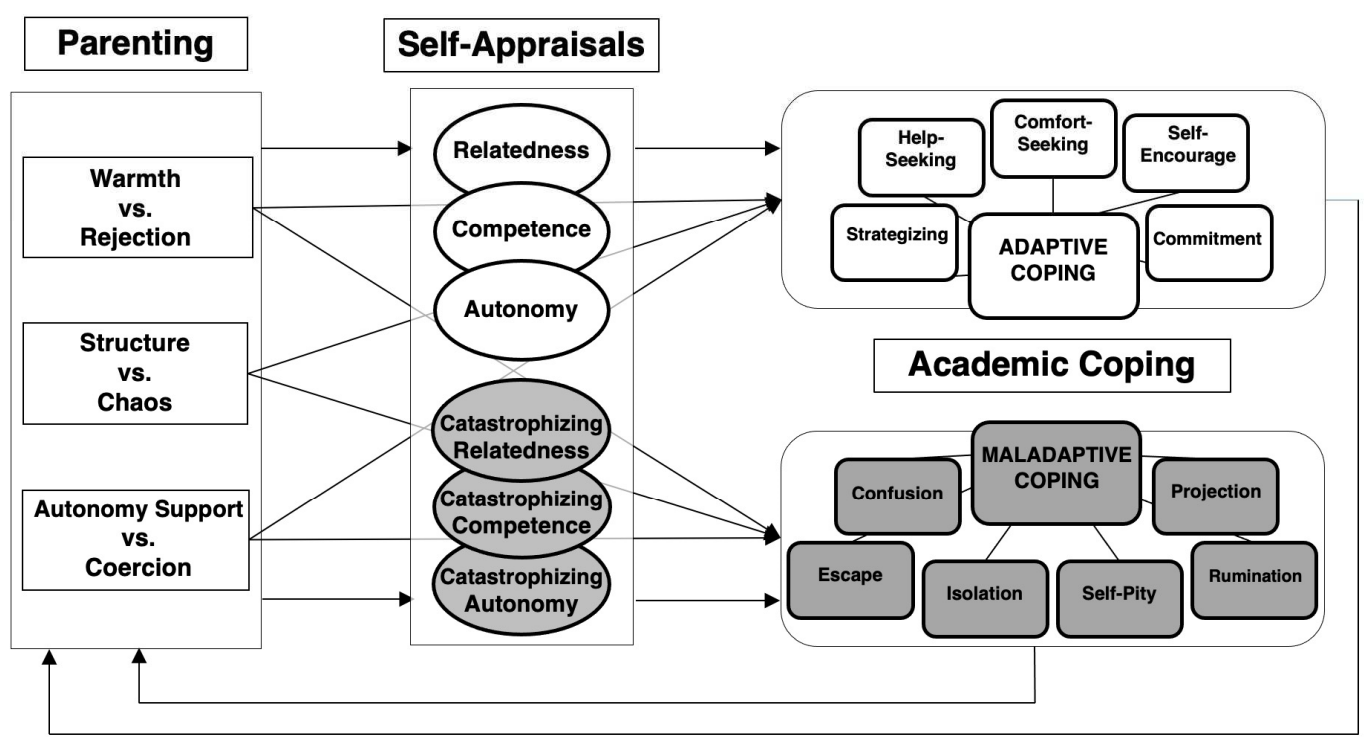




\section{PARENTING AND ACADEMIC COPING}

\section{Parenting and Academic Coping}

Parents or other primary caregivers, as the immediate adults in children's lives, have a unique ability to influence the development of these coping abilities. Multiple studies, including a handful in the academic domain, demonstrate that high-quality parenting facilitates more adaptive coping and buffers children against the use of

maladaptive coping strategies (Power, 2004; Raftery et al., 2012). However, theories and studies do not converge on what features of parenting are most supportive or the mediating processes through which parenting has its effects, and none focus on the dynamic process through which children's coping may shape the kinds of supports they receive. This study aims to separate these feedforward and feedback effects through the use of longitudinal data analysis as well as to propose mediators rooted in a motivational framework in order to test specific mechanisms through which parents affect academic coping.

Parenting provisions that shape academic coping. SDT highlights the role that parents can play in the development of academic coping through their day-to-day interactions with children in which they provide psychological resources and motivational supports. This perspective suggests that parents can contribute to the development of positive coping strategies and protect children from the use of maladaptive strategies by offering specific resources that bolster their psychological needs for relatedness, competence, and autonomy. These specific supports have been described by research on SDT as parental involvement, structure, and autonomy support (Skinner et al., 2005). 


\section{PARENTING AND ACADEMIC COPING}

Parental involvement refers to emotional support that includes, love, warmth, and affection as well as emotional availability and responsiveness; while the lack of this resource is characterized by rejection, hostility, neglect, or harsh, critical parenting. When children run into difficulties and parents respond with warmth, affection, and support, their offspring should be able to cope more constructively. Most obviously, children would be encouraged to cope via comfort and help seeking, and thereby gain access to further parental reassurance, guidance, and understanding. However, emotional support may not only foster adaptive ways of coping that involve turning to others. Attachment theory suggests that having a secure, loving base enables a child to be more independent and self-sufficient, which subsequently may lead them to engage in more problemsolving on their own (via strategizing coping), bolster their own flagging spirits (via selfencouragement), and support themselves motivationally (via commitment). This type of emotional presence also buffers against the use of more maladaptive strategies, most obviously lessening the extent to which students feel they need to conceal the problems they are having or how sorry they feel for themselves, but also reducing the likelihood they will blame others (via projection coping), obsess over their shortcomings (via rumination), or retreat into a fantasy world (via avoidance or escape coping).

A second way SDT suggests that parents can provide motivational resources during coping is captured by the construct of parental structure. Structure refers to the instrumental support parents give their children when they provide guidelines, advice, well-scaffolded assistance, and set developmentally appropriate limits; the opposite of structure can be referred to as chaos and is characterized by parenting that is 


\section{PARENTING AND ACADEMIC COPING}

unpredictable, permissive, or neglectful. When parents respond to a child's problems and difficulties with clear expectations and suggestions for effective action, this allows that child the opportunity to try out these tactics, thus fostering strategizing coping. Such parental actions also make it more likely that children will go to their parents for help and comfort since they are being handed effective supports. Parents who provide ideas about how to deal with challenging situations also lead students to feel encouraged and much more committed to actually completing the task, thus fostering other adaptive ways of coping like self-encouragement and commitment. In contrast, a lack of parental structure in the face of difficulty contributes to confusion in children's coping and may suggest that their only option is avoiding and concealing their problems because they are uncertain of what their parents will do or think when they find out. Similarly, unpredictable parent behavior may lead children to feel sorry for themselves, resulting in self-pity, focus on their failures and distress (via rumination coping), or blaming others (as seen in projection coping).

Finally, parents foster children's coping by supporting their children's autonomy. Autonomy supportive parents genuinely follow their children's lead, paying attention and providing asked for support, but not taking over for their child during a task; the flip side of this is coercion, when parents are controlling, over-involved, or use guilt or shame to get their children to behave. When children encounter problems, the presence of parents who encourage their child to attempt things on their own may lead to the use of more adaptive coping strategies. Children may feel more encouraged to attempt new ideas and problem-solving strategies, feel encouraged that they can handle things on their own (as 


\section{PARENTING AND ACADEMIC COPING}

seen in self-encouragement coping) and therefore commit more to completing the task (via commitment coping). Less obviously, autonomy support can also help children feel more welcome to seek help and comfort from a parent who has made it clear that the child is still in charge but has a "helpful friend in their corner." Without this support, children may get stuck, unable to figure out how to come up with strategies on their own (and so show confusion coping), or feel so coerced that they retreat through mental escape or lash out at others (via projection coping). The pressure created by a lack of autonomy support may lead anxious children to ruminate over their failures, feel sorry for themselves, or conceal their difficulties pulling inside rather than reaching out for the comfort or help they need.

In sum, SDT suggests that these three parental provisions, namely, involvement, structure, and autonomy support, are key in nurturing the development of children's constructive coping in the academic domain and protect them from falling back on the use of unproductive or maladaptive responses to problems and difficulties with their schoolwork. These motivational resources may be especially important to students during the run up to and across the transition to middle school, as students prepare to take on the additional challenges and demands typically associated with this school transition. Hence, the first research question in the current study addressed this connection, and examined whether the involvement, structure, and autonomy support parents provide at the beginning of the school year predict changes in third through sixth graders' academic coping from fall to spring of the same school year. Following the ways of coping identified by SDT, these connections were examined for five adaptive strategies (i.e., 


\section{PARENTING AND ACADEMIC COPING}

strategizing, help-seeking, comfort-seeking, self-encouragement, and commitment) and six maladaptive ways of coping (i.e., escape, confusion, concealment, self-pity, rumination, and projection).

\section{Feedback effects from children's coping to parent provision of support.}

Research has focused on how parents shape children's coping, but much less is said about how children's coping behaviors and actions may impact parent's future provision of motivational supports. SDT, with its underlying organismic-dialectical metatheory, suggests that the parent-child relationship is inherently dynamic: An active individual (the child) is bringing their whole self when engaging with an active and changing context (the parent) who is providing its own affordances to that individual. Previous literature, beginning with Bell in 1968, highlights the reciprocal nature of these interactions by hypothesizing feedback effects from child to parent, suggesting that parents alter their behavior based upon their children's actions and temperament (citations), although no research to date has specifically examined whether children's coping has an effect on the motivational supports their parents subsequently offer.

The dynamic, bidirectional nature of the relationship between parent and child described by SDT and previous research suggests there may be direct feedback effects from children's coping to subsequent parent support. Constructive coping strategies may actively pull parents in, whereas maladaptive ones can push them away or exacerbate already tense relationships. A child who asks for comfort from a parent is drawing out warmth and involvement and the parent is more likely to react warmly in the future. Similarly, if children are consistently coming to parents for help, they are more likely to 


\section{PARENTING AND ACADEMIC COPING}

hand that child helpful strategies in the future, even without an explicit ask for assistance. In contrast, parents whose children instead cope with difficult homework by blaming the parent (through projection) may react with hostility or rejection, leading to the further use of projection or other maladaptive strategies in the future. Additionally, a child who is using escape or concealment as a strategy to deal with challenging tasks may be actively avoiding engaging with their parents, leading parents to withdraw future involvement.

As these interactions persist over time, a feedback loop may be established that perpetuates and increases either adaptive or maladaptive coping strategies and positive or negative parental support. A "virtuous" cycle can be created, if parental motivational supports lead children to use more adaptive coping strategies, which in turn result in the provision of additional involvement, structure, and autonomy support. Over time, this dynamic should increase a child's ability to constructively cope with challenge.

Alternatively, a "vicious" cycle of maladaptive coping could be imagined, where without parental motivational support a child is more inclined to use maladaptive strategies, pushing their parents further away, increasing their likelihood of using less constructive strategies in the future. As these proximal processes between parent and child continue to unfold over time, they become the engine of the development of academic coping, materially impacting the overall arc of children's academic experiences. Therefore, an important issue that the current study addressed was the possible connection between children's initial overall coping profile and individual ways of coping, and changes in parents' subsequent offering of motivational supports across the school year. 


\section{PARENTING AND ACADEMIC COPING}

\section{Processes mediating the relationship between parental supports and}

children's academic coping. Multiple studies indicate that supportive parent behavior can promote constructive coping in children, but much less is known about the mediational pathways through which parents exert their impact. Self-determination theory suggests a possible mechanism by which interpersonal supports promote children's coping strategies, namely by nurturing children's self-system processes. Parental provisions of involvement, structure, and autonomy support can shape the development of these personal resources, specifically the self-system processes of relatedness, competence, and autonomy, so that children have them available to draw upon in times of stress, and in turn the store of resources that children build up can impact how constructively they will cope with this stress. Thus, these self-system processes may be a means by which parental motivational support is shaping children's academic coping. At the same time, a lack of parental support may put children at risk when they encounter academic stresses, making it more likely for them to catastrophize about these events. These kinds of catastrophizing appraisals, especially when they are focused on relatedness, competence, and autonomy, may render children more likely to fall back on maladaptive ways of coping.

Relatedness. The first of the mediational processes through which interpersonal resources may shape coping is relatedness. A sense of relatedness refers to the beliefs children hold about their own worthiness of affection, security, and belonging, based on the internal working models they have constructed from interactions with their attachment figures. The feature of parenting most central to relatedness is involvement. A 


\section{PARENTING AND ACADEMIC COPING}

context rich in love, affection and warmth that is characteristic of high parental involvement teaches children that they are worthwhile human beings who are valued by the people around them. Structure can also bolster relatedness through caregiver behavior that is responsive, predictable, consistent, and supportive, strengthening human connection and upholding the knowledge that parents are a dependable source of assistance. Parental provision of autonomy support may also strengthen relatedness in its unconditional support and acceptance of children's genuine, true self, signaling that their caretaker has the child's best interests at heart and truly values the child's opinions and goals.

Children who have high relatedness, that is, who experience themselves as lovable and worthwhile, may be more likely to turn to adaptive coping methods in times of academic stress. When students feel connected and that they belong they are more able to seek trusted others when they encounter problems. Secure attachments not only allow them to turn to others for comfort and help but also encourages the independence characteristic of other forms of coping. These feelings of security and belief in themselves may also lead to constructive coping that includes self-encouragement, strategizing, and commitment. Without these nutriments, when children encounter academic problems, they may catastrophize about how their difficulties threaten the extent to which they belong or feel connected, leading to feelings of insecurity, rejection, and shame. These feelings may make children especially vulnerable to maladaptive ways of coping. Specifically, such catastrophizing appraisals may make it more likely for children to conceal their problems or pity themselves, and not having a trusted other to 


\section{PARENTING AND ACADEMIC COPING}

turn to in times of need may lead them to become more confused, try to escape, or fall into rumination or blaming others for their problems.

Competence. A second appraisal through which parenting may affect children's academic coping is competence. Perceived competence refers to the feeling that one's actions are effective in achieving desired outcomes. These self-systems have also been studied as self-efficacy, effectance, perceived control, and conceptions of ability (Bandura, 1997; Elliot \& Dweck, 2005; Skinner, 1995; White, 1959). Parental structure supports a child's sense of competence through scaffolded guidance, provision of strategies, and modeling of effective behavior that can help children understand how their actions lead to intended results. Without this scaffolding, children may flounder, falling victim to feelings of incompetence as they struggle with demanding tasks. Warmth and involvement are also vital to competence because parent's affection and caring give children a sense of confidence that they have what it takes to succeed academically. Autonomy supportive parenting bolsters competence by allowing children the freedom to try out their own ideas and learn from their own mistakes, thereby supporting real learning. This also reinforces the notion that failure and mistakes are not horrific setbacks to be avoided, but instead a natural part of the learning process.

When faced with difficult academic tasks, feeling able to effect desired change can lead children to more constructive coping. Competence specifically supports strategizing and help-seeking behaviors when coping, as children feel confident enough in their own abilities to try out different solutions to their problems and understand the value of seeking advice about more effective strategies. Additionally, a child who feels 


\section{PARENTING AND ACADEMIC COPING}

more self-efficacious is more likely to encourage themselves to continue working or renew their commitment to a difficult task. These feelings may even support comfortseeking behaviors as children who feel confident may find it easier to go to other people not just for help but for emotional support. When feelings of competence are low and children encounter difficulty, a catastrophizing appraisal may be triggered in which they perceive this difficulty as evidence of their incompetence and "stupidity." If children pessimistically view themselves as so incapable that they will always fail, these appraisals may lead them to react to academic stress with confusion or escape, as their feelings of stress overwhelm their ability to come up with solutions. Feeling pessimistic and "idiotic" could also lead a child to conceal their struggles, wanting to hide any perceived outward signs of incompetence from others and subsequently eliminating the opportunity to rely on others for assistance. Additionally, children may get lost in ruminating on their perceived incompetence, or lash out, blaming others to avoid feelings of failure.

Autonomy. The third mechanism through which parents can affect children's coping is autonomy. Perceived autonomy refers to the extent to which children feel free to express their true, authentic selves, ideas, preferences, and goals. In the academic realm, this can be expressed through the personal endorsement of the value of the activities that students are involved in, as well as genuine enthusiasm for academic tasks. The primary way in which parents can nurture autonomy is through autonomy support. Parental autonomy support can increase feelings of autonomy in children by directly encouraging the expression of their inner selves, respecting their opinions and desires, 


\section{PARENTING AND ACADEMIC COPING}

and fostering healthy independence. Parents also help strengthen autonomy through their provision of involvement by being available, warm, and affectionate - a secure base to return to in times of stress that is unconditional and not contingent upon the child's actions and behaviors. Children whose parents love them for who they genuinely are feel freer to express their true thoughts, feelings, and ideas. Parental structure can also fulfill this need through the provision of clear rules, limits, and guidance that help children develop the tools to successfully make their own informed, independent choices.

A sense of autonomy, that is, being able to freely express their true inner selves may enable children to use more constructive coping strategies when encountering academic difficulty. A strong sense of autonomy promotes commitment as a coping strategy as children feel they can motivate themselves to continue working and renew their belief in the value of the activity. These feelings can also promote other ways of adaptive coping as students take ownership of the task, bolstering problem-solving, selfencouragement, and even seeking help or comfort, as the child remains invested enough to recognize they may need additional strategic or emotional resources from others. Without a strong sense of autonomy, when children encounter academic stressors, they may be more likely to interpret difficulty as a deeply personal failure that "salts the earth" of the academic task. Feeling alienated from the academic work and as if everything is ruined may lead children to fall into intense self-blame which can in turn lead them to rumination, obsessing over their own shortcomings, or projection, focusing the blame on others. These feelings may also result in self-pity, escape, concealment, or confusion, as 


\section{PARENTING AND ACADEMIC COPING}

children struggle to come up with productive methods for dealing with their problems when experiencing these internal pressures.

Theories and research grounded in SDT suggest that interpersonal supports provided by parents can promote children's self-system processes and buffer them from catastrophizing appraisals when they encounter academic problems and setbacks. At the same time, work form SDT also suggests that these personal resources play an important role in shaping the kinds of academic coping a student eventually employs. Hence, the third primary question examined in the current study was whether these three self-system processes mediate the connections between the dimensions of parenting specified by SDT and the kinds of coping that are prevalent when students are dealing with academic problems.

Before the details of the present study are explained, I will provide a literature review (Chapter II) that contains evidence supporting the arguments made in this problem statement, and a detailed description of the purpose of study, research questions, and hypotheses (Chapter III). Then the study design and methods will be described (Chapter IV), followed by study results (Chapter V), and a subsequent discussion of strengths, limitations, and implications for future research and practitioners (Chapter VI). 


\section{PARENTING AND ACADEMIC COPING}

\section{Chapter II. Review of the Literature}

\section{Academic Coping Outcomes}

Children's ability to constructively cope with the demands placed on them in school is associated with numerous positive outcomes, including both academic performance and functioning. Adaptive coping profiles, or those built upon the consistent use of individual constructive ways of coping, have been linked with higher grades and achievement test scores as well as greater learning, engagement and re-engagement, persistence, and feelings of effectiveness and life satisfaction (Skinner \& Saxton, 2019). In the realm of academic achievement, Gonçalves et al. (2019), found that adaptive ways of coping such as problem-solving, support-seeking, and accommodation, as well as an over-all adaptive coping profile, were positively associated with higher math and language grades in fourth, sixth and ninth grade students. Consistent with this pattern of results, maladaptive coping strategies were similarly negatively correlated with subject grades. Beyond school performance, a short-term longitudinal study of fourth through sixth grade students found that the use of adaptive coping strategies in the fall predicted increases in persistence and re-engagement across the school year and, to a lesser degree, protected students from giving up when faced with difficulty (Skinner et al., 2016). These researchers also found that the use of maladaptive coping strategies in the fall lead to somewhat decreased persistence and a marked increase in giving up from fall to spring.

Outcomes of individual ways of coping. In addition to the benefits of a generally adaptive coping profile, specific adaptive coping strategies have also been shown to positively shape achievement and motivational outcomes. For example, children's ability 


\section{PARENTING AND ACADEMIC COPING}

to problem-solve solutions in the face of difficult tasks (i.e., strategizing) has been consistently found to be a predictor of higher levels of school performance, reengagement, persistence, and life-satisfaction, and lower levels of giving-up and burnout (Skinner \& Saxton, 2019). Both studies mentioned above confirmed this pattern of results with higher levels of problem-solving both being associated with higher grades at a single time point (Gonçalves et al., 2019), as well as predicting increases in persistence (Skinner et al., 2013) and re-engagement across the school year (Skinner et al., 2016). Even further, higher initial levels of problem-solving in the fall predicted decreases in giving up from fall to spring (Skinner et al., 2016). Problem-solving has also been shown to impact other indicators of psychological well-being, with higher levels being associated with lower levels of emotional exhaustion, cynicism, psychopathology, school suspension, and burnout in middle and high schoolers (Boon, 2011; Shih, 2015a, 2015b; Suldo et al., 2018). This wealth of evidence, both cross-sectional and longitudinal, support the conception of problem-solving, and possibly other adaptive coping strategies, as a powerful coping tool that is facilitating student learning, engagement, and motivation. Other adaptive ways of coping, such as help-seeking and commitment, have generally found similar patterns of results, though less empirical work has been done with these individual ways of coping, and results have been less consistent possibly due to the reliance upon average coping scores, that do not factor in overall level of a child's need to cope, over allocation scores, that do include total coping in their calculation (Skinner \& Saxton, 2019). Using strategizing as a clear example, this research suggests that individual ways and general adaptive coping profiles both bolster motivational and 


\section{PARENTING AND ACADEMIC COPING}

achievement outcomes, as well as protect against harmful ones, though further research delineating how beneficial each individual way may be would further clarify our understanding.

Similar to strategizing, escape, as an individual way of maladaptive coping, has the largest body of evidence of its influence on academic outcomes. In multiple studies, students who more often used escape to handle the difficulties they encountered at school experienced higher levels of school burnout, academic stress, disengagement, and giving up in the face of difficulty, as well as lower levels of re-engagement, persistence, and interest in math (Arsenio \& Loria, 2014; Lau \& Nie, 2008; Skinner et al., 2016; Suldo et al., 2018). Evidence for poorer well-being outcomes for students who relied more upon escape is also present, including greater emotional exhaustion, cynicism, psychopathology, and behavior problems (Eppelmann et al., 2016; Shih, 2015a, 2015b; Suldo et al., 2018). Other individual maladaptive ways of coping have also been connected to poorer academic outcomes, but have been studied much less often, with the strongest effects recorded for projection and concealment (Skinner \& Saxton, 2019). This research is generally consistent with the results for overall maladaptive coping profiles as stated above, indicating that both specific ways and general unproductive coping may be detrimental to academic achievement and functioning.

Virtuous and vicious cycles. Within the larger framework of everyday resilience, coping is a pathway through which children can overcome the difficulty and challenge they experience in school to meaningfully re-engage with their work (Boon, 2014). As children successfully cope with their academic demands, persisting and re-engaging, a 


\section{PARENTING AND ACADEMIC COPING}

virtuous cycle may be created wherein positive academic functioning outcomes result in more constructive coping in the future. Little direct empirical evidence exists concerning feedback effects and adaptive coping, but generally patterns of research suggest that higher levels of adaptive coping lead to more positive academic outcomes, and that markers of academic functioning also lead to higher levels of adaptive coping. For example, a study of fourth through sixth graders found that students who had higher levels of engagement at the beginning of the school year both increased their use of adaptive strategies and decreased their use of maladaptive ones from fall to spring (Skinner et al., 2016). Other longitudinal research has found that when following students from grades four through seven, those with higher initial levels of school enjoyment that continued to increase over time generally also had higher initial levels and an increasing preference for problem-solving and lower initial levels and decreasing reliance upon avoidant coping (Vierhaus et al., 2016). Multiple researchers have argued that the use of these adaptive strategies during key developmental windows, such as school transitions, may result in further constructive coping and greater resilience in the face of stress later in life (Frydenberg, 2017; Seiffge-Krenke, 1995). Together, this evidence supports a conceptualization of coping as a process that builds over time, even though little of this research directly tested a cyclical relationship between coping and academic functioning.

The flip side of this is that the use of maladaptive strategies may lead to a vicious cycle over time: As children struggle with difficult tasks and use less constructive ways of coping to deal with this stress, they may cement a narrative that they are less capable of handling difficult work, leading to poor academic functioning and motivational 


\section{PARENTING AND ACADEMIC COPING}

outcomes, adding to their stress, and increasing the likelihood they will rely upon unproductive ways of coping later on. As demonstrated above, both a combined maladaptive profile and reliance upon individual maladaptive ways have been shown to be connected to poor academic functioning, such as giving up and disengagement. But a small number of studies focused on feedback effects have also found that these academic functioning outcomes have an impact on future coping. For example, a longitudinal study concerning student perceptions of classroom achievement goals across the transition to middle school found that higher levels of positive affect at time one predicted decreases in projective and denial coping at time three (Kaplan \& Midgley, 1999). Additionally, when following students through the transition to middle school across a four-year period, researchers found that students experiencing high initial levels of boredom that increased across this timeframe also had a similar pattern of avoidant coping and angerrelated emotion regulation, as well as lower initial levels and decreases in problemsolving (Vierhaus et al., 2016). Though all together this work does not specifically model cyclical effects, when combined with research on the impacts of coping on academic outcomes it suggests a possible pattern that is comprised of feedforward and feedback effects, where coping episodes and their outcomes build on one another over time.

Summary. This overall pattern of results emphasizes the important role academic coping plays in educational outcomes, with adaptive coping facilitating positive outcomes and reducing reliance upon poorer ones, and maladaptive coping encouraging negative ones while lessening the likelihood children will be resilient against everyday hardship. Taking these findings even further, a small body of longitudinal work also 


\section{PARENTING AND ACADEMIC COPING}

suggests that adaptive and maladaptive coping play an important role in feedback loops of academic achievement and functioning that build up over time, ultimately impacting the development of motivational resilience. These conclusions suggest that the extent to which social, physical, and societal contexts can bolster adaptive coping and discourage maladaptive coping may actively contribute to children's larger motivational resilience in the face of academic challenge, setting them up for positive educational outcomes later on in their educational careers.

\section{Transition to Middle School}

As adolescents leave elementary school and transition into middle school, the disconnect between their developmental needs and the ability of the school context to fulfill these needs can lead to declines in academic motivation and engagement (Eccles \& Roeser, 2009). Specifically, as adolescents' need for more autonomy, connection to others, and feelings of mastery rises, middle and junior high schools provide less of these resources, instead becoming more coercive, focused more on social comparison, highstakes grading, and performance goals, and providing fewer opportunities for selfdirected, intrinsically interesting, cognitively challenging work (Anderman \& Mueller, 2010; Wigfield et al., 2015). Previous research has shown that this mismatch is associated with numerous motivational declines, including lower endorsement of mastery goals, decreases in intrinsic motivation, higher disengagement, and the decreased valuing of academics (Anderman \& Mueller, 2010).

This lack of alignment between the needs of the developing adolescent and the school context may result in a period of increased stress over the transition. Duineveld et 


\section{PARENTING AND ACADEMIC COPING}

al. (2017) found evidence for decreases in psychological well-being, seeing both a decline in life satisfaction and increase in emotional exhaustion during this period. Longitudinal, quasi-experimental studies comparing students who transitioned from a K6 school to a 7-8 school with those who continuously attended a K-8 school have shown that those students transitioning to a larger junior high had a greater likelihood of experiencing negative outcomes, including lower academic functioning, participation in extracurricular activities, and grade and achievement scores (Simmons \& Blyth, 1987). Declines in self-esteem and self-image for girls, and increases in victimization for boys were also found, emphasizing that this period may be especially stressful and taxing for adolescent students.

While objective levels of stress are increasing due to the misalignment between the needs of adolescents and the resources present in the middle school environment, perceived stress is also increasing over this period. During the pubertal shift, youth begin to become more sensitive to interpersonal conflict, and are more likely to interpret these interactions as stressful (Skinner \& Zimmer-Gembeck, 2016). Though this may have advantages during this developmental period, including increased independence and the fostering of non-familial relationships, it may also have the side-effect of increasing the total amount of threat adolescents feel they are experiencing.

This overall increase in stress from the convergence of these factors may result in a greater need for adolescent students to cope with the additional demands placed on them in middle school. Academic coping can be an effective mechanism through which adolescents re-engage with the challenging or threatening material and situations they are 


\section{PARENTING AND ACADEMIC COPING}

encountering during this period (Martin, 2013; Skinner \& Pitzer, 2012). The importance of adaptive coping strategies specifically during the transition to middle school has been demonstrated through research showing their buffering effect on stress-related outcomes. For example, Leung and $\mathrm{He}$ (2010) found that problem-solving reduced the negative effect of academic stress on language and math grades of $5^{\text {th }}$ and $6^{\text {th }}$ grade students. Additional research found that a combined measure of problem-solving and supportseeking eased students' transition by reducing the amount of difficulty they experienced adapting to stressors (Causey \& Dubow, 1993). Unfortunately, during this period of decline in motivational functioning, students' use of unproductive coping strategies is going up while their use of constructive strategies is going down (Ben-Eliyahu \& Kaplan, 2015; Skinner \& Saxton, 2020; Zimmer-Gembeck \& Skinner, 2011). This shift in the developmental trajectory of children's coping may have multiple explanations, with a "perfect storm" of neurophysiological vulnerabilities, misalignment of needs and resources during the transition, and increases in both objective and perceived levels of stress negatively impacting coping (Skinner \& Zimmer-Gembeck, 2016).

Ultimately, this evidence suggests that adolescents' ability to handle the everyday difficulties they encounter at school may become even more important during this period of their development when they are both experiencing higher levels of stress and interpreting more events as threatening. It also suggests that this particular time of life, when youth become even more focused on their interpersonal relationships, may be especially sensitive to how social contexts are either fostering or hindering constructive 


\section{PARENTING AND ACADEMIC COPING}

or unproductive coping, emphasizing the role parents, teachers, and peers may have on the differential development of these processes.

\section{Ways of Coping}

Given the important role that coping likely plays in students' adjustment over the transition to middle school, it is essential to have a clear and comprehensive understanding of the core categories of coping as well as a delineation of the ways of coping that are going to be constructive and helpful (i.e., adaptive) versus unproductive (i.e., maladaptive). Core categories of coping, as the building blocks of the field, represent the different ways children can cope, and refer to specific strategies, like problem-solving and help-seeking, children use when dealing with the challenges and setbacks they encounter in their day-to-day lives. These classifications show up concretely as subscales on measures of academic coping, are used empirically to predict target outcomes, and are the focus of interventions designed to promote the use of adaptive ways and reduce students' reliance upon maladaptive ways.

Although there is agreement in the field that certain ways of coping represent core categories and that particular categories are likely to be adaptive or maladaptive, there is not complete consensus about what constitutes a comprehensive list of core categories nor complete clarity about how ways of coping are similar or different from one another. Some productive ways of coping, such as problem-solving and help-seeking, appear across all programs of study; and some unproductive ways, like escape, are common across all measures. But beyond these individual ways there is a great deal of variability both in the number and definitions of these categories. Nowhere is this variability more 


\section{PARENTING AND ACADEMIC COPING}

apparent than in the 22 different measures of academic coping used in the field today: No two include the same set of categories (Skinner \& Saxton, 2019). As a group, current measures of academic coping do not completely converge on the (1) distinctiveness, (2) comprehensiveness, and (3) adaptiveness of core categories of coping.

Distinctiveness. Lack of clarity about which categories should be distinguished from one another and which should be combined is apparent in the differing and partially overlapping subscales present in measures of academic coping. Commonly, especially when categorizing adaptive coping, measures combine multiple individual ways into one construct. Tero and Connell (1984), for example, include both problem-solving and support seeking in a subscale they label as "positive coping." And several measures combine conceptually distinct strategies into one category, labelled "social support seeking", rather than distinguishing between the seeking of informational versus emotional support (Causey \& Dubow, 1992; Rijavec \& Brdar, 1997). In some cases, more differentiation than necessary can be seen in some coping scales, where multiple labels are used for similar ways of coping, such as breaking up problem-solving strategies into direct action and planning (Carver et al., 1989), or breaking up distraction into various sources of diversion (e.g., social, athletic, creative, and technological diversions, Suldo et al., 2015).

Without conceptual clarity, researchers lose the ability to compare findings from different measures, making the integration of results impossible and slowing progress in the field. The explicit identification of which categories should be distinguished from one another and which should be combined increases the likelihood that studies will produce 


\section{PARENTING AND ACADEMIC COPING}

comparable empirical findings that can be consolidated. Distinguishing between different ways of coping allows educators to create contexts where constructive coping is more likely to develop. Interventionists can also more precisely target those specific ways when designing interventions and evaluating their effectiveness.

Comprehensiveness. Measures of academic coping also do not agree upon what constitutes an exhaustive list of the ways children cope in the academic domain. Currently, across all 22 scales, measures include anywhere from 2 to 16 individual ways of coping (Skinner \& Saxton, 2019). If researchers, educators, and caregivers want to help adolescents successfully negotiate school transitions, students will need a full repertoire of effective coping strategies to both help them get ready to enter middle school and sustain them through this period of transition. In order to accomplish this, parents, educators, and interventionists need a clear, comprehensive view of what the core categories of coping are, and measures cannot be considered complete until they contain a full range of core categories.

Adaptiveness. Not only is there lack of consensus on the core categories both in clarity and comprehensiveness, but also about whether categories are adaptive or maladaptive for students. Conceptually, ways of coping are considered adaptive when they allow students to reengage constructively and bring additional resources to a challenging or stressful task. This is empirically supported in the strong positive correlations between many adaptive ways of coping and motivation, engagement, and academic performance (Gonçalves et al., 2019; Skinner et al., 2016). Similarly, maladaptive ways of coping are considered unproductive because they inhibit students 


\section{PARENTING AND ACADEMIC COPING}

from re-engaging when they encounter challenges and setbacks, instead actively promoting disaffection as demonstrated by their positive correlation with giving up in the face of difficulty (Skinner et al., 2016) and negative correlations with academic performance and achievement (Gonçalves et al., 2019). Unfortunately, the empirical evidence regarding the value of individual ways of coping can sometimes be murkier than this theoretical picture suggests.

Some ways of coping are clearly positive and have dedicated bodies of research demonstrating their unique effects on important outcomes, like engagement, motivation, and academic achievement and functioning; these include adaptive ways of coping like problem-solving (Amemiya \& Wang, 2018; Causey \& Dubow, 1992; Connell \& Ilardi, 1987; Gonçalves et al., 2019; Skinner et al., 2013), certain types of help-seeking (Karabenick \& Knapp, 1991), self-encouragement (Amemiya \& Wang, 2018; Skinner et al., 2013), and committing to the task (Gonçalves et al., 2019; Skinner et al., 2013). Similarly, some unproductive ways of coping, such as avoidance and blaming others, have consistently been associated with negative academic and motivational outcomes (Causey \& Dubow, 1992; Connell \& Ilardi, 1987; Deci et al., 1992; Gonçalves et al., 2019).

At the same time, there has continued to be some confusion across constructs about whether some ways of coping truly represent "good news" or "bad news" for students. In some cases, individual categories appear to be "double-edged swords." For example, submission strategies such as ruminating over perceived failure have been positively correlated with student reports of catastrophizing and emotional reactivity, but 


\section{PARENTING AND ACADEMIC COPING}

they have also been found to predict increases in teacher-reported student re-engagement and decreases in teacher-reported giving up across the school year (in a sample of $4^{\text {th }}-6^{\text {th }}$ graders, Skinner et al., 2016). Although students who ruminate seem to be experiencing negative emotional states, the fact that rumination contains both negative affect and a persistent concentration and focus reminiscent of the persistence present in engagement may help to explain why teachers may see evidence of behavioral engagement in these students.

Additionally, some constructive coping categories appear related to negative outcomes; however, this may be due to their increased use by students who are struggling. Coping that is characterized by the seeking out of instrumental support from knowledgeable others may be an example of this phenomenon, as it has been correlated with indicators or both positive and negative academic achievement and functioning. The nature of help-seeking, with its reliance on others for constructive assistance, may mean that students who are struggling academically are more likely to utilize it as a coping strategy because they are having trouble solving difficult academic tasks on their own. Children who are seeking information from social partners may therefore be experiencing higher levels of stress, displaying more negative affect than those using other adaptive strategies, such as problem-solving or commitment, even if the act of seeking help is ultimately going to aid their re-engagement with the task. Evidence for this dual nature is apparent in inconsistent patterns of results, in that some studies find that help-seeking is a unique predictor of positive academic achievement and functioning outcomes and negatively associated with poorer outcomes (Gonçalves et al., 2019; Karabenick \& 


\section{PARENTING AND ACADEMIC COPING}

Knapp, 1991; Shih, 2015a; Skinner et al., 2016; Suldo et al., 2015), while other studies have found it to be associated with higher levels of worry and tension (Putwain et al., 2012) as well as lower exam performance (Putwain et al., 2016), and increases in worry across a five-month period (Altermatt, 2007). Students experiencing these negative outcomes may still find help-seeking to be a useful strategy and path back to effective learning, but these positive effects are being overshadowed by the negative situation causing them to utilize this way of coping in the first place.

Allocation scores. Another symptom of the murkiness surrounding the constructiveness of individual ways of coping is the positive intercorrelation between adaptive and maladaptive ways (Compas et al., 2001; Connor-Smith et al., 2000). Some researchers attribute this intercorrelation to the fact that higher levels of stress or distress lead to more coping of all kinds. The reliance of most research to date upon average coping scores may contribute methodologically to this confusion, as such scores are "double-barreled": They incorporate both the amount of stress a child is under as well as their actual coping (Skinner et al., 2013; Vitaliano et al., 1987). Children who are under more stress will necessarily need to cope more, in both "good" and "bad" ways. This often causes positive ways to "wash out" of regression results and maladaptive ones to have much larger effects (Vitaliano et al., 1987). A solution to this problem is to use allocation scores instead. These scores divide average coping scores by the total amount of coping a student experiences, therefore presenting it as a relative proportion. To remove the cumulative stressfulness of events that require coping from the act of coping 


\section{PARENTING AND ACADEMIC COPING}

itself, researchers recommend the use of allocation scores (in addition to or instead of average scoring) in situations that look closely at adaptive coping.

In sum, the lack of clarity about the distinctiveness, comprehensiveness, and adaptiveness of the core categories of coping demonstrates the need for an overarching theoretical framework to anchor these fundamental building blocks. In the larger literature, researchers have attempted to answer these questions using the dominant model in the field of coping today, namely, the transactional model of coping suggested in the work of Lazarus and Folkman (1984). This model uses a situational perspective to investigate how adults deal with major traumatic events in their lives and how their immediate appraisals and social supports influence their subsequent coping. It is not clear that this would be an appropriate framework for understanding how children are coping in everyday situations in the academic domain. Children's "everyday stress," as explained in the handbook by Wolchick and Sandler (1997), is distinct from experiences of trauma in adults, and may require an alternative framework to accurately describe and capture the processes children rely on to deal with academic stressors in their daily lives. A theoretical framework is needed that offers solutions to all three of these difficulties, while also fitting within the existing academic coping literature.

\section{Self-determination Theory as a Conceptual Framework for Academic Coping}

To provide an overarching organizing structure for the examination of children's academic coping with everyday stressors, this study relied upon a motivational framework (Figure 2.1; Skinner \& Wellborn, 1994, 1997) based on the principles of selfdetermination theory . SDT, with its focus on children's needs for relatedness, 


\section{PARENTING AND ACADEMIC COPING}

competence, and autonomy, clearly identifies the processes through which children cope with academic challenges and setbacks. The existence of fundamental and universal human needs suggests that children's stress can be a manifestation of the impingement of these needs, and that there is a set of personal appraisals and a set of contextual conditions that support or thwart the fulfillment of these needs that may support or hinder students' ability to cope. But most essentially to the larger field, they suggest a comprehensive set of families of coping that are distinct from one another and clearly adaptive or maladaptive. In the following section, I will review current research on how these three needs relate to children's coping processes and how they can be used to directly derive 12 core families of coping in the academic domain.

Figure 2.1

A Self-determination Theory Based Model of Children's Academic Coping

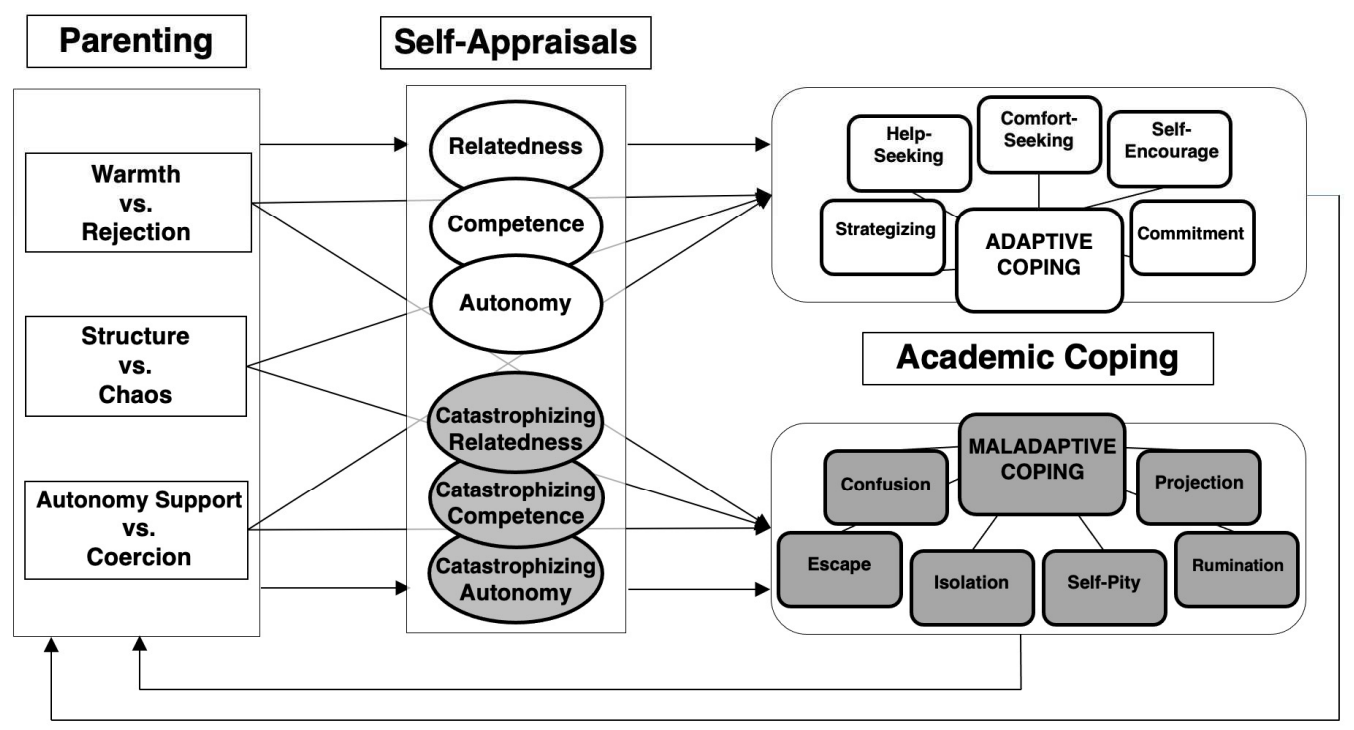

Relatedness. Relatedness is defined as the need to belong, be worthy of affection, and experience connection with others. In attachment theory its fulfillment is represented 


\section{PARENTING AND ACADEMIC COPING}

in a child's secure attachment with their caregiver (Ainsworth, 1979). Children who have a history of loving and warm interactions with a sensitive, responsive caregiver are more likely to turn to trusted adults for comfort when they encounter obstacles and setbacks. At the same time, the feeling that trusted others "have their back" also enables children to feel supported enough to independently encourage themselves when they run into trouble. Hence, a history of having the need for relatedness met supports the utilization of these two ways of coping, comfort-seeking and self-encouragement. Both are considered adaptive because they help bolster children's emotional reserves, even though this occurs through two seemingly opposing, but actually complementary actions, that of stepping away to make contact with a trusted other or holding fast and relying upon oneself. In contrast, when children have a history of unresponsive, inconsistent, or rejecting interactions with others, during stressful episodes they may be more likely to conceal their difficulties out of concern that others will react negatively. In the same vein, children who have not had their need for relatedness met may react with resentment by unconstructively reaching out to lament their situation and expecting others to solve their problems. These two ways of coping, concealment and self-pity, are maladaptive because they inhibit children from developing the ability to handle their problems on their own, either by walling themselves off from any possible comfort or aid from their social partners or by pushing those partners away by complaining and feeling sorry for themselves.

Studies examining attachment and coping have confirmed that securely attached children and young adults use more positive coping techniques (such as support-seeking) 


\section{PARENTING AND ACADEMIC COPING}

and fewer unproductive strategies (such as distancing or social isolation) (Bishop et al., 2019; Guo, 2019; Hébert et al., 2018). In a study of students' academic stress during their transition to college, lower levels of parental attachment to both mothers and fathers significantly predicted higher levels of avoidant coping (Bishop et al., 2019). Direct support for the relationship between relatedness and these four ways of coping was provided in a short-term longitudinal study focusing on $3^{\text {rd }}-6^{\text {th }}$ graders that found that a sense of relatedness with both teachers and parents was associated with the increased use of comfort-seeking and self-encouragement, and decreased use of concealment and selfpity over the school year (Skinner et al., 2013). Whether children feel fulfilled or thwarted in their need for relatedness therefore has consequences for their subsequent coping ability, and directly suggests four distinct ways of coping, comfort-seeking, selfencouragement, concealment, and self-pity.

Competence. The need for competence represents the intrinsic desire to achieve mastery and be effective in one's interactions with the environment. When confronted with challenges, students who have a history of successfully attaining their desired goals prefer to exert effort, think of alternative strategies, try out possible actions, or utilize other problem-solving techniques. When they find they cannot succeed independently, they seek out more effective strategies by going to knowledgeable others for advice and assistance. These two ways of coping, strategizing and help-seeking, are considered adaptive because they enable the child to re-engage with the troublesome task fortified with additional ideas and actions that will increase their effectiveness. In contrast, if a child has a history of ineffectiveness and failure when struggling with academic tasks, 


\section{PARENTING AND ACADEMIC COPING}

when they run into difficulties they are more likely to react with helplessness and confusion or to try to avoid dealing with the task all together. These ways of coping, confusion and escape, are considered maladaptive because they provide no actionable path back to the task, so the student forfeits the opportunity to learn, develop more effective strategies, and succeed.

Numerous studies support the connection between perceived competence and academic coping. Perceived competence has been found to be significantly positively correlated with strategizing and help-seeking and negatively associated with confusion and escape (Gonçalves et al., 2019; Skinner et al., 2013). Additionally, the degree to which a child attributes outcomes to themselves (rather than outside forces or luck) has positively predicted an increased use of approach coping (Causey \& Dubow, 1993) and negatively predicted defensive coping (Raftery-Helmer \& Grolnick, 2016). Therefore, SDT holds that the extent to which a child's need for competence has been met or hindered has an impact on their patterns of action in the face of setbacks, and suggests four core ways of coping, strategizing, help-seeking, confusion, and escape.

Autonomy. SDT states that individuals have a fundamental and innate need to feel self-determined, autonomous, or authentic in every aspect of their lives (Deci \& Ryan, 1985; Ryan \& Deci, 2017). This includes feeling free to express genuine feelings, thoughts, and actions without pressure or coercion from external forces. Children with a history of being able to express their genuine preferences expect others to care about their opinions and are more likely to negotiate to defend their goals. Similarly, with this history of the environment respecting their opinions, they are also more likely to 


\section{PARENTING AND ACADEMIC COPING}

reciprocate and so feel comfortable accommodating the goals of others without feeling coerced. This suggests two ways of coping, negotiation and commitment, that are both considered adaptive because they allow the child to either hold fast to or adjust their true goals in close and productive coordination with the demands of others. When students instead have a history of being coerced in their academic or home environment, during difficult experiences they are more likely to lash out at others or obsess over failure. These ways of coping, projection and rumination, are typically maladaptive because they serve goals that are entirely dictated by others, resulting in either complete deference or rigid opposition, neither of which reflect the individual's genuine goals or preferences.

Research has found that students who are highly autonomous are more likely to use positive coping strategies, including greater commitment to the task (Connell \& Ilardi, 1987; Mantzicopoulos, 1997; Ryan \& Connell, 1989). A short-term longitudinal study of college students found that those higher in autonomy at the beginning of the semester decreased their use of defensive coping strategies (such as rumination) by semester's end (Knee \& Zuckerman, 1998). In contrast, in studies examining the effects of non-autonomous contexts, researchers have found that students in highly coercive educational environments used more internalizing (e.g., rumination) and externalizing (e.g., projection) coping strategies (Patrick et al., 2019). Whether students feel fulfilled or thwarted in their need for autonomy therefore has demonstrated consequences for the ways they cope with everyday stressors, and directly suggests specific ways, commitment, negotiation, rumination, and projection, that they may use to handle this stress. 


\section{PARENTING AND ACADEMIC COPING}

In sum, the application of a motivational framework based in SDT allows researchers to organize disparate and overlapping conceptions of academic coping into 12 overarching families. These ways are sorted into generally adaptive and maladaptive categories, with positive ways including problem-solving, help-seeking, comfort-seeking, self-encouragement, and commitment, and less constructive ways consisting of confusion, escape, concealment, self-pity, rumination, and projection (for descriptions of each way of coping and example items, see Table 2.1). Negotiation, although it can be an essential coping strategy for dealing with non-educational stressors, such as interpersonal or health problems, is not generally considered accessible to students in classroom contexts due to the power differential between teachers and students, and is not often observed or reported in studies of academic coping. For example, it does not appear as a subscale in any of the 22 measures of academic coping used to date (Skinner \& Saxton, 2019). Hence, negotiation was not included in the current study, resulting in the utilization of five adaptive and six maladaptive ways of academic coping.

Structural analyses of this multidimensional model of coping have confirmed a theorized structure of these 11 individual ways of coping. Two separate confirmatory factor analyses have demonstrated this, in both a sample of $3^{\text {rd }}$ through $6^{\text {th }}$ graders in the northeastern United States and a sample of $4^{\text {th }}, 6^{\text {th }}$ and $9^{\text {th }}$ grade students in Portugal (Gonçalves et al., 2019; Skinner et al., 2013). These factor analyses support the idea that the application of self-determination theory provides categories of academic coping with the distinctiveness that was previously lacking. And a comparison of these 11 families with all the ways of coping included in the 22 measures of academic coping used to date 


\section{PARENTING AND ACADEMIC COPING}

also suggests that this list is relatively comprehensive. The vast majority of the ways of coping included in these measures fits within one of the 11 families suggested by SDT (Skinner et al., 2013; Skinner \& Saxton, 2019). Hence, these families were the target of study in the current investigation of academic coping.

Table 2.1

Ways of Coping in the Academic Domain

\begin{tabular}{|c|c|c|}
\hline $\begin{array}{l}\text { Adaptive Ways of Coping } \\
\text { Way }\end{array}$ & Description & $\begin{array}{l}\text { Presence in Coping } \\
\text { Measures }\end{array}$ \\
\hline Strategizing & $\begin{array}{l}\text { Tries to find solutions to } \\
\text { problems or keep them from } \\
\text { happening in the future }\end{array}$ & $\begin{array}{l}1,2,3,4,5,6,7,8,9 \\
10,11,12\end{array}$ \\
\hline Help-seeking & $\begin{array}{l}\text { Goes to knowledgeable others } \\
\text { for possible solutions or } \\
\text { learning tools }\end{array}$ & $1,6,7,9,12$ \\
\hline Comfort-seeking & $\begin{array}{l}\text { Seeks trusted others for } \\
\text { emotional supports }\end{array}$ & $\begin{array}{l}1,2,3,4,5,6,7,8 \\
10,11\end{array}$ \\
\hline Self-encouragement & Tries to lift own emotions & $1,2,3,4,8,10$ \\
\hline Commitment & $\begin{array}{l}\text { Reminds oneself of the value of } \\
\text { the difficult task }\end{array}$ & $1,2,4,5,6,7,9,10$ \\
\hline $\begin{array}{l}\text { Maladaptive Ways of Coping } \\
\text { Way }\end{array}$ & Description & $\begin{array}{l}\text { Presence in Coping } \\
\text { Measures }\end{array}$ \\
\hline Confusion & $\begin{array}{l}\text { Uncertainty or disorganization } \\
\text { regarding what to do next }\end{array}$ & $2,4,7,10$ \\
\hline Escape & $\begin{array}{l}\text { Mentally tries to avoid } \\
\text { difficulty }\end{array}$ & $\begin{array}{l}1,2,3,4,6,7,8,9 \\
10,11,12\end{array}$ \\
\hline Concealment & $\begin{array}{l}\text { Tries to hide poor outcomes or } \\
\text { difficulty from others }\end{array}$ & $2,3,7,10$ \\
\hline Self-pity & Lamenting one's situation & 3 \\
\hline Rumination & $\begin{array}{l}\text { Consuming focus on bad parts } \\
\text { of a difficult situation }\end{array}$ & $2,3,5,6,7,10,12$ \\
\hline Projection & $\begin{array}{l}\text { Blaming others for difficulty or } \\
\text { poor outcomes }\end{array}$ & $3,4,5,6,10,12$ \\
\hline
\end{tabular}

Note. Adapted from Skinner, Pitzer, \& Steele, 2013. 1. Ayers et al., 1996; 2. Brown et al., 1986; 3. Causey \& Dubow, 1992; 4. Coleman, 1992; 5. Dickey \& Henderson, 1989; 6. Ebata \& Moos, 1994; 7. Lewis \& Frydenburg, 2002; 8. Roth \& Cohen, 1986; 9. SeiffgeKrenke, 1995; 10. Spirito et al., 1991; 11. Stöber, 2004; 12. Tero \& Connell, 1984. 


\section{PARENTING AND ACADEMIC COPING}

\section{Parenting and the Development of Academic Coping}

Outside the academic domain, there is general consensus among researchers that parents and primary caregivers play an essential role in the development of coping during childhood and adolescence. Reviews of how parenting and caregiving influence stress and coping in children highlight parents' impact on each step of the coping process, from the amount or type of stress to which children are exposed, to how they appraise stressors, all the way through the on-the-ground ways children cope with the hardships they encounter (Power, 2004; Skinner \& Edge, 2002; Skinner \& Zimmer-Gembeck, 2016). However, the bulk of research evaluating contextual influences on coping in the academic domain has focused on teachers and schools, and how they can facilitate or hinder the use and development of adaptive and maladaptive coping. Despite the fact that parents and caregivers are a consistent adult presence in children's lives before and throughout their educational career, only a small body of research examines their connection to students' academic coping.

Consistent with research that highlights the quality of the parent-child relationship, SDT argues that a crucial pathway through which parents influence academic coping processes is via their displays of warmth, provision of structure, and support of their children's genuine thoughts, feelings, goals, and preferences. SDT suggests that these aspects of high-quality parenting benefit children through the provision of psychological resources and motivational supports. These environmental affordances are then theorized to have a direct impact on whether children cope constructively or unproductively with the stressors they encounter. Reviews of these 


\section{PARENTING AND ACADEMIC COPING}

parenting dimensions, referred to as involvement, structure, and autonomy support, confirm their importance to outcomes in the academic domain (Grolnick et al., 2009; Raftery et al., 2012; Skinner et al., 2005). But to date only nine studies have looked directly at how parenting and parenting dimensions impact academic coping specifically (see Table 2.2). Of those studies only three used an SDT framework and looked at all three motivational supports together, indicating much more research can be done to explore this hypothesized connection. 


\section{PARENTING AND ACADEMIC COPING}

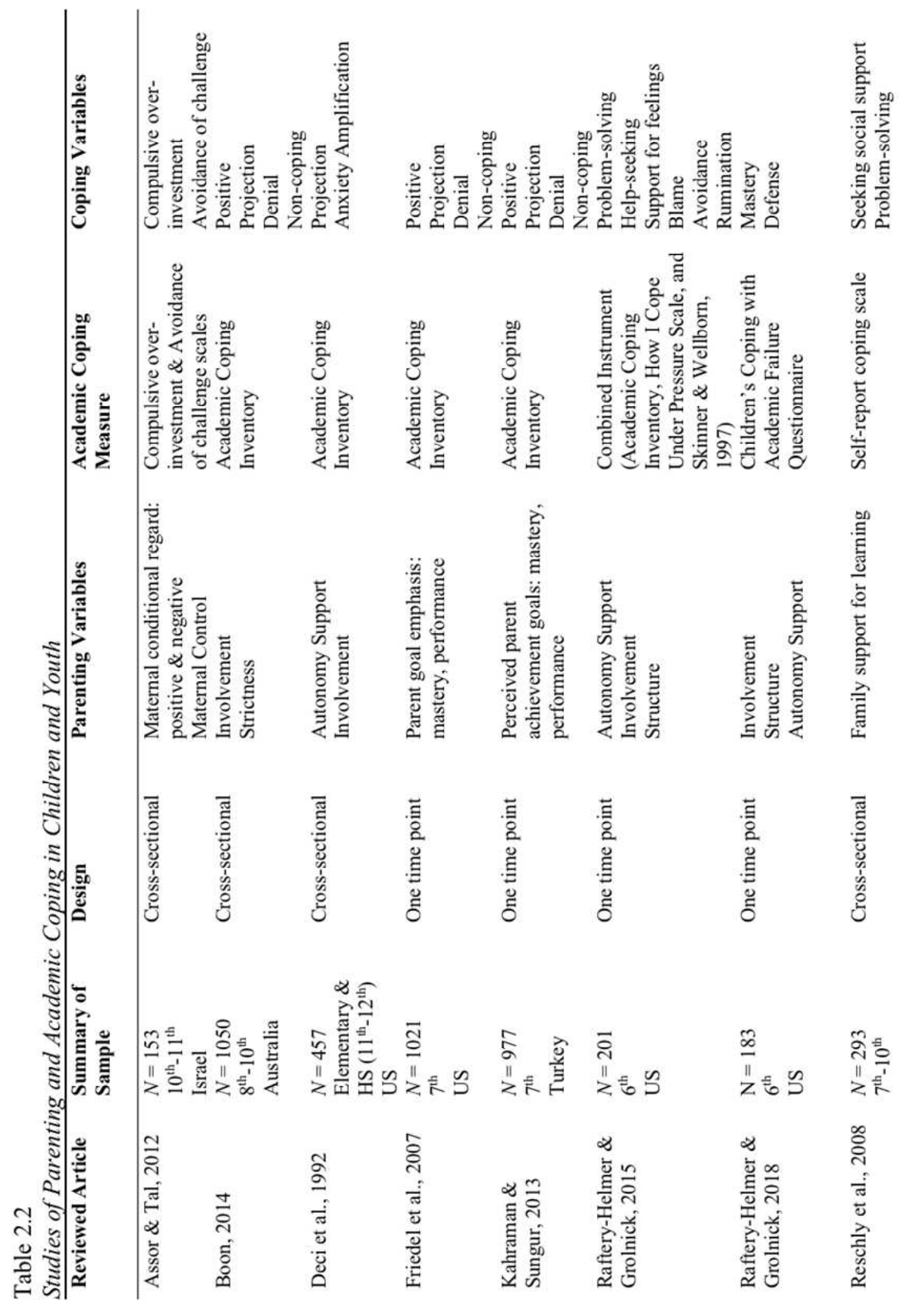




\section{PARENTING AND ACADEMIC COPING}

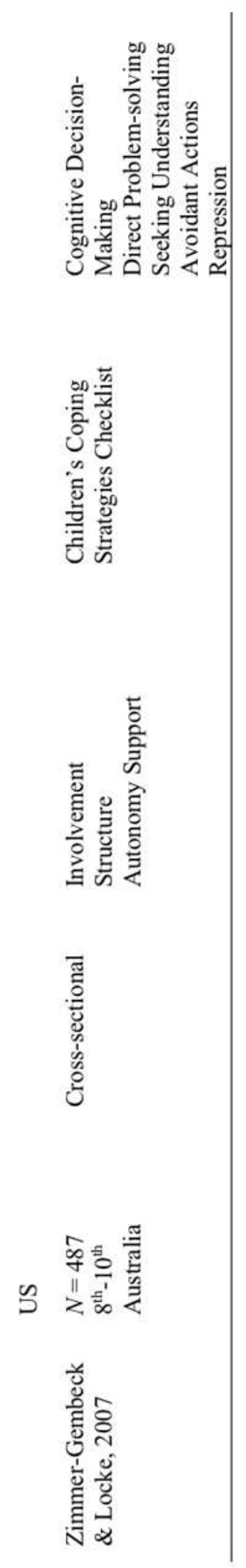




\section{PARENTING AND ACADEMIC COPING}

As presented in Table 2.2, the nine studies performed to date that investigate the possible link between parenting and academic coping are heterogeneous in multiple ways. They encompass an age range of 8 to 21 years old, the largest concentration being students in middle school and high school, and utilize varying coping scales that measure between 2 to 6 individual ways of coping; none considers all 11. These studies also focus on a wide-range of parenting dimensions, including those drawn from SDT as well as other motivational and coping theories, making integrative cross-study comparison of findings difficult.

In an attempt to organize and draw broader conclusions from the limited work done in this domain, I will use an SDT based motivational framework as a focusing lens to highlight the evidence for how parental involvement, structure and autonomy support bolster the development of children's adaptive coping and protect them from the use of maladaptive ways through their promotion of children's fundamental psychological needs of relatedness, competence, and autonomy (Skinner \& Wellborn, 1994, 1997). This model gives an underlying structure to the role of the parenting context in children's ability to handle the hardships they encounter in school that has been supported in the handful of studies that looked directly at these variables. In the following section, I will consider the importance of each of the dimensions this SDT-based framework proposes individually and provide evidence of its connection to academic coping. Then I will look at studies that combine multiple dimensions or use dimensions outside of this framework to evaluate their contributions to our understanding of parenting and coping. As these studies are somewhat scattered in the variables and constructs they examined, to integrate 


\section{PARENTING AND ACADEMIC COPING}

findings I will focus not only on unique effects but also zero-order correlations, as the variables of interest in the current investigation were often not the hypothesized focus of individual studies.

Involvement. Social contexts are considered high in warmth or involvement when they are characterized by loving interactions with emotionally available, affectionate social partners who are aware of and engaged with their children's education. The opposite of this is characterized by hostility or rejection, in which children experience others as unreliable or neglectful. Reviews and meta-analyses of parental involvement in children's education both at school and at home converge on its value in the support of both academic achievement, engagement, and motivation (Barger et al., 2019; Boonk et al., 2018; Fan \& Chen, 2001; Grolnick, 2016). Behaviors typical of involved parents such as encouragement and support, high aspirations and expectations, as well as their valuing of academic achievement have been consistently significantly associated with higher achievement in math and literacy (Boonk et al., 2018; Fan \& Chen, 2001). Similar positive outcomes have been found in the realm of motivation, with parental involvement, especially valuing of school performance and interest in education, predicting perceived competence and engagement (Barger et al., 2019; Grolnick, 2016). Clearly, parental involvement has a material impact on academic outcomes, and this is reflected in it being the most common dimension included in the nine aforementioned studies regarding parenting and academic coping which overall found that children whose parents provided higher levels of involvement reported higher levels of problem-solving, help-seeking, and support-seeking, and lower levels of rumination 


\section{PARENTING AND ACADEMIC COPING}

and blame. Additionally, involvement was a unique predictor of increased mastery coping in sixth-grade students (Raftery-Helmer \& Grolnick, 2016, 2018). Other work focused on children and youth in high school special education classes found it associated with the use of lower levels of coping characterized by anxiety-amplification (Deci et al., 1992). Overall, although this work provides only limited evidence for the importance of involvement to academic coping, these initial results (taken together with decades of research showing the centrality of parental involvement to children's academic functioning more generally) indicate that it may be a worthwhile predictor that warrants further investigation.

Table 2.3

Significant Pearson Correlation Coefficients of Studies on Involvement and Academic Coping

\section{Involvement}

\section{Adaptive Ways of Coping}

Strategizing $.49 * * 2$

Help-seeking $.44 * * 2$

Comfort-seeking $.37 * * 2$ (support for feeling)

Self-encouragement

Commitment

Adaptive Coping $.51^{* * 3}$ (mastery coping)

\section{Maladaptive Ways of Coping}

Confusion

Escape (Avoidance)

$n s^{1}, n s^{2}$

Concealment

Self-pity

Rumination (Anxiety-Amplification)

$$
-.20 * * 1 \text { (HS), }-.14 * 2
$$

Projection (Blame)

$$
n s^{1},-.24 * * 2
$$

Maladaptive Coping

$n s^{3}$ (defensive coping)

Note. 1. Deci et al., 1992; 2, Raftery-Helmer \& Grolnick, 2015; 3. Raftery-Helmer \& Grolnick, 2018. ns = non-significant correlation; $H S=$ high school ${ }^{*} p<.05 * * p<.01$ 


\section{PARENTING AND ACADEMIC COPING}

Structure. Parents provide their children with structure when they have developmentally appropriate and attuned expectations, limits, rules, guidelines, and scaffolds that support their child's learning. This is characterized by predictable routine, contingent responses, constructive feedback, a supportive learning environment, and reasonable explanations behind rules and expectations (Farkas \& Grolnick, 2010). When structure is lacking, children may experience a chaotic, unpredictable environment, where there is no guarantee that what they expect to happen will happen. Though studied less than involvement and autonomy support, parental structure has been linked to positive outcomes in the academic domain in multiple studies and reviews, including greater perceived control and competence, engagement, and self-worth (Farkas \& Grolnick, 2010; Grolnick et al., 2014; Skinner et al., 2005). Parental structure has even been found to be a unique predictor of positive child outcomes when controlling for the other parenting dimensions suggested by SDT, involvement and autonomy support (Farkas \& Grolnick, 2010).

Studies focusing specifically on how parental provision of structure affects children's academic coping have found that children who experience their parents as higher in structure also report higher levels of problem-solving and help-seeking, and lower levels of avoidance, rumination, and projection (Raftery-Helmer \& Grolnick, 2016). As these two constructive ways of coping are directly suggested by the fulfillment of a person's need for competence, this evidence supports the idea that parental structure may be a part of the satisfaction of this need. Structure also predicted less reliance upon maladaptive ways of coping generally, suggesting it may be a unique protective factor 


\section{PARENTING AND ACADEMIC COPING}

against less constructive coping (Raftery-Helmer \& Grolnick, 2016, 2018). Though

evidence supporting the relationship between structure and coping is limited to these two studies, their results, and previous research showing its importance to academic and motivational outcomes, strengthen the idea that parenting that is characterized by appropriate limits and high expectations may affect a child's ability to cope with school.

Table 2.4

Significant Pearson Correlation Coefficients of Studies on Structure and Academic Coping

\section{Structure}

\section{Adaptive Ways of Coping}

Strategizing

Help-seeking

Comfort-seeking

Self-encouragement

Commitment

Adaptive Coping

Maladaptive Ways of Coping

Confusion

Escape (Avoidance)

Concealment

Self-pity

Rumination (Anxiety-Amplification)

Projection (Blame)

Maladaptive Coping

\section{$.23 * * 1$}

$.19 * * 1$

$n s^{1}$ (support for feeling)

$n s^{2}$ (mastery coping)

Note. 1. Raftery-Helmer \& Grolnick, 2015; 2. Raftery-Helmer \& Grolnick, 2018

$n s=$ non-significant correlation

$*_{p}<.05 . * * p<.01$ 


\section{PARENTING AND ACADEMIC COPING}

Autonomy support. Parents support their children's autonomy by taking their perspective, empathizing with them, including them in decision-making, and giving them the opportunity to make developmentally appropriate choices. The antithesis of this is coercion, examples of which include using threats and punishments to control behavior, not considering a child's genuine wants and needs when making decisions, and disregarding or demeaning their input. A meta-analysis investigating the connection between autonomy supportive parenting and children's adaptive functioning found it associated with higher academic achievement, autonomous motivation, psychological health, perceived competence and control, engagement, attitudes toward school, executive functioning, and self-regulation (Vasquez et al., 2016).

The documentation of such clear and consistent connections with positive achievement and motivational outcomes suggests that autonomy support could also foster the use of adaptive coping or reduce students' reliance on maladaptive coping, and the literature concerning parental autonomy support and coping bears this out. Three studies looking specifically at autonomy support mostly found evidence for its influence on the reduction of maladaptive ways, specifically rumination and blame (Deci et al., 1992; Raftery-Helmer \& Grolnick, 2016, 2018). As these are the two ways of coping suggested as responses to threats to individuals' need for autonomy, it is not surprising that autonomy support may lessen the inclination to use these approaches. Autonomy support was also correlated with help-seeking, but no other adaptive ways of coping (RafteryHelmer \& Grolnick, 2016). When considered as a unique predictor of academic coping, autonomy support was also associated with less reliance upon defensive coping, a 


\section{PARENTING AND ACADEMIC COPING}

combined measure of avoidance, rumination, and blame (Raftery-Helmer \& Grolnick, 2016, 2018). It appears these three studies, when added to the large body of evidence demonstrating how essential autonomy support is to children's academic outcomes, provide the most consistent evidence of the protective role it may play in reducing children's reliance on maladaptive academic coping, encouraging further research into its effect on children's patterns of actions in the face of challenges and setbacks.

Table 2.5

Significant Pearson Correlation Coefficients of Studies on Autonomy Support and Academic Coping

\section{Autonomy Support}

\section{Adaptive Ways of Coping}

Strategizing

$n s^{2}$

Help-seeking

$.16^{* 2}$

Comfort-seeking

$n s^{2}$ (support for feeling)

Self-encouragement

Commitment

Adaptive Coping

$n s^{3}$ (mastery coping)

\section{Maladaptive Ways of Coping}

Confusion

Escape (Avoidance)

$$
n s^{2}
$$

Concealment

Self-pity

Rumination (Anxiety-Amplification)

$$
-.35 * 1 \text { (ES), }-.23 * * 1 \text { (HS), }-.24 * * 2
$$

Projection (Blame)

$$
-.26 * 1 \text { (ES), }-.21 * 1 \text { (HS), }-.29 * * 2
$$

Maladaptive Coping $-.43^{* * 3}$ (defensive coping)

Note. 1. Deci et al., 1992; 2, Raftery-Helmer \& Grolnick, 2015; 3. Raftery-Helmer \& Grolnick, 2018; NS = non-significant; ES = elementary school; HS = high school $* p<.05 * * p<.01$. 


\section{PARENTING AND ACADEMIC COPING}

Combined effects and quality of parenting. In addition to research looking at the unique effects of these individual parenting dimensions, four other studies used the theoretical framework of self-determination theory to evaluate the impact of high-quality parenting on children's academic coping. Zimmer-Gembeck and Locke (2007) found that parenting that overall was high on involvement, structure, and autonomy support all together predicted higher levels of active coping at school, even when controlling for quality of teaching. At home, parents had even more of an impact, with this positive family context predicting both higher levels of active coping and lower levels of coping characterized by avoidance and wishful thinking. Other researchers have found similar effects from parenting style, specifically that children whose parents had an authoritative style (characterized by high involvement and strictness) were more likely to use positive coping strategies, and less likely to use projective responses; the opposite was found for parenting characterized as neglectful (low on both involvement and strictness) or permissive (high on involvement and low on strictness) (Boon, 2014). Researchers focused on family support for learning, which is often included as one dimension of parental involvement, found higher levels connected to greater use of social support seeking and self-reliant problem-solving during middle and high school (Reschly et al., 2008). Negative parenting behaviors and their relationship to academic coping have also been studied, specifically finding maternal control (similar to coercion, the opposite of autonomy support) to be linked to higher levels of coping through challenge avoidance (Assor \& Tal, 2012). 


\section{PARENTING AND ACADEMIC COPING}

Other frameworks. Finally, two studies an alternative motivational framework, achievement goal theory (Urdan \& Kaplan, 2020) to investigate the relationship between parenting and academic coping. When looking at zero-order correlations, one of these studies found that parent perceived mastery goals were associated with higher levels of positive coping and less projective and denial coping, while parent performance goals were associated with the use of more projection and non-coping, but no unique direct effects from parent goals to coping (Friedel et al., 2007). Another study found that perceived parent mastery goals predicted higher levels of positive coping, but no effects for parent performance goals. Zero-order correlations for this study found parent mastery and performance goals to be associated with higher levels of both adaptive and maladaptive coping, muddying the picture of what effect parent achievement goals have one children's coping (Kahraman \& Sungur, 2013).

In the academic coping literature more generally, perceived parent and teacher orientations have not been consistent predictors of adaptive or maladaptive coping profiles or individual ways of coping, while student mastery goal orientations have only somewhat consistently predicted higher levels of adaptive coping and performance goals have not (Skinner \& Saxton, 2019). This suggests that individual goal orientations themselves may not be the best predictors of coping across the board, and even further that contextual orientations, such as those from parents and teachers, may be even less useful as predictors. Additionally, these patterns of results indicate that this framework may be less helpful than that suggested by SDT when examining parental effects. 


\section{PARENTING AND ACADEMIC COPING}

In sum, some research suggests that high-quality caregiving, characterized by provision of involvement, structure, and autonomy support, may have an impact on how children are coping in the moment and may even act as a protective factor against unproductive coping practices while actively promoting constructive ones. Although this body of research is limited, it provides an encouraging foundation, consistent with the large body of research outside the academic domain, for the fundamental importance of parental interactions to children's action tendencies under stress. Still, as all nine studies were cross-sectional in nature, with data collected at only one time point, further work is needed to fully explicate how all three facets of parenting together influence coping, whether each exerts unique effects, the direction of these effects, how they may change over time, and through what processes this change is occurring.

\section{Effects of Children's Academic Coping on Parenting}

Motivational, transactional, and bio-ecological traditions are all fundamentally based upon the premise that interactions between social partners are the engine of human development, and that these interactions are not merely unidirectional from adults to children but instead mutually impactful processes where each partner is influencing the other (Bronfenbrenner \& Morris, 1998; Ryan \& Deci, 2017; Sameroff, 2010; Skinner et al., 2019). Despite this consistent meta-theoretical theme across contemporary lifespan developmental research, few researchers have explicitly studied the reciprocal nature of the parent-child relationship, instead focusing primarily on one-way effects from parents to children. But it makes a certain amount of logical sense that children's temperament, behavior, personality, and actions under stress would alter their parents' in-the-moment 


\section{PARENTING AND ACADEMIC COPING}

actions, and that the build-up of these episodes over time would have an impact on parenting practices and maybe even on changes in parenting over time.

Beginning with Bell's $(1964,1968,1979)$ call for a reinterpretation of the directionality of socializing effects in parent-child interactions, a small number of researchers have tackled the idea that the parent-child relationship is fundamentally a bidirectional, transactional system, with causal flow occurring between both social partners. Classic experimental and quasi-experimental studies on the subject have found support for this transactional model, with demonstrated causal effects of child behavior on parents' behavioral responses. For example, in a laboratory experiment, Anderson et al. (1986) switched mothers of children with or without conduct disorders and their individual children and had them perform three tasks together, finding that mothers, irrespective of their own child's diagnosis, used more negative communication and requests when paired with conduct disordered children.

In other observational work, two children were trained as research "confederates" to display either conduct problems or anxious-withdrawn behavior to individual parents in a laboratory setting (Brunk \& Henggeler, 1984). Results indicated that adults exhibited different levels of behaviors depending on which child they were interacting with, displaying more verbal helping in the anxious-withdrawn portrayal than the conductdisorder, and more ignoring in the conduct-disorder condition than the anxiouswithdrawn. In a similar study that manipulated conditions to elicit specific behaviors from children, both mothers and fathers were found to be more controlling when their daughters were acting in a more dependent manner than those in the independence 


\section{PARENTING AND ACADEMIC COPING}

inducing condition (Osofsky \& O'Connell, 1972). Altogether, this experimental work provides strong evidence for children's reciprocal causal influence on their parents through their emotions and behaviors, implying that this direction of effects could also possibly occur during academic coping episodes when parents are participating. As a complement to laboratory research, observational sequential, continuous real-time coding studies in the family home that examined natural interactions confirmed that these processes also occur outside of the laboratory setting (Patterson, 1982).

Self-determination theory. Though this experimental and observational work has traditionally been situated in the realm of child temperament and mental health, motivational researchers based in SDT have also investigated how child orientations, goals, motivational regulation, and self-system processes may reciprocally influence the motivational supports subsequently offered by parents. While this research has not looked specifically at how children's coping impacts parent's offering of involvement, structure, and autonomy support, some longitudinal work using cross-lagged models has been done concerning reciprocal effects between these individual parenting dimensions and other child behaviors, motivational regulation, or general well-being.

Researchers focused on the bidirectional relationship between parental psychological control and children's depressive symptoms in middle and late adolescence found that higher levels of parental control in the beginning of the school year not only led to increases in children's depressive symptoms from fall to spring, but also that higher levels of children's depressive symptoms led to increases in parental psychological control (Soenens et al., 2008). This pattern of effects has also been found 


\section{PARENTING AND ACADEMIC COPING}

in research on adolescent autonomous regulation, oppositional defiance, and parental autonomy support. Adolescent identified regulation at time one was associated with increased autonomy supportive parenting a year later, while higher extrinsic regulation led to decreased autonomy-supportive parenting and increased control; and in a similar vein higher adolescent oppositional defiance predicted decreases in autonomy support across the year (Vansteenkiste et al., 2014). Similar reciprocal effects have been found for other parenting dimensions, with higher levels of child effort on a homework task leading to increases in an individual facet of involvement, namely autonomy-oriented homework support, from fall to spring of the school year (Xu et al., 2018). Models specifically focused on transactional processes between social partners have also been investigated, finding that autonomous goal orientations in college students led to increases in perceived autonomy support from their social partners, which in turn led to increases in subsequent autonomous motivation, positive affect, and goal progress (Levine et al., 2020). Though not specifically focused on the relationship between parent and child, this research adds to the growing evidence that individual characteristics impact the supports offered by their social contexts.

Although not published in a peer-reviewed journal, an empirical illustration presented in a larger symposium book chapter concerning parenting and academic coping touches on possible feedback effects from children's coping to subsequent parent motivational supports (Skinner \& Edge, 2002). Results from this illustration indicated that in a sample of fourth through seventh graders, children who showed higher levels of support-seeking in the fall reported increases in parental warmth from fall to spring, and 


\section{PARENTING AND ACADEMIC COPING}

those showing higher problem-solving reported increased parental structure. It appears that these ways of coping may serve to evoke certain reactions from parents, because the coping actions themselves may communicate to social partners what children need in that moment. Specifically, support-seeking (i.e., comfort-seeking) behaviors may tell parents that children need additional warmth and affection, while problem-solving may give the signal that they are ready for additional learning scaffolds. The communication of these needs may lead to attuned feedback effects, where the transactional relationship between parents and children becomes visible.

When looking instead at parental responses to maladaptive ways of coping, children who reported higher confusion in the fall experienced decreases in parental structure across the school year, and those who more often relied upon opposition reported decreases in autonomy support. Reacting to stressful academic tasks with confusion may send inconsistent and perplexing signals to parents about how to assist, leading them to provide either unhelpful or inappropriate scaffolding and assistance, or to give-up entirely. Similarly, children who react to difficulty by blaming others (i.e., opposition or projection) may push their social partners away, lessening the number of supportive resources that are offered, or alternatively elicit more coercion as parents attempt to alter perceived negative behavior through more forceful contact. Again, these coping actions may act as communications to parents that impact the supports they subsequently offer, even if these messages are inaccurate, maladaptive, or misaligned with the actual needs of the child. When taken together, these results, and their theoretical implications, though preliminary in nature and concerning only a limited number of 


\section{PARENTING AND ACADEMIC COPING}

individual ways of coping, provide some of the first direct evidence for a bidirectional connection between children's coping and parenting.

Summary. As described above, there is little explicit empirical evidence documenting feedback effects from children's academic coping to parents' offering of warmth, structure, and autonomy support, but the studies referenced previously lend support to this theorized connection. For example, the impact of children's oppositional defiant behavior on changes in parental autonomy support suggests that coping characterized by opposition and projection could also have an effect on this dimension of parenting. Evidence that the effort children displayed while completing a homework task influenced future parental involvement suggests that strategizing and problem-solving may also impact subsequent parent behaviors. Taken together, this body of evidence suggests that parents or other social partners may alter their actions and behavior in response to what children are doing, becoming more coercive in response to problem behavior, or feeling more able to support their children's autonomy when their children internally value their goals. When parents are working together with their children on academic tasks, they may be responding to actions and behaviors in the moment as well as embodying their typical parenting style.

Despite a general consensus within the larger field of lifespan developmental science concerning the transactional nature of the parent-child relationship, most research is still conducted with an assumption of a unidirectional flow of influence from parent to child. This assumption is most evident when looking at research that concerns nonexperimental data collected at a single time point. These studies almost universally 


\section{PARENTING AND ACADEMIC COPING}

interpret correlations as indicating a directional relationship from parent to child, despite the absence of experimental or temporal conditions to establish this connection. In fact, this type of correlational and cross-sectional work provides just as much evidence for the reverse effects, namely, children's impact on parents. This implies that all nine parenting studies referenced in the previous section on parenting effects (see Table 2.2), while most often explicitly concerned with parental or contextual effects, could also be interpreted as evidence of child effects on parenting as all rely on cross-sectional designs. This emphasizes the importance of using data gathered at multiple time points to differentiate the direction of these effects, as temporal precedence or experimental conditions are required for any argument that posits directionality of influence from one social partner to the other. While it may be the case that the strongest effects are occurring from parent to child, there is no way to determine this in a non-experimental condition using a single time point, and as transactional models suggest, social partners are most likely influencing each other continually over time, and these effects must be disentangled from one another to fully describe what is being observed, explain how it is happening, and optimize outcomes for all parties.

\section{Children's Self-system Processes as Mediators of Parenting and Academic Coping}

Self-determination theory is useful as an overarching framework not only because it suggests contextual supports and fundamental human needs that may impact children's coping, but also because it specifies the processes through which social contexts should be exerting their influence. Studies focused on these processes suggest that parents, like other contexts or social partners, may impact coping indirectly through their influence on 


\section{PARENTING AND ACADEMIC COPING}

children's motivation and appraisals. Researchers based in other motivational frameworks have hypothesized different mechanisms behind these associations (such as children's achievement goals). Those working within the framework of SDT most often look to children's self-system processes of relatedness, competence, and autonomy, or other parallel self-systems such as perceived control, to explain how parents are impacting academic coping (Connell \& Wellborn, 1991; Skinner \& Wellborn, 1994, 1997).

The notion of a "self-system" has a specific meaning within SDT. It refers to the internal working models children construct (and rework) about themselves and their worlds in relation to the three needs. The core idea is that, in their day-to-day lives, as children interact with social partners and their environments, they are consistently taking mental "notes" regarding their experiences. This "note-taking" builds toward larger representations and more complex models over time, creating certain sets of beliefs about the self and others. These beliefs or working models consist of "hot" cognitions and play a powerful role in shaping children's experiences. They are used to interpret previous transactions, form expectations about future encounters, and guide subsequent actions and reactions. Hence, they create a kind of "apparent reality" that surrounds and colors children's interactions with the social and physical worlds.

SDT posits that these internal working models and self-system processes are organized around children's convictions about their worthiness of love and sense of belonging (i.e., relatedness), feelings of mastery and control over outcomes (i.e., competence), and opportunities for self-determination (i.e., autonomy) (Connell \& 


\section{PARENTING AND ACADEMIC COPING}

Wellborn, 1991). These self-systems likely serve as mediators between parenting and coping because they are partially constructed from the history of interactions children have with their parents, and then themselves in turn help shape children's subsequent behaviors, emotions, cognitions, and in this case, their coping actions (Skinner \& Wellborn, 1994).

These internal models can go "wrong" when feelings of competence, autonomy, or relatedness are threatened and the self-systems that have been constructed instead communicate to children that they can expect only poor outcomes when things go wrong. Children who appraise stressful events this way are more likely to interpret challenging experiences as distressing, while simultaneously magnifying their negative implications (Lewis \& Frydenberg, 2002; Tero \& Connell, 1984). These catastrophizing appraisals are also organized around the three self-systems: Catastrophizing of relatedness which is characterized by expectations that hardships will push people away and threaten belonging, catastrophizing of competence in which they see failure as evidence of being perennially incapable, and catastrophizing of autonomy where difficulty confirms personal shortcomings and ruins the endeavor. Although no work to date has expressly investigated catastrophizing appraisals as possible mediators between contextual supports and coping, they have been negatively associated with all adaptive ways and positively with all maladaptive ways of coping (Skinner et al., 2013). This suggests that they may be significant predictors of children's coping, and as they can be viewed as manifestations of self-system processes under threat, it follows that they may be predicted themselves by low levels of parental motivational supports. 


\section{PARENTING AND ACADEMIC COPING}

Much like the small body of work concerning direct effects of parenting on children's coping, only a limited amount of work has been done concerning these processes. Altogether, five studies have been conducted that specifically examined possible mediators between parenting and academic coping, all situated within the larger field of motivation (see Table 2.6).

Table 2.6 Mediational Studies of Parenting and Academic Coping

\begin{tabular}{|c|c|c|c|c|}
\hline $\begin{array}{l}\text { Reviewed } \\
\text { Article }\end{array}$ & $\begin{array}{l}\text { Summary } \\
\text { of Sample }\end{array}$ & $\begin{array}{l}\text { Parenting } \\
\text { Variables } \\
\text { Studied }\end{array}$ & Mediator Variables & Coping Variables \\
\hline $\begin{array}{l}\text { Assor \& Tal, } \\
2012\end{array}$ & $\begin{array}{l}N=153 \\
10^{\text {th }}-11^{\text {th }} \\
\text { Israel }\end{array}$ & $\begin{array}{l}\text { Maternal } \\
\text { conditional } \\
\text { regard: positive \& } \\
\text { negative } \\
\text { Maternal Control }\end{array}$ & $\begin{array}{l}\text { Self-aggrandizement } \\
\text { Self-devaluation }\end{array}$ & $\begin{array}{l}\text { Compulsive over- } \\
\text { investment } \\
\text { Avoidance of } \\
\text { challenge }\end{array}$ \\
\hline $\begin{array}{l}\text { Friedel et al., } \\
2007\end{array}$ & $\begin{array}{l}N=1021 \\
7^{\text {th }} \\
\text { US }\end{array}$ & $\begin{array}{l}\text { Parent goal } \\
\text { emphasis: } \\
\text { mastery, } \\
\text { performance }\end{array}$ & $\begin{array}{l}\text { Mastery Orientation } \\
\text { Performance } \\
\text { Orientation }\end{array}$ & $\begin{array}{l}\text { Positive } \\
\text { Projection } \\
\text { Denial } \\
\text { Non-coping }\end{array}$ \\
\hline $\begin{array}{l}\text { Kahraman \& } \\
\text { Sungur, } 2013\end{array}$ & $\begin{array}{l}N=977 \\
7^{\text {th }} \\
\text { Turkey }\end{array}$ & $\begin{array}{l}\text { Perceived parent } \\
\text { achievement } \\
\text { goals: mastery, } \\
\text { performance }\end{array}$ & $\begin{array}{l}\text { Mastery Approach } \\
\text { Goals } \\
\text { Mastery Avoidance } \\
\text { Goals } \\
\text { Performance } \\
\text { Approach Goals } \\
\text { Performance } \\
\text { Avoidance Goals }\end{array}$ & $\begin{array}{l}\text { Positive } \\
\text { Projection } \\
\text { Denial } \\
\text { Non-coping }\end{array}$ \\
\hline $\begin{array}{l}\text { Raftery-Helmer } \\
\text { \& Grolnick, } \\
2016\end{array}$ & $\begin{array}{l}N=201 \\
6^{\text {th }} \\
\text { US }\end{array}$ & $\begin{array}{l}\text { Autonomy } \\
\text { Support } \\
\text { Involvement } \\
\text { Structure }\end{array}$ & $\begin{array}{l}\text { Perceived Control } \\
\text { Perceived } \\
\text { Competence }\end{array}$ & $\begin{array}{l}\text { Mastery } \\
\text { Defense }\end{array}$ \\
\hline $\begin{array}{l}\text { Raftery-Helmer } \\
\text { \& Grolnick, } \\
2018\end{array}$ & $\begin{array}{l}\mathrm{N}=183 \\
6^{\text {th }} \\
\text { US }\end{array}$ & $\begin{array}{l}\text { Involvement } \\
\text { Structure } \\
\text { Autonomy } \\
\text { Support } \\
\end{array}$ & $\begin{array}{l}\text { Challenge Appraisals } \\
\text { Threat Appraisals }\end{array}$ & $\begin{array}{l}\text { Mastery } \\
\text { Defense }\end{array}$ \\
\hline
\end{tabular}

Mediators based in self-determination theory. Three studies have been conducted using SDT as a theoretical framework for examining possible pathways between parent's provision of motivational supports and children's academic coping. Of 


\section{PARENTING AND ACADEMIC COPING}

these, only one included at least one of the self-system processes suggested by SDT, while the other two focused on other child appraisals, leaving the possibility of selfsystem processes as mediators of parenting and coping largely unexplored. These latter two studies are still rooted in SDT despite the absence of self-system processes as mediators, since their predictors reflect the contextual supports suggested by this framework.

Raftery-Helmer and Grolnick (2016) looked at perceived control and competence as possible processes through which parental involvement, structure, and autonomy support influenced the academic coping of sixth graders. They found that for structure and autonomy support, perceived control partially mediated their negative direct impact on defensive coping, indicating that higher levels of these kinds of parenting resulted in a greater feeling that children's actions would achieve desired consequences, which then lessened their reliance upon maladaptive ways of coping. In a separate paper using the same dataset, these researchers also hypothesized that threat and challenge appraisals would mediate the connection between parenting and coping (Raftery-Helmer \& Grolnick, 2018). Results indicated that only threat appraisals mediated the relationship between autonomy support and defensive coping, suggesting that when parental autonomy support is low, children are more likely to appraise difficult academic tasks as threatening and cope using blame, avoidance, or rumination.

Researchers focused on parental conditional regard and control (here referring to coercive parenting, or the opposite of autonomy support) looked at whether feelings of self-aggrandizement following success or shame following failure mediated the 


\section{PARENTING AND ACADEMIC COPING}

relationship between these types of parenting and maladaptive coping, which they separated into compulsive over-investment (i.e., rumination) and avoidance of challenge (i.e., escape) (Assor \& Tal, 2012). Their results suggested that the link between children's perception of their parent's affection as conditional on their achievement and unproductive coping was fully mediated by their feelings of grandeur when they were successful and shame when they failed. The impact of parental control (i.e., coercion) on avoidance coping was similarly fully mediated by the feeling of shame, suggesting that the pathway through which coercive parenting has an impact is through its effect on children's feelings and self-perceptions.

Although these three studies concern different types of mediators, predictors, and outcomes, only some of which are directly suggested by the SDT motivational framework, all together they support the idea that children's internalized beliefs about the self and others are shaped by their parents and themselves shape coping. Even further, they support the hypothesis that these may be the process through which parenting is having its own impact on coping, even if they are not directly looking at the same processes proposed by SDT. If children's self-beliefs and appraisals are a pathway through which parents impact coping, as this literature suggests, then it follows that their self-system processes of relatedness, competence, and autonomy may have the potential to play a similar role.

Other motivational frameworks. In addition to research based in SDT, two studies examined possible mediators of parenting and academic coping within the framework of achievement goal theory (Urdan \& Kaplan, 2020). These researchers have 


\section{PARENTING AND ACADEMIC COPING}

found that children's own mastery and performance goal orientations mediated the connection between perceived parental goal orientations and coping strategies or profiles (Friedel et al., 2007; Kahraman \& Sungur, 2013). Friedel et al, (2007) found that seventh graders' perceptions of parent's goal orientations were having their effect on children's positive, denial, projection, and non-coping indirectly through their influence on children's own goal orientations, over and above the effect of teachers orientations. Specifically, these results indicated that youth were more likely to have mastery orientations themselves if they perceived their parents as having mastery orientations as well, and that their own endorsement of mastery goals was linked to the use of more positive and less denial and projection coping. In a similar pattern of results, perceived parent performance goals predicted student performance goals, and led to higher levels of denial, projection, and non-coping, and lower levels of positive coping.

Other researchers have distinguished between children's mastery approach and avoidance, and performance approach and avoidance goals arguing that they act as distinct processes behind parents' effects on coping, though in differing ways than described above, where no approach and avoidance distinctions were made. In a study of Turkish seventh graders, only parent's perceived mastery goals predicted both students' mastery approach and avoidance goals, which mediated the connection between parenting and coping (Kahraman \& Sungur, 2013). Children's mastery approach goals were the pathway through which parent mastery goals predicted higher levels of positive coping and lower levels of projective coping, while mastery avoidance goals, which were also more likely to occur when parents were perceived to have mastery orientations, 


\section{PARENTING AND ACADEMIC COPING}

predicted higher levels of both projection and non-coping. No mediational models were supported between parent performance goals, child performance goals, and any way of coping.

Just as when the direct effects from these studies were considered as evidence for how parents' shape coping, together mediational findings present a somewhat confused case for whether children's goal orientations are consistently a mechanism by which this occurs. What they do support, by demonstrating some mediational, though inconsistent, connections, is that parents may have an impact on their children's beliefs about themselves and the world around them, and these beliefs in turn may shape the individual ways and general profiles of coping children turn to when faced with difficulty and hardship. This also bolsters the hypothesis that other types of internal working models that children create, such as self-system processes, are worthwhile candidates for mediators of the relationship between parenting and academic coping.

Summary. Overall, these studies suggest that the beliefs children hold about themselves could be a possible pathway through which parents influence children's ability to handle the stressors they regularly encounter in school. Though these studies support this conception of self-beliefs, none looked at all three of the self-system processes based in SDT as possible mediators, nor did they use a comprehensive set of coping categories as outcomes. Additionally, all five studies, although testing mediational models, used cross-sectional designs, making it impossible to establish the direction of effects. The paucity of research done in this area emphasizes the importance of 


\section{PARENTING AND ACADEMIC COPING}

continuing to explore these lines of inquiry, using longitudinal data as well as theoryderived mediators and ways of coping.

\section{Summary Critique of Research Examining Parenting Effects on Academic Coping}

Despite research confirming that parenting is essential to academic functioning and coping, there are few studies that explicitly concern these topics, with only nine identified at the time of this writing. Even further, this small body of research has additional limitations that generally fall into three main categories. First, the absence of a theoretical framework identifying the core categories of coping has led to unclear, incomplete, and overlapping coping constructs, making cross-study comparison and integration of findings especially difficult. Second, the area has suffered from an overreliance upon cross-sectional research. Studies' consistent use of only a single time point has caused confusion because this design precludes definitive conclusions concerning the directions of effects between social partners. Third, the incomplete and inconsistent inclusion of possible mediational processes through which parenting is impacting coping has led to little progress identifying these pathways. The small handful of studies that explicitly looked at these mechanisms all used different mediators, with varying results, none explicitly looking at all the processes suggested by SDT, nor using multiple time-points over the school year. Ultimately these limitations represent an opportunity for future research, including the present study, to further our understanding of this dynamic relationship and how it connects to children's actions under stress by addressing unanswered questions and methodological shortcomings present in the field. 


\section{PARENTING AND ACADEMIC COPING}

\section{Chapter III. Purpose of Study}

The goal of this study is to broaden our knowledge regarding how parents, through their provision of motivational supports, affect children's ability to handle the challenges and setbacks they regularly encounter at school. Specifically, the aim is to deepen our understanding of exactly how high-quality parenting directly impacts academic coping, investigate possible feedback effects from children's coping to parents' subsequent offering of supports, and explicate the mechanisms through which parenting shapes coping, all during late elementary and the transition to middle school. In order to better understand this reciprocal relationship and explore the possible self-system processes that may mediate parenting and coping, data from a study of third through sixth graders in a rural-suburban public school district in the northeastern United States was used that employed a cohort-sequential design.

\section{Contributions of the Present Study}

The structure of the present study, including its predictors, mediators, outcomes, and feedforward and feedback effects, emerged directly out of the conceptual framework of self-determination theory (Figure 3.1). SDT, with its focus on fundamental psychological needs, allowed for the creation of a complete model describing the coping process, including a multidimensional conception of coping, and specifying particular contextual antecedents and possible pathways through which these contextual supports impact subsequent coping. While these ideas were theoretically derived, subsequent reviews of the literature found evidence to be limited although generally encouraging, confirming that the current study may be able to substantially expand the empirical base 


\section{PARENTING AND ACADEMIC COPING}

on these issues. Specifically, the study's primary contributions consist of (1) a clear conception of the core categories of coping, (2) a complete set of parental motivational provisions, and (3) identification of possible pathways through which parents impact coping. Each of these contributions will be explained further before the research questions are described.

Figure 3.1

The Dynamic Relationship between Parenting and Children's Adaptive and Maladaptive Coping

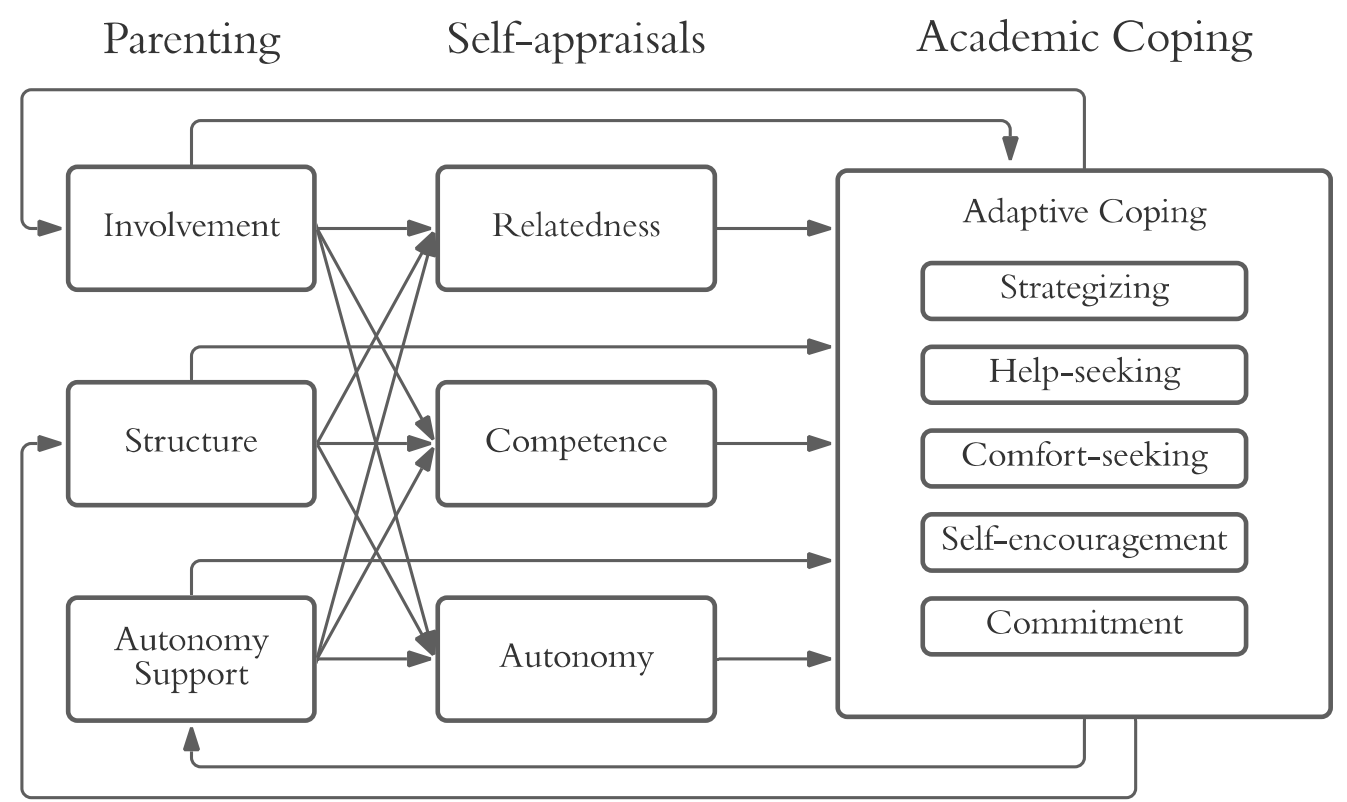




\section{PARENTING AND ACADEMIC COPING}

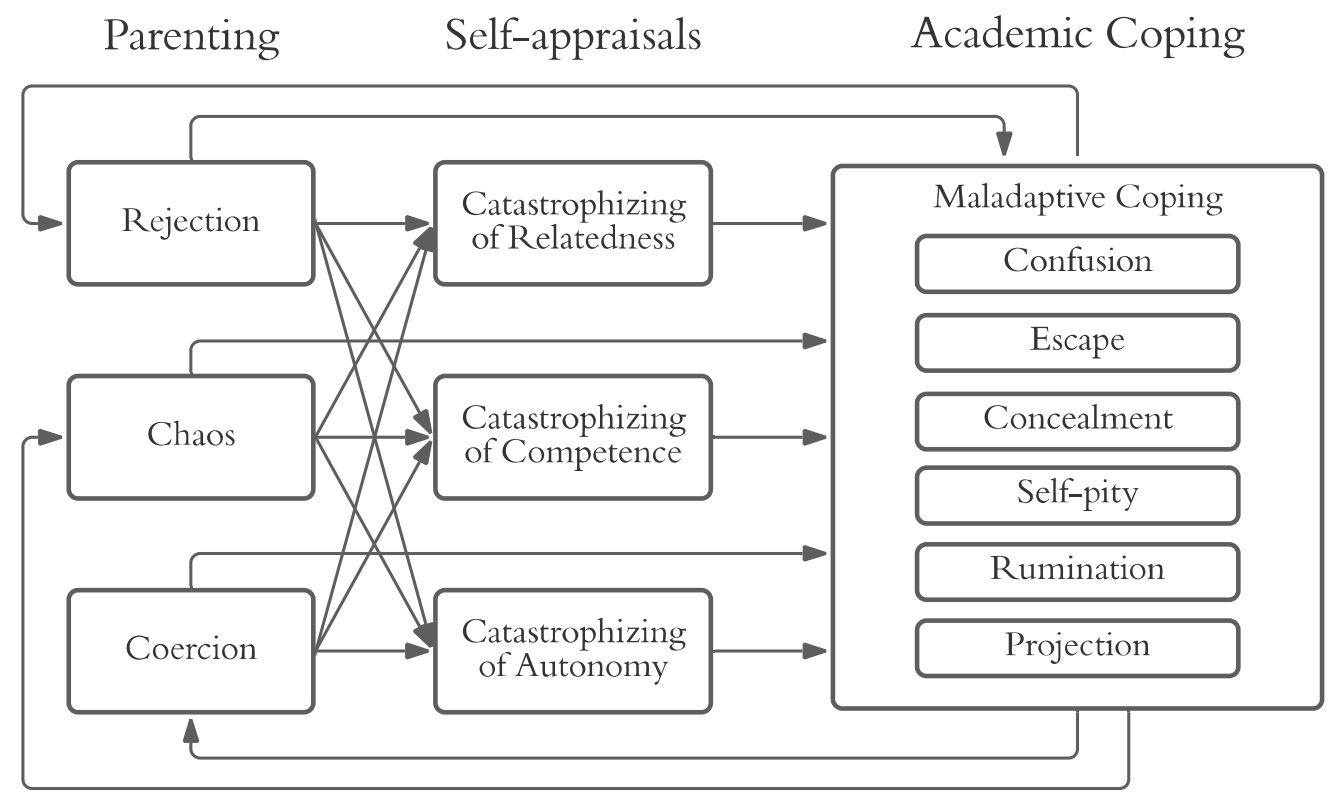

Core categories of coping. As stated above, one of the essential contributions of this study is the application of a motivational theoretical framework based in SDT to identify the contexts, antecedents, processes, and outcomes of children's coping. But SDT not only suggests particular variables of interest for the present research, it also serves as the structure upon which a comprehensive and comprehensible list of categories of academic coping has been constructed (Skinner et al., 2003). The inclusion of this conception of coping is a noteworthy contribution of this study, both theoretically and methodologically, as few studies concerning academic coping contain a complete conceptualization of the ways children and adolescents cope in the academic domain. This comprehensive list of ways is a fundamental addition to the field because it ensures that constructs are capturing as many coping actions as possible, allows us to make statements about individual differences in coping profiles that include a repertoire of 


\section{PARENTING AND ACADEMIC COPING}

ways of coping, as well as to consider how different aspects of parenting may promote or hinder specific ways, and to test whether different self-appraisals mediate the effects of parenting on particular ways of coping.

Allocation scores. To accurately evaluate these comprehensive categories of both children's adaptive and maladaptive coping, the current study will utilize allocation scores in addition to traditional average scores. Allocation scores factor into their calculation children's total amount of coping, and therefore, arguably, the total amount of stress they are experiencing, by dividing individual scores for ways of coping by the total amount of coping (adaptive and maladaptive) that children show. This proportion disentangles the amount of stress children experience from the amount of coping itself, keeping adaptive coping scores from being artificially lowered and maladaptive ones from being inflated by higher levels of distress. Through the use of allocation scores in addition to average scores, the current study was able to more accurately capture children's levels of academic coping, contributing to our greater understanding of these processes. These scores were especially useful in providing information about adaptive ways of coping, whose contributions may be underestimated by average scores.

Parental provisions and academic coping. The present study hypothesizes that parents impact their children's academic coping, and potentially its development, by offering motivational supports, specifically those suggested by self-determination theory: Involvement, structure, and autonomy support (Connell \& Wellborn, 1991; Ryan \& Deci, 2017; Skinner et al., 2005). As demonstrated in the review of current studies of parenting and coping, only a few have explicitly looked at all three of these dimensions, instead 


\section{PARENTING AND ACADEMIC COPING}

primarily focusing on a subset or combination of constructs. By including all three as separate criterion variables, this study is able to identify both the unique contributions of these dimensions as well as the possible benefit from the presence of all three. Additionally, by utilizing a short-term longitudinal design, this study can examine parenting dimensions as predictors of change in children's coping over the school year. As a result, this study can not only hypothesize that there is an association between parental supports and children's coping but also posit directional relationships both from parents to children and from children to their parents, describing this relationship in greater detail.

Involvement. Parental involvement, as a primary build block of high-quality parent-child relationships, is of foundational importance to the development of academic coping through its encouragement of proximity, trust, communication, and comfort. Specifically, parenting that is characterized as warm, loving, affectionate, and involved is expected to lead to increases in all individual ways of adaptive coping. A warm and affectionate parent or caregiver will most clearly support children's use of comfortseeking to handle problems, as having trusted others to go to in times of stress is one of the most fundamental components to a secure attachment. A secure attachment may also encourage a child's feelings of worthiness, which may lead to the greater use of selfencouragement when faced with difficulty, as these children may be more likely to be supportive of themselves. A secure base may also encourage students to try to solve academic problems on their own, using strategizing, confident in the knowledge that others are there to support them, or give them the idea that other people can be trusted 


\section{PARENTING AND ACADEMIC COPING}

enough to provide informational support through help-seeking. Involvement may also lead children to use more accommodation strategies, i.e., commitment, as the presence of a loving parent may help children understand and internalize the value of their task.

This study also posits that involved parenting may lead to a reduction in the use of maladaptive ways of coping, both overall and in each individual way. A secure attachment with involved parents would most clearly lead to a decline in children's reliance upon concealment and self-pity, as strong and healthy relationships with others lessen the desire to hide or lament their situation. Coping characterized by disorganization and helplessness (i.e., confusion) may also be reduced when children know their parents are present, loving, and available when they run into trouble. Their impulse to escape their problems may also be reduced when they experience their parents' love as unconditional and not dependent upon success or failure, lessening their fear of confronting difficulty. Warmth would also likely reduce their inclination to blame themselves (i.e., rumination) or others (i.e., projection), and focus instead on the task at hand. These connections between involvement and all ways of coping, although theoretical in nature, reveal how important it is to look directly at this parenting dimension and its impact on both children's general adaptive coping profile and their use of individual ways. While much research has been conducted concerning the importance of parental warmth, involvement and the benefit of a secure attachment to coping in general (e.g., Zimmer-Gembeck et al., 2017), little of this work has been done in the academic coping realm, thus, the current study can add further dimensions to our 


\section{PARENTING AND ACADEMIC COPING}

understanding of how involvement can impact children's academic functioning and their ability to handle academic difficulty in particular.

Structure. Parents' provision of structure is also essential to children's coping, as it supplies the specific nutriments needed to handle academic difficulty. As structure is comprised of things like high standards, appropriate limits, provision of instrumental aid, and scaffolding, parents who are high on this dimension may directly support adaptive coping while discouraging maladaptive by handing children strategies, being consistent, or building skills that might be necessary for future tasks. In particular, structure bolsters help-seeking as children know that their parents are a resource for the provision of specific strategies and ideas that may lead them out of difficulty. Experiences of parents as providers of assistance may also lead to increases in strategizing, as children have learned how to solve their own problems from repeated scaffolding. Less obviously, structure may also strengthen comfort-seeking, as children may be more likely to seek emotional support from parents whose actions are predictable rather than chaotic and non-contingent. Self-encouragement and commitment may also be supported as children may have increased confidence or value academic tasks when their interactions with their parents are characterized by reasonable high standards.

Structure may also directly lessen children's reliance upon maladaptive coping, especially confusion, as they have a history of contextual interactions that have helped them develop effective strategies in the face of stress. They may also use escape less often, having been taught to face their problems head on with assistance from a skilled partner. Children may also be less likely to hide their difficulty through concealment, as 


\section{PARENTING AND ACADEMIC COPING}

they are used to their parents being steady sources of help rather than undependable partners whose reactions cannot be predicted. When more focused inward, structure may protect against the use of self-pity as well, lessening children's need to feel sorry for themselves because they can envision a path forward with or without the help of others. The inclination to obsessively blame oneself (i.e., rumination), or lash out at others (i.e., projection), may also be reduced when parents are actively teaching them that the world is contingent upon their actions rather than uncertain and erratic.

These theoretical pathways between structure and individual ways of coping emphasize the essential role it may play as a possible predictor of the development of these strategies. Of the three motivational supports, the connection between structure and academic achievement and functioning outcomes has been studied the least with even less work specifically devoted to its impact on coping. Therefore, the current study can expand our understanding of the direct effects of structure on coping, leading to both a more thorough description of the antecedents of coping as well as the possibility of informing more effective parenting.

Autonomy support. Autonomy supportive parenting is necessary to children's coping as it actively bolsters both their ability to handle things on their own as well as reduces the personal threat they feel from challenges and setbacks. As children may most often be coping in situations where their parents are not directly present, a history of experiences that have taught them to be both confident in their own decisions and to understand the value of others' perspectives should prove valuable when they encounter difficulties in the academic domain. Parents' autonomy supportive actions may lead 


\section{PARENTING AND ACADEMIC COPING}

children to rely more upon commitment when faced with academic stress, as they may more easily remind themselves of the value of the task. They may also feel their parents respect and confidence in them, bolstering strategizing, while this boost of independence also makes seeking the help of others (i.e., help-seeking) non-threatening. Children who feel listened to and respected are also more likely to seek out others when they run into trouble, relying upon comfort-seeking strategies. Even further, they may not even need to directly seek this emotional support, but instead use self-encouragement strategies on their own, as they know their parents respect their choices and opinions.

Autonomy support may also actively buffer children from maladaptive strategies such as projection, as children feel less of a need to blame others when they know people value their perspective and decisions. Similarly, this genuine respect from parents may reduce children's inclination to ruminate on their failures or react with self-pity. Children may not feel the need to hide their troubles, using concealment, or to try to escape them, when they are experiencing their parents as genuinely supportive of their goals. The selfconfidence bourn from having people around who truly believe in you may also help avoid confusion, giving children the sense that they can create a path forward. From the hypothesized connections between autonomy support and these individual ways of coping, it follows that this motivational support is pivotal to the promotion of adaptive coping and protection against maladaptive coping. Thus, the inclusion of autonomy support as a predictor of academic coping will also increase our understanding of the parent-child dyad and how it can shape the development of children's coping. In sum, the establishment of a clear, directional connection between these three aspects of parenting 


\section{PARENTING AND ACADEMIC COPING}

and coping would aid in the development of effective interventions, help guide parent education, and further our understanding of the role of the complex parent-child relationship when students are experiencing everyday academic stress.

Feedback effects. The use of data collected at two time points also allows this study to examine possible feedback effects from children's academic coping to changes in parents' subsequent offering of motivational supports. Children's coping is anticipated to have an impact on parenting not only because of the transactional nature of their interpersonal relationship, but also because children's action regulation under stress may be sending messages, reliable or not, to parents about what they may need. Visible proximal processes between children and academic tasks during times of distress may send specific signals to parents about what is occurring and what types of supports would be most helpful. For example, a child who has encountered a particularly difficult homework problem and decides to then ask their caregiver for ideas about how to solve it (e.g., help-seeking) will most likely then receive assistance (i.e., structure). The adult may then even stick around to see how the child implements these ideas in subsequent interactions with the tricky problem (via strategizing), providing additional encouragement (i.e., involvement) and suggestions (i.e., structure) for subsequent homework tasks. In this hypothetical example, although the child may not continue to actively seek out strategies, the initial act of help-seeking may lead to additional scaffolding (i.e., structure) and encouragement (i.e., involvement) that might lessen the amount of stress experienced overall. When instead a child turns to a maladaptive way of coping such as concealment, actively trying to hide their struggles from others, their 


\section{PARENTING AND ACADEMIC COPING}

parent cannot even attempt to offer comfort (i.e., warmth or involvement) or structure, as they are not aware that their child is in distress.

Despite a lack of research concerning the issue, feedback effects from children to parents could be expected when examining the relationship between coping and motivational supports. Coping happens on the plane of action, is visible to parents, and contains the kind of behaviors and emotions that should draw their attention and so elicit a reaction. Parents also have an investment in their children's completion of schoolwork, so they are not as likely to allow children to resolve academic demands via escape or blaming others. As the current study is the first to look directly at these hypothesized effects, its inclusion is a significant contribution to the field. The addition of evidence regarding feedback effects could lead not only to a deeper understanding of the parentchild relationship, but also to more effective parent education, as parents could be taught to interpret and diagnose their children's reactions to academic difficulty as signals about their underlying needs.

Processes through which parenting affects coping. The present study is also anticipated to make contributions to the field of academic coping by investigating all three self-system processes posited by SDT and self-system theory (i.e., relatedness, competence, and autonomy), and their catastrophizing appraisals, as possible pathways through which parents are influencing children's coping. No previous studies have looked at all of these systems together as possible mediators, so this investigation should provide a more complete empirical picture of how children's internal working models are both 


\section{PARENTING AND ACADEMIC COPING}

influenced by their parents' provision of resources and in turn are influencing children's action tendencies in the face of stress.

Relatedness. Children and youth's self-systems organized around their sense of belonging and relatedness are essential to coping as they reflect internal models regarding others as trustworthy and the self as lovable. These two beliefs are required for children to utilize adaptive coping strategies in the face of stress, as they must feel comfortable both turning to others for assistance, whether for emotional or instrumental support, as well as providing this type of encouragement to themselves. Relatedness is in turn bolstered by parents' offering of motivational supports, as these self-systems are partially created from the history of interactions that children have with their social context. When parents are warm and involved, provide appropriate limits and predictable structure, and genuinely listen, respect, and value their children and their perspective, they are providing necessary nutriments for the construction of positive internal working models regarding belonging. For example, the sense of relatedness resulting from high-quality parenting may encourage students to seek out their parents when they need additional emotional resources or strategies (i.e., comfort-seeking or help-seeking) while working on difficult academic tasks. Similarly, the child may "feel" the presence of this involved parent from afar even when the parent is not physically there, and through the knowledge that they have trusted other in their corner, may be more likely to bolster their own flagging spirits, or develop their own problem-solving techniques. Ultimately, these two pathways suggest that relatedness should be a mediator between parenting and all adaptive ways of coping. 


\section{PARENTING AND ACADEMIC COPING}

Competence. Self-systems regarding children's competence are also fundamental to children's coping as they represent their beliefs about what they are capable of, how they expect the environment to react to their actions, and whether they are in control of desired outcomes. Children who have strong feelings of mastery are likely to cope with academic stressors more constructively as they believe they have the skills, or are capable of gaining the skills, necessary to handle whatever is thrown at them. These internal feelings of competence are expected themselves to be positively impacted by parents' provision of involvement, structure, and autonomy support. This is because parents who are invested and aware of their child's academic life, hold their children to high, reasonable, and consistent standards, and believe in their child's genuine goals and preferences are more likely to foster internal working models that reflect mastery. For instance, when a child with a history of these experiences with their parents then confronts a stressful challenge at school, such as a difficult math problem, the strong feelings of competence that may result mean that the child likely feels confident enough to try strategies on their own and encourage themselves to persist, while at the same time, they can turn to teachers or peers for comfort or helpful ideas as a fallback if initial strategies prove ineffective. Altogether, this suggests that competence should be a mediator of parenting and student's adaptive coping.

Autonomy. A sense of autonomy is similarly central to academic coping because children's feelings that they are free to express their genuine goals and preferences may lead to more adaptive action in the face of challenging tasks. These feelings may both bolster children's belief in their own goals as well as lessen the pressure they feel from 


\section{PARENTING AND ACADEMIC COPING}

externally imposed tasks, as schoolwork often involves tasks that students do not find intrinsically rewarding. High-quality parenting, or that which is high in all three motivational supports, may in turn increase student's self-system process of autonomy because the history of interactions over time are those that value the child's perspective, create a secure attachment, and help children develop the skills to accomplish things on their own. Namely, a parent who when helping with homework listens to their child's opinions, actively helping them understand the value of the task, contributes to the fulfillment of that child's need for autonomy, possibly leading to a positive internal working model regarding this particular self-system process. These feelings of selfdetermination, created from such proximal processes, then serve as motivational resources during stressful events, such as when the child is required to take a boring standardized test. Though this task provides no inherent interest or joy for students, they may more easily understand why its completion is important and be able to more adaptively cope with the challenge it presents. This temporal pattern of effects suggests that a child's perceived autonomy may be a pathway through which parents are influencing changes in adaptive coping.

Catastrophizing of relatedness. Children's self-system processes are likely the primary mediators between parenting motivational supports and adaptive coping, but SDT also suggests a complementary set of catastrophizing appraisals that should similarly mediate the relationship between parenting and maladaptive coping. When children have a history of interactions that do not meet their needs for relatedness, they are more likely to appraise stressful events as threats to their relationships with others, 


\section{PARENTING AND ACADEMIC COPING}

that is, negative school experiences could then trigger fear of rejection and loss of belonging. This type of appraisal should increase the likelihood of maladaptive coping because those specific ways of handling difficulty at school can be characterized by wanting to actively hide, avoid problems, or even blame others. Parents who offer low levels of motivational supports, and instead are chaotic, rejecting, or coercive, may contribute to this reliance upon catastrophizing appraisals of relatedness as well because children are used to failure eliciting less support from their caregivers. These two hypothesized effects imply that parents may influence children's coping through their impact on catastrophizing of relatedness.

Catastrophizing of competence. Similarly, when children catastrophize about their sense of competence, they are likely to dramatically increase their use of unproductive ways of coping because the inclination to appraise poor academic outcomes as a sign of their ineptitude may lead them to amplify the threatening aspects of these experiences. Parents may be facilitating the formation of these appraisals when they are less involved in their children's academic lives, do not scaffold learning or enforce appropriate limits, and coerce their child into uninteresting activities with rewards and punishments. For example, when children in families that provide low levels of these motivational supports encounter a homework problem they cannot figure out how to complete, they may be more likely to interpret it as evidence of their incompetence. This appraisal may then lead them to more heavily rely upon maladaptive coping strategies, such as confusion, escape, or self-blame (i.e., rumination) as they become overwhelmed by their fear of failure when trying to deal with difficult academic work. Therefore, 


\section{PARENTING AND ACADEMIC COPING}

catastrophizing of competence is most likely a mediator of the effect of parental provisions on maladaptive coping.

Catastrophizing of autonomy. Catastrophizing of autonomy, or a tendency to interpret stressful events in ways that induce guilt and taint future endeavors, may result from a history of interactions that not only thwart children's need for autonomy through coercion, but also through a lack of parental involvement and structure. Children's catastrophizing of autonomy itself may then lead to an increased use of maladaptive coping strategies when they encounter academic setbacks, heightening the total amount of perceived stress they experience. For instance, when parents make offerings of affection contingent upon high achievement, a child may view academic difficulties, such as not being able to immediately understand how to complete an assignment, as a personal failure, evincing strong feelings of guilt and self-blame. This catastrophizing or self-derogation of their sense of autonomy may increase the likelihood that they react to future stressors with maladaptive ways of coping such as rumination or projection, as these feelings of guilt manifest as obsession or lashing outwards. Other maladaptive ways may also emerge as children attempt to avoid, escape, or whine about their trouble, convinced that the task holds no worth for them or that they are inherently at fault. This suggests that catastrophizing of autonomy is also a likely mediator between parenting and children's academic coping.

Summary. As stated above, the examination of all six of these self-systems and catastrophizing appraisals as mediators are anticipated to be a major contribution to the field of parenting and academic coping. This is meaningful because it is difficult to 


\section{PARENTING AND ACADEMIC COPING}

ascertain which processes may be essential or if all should be considered equally without including all as possible mediators. SDT posits that the extent to which an individual's context fulfills or hinders their need for relatedness, competence, and autonomy is of fundamental importance to their psychological well-being. Social partners, including parents, can support or thwart these needs through their varying level of involvement, structure, and autonomy support. These supports then impact children's development of self-systems organized around these three needs, which in turn inform their action tendencies in the face of academic stressors, that is, how they cope. It follows, then that all of these self-systems, and their catastrophizing appraisals, should therefore mediate the effect of parenting motivational supports on children's academic coping.

\section{Research Questions and Hypotheses}

The three main contributions of the present study, mentioned above, are 1) the inclusion of a precise and complete list of categories of coping, 2) the use of all three parental motivational supports suggested by SDT, and 3) hypothesized pathways through which parenting relates to coping including possible feedback effects. These lead directly into a set of specific research questions that address each point using a theoretical frame of self-determination theory designed to fill gaps in the larger academic coping literature. These research questions and their accompanying hypotheses will be described in detail below.

Research Question 1: How do parents, through their initial levels of motivational support, defined here as involvement, structure, and autonomy support, shape the development of children's coping in the academic domain? 


\section{PARENTING AND ACADEMIC COPING}

Parents provide differing levels of involvement, structure, and autonomy support when interacting with their children on a day-to-day basis. It is proposed in this study that initial levels of parental support in the fall of a given school year will predict changes in how children will cope with academic stressors as the school year progresses.

RQ1.a. Do higher initial levels of parental motivational support in the fall predict increases in children's adaptive coping strategies from fall to spring? (Figure 3.2)

Figure 3.2

Hypothesized Relationship Between Parental Provisions and Adaptive Coping.

Parenting in the Fall Changes from Fall to Spring

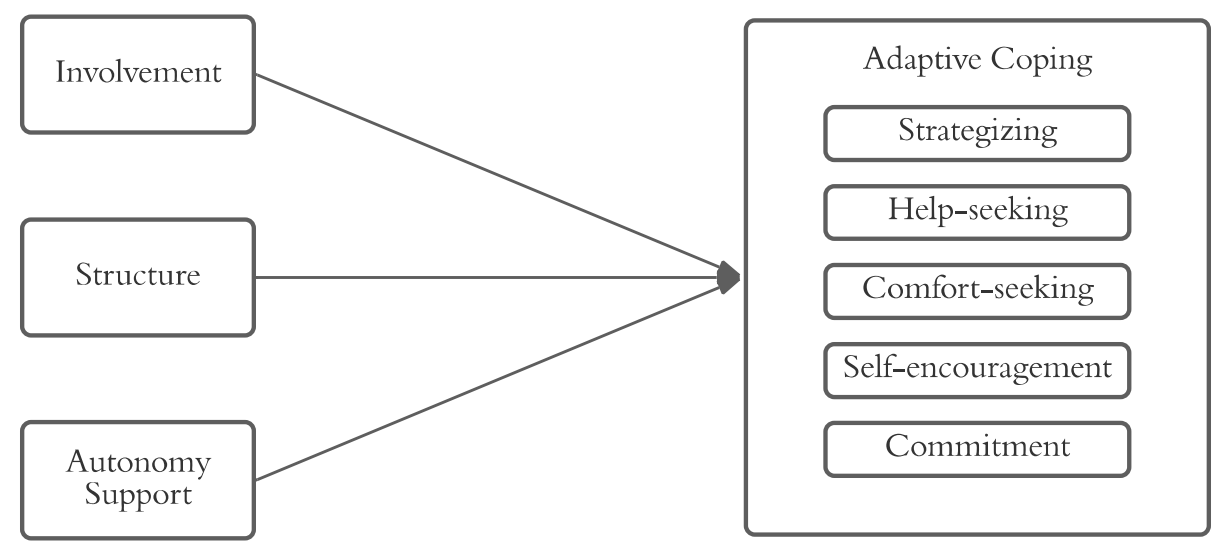

Hypothesis 1.a.1. Higher initial levels of parental involvement, structure, and autonomy support in the fall will significantly and uniquely predict increases in profiles of adaptive coping from fall to spring.

Hypothesis 1.a.2. Higher initial levels of parental involvement, structure, and autonomy support in the fall will significantly and uniquely predict increases in each 


\section{PARENTING AND ACADEMIC COPING}

individual way of adaptive coping, i.e., strategizing, help-seeking, comfort-seeking, selfencouragement, and commitment.

RQ1.b. Do higher initial levels of parental motivational support in the fall predict decreases in children's maladaptive coping strategies from fall to spring? (Figure 3.3)

Figure 3.3

Hypothesized Relationship Between Parental Motivational Supports and Maladaptive Coping Profiles and Individual Ways
Parenting in the Fall
Changes from Fall to Spring

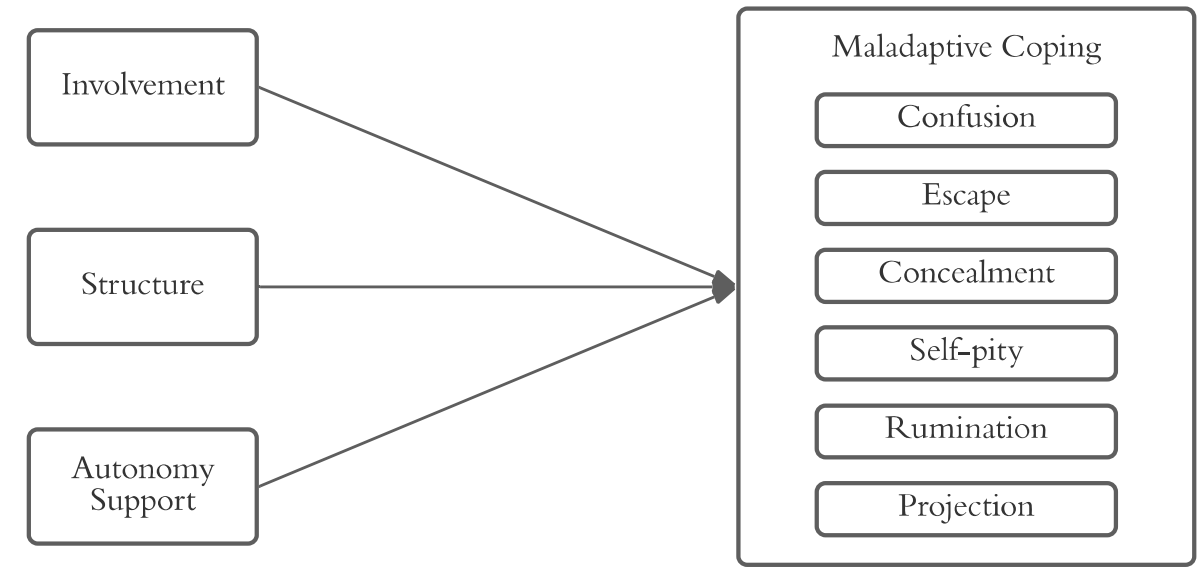

Hypothesis 1.b.1. Higher initial levels of involvement, structure, and autonomy support in the fall will significantly and uniquely predict decreases in children's profiles of maladaptive coping from fall to spring.

Hypothesis 1.b.2. Higher initial levels of all parental motivational supports in the fall will significantly and uniquely predict decreases in each individual way of maladaptive coping, i.e., confusion, escape, concealment, self-pity, rumination, and projection. 


\section{PARENTING AND ACADEMIC COPING}

\section{Research Question 2: How do children's initial levels of adaptive or}

\section{maladaptive academic coping affect changes in parent's level of involvement,}

structure, and autonomy support? Although it is expected that parents may be influencing their children during academic coping episodes, it also seems likely that parents are also reacting to and being influenced by their child's behavior. Therefore, this study posits that the ways in which children cope with their academic tasks will also shape how much involvement, structure and autonomy support parents subsequently provide.

RQ2.a. Do initially higher levels of adaptive coping in the fall lead to increases in parental motivational support from fall to spring? (Figure 3.4)

Figure 3.4

Feedback Effects from Children's Adaptive Coping to Parental Motivational Supports
Coping in the Fall
Changes from Fall to Spring

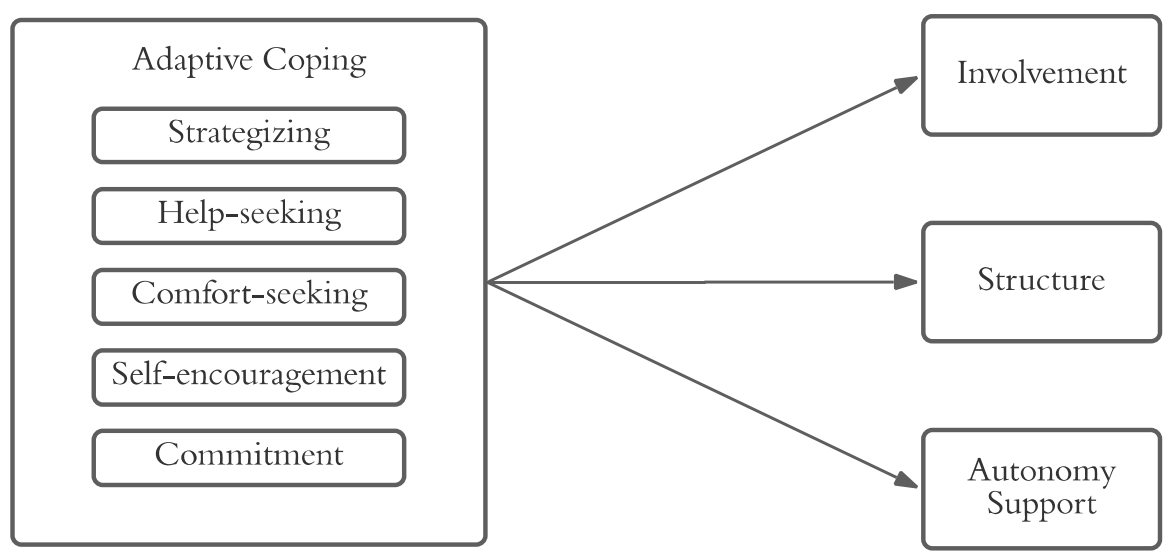




\section{PARENTING AND ACADEMIC COPING}

Hypothesis 2.a.1. Initially higher levels of profiles of adaptive coping in the fall will predict increases in involvement, structure, and autonomy support across the school year.

Hypothesis 2.a.2. Initially higher levels of strategizing, help-seeking, comfortseeking, self-encouragement, and commitment in the fall will uniquely predict increases in involvement, structure, and autonomy support from fall to spring.

RQ2.b. Do initially higher levels of maladaptive coping in the fall lead to decreases in parental motivational support from fall to spring? (Figure 3.5)

Figure 3.5

Feedback Effects from Children's Maladaptive Coping to Parent's Offering of Motivational Supports
Coping in the Fall
Changes from Fall to Spring

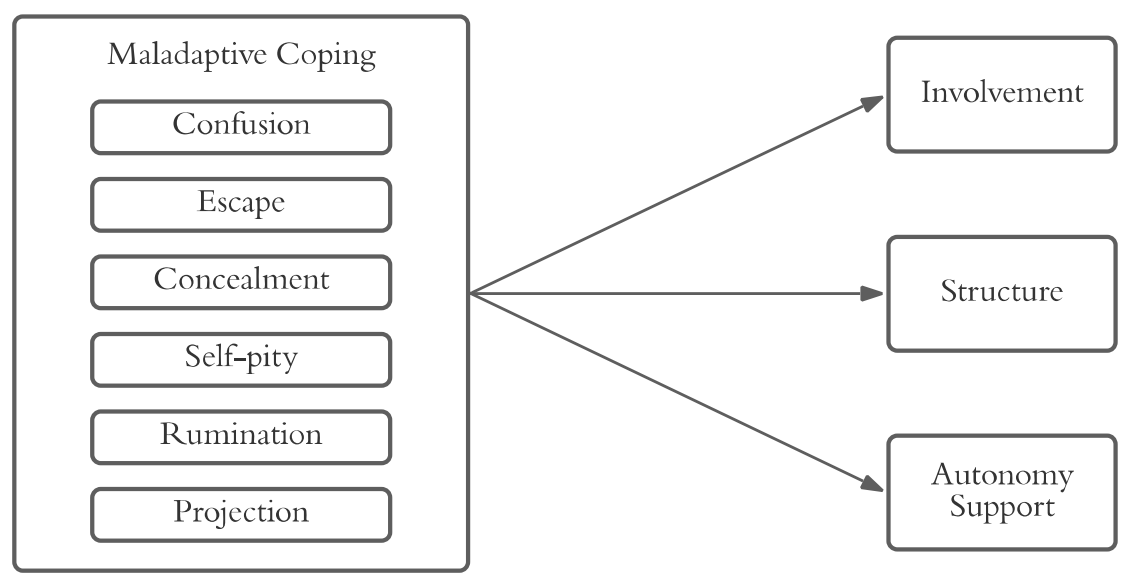

Hypothesis 2.b.1. Higher initial levels of profiles of maladaptive coping in the fall will predict decreases in involvement, structure, and autonomy support across the school year. 


\section{PARENTING AND ACADEMIC COPING}

Hypothesis 2.b.2. Higher initial levels of confusion, escape, concealment, selfpity, rumination, and projection in the fall will uniquely predict decreases in all parental motivational supports from fall to spring.

\section{Research Question 3: Through what processes do parental involvement,} structure, and autonomy support contribute to children's academic coping strategies? To further investigate the effects of parenting on the development of children's coping, this study will explore the processes through which parenting quality may be shaping children's academic coping. Children's experience of the world shapes the understandings they construct about themselves and their capacities, impacting their future actions. These internal processes may be a result of parents' involvement, structure, and autonomy support, and in turn affect the strategies they use when coping with difficult academic tasks.

RQ3.a. Is the effect of initial parental motivational support in the fall on changes in children's adaptive academic coping from fall to spring mediated by children's selfsystem processes of relatedness, competence, and autonomy in the spring? (Figure 3.6) 


\section{PARENTING AND ACADEMIC COPING}

Figure 3.6.

Children's Self-system Processes as Mediators of Parents' Motivational Supports and Children's Academic Coping

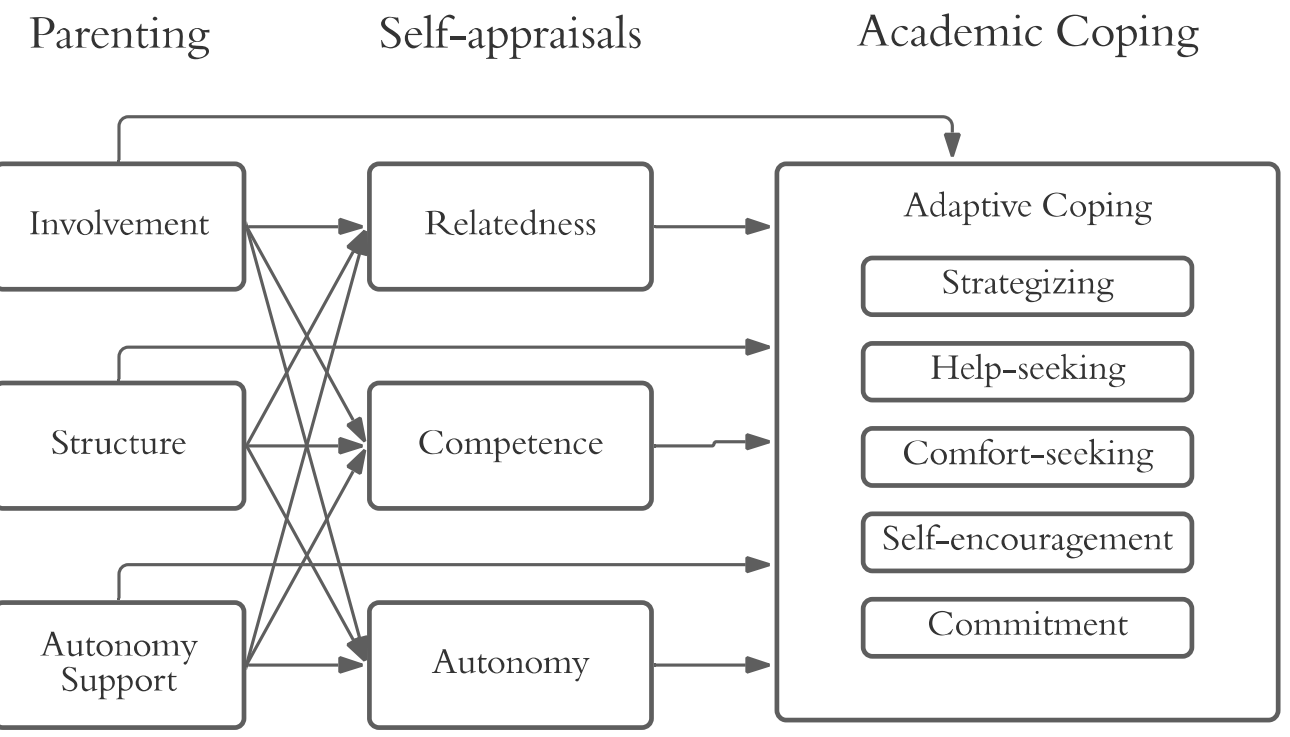

Hypothesis 3.a.1. Children's self-system processes in the spring will mediate the connection between initial levels of parental motivational supports in the fall and changes in children's profiles of adaptive academic coping across the school year.

Hypothesis 3.a.2. Spring levels of children's self-system processes will mediate the connection between initial levels of parental motivational supports in the fall and changes in strategizing, help-seeking, comfort-seeking, self-encouragement, and commitment from fall to spring.

RQ3.b. Is the effect of initial parental motivational support in the fall on changes in children's maladaptive academic coping from fall to spring mediated by children's catastrophizing of relatedness, competence, and autonomy in the spring? (Figure 3.7) 


\section{PARENTING AND ACADEMIC COPING}

Figure 3.7

Children's Catastrophizing Appraisals as Mediators of Parental Motivational Supports and Maladaptive Academic Coping

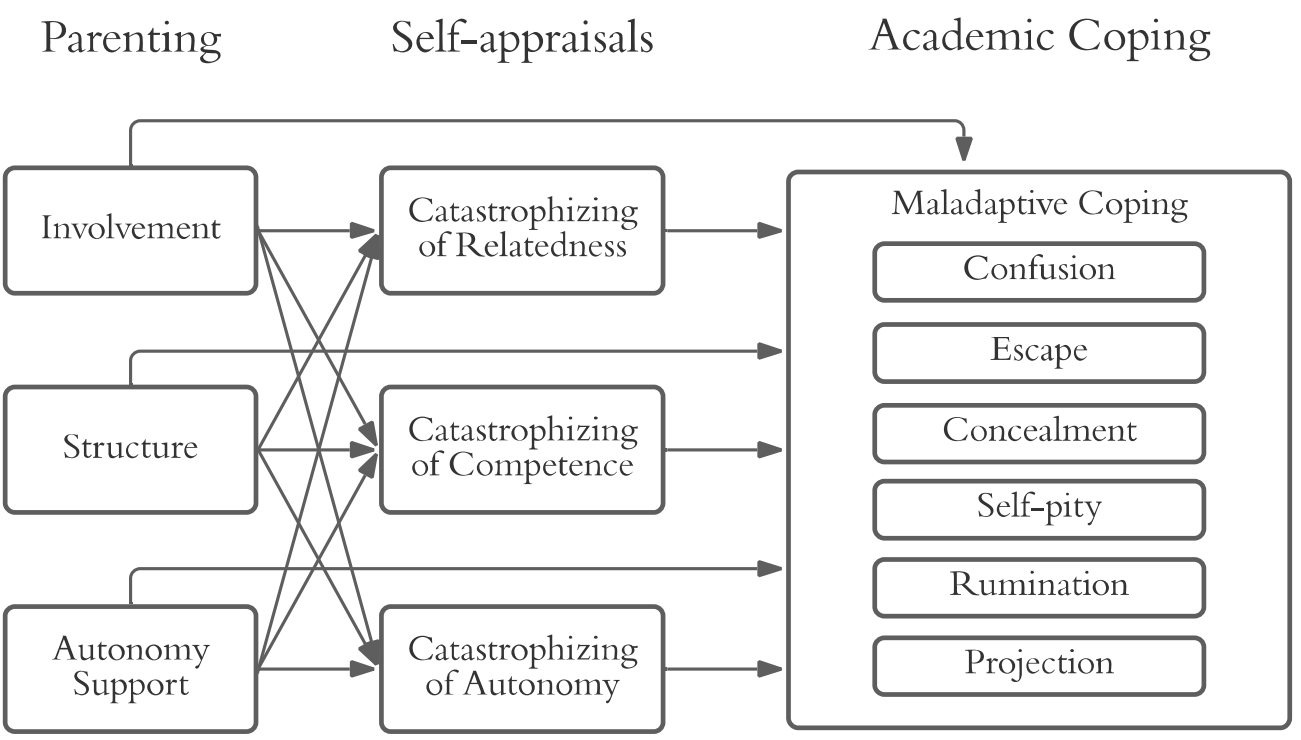

Hypothesis 3.b.1. Children's catastrophizing appraisals in the spring will mediate the connection between initial levels of parental motivational supports and changes in children's profiles of maladaptive academic coping across the school year.

Hypothesis 3.b.2. The level of children's catastrophizing appraisals in the spring will mediate the connection between initial levels of parent motivational supports in the fall and changes in children's maladaptive academic coping from fall to spring. 


\section{PARENTING AND ACADEMIC COPING}

\section{Chapter IV. Method}

\section{Sample}

Participants consisted of 1,020 third through sixth graders in a rural-suburban northeastern United States school district. This included 135 third graders, 340 fourth graders, 166 fifth graders, and 363 sixth graders, with grade level missing for 16 students. Student ages ranged from 8 - 13 and their gender was roughly evenly split between boys and girls. Family socioeconomic status was lower middle to middle class, as defined by parents' level of education and occupation. The sample was predominantly White, with $5 \%$ of students identifying as non-White.

\section{Design and Procedure}

The current study draws from a larger cohort-sequential study concerning academic motivation and coping that spanned four consecutive years and gathered data at two time points each year, October and May, as part of normally occurring assessments. At each time of measurement two trained interviewers administered questionnaires to students in their normal classrooms over three 40-minute sessions, when teachers were not present, with one interviewer reading questions aloud and the second interviewer answering clarifying questions.

\section{Measures}

Self-reported questionnaires assessed students' perception of parents' involvement, structure, and autonomy support, ability to cope in the face of academic difficulty at school, self-system processes of relatedness, competence, and autonomy support, and catastrophizing appraisals of relatedness, competence, and autonomy 


\section{PARENTING AND ACADEMIC COPING}

support. All scales had roughly equal numbers of negatively and positively worded items and used a 1-4 Likert-type scale, consisting of "not at all true", "not very true", "sort of true", and "very true". Negatively worded items were reverse scored, resulting in higher scores that reflect higher levels of a construct (see Appendix A for a complete list of all items).

Academic coping. Academic coping was assessed using a self-reported multidimensional measure of how children handled everyday academic stressors that utilized 11 subscales of individual ways of coping. Each individual subscale contained five items, and all have shown good internal consistency (Cronbach's $\alpha=.59-.85$, McDonald's $\omega=.59-.85)$ and reliability from fall to spring $(r=.47-.70)$ (Skinner et al., 2013). Subscales prompted students to consider what they do when they run into difficulty in school using four different stems, "When something bad happens to me in school (like not doing well on a test or not being able to answer an important questions)," "When I run into a problem on an important test," "When I can't answer a hard question or problem in class," and "When I have trouble with a subject in school." These individual subscales made up larger categories of adaptive and maladaptive ways of coping, with five adaptive ways including strategizing (e.g., "I try to figure out how to do better next time"), help-seeking (e.g., "I get some help to understand the material better"), comfort-seeking (e.g., "I spend time with someone I am close to"), self-encouragement (e.g., "I tell myself I'll do better next time"), and commitment (e.g., "I remind myself that it's worth it to me in the long run"). Six maladaptive ways were evaluated as well: Confusion (e.g., "My mind goes blank"), escape (e.g., "I tell myself it didn’t matter"), 


\section{PARENTING AND ACADEMIC COPING}

concealment (e.g., "I try to hide it"), self-pity (e.g., "I can't believe this is always happening to me"), rumination (e.g., "I can't get it out of my head"), and projection (e.g., "I say it was the teacher's fault"). Two separate confirmatory factor analyses have found support for the multidimensional nature of both the adaptive and maladaptive coping scale, upholding the conception of these scales as consisting of distinguishable categories (Gonçalves et al., 2019; Skinner et al., 2013). Average scores for each way of coping will be calculated by averaging the five items from that subscale individually. In addition, children's overall adaptive and maladaptive coping profiles will be computed by averaging participants' scores across either the five adaptive ways or six maladaptive ways.

Allocation scores. In addition to computing averages for children's individual ways of coping and adaptive and maladaptive coping profiles, allocation scores will be calculated to account for the overall level of coping and stress children are experiencing (Vitaliano et al., 1987). These scores will be calculated by taking the total score of all items from an individual way of coping, dividing it by the sum of all the ways of coping without reverse coding maladaptive ways, and multiplying this amount by 100 .

Parent motivational supports. Students' perceptions of their parents' offering of motivational supports was measured using three variables, namely involvement, structure, and autonomy support. All three constructs contained 5-items each and concerned these parental supports within the context of students' educational experiences.

Parental involvement. Student perceived parental warmth and involvement were assessed using five items drawn from a larger set of 18 -items designed to tap parent 


\section{PARENTING AND ACADEMIC COPING}

knowledge about their children's schooling (e.g., "My parents know a lot about what is important to me in school"), their time spent with their children on schoolwork or school activities (e.g., "My parents talk with me about schoolwork"), affection (e.g., "My parents enjoy hearing about my day", "My parents think that what I have to say about school is important"), and availability (e.g., "My parents don't seem to have enough time for me," reverse coded).

Parental structure. Parent's perceived level of structure was evaluated using six items designed to tap whether children were interpreting their parents' behavior and rulesetting as consistent, dependable, and appropriate, or instead as chaotic and unpredictable. Examples included "I can count on my parents when I have trouble in school" and "When my parents punish me they don't explain why" (reverse coded.)

Parental autonomy support. Perceived parental autonomy support was similarly assessed using four items that captured whether children thought their parents took their perspectives, listened to them, and valued their opinions (e.g., "When my parents find out I did something at school they don't like, they listen to me before they decide what they are going to do"), or were coercive and controlling (e.g., "When decisions are made about my schoolwork, my parents usually don't ask me what I think;" reverse coded).

Children's self-system processes. Children's appraisal of relatedness was assessed using 20 items concerning how connected they felt to their parents, teachers, peers, and friends (Connell \& Wellborn, 1991; Furrer \& Skinner, 2003). Students were prompted to think about when they were with specific social partners (e.g., "When I'm 


\section{PARENTING AND ACADEMIC COPING}

with my mother"), then asked four items, "I feel accepted", "I feel like someone special", "I feel ignored", and "I feel important", with the last two reverse coded.

Their perceived competence was evaluated using six items from a larger measure of students' perceived control, the Student Perceptions of Control Questionnaire (Skinner et al., 1998). These control belief items were designed to tap students' beliefs about the extent to which they can produce desired and prevent undesired academic outcomes (e.g., "If I decide to learn something hard, I can" and "I can’t stop myself from doing poorly in school", reverse coded).

Children's autonomy was assessed using 17 items that measured four types of regulation underlying their academic goals that lay along a spectrum from externally to autonomously regulated (Ryan \& Connell, 1989). These four regulations were, 1) external, or participating based on rewards or punishments (e.g., "Why do I do my homework? Because I'll get in trouble if I don't'), 2) introjected, or being motivated by guilt, shame, or to protect or bolster the ego (e.g., "Why do I do my classwork? Because I'll be ashamed of myself if it doesn't get done"), 3) identified, or because one sees the value of the task (e.g., Why do I try to do well in school? Because doing well in school is important to me"), and 4) intrinsic, or because it is inherently interesting or enjoyable (e.g., "Why do I do my classwork? Because it's fun"). These four types of regulation will be combined into a summary score, referred to as the Relative Autonomy Index (RAI; Ryan \& Connell, 1989), by weighting external, introjected, identified, and intrinsic by their level of autonomy, $-3,-1,+1,+3$, respectively. Higher levels of this summary score will then reflect higher levels of perceived autonomy in learning activities. 


\section{PARENTING AND ACADEMIC COPING}

Catastrophizing appraisals. Student's negative, catastrophizing appraisals of relatedness, competence, and autonomy will also be measured using three scales with nine items each that tapped appraisals that magnify or amplify the negative consequences of a stressful event. All three utilized the same stems as the individual coping scales designed to prompt students to think about their responses to negative academic experiences (e.g., "When something bad happens to me at school (like not doing well on a test or not being able to answer an important question)" or "When I have trouble with a subject in school"). Catastrophizing of relatedness items concerned student's feelings of rejection, insecurity, and shame, for example, "I feel like no one will like me" and "I feel like I let everyone down." Catastrophizing of competence items captured students' pessimism regarding their capabilities (e.g., "I feel totally stupid") or future achievement (e.g., "I worry that I won't do well on anything") and catastrophizing of autonomy tapped feelings of alienation and self-blame and included items such as "It's never the same for me again", and "I feel like I'm to blame." 


\section{PARENTING AND ACADEMIC COPING}

\section{Chapter V. Results}

A study was conducted with 1,020 students in grades three through six to investigate the relationship between parental motivational supports, children's selfsystem processes, and academic coping. The following sections describe the results of this study in detail. Analyses were conducted in three steps: first missingness was investigated, then descriptive statistics were calculated, and finally the study's three research questions were examined.

\section{Initial Analyses}

Missing data. The present study included a total of 278 individual items, all of which had at least one missing value. Out of a total 1,020 students, 210 had no missing data, while 810 had at least one. At the fall time point, 444 participants had no missing values, while 576 had some, and missingness of individual items ranged from $10.49 \%$ to $18.73 \%$. In the spring, 359 had no missing items, 661 had at least one, and 124 students had no spring data at all. Missingness on spring items ranged from 10.49\% - 27.45\%.

Data were examined to determine whether missingness occurred completely at random (MCAR), at random (MAR), or not at random (MNAR). Little's test for MCAR was not significant, $\chi^{2}(12945)=6790.99, p=1$, initially suggesting data could be missing completely at random. To further confirm the lack of relationship between missingness on one variable and values on another variable, all were investigated for significant mean differences using t-tests that compared participants who were missing on that variable and those who were not. Though some differences reached the level of 


\section{PARENTING AND ACADEMIC COPING}

significance, all effect sizes for those differences were small $(d=.14-.39)$, suggesting that significance may have been due to the large sample size $(N=1020)$. Multiple logistic regression was used to evaluate whether students' complete lack of data in the spring was significantly predicted by any study variables in the fall. Results indicated that values on these predictors did not significantly predict a complete absence of data in the spring. Though there is no way to determine definitively whether data were missing completely at random, altogether this evidence suggested that the use of full information maximum likelihood (FIML; Dempster et al., 1977) to account for missingness was appropriate for this dataset, and therefore all subsequent analyses utilized this method.

\section{Descriptive Analyses and Measurement Properties}

Descriptive statistics. To examine descriptive information, initial analyses were conducted including the calculation of means, standard deviations, minimum and maximum values, ranges, and correlations for all variables at each time point, collapsing across grades. Table 5.1 includes a summary of a portion of these statistics, specifically number of items, Cronbach's alpha, means, standard deviations, and cross-time stabilities. Internal consistency of all measures was assessed using Cronbach's alpha and McDonald's omega, with values at or above .75 indicating acceptable reliability, given that all measures were student-report. Previous research evaluating the measurement properties of the multidimensional academic coping scale found alphas that ranged from .59 to .85 with an average of .75 (Skinner et al., 2013), and the present study found alphas that were in roughly the same range, with higher reliabilities in the spring (.57 .85; Table 5.1). Specifically, strategizing, self-encouragement, and commitment in the 


\section{PARENTING AND ACADEMIC COPING}

fall, self-encouragement in the spring, and rumination in the fall all had reliabilities below .70, and therefore correlations with these ways of coping may be attenuated. All others were at or above .70. For all ways of coping, reliabilities increased from fall to spring.

Parenting measures (alphas ranging from.48 - .76) did not reach the threshold of acceptable reliability, except for involvement in the spring, $a=.76$. Because all three measures were multidimensional, McDonald's omega was also calculated and returned slightly higher reliabilities for autonomy support, $($ fall $\mathrm{w}=.49$, spring $\mathrm{w}=.54)$. Autonomy support had particularly poor reliability. This measure also had the fewest items, which also could account for its low internal consistencies. In terms of self-system processes and appraisals, internal consistencies for relatedness and autonomy reached acceptable levels, but those for competence did not (fall $\mathrm{a}=.61$, spring $\mathrm{a}=.69$ ), most likely due to it having only six items. All three catastrophizing variables returned very good alphas in the fall and spring (.80 - .89), suggesting they were internally consistent. Cross-time stabilities for all constructs were high $(r=.443-.794)$, with those for both adaptive and maladaptive coping allocation scores the highest $(r=.794)$, suggesting that it may be particularly difficult to predict change in these variables. These high cross-time stabilities also suggest that the low internal consistencies of some ways of coping, competence, parental involvement, structure, and autonomy support may be a product of the low number of items.

Means and standard deviations. Means and standard deviations for all study variables are also presented in Table 5.1. Mean levels of coping indicated that students 


\section{PARENTING AND ACADEMIC COPING}

generally utilized adaptive coping strategies at higher levels than maladaptive strategies, with adaptive ways consistently higher than the mid-point of the scale (2.5) and maladaptive ways generally below. Strategizing was the most common adaptive way of coping in the fall $(M=3.20, S D=.56)$, while help-seeking was in the spring $(M=3.15$, $S D=.62)$. Rumination was the most utilized maladaptive way of coping in both the fall $(M=2.65, S D=.66)$ and spring $(M=2.50, S D=.71)$. Overall, the least common way of coping during the school year was projection (Fall: $M=1.71, S D=.66$; Spring $M=1.73$, $S D=.67)$. Standard deviations were smaller for adaptive ways of coping when compared with maladaptive, indicating that in general these values were closer to their means.

Because all mean levels were outside of one standard deviation of the maximum value of coping measures, it is unlikely that ceiling effects were occurring.

On average, all parenting variables were high in both the fall and spring $(M=3.00$ $-3.38, S D=.55-.63)$, suggesting that overall students experienced their parents as being involved, autonomy supportive, and providing structure. Students also generally reported high levels of relatedness and competence at both time points, but mean levels of autonomy summary scores (which were centered on zero and could range from -12 to 12) were more centrally located with a mean in the fall of $.10(S D=4.60)$, and the spring -.41 $(S D=4.84)$. As expected, given the high levels of student self-system processes, mean levels of all three catastrophizing variables were low in both fall and spring $(M=1.77-$ $2.09, S D=.61-.71)$. As with coping measures, mean levels of parenting, self-system process, and catastrophizing measures all fell outside of one standard deviation of either 


\section{PARENTING AND ACADEMIC COPING}

their maximum or minimum value, suggesting the absence of either ceiling or floor effects. 


\section{PARENTING AND ACADEMIC COPING}

Table 5.1

Summary of Descriptive Statistics

\begin{tabular}{|c|c|c|c|c|c|c|c|c|c|c|}
\hline \multirow[b]{2}{*}{ Scale } & \multirow{2}{*}{$\begin{array}{c}\text { Numbe } \\
r \\
\text { of } \\
\text { Items }\end{array}$} & \multicolumn{5}{|c|}{ Fall } & \multicolumn{3}{|c|}{ Spring } & \multirow[b]{2}{*}{$\begin{array}{c}\text { Cross } \\
\text { time } \\
\text { stabilities }\end{array}$} \\
\hline & & $\alpha$ & $\mathrm{w}$ & $M$ & $S D$ & $\alpha$ & $\mathrm{w}$ & $M$ & $S D$ & \\
\hline \multicolumn{11}{|l|}{ Parenting } \\
\hline Involvement & 5 & .69 & .69 & 3.38 & .56 & .76 & .76 & 3.32 & .63 & $.606^{* * *}$ \\
\hline Structure & 6 & .58 & .58 & 3.00 & .59 & .62 & .62 & 3.06 & .59 & $.503^{* * *}$ \\
\hline $\begin{array}{l}\text { Autonomy } \\
\text { Support }\end{array}$ & 4 & .48 & .49 & 3.19 & .56 & .53 & .54 & 3.26 & .55 & $.507 * * *$ \\
\hline \multicolumn{11}{|l|}{ Coping } \\
\hline \multicolumn{11}{|l|}{ Adaptive } \\
\hline Strategizing & 5 & .66 & & 3.20 & .56 & .77 & & 3.06 & .65 & $.443 * * *$ \\
\hline Help-Seeking & 5 & .70 & & 3.18 & .60 & .76 & & 3.15 & .62 & $.631 * * *$ \\
\hline Comfort-seeking & 5 & .73 & & 3.06 & .65 & .81 & & 2.97 & .72 & $.537 * * *$ \\
\hline $\begin{array}{l}\text { Self- } \\
\text { encouragement }\end{array}$ & 5 & .57 & & 3.11 & .55 & .65 & & 2.99 & .61 & $.542 * * *$ \\
\hline Commitment & 5 & .64 & & 3.03 & .59 & .76 & & 3.01 & .64 & $.519 * * *$ \\
\hline Adaptive Profile & 25 & & & 3.12 & .46 & & & 3.05 & .53 & $.794 * * *$ \\
\hline \multicolumn{11}{|l|}{ Maladaptive } \\
\hline Confusion & 5 & .75 & & 2.23 & .71 & .79 & & 2.21 & .75 & $.613^{* * *}$ \\
\hline Escape & 5 & .71 & & 1.89 & .63 & .73 & & 1.90 & .62 & $.510 * * *$ \\
\hline Concealment & 5 & .75 & & 2.00 & .70 & .80 & & 1.92 & .70 & $.590 * * *$ \\
\hline Self-pity & 5 & .80 & & 2.08 & .76 & .85 & & 1.97 & .79 & $.567 * * *$ \\
\hline Rumination & 5 & .69 & & 2.65 & .66 & .76 & & 2.50 & .71 & $.616^{* * *}$ \\
\hline Projection & 5 & .77 & & 1.71 & .66 & .79 & & 1.73 & .67 & $.521 * * *$ \\
\hline $\begin{array}{l}\quad \text { Maladaptive } \\
\text { Profile } \\
\text { Self-systems }\end{array}$ & 30 & & & 2.07 & .50 & & & 2.04 & .52 & $.794 * * *$ \\
\hline Relatedness & 19 & .86 & .89 & 3.37 & .47 & .89 & .91 & 3.41 & .51 & $.718^{* * *}$ \\
\hline Competence & 6 & .61 & .62 & 3.45 & .50 & .69 & .67 & 3.46 & .52 & $.605 * * *$ \\
\hline Autonomy & 17 & .78 & .69 & .10 & 4.60 & .80 & .76 & -.41 & 4.84 & $.701^{* * *}$ \\
\hline \multicolumn{11}{|l|}{ Catastrophizing } \\
\hline $\begin{array}{l}\text { Catastrophizing of } \\
\text { Relatedness }\end{array}$ & 9 & .88 & .89 & 1.83 & .69 & .89 & .90 & 1.77 & .68 & $.693 * * *$ \\
\hline
\end{tabular}


PARENTING AND ACADEMIC COPING

Competence

$\begin{array}{llllllllll}9 & .80 & .79 & 2.03 & .61 & .83 & .84 & 1.99 & .63 & .685^{* * *}\end{array}$

Catastrophizing of

Autonomy

Note. All variables can range from 1 - 4, except for Autonomy which can range from -12 - 12 .

Coping cross-time stabilities were calculated from allocation scores because those will be used in all analyses.

$* p<.05, * * p<.01, * * * p<.001$

Correlations. Bivariate concurrent intra-construct correlations were calculated for all measures. Table 5.2 contains correlations between all individual ways of coping in the fall and spring. When examining individual ways of coping, overall, adaptive ways were almost always positively correlated with each other and negatively correlated with maladaptive ways, while maladaptive ways were typically positively correlated with each other and negatively correlated with adaptive ways. The notable exception to this pattern was rumination, which although largely negatively correlated with adaptive ways of coping, these correlations were not of a magnitude consistent with other maladaptive ways of coping, culminating with a non-significant correlation with strategizing in the fall. Even further, it did not consistently show the expected positive correlations with other maladaptive ways: It was positively correlated with some maladaptive ways, especially in spring, but was not significantly correlated with two maladaptive ways in the fall (i.e., concealment and self-pity), and was even negatively correlated with two other maladaptive ways, escape and projection, at both time points. 


\section{PARENTING AND ACADEMIC COPING}

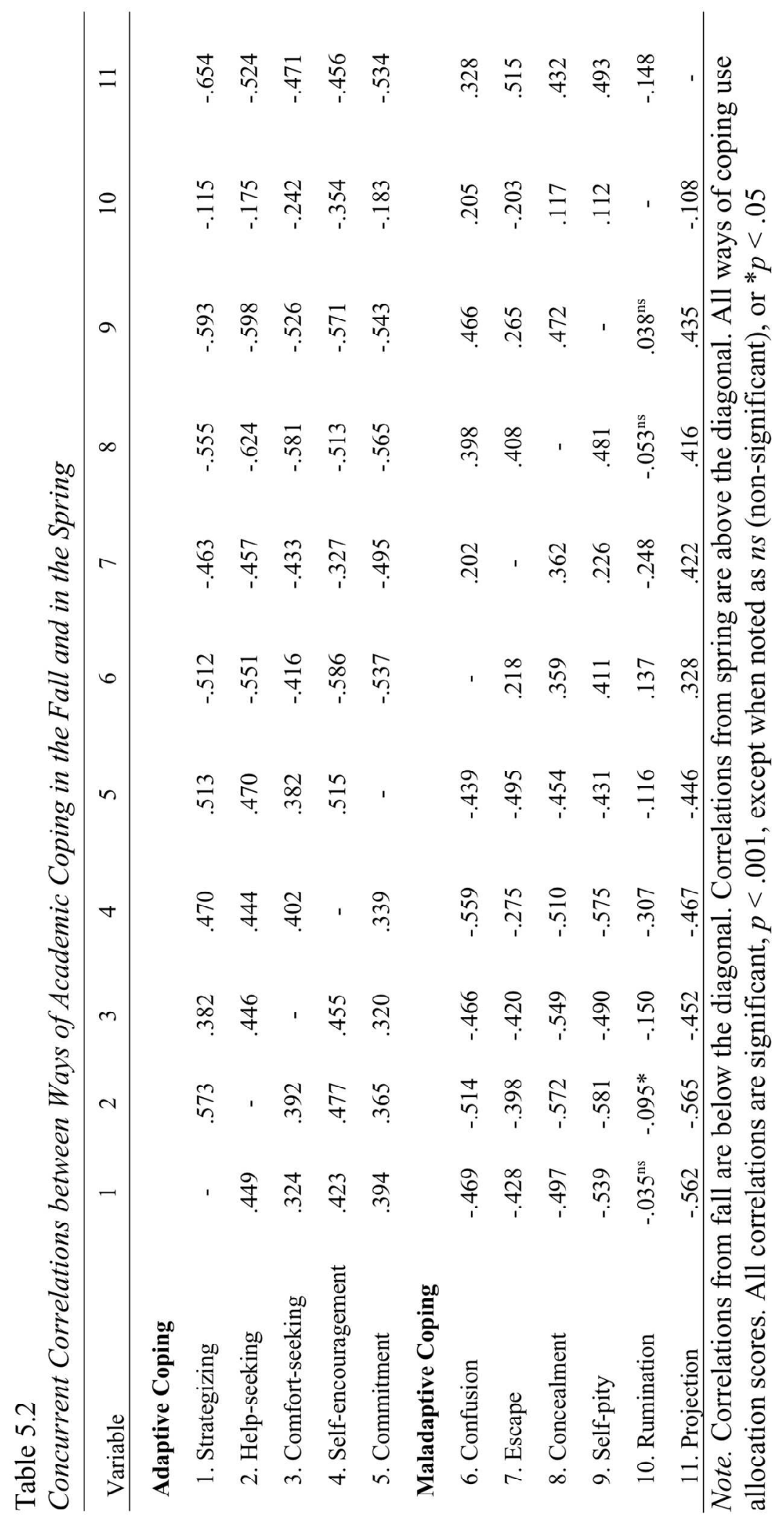




\section{PARENTING AND ACADEMIC COPING}

Correlations between parental motivational supports were all significant and positive in both the fall and spring, as shown in Table 5.3. Although none of these correlations were high enough to suggest possible multicollinearity between predictors on their own, some were higher than the internal consistencies of the individual constructs. Specifically, alphas and omegas for autonomy support in the fall and spring were lower than its correlations with involvement and structure, indicating possible construct overlap. Table 5.4 depicts correlations between self-system processes and catastrophizing, which all show a pattern consistent with theorized relationships with relatedness, competence, and autonomy being positively correlated with each other and negatively correlated with catastrophizing, and catastrophizing variables positively correlated with each other and negatively with all self-system processes. While still following this pattern, autonomy did differ from the other appraisals, in that its correlations were much lower than the other SSPs or catastrophizing.

\section{Table 5.3}

Concurrent Correlations between Parent Motivational Supports in the Fall and in the Spring

\begin{tabular}{lccc}
\hline \multicolumn{1}{c}{ Variable } & 1 & 2 & 3 \\
\hline 1. Involvement & - & .662 & .638 \\
2. Structure & .519 & - & .552 \\
3. Autonomy Support & .533 & .497 & - \\
\hline
\end{tabular}

Note. Fall correlations are below the diagonal, spring above.

All correlations are significant, $p<.001$, except when noted as $n s$ (non-significant). 


\section{PARENTING AND ACADEMIC COPING}

Table 5.4.

Concurrent Correlations between Children's Self-system Processes and Catastrophizing in the Fall and in the Spring

\begin{tabular}{lcccccc}
\hline \multicolumn{1}{c}{ Variable } & 1 & 2 & 3 & 4 & 5 & 6 \\
\hline 1. Relatedness & - & .478 & .225 & -.561 & -.432 & -.493 \\
2. Competence & .543 & - & .195 & -.526 & -.432 & -.448 \\
3. Autonomy & .287 & .264 & - & -.203 & -.312 & -.345 \\
4. Catastrophizing of Relatedness & -.559 & -.532 & -.284 & - & .827 & .793 \\
5. Catastrophizing of Competence & -.483 & -.459 & -.346 & .831 & - & .823 \\
6. Catastrophizing of Autonomy & -.482 & -.459 & -.376 & .797 & .813 & - \\
\hline
\end{tabular}

Note. Fall correlations are below the diagonal, while spring are above.

All correlations are significant, $p<.001$, except when noted as $n s$ (non-significant).

Inter-construct correlations. Concurrent correlations were also calculated

between all study constructs. Much like the patterns observed in intra-construct concurrent correlations, parental motivational supports were positively correlated with individual ways of adaptive coping and negatively correlated with maladaptive coping, except for rumination, which was not significantly correlated with any parenting variables (Table 5.5). Parental supports were also positively correlated with all selfsystem processes and negatively correlated with all catastrophizing variables, with correlations with autonomy lower than all others (Table 5.6). When examining concurrent associations between self-system processes, catastrophizing, and academic coping, all self-system processes were positively correlated with adaptive ways of coping and negatively correlated with maladaptive ways, while catastrophizing was positively correlated with maladaptive ways and negatively correlated with adaptive (Table 5.7). Again, the exceptions to this pattern were autonomy, which had lower correlations with all variables, and rumination, which showed low significant positive correlations with 


\section{PARENTING AND ACADEMIC COPING}

catastrophizing, but was negatively correlated only with autonomy and not with the other self-system processes.

Altogether these correlations begin to suggest an emerging pattern of findings that is consistent with study hypotheses: adaptive ways of coping were positively connected with parenting dimensions and self-system processes, whereas maladaptive ways of coping (with the exception of rumination) were negative connected with parenting and positively connected with catastrophizing. These issues are more fully addressed in the examination of study research questions. Following a discussion of regression assumptions, a subsequent section will describe and explain results obtained for each research question and hypothesis in more detail.

Table 5.5

Concurrent Correlations between Parenting and Academic Coping Variables in the Fall and in the Spring

\begin{tabular}{lcccccc}
\hline \multirow{2}{*}{ Coping Variable } & \multicolumn{2}{c}{ Involvement } & \multicolumn{2}{c}{ Structure } & \multicolumn{2}{c}{ Autonomy Support } \\
\cline { 2 - 7 } & Fall & Spring & Fall & Spring & Fall & Spring \\
\hline Adaptive Coping & & & & & & \\
Strategizing & .465 & .524 & .343 & .437 & .372 & .474 \\
Help-seeking & .420 & .465 & .412 & .391 & .434 & .459 \\
Comfort-seeking & .396 & .426 & .336 & .364 & .329 & .381 \\
Self-encouragement & .369 & .446 & .261 & .358 & .310 & .407 \\
Commitment & .361 & .457 & .214 & .399 & .285 & .389 \\
Adaptive Profile & .477 & .444 & .195 & .296 & .251 & .274 \\
Maladaptive Coping & & & & & & \\
Confusion & -.369 & -.426 & -.265 & -.394 & -.315 & -.367 \\
Escape & -.367 & -.384 & -.203 & -.267 & -.201 & -.304 \\
Concealment & -.450 & -.469 & -.373 & -.423 & -.372 & -.465 \\
Self-pity & -.420 & -.517 & -.434 & -.433 & -.471 & -.527 \\
Rumination & $.060^{\text {ns }}$ & $.002^{\text {ns }}$ & $.039^{\text {ns }}$ & $.022^{\text {ns }}$ & $.040^{\text {ns }}$ & $-.005^{\text {ns }}$ \\
Projection & -.449 & -.511 & -.330 & -.442 & -.406 & -.429 \\
Maladaptive Profile & -.371 & -.501 & -.423 & -.505 & -.450 & -.569 \\
\hline
\end{tabular}

Note. All correlations are between each variable in either the fall or the spring. All correlations are significant, $p<.001$, except when noted as $n s$ (non-significant). 


\section{PARENTING AND ACADEMIC COPING}

Table 5.6

Concurrent Correlations between Parenting, Self-system, and Catastrophizing Variables in the Fall and in the Spring

\begin{tabular}{lcccccc}
\hline \multirow{2}{*}{ Child Variable } & \multicolumn{2}{c}{ Involvement } & \multicolumn{2}{c}{ Structure } & \multicolumn{2}{c}{ Autonomy Support } \\
\cline { 2 - 7 } & Fall & Spring & Fall & Spring & Fall & Spring \\
\hline Self-system & & & & & & \\
$\quad$ Relatedness & .570 & .570 & .462 & .439 & .443 & .503 \\
$\quad$ Competence & .450 & .488 & .389 & .424 & .409 & .483 \\
$\quad$ Autonomy & .250 & .219 & .165 & .177 & .230 & .192 \\
$\quad$ Catastrophizing & & & & & & \\
$\quad$ Catastrophizing of Relatedness & -.419 & -.456 & -.439 & -.479 & -.430 & -.535 \\
$\quad$ Catastrophizing of Competence & -.359 & -.389 & -.386 & -.417 & -.405 & -.437 \\
$\quad$ Catastrophizing of Autonomy & -.370 & -.428 & -.384 & -.443 & -.427 & -.501 \\
\hline
\end{tabular}

Note. All correlations are between each variable in either the fall or the spring. All correlations are significant, $p<.001$, except when noted as $n s$ (non-significant). 


\section{PARENTING AND ACADEMIC COPING}

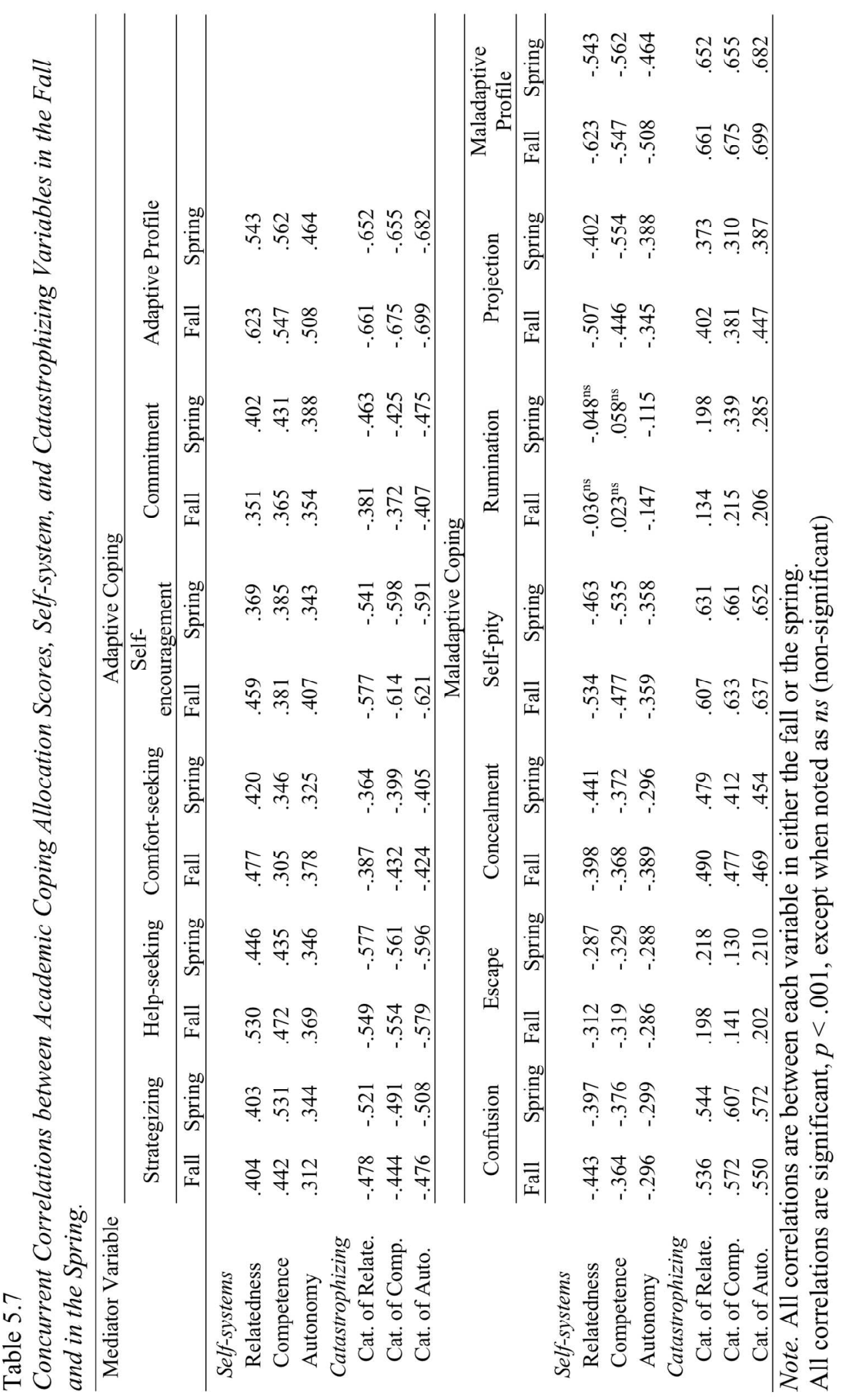




\section{PARENTING AND ACADEMIC COPING}

Regression assumptions. Because all analyses to examine study research

questions involved ordinary least square (OLS) regression, diagnostic statistics and visual inspection of graphical plots were used to assess whether OLS regression assumptions, such as the normal distribution of residuals and that residuals are independently and identically distributed, have been violated. Examination of residual and Q-Q plots suggested that residuals were normally distributed, and homogeneity of variance was met. Diagnostic values confirmed the conclusions drawn from these plots and suggested that no individual cases were significant outliers or influential cases on predictor or outcome variables. Skew was less than one for all variables, indicating that none were at a great enough magnitude to cause concerns of non-normality, but confirming that parenting, self-system process, and adaptive coping variables tended to have higher values, skewing negative, while catastrophizing and maladaptive coping variables tended to a positive skew, indicating lower overall values. Kurtosis only reached levels of concern for rumination allocation scores (fall $=2.40$, spring $=5.49$ ), suggesting that the distribution for this variable was particularly leptokurtic, especially in the spring, with values more concentrated around the mean.

Possible multicollinearity between predictor variables was examined using both correlations and the variance inflation factor (VIF), a measure of how much the variance in each coefficient has increased compared to if predictors were uncorrelated. All VIFs on predictor and mediator variables were less than 10 , the level that suggests problematic multicollinearity, and no correlations reached the level that leads to unstable coefficients and inflated standard errors, $r>.949$ (Cohen et al., 2013). Despite high correlations 


\section{PARENTING AND ACADEMIC COPING}

between catastrophizing variables in both the fall and spring (Table 5.4; $r=.793-.831$ )

VIF values did not reach a concerning level but were the highest of any study variable (3.85 - 4.12). Additional care will be taken for the interpretation of analyses that include catastrophizing, including an examination of standard errors, and the presence of possible multicollinearity will be discussed in study limitations. The next section describes in detail results obtained through the analysis of this study's three research questions and hypotheses. All analyses utilize an alpha level of .05 as the cutoff for significance.

\section{Research Question 1: Effects of Parental Motivational Support on Changes in}

\section{Children's Coping}

\section{Research question 1a. Do initial levels of parental motivational support in the} fall predict changes in children's adaptive coping strategies from fall to spring?

Research questions 1a1. To investigate this research question, multiple regression was used, with parental involvement, structure, and autonomy support in the fall as well as children's adaptive coping profile in the fall entered simultaneously as predictors of children's adaptive coping profile in the spring. Initial levels of parental motivational support in the fall were anticipated to predict changes in children's profiles of adaptive coping from fall to spring, but this hypothesis was not supported. Although correlations calculated between these variables (see Table 5.8) found that all three supports in the fall were significantly and positively correlated with adaptive coping in the spring (involvement, $r=.48$; structure, $r=.40$, autonomy support, $r=.42$ ), as unique predictors they did not account for a significant amount of variance in adaptive coping in the spring when controlling for adaptive coping in the fall (Figure 5.1). 


\section{PARENTING AND ACADEMIC COPING}

Table 5.8

Correlations between Fall Parenting and Spring Academic Coping Variables.

\begin{tabular}{lccc}
\hline \multirow{2}{*}{ Coping in Spring } & \multicolumn{3}{c}{ Parenting in Fall } \\
\cline { 2 - 4 } Adaptive Coping & Involvement & Structure & Autonomy Support \\
Strategizing & .402 & .328 & .348 \\
Help-seeking & .373 & .412 & .393 \\
Comfort-seeking & .379 & .297 & .304 \\
Self-encouragement & .265 & .199 & .254 \\
Commitment & .399 & .275 & .294 \\
Adaptive Profile & .483 & .403 & .424 \\
Maladaptive Coping & & & \\
Confusion & -.350 & -.272 & -.269 \\
Escape & -.273 & -.152 & -.164 \\
Concealment & -.416 & -.354 & -.365 \\
Self-pity & -.400 & -.442 & -.440 \\
Rumination & $.011^{\mathrm{ns}}$ & $-.029^{\mathrm{ns}}$ & $-.052^{\mathrm{ns}}$ \\
Projection & -.384 & -.257 & -.294 \\
Maladaptive Profile & -.483 & -.403 & -.424 \\
\hline
\end{tabular}

Note. All correlations are significant, $p<.001$, unless noted as $n s$ (non-significant).

Figure 5.1

Regression Coefficients for all Fall Parenting Motivational Supports Predicting Spring Adaptive Coping While Controlling for Fall Adaptive Coping

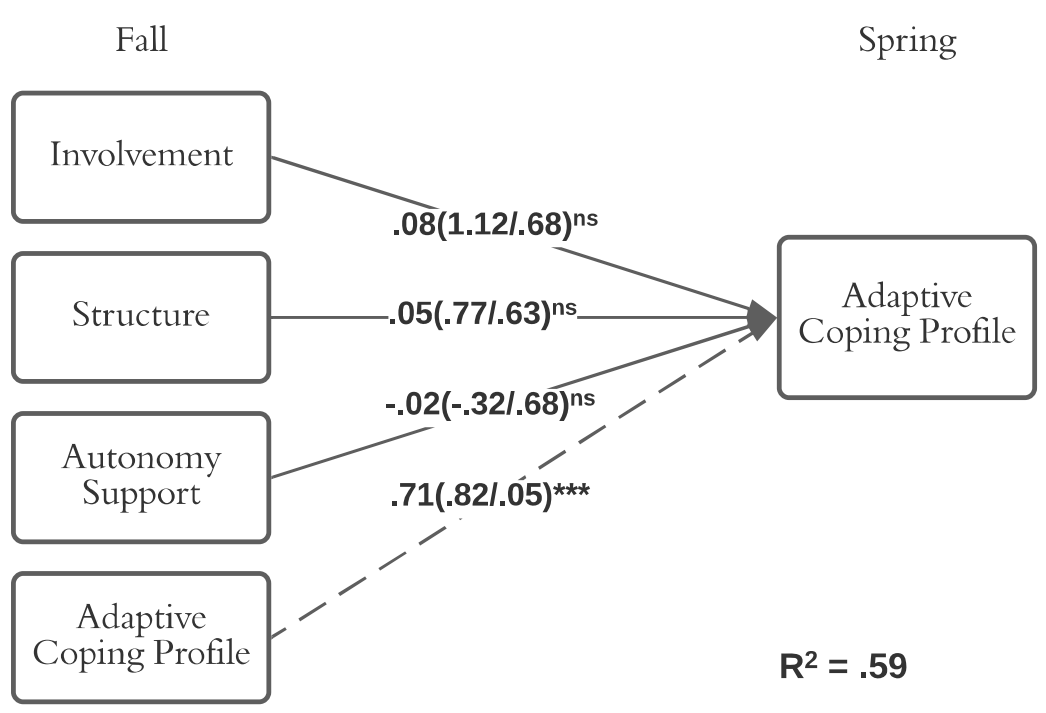

Note. Standardized coefficients (unstandardized coefficient/standard error) $* p<.05, * * p<.01, * * * p<.001, \mathrm{~ns}=$ non-significant 


\section{PARENTING AND ACADEMIC COPING}

Because of this unexpected result, additional regression equations were used to further investigate the possible reasons for these findings. First, to examine whether this result was due to the high cross-time stabilities of adaptive coping $(r=.794)$, parental motivational supports in the fall were investigated as unique predictors of adaptive coping in the spring without controlling for fall adaptive coping. All were found to be significant, unique predictors of spring adaptive coping (Figure 5.2): Involvement, $b=$

$4.35, S E=.81, \beta=.30, p=.000$, structure, $b=2.26, S E=.78, \beta=.16, p=.004$ and autonomy support, $b=2.47, S E=.81, \beta=.17, p=.002$. An overall R-square of .27 suggested that altogether these three parental supports in the fall accounted for approximately $27 \%$ of the variance in spring adaptive coping. These results suggested that one reason parenting dimensions did not uniquely predict change in adaptive coping profiles was the high cross-time stability of coping profiles, since parenting variables did uniquely predict adaptive coping in the spring when fall levels of coping were not included. 


\section{PARENTING AND ACADEMIC COPING}

Figure 5.2

Unique Effects from Parent Motivational Supports in Fall to Adaptive Coping in Spring

Fall

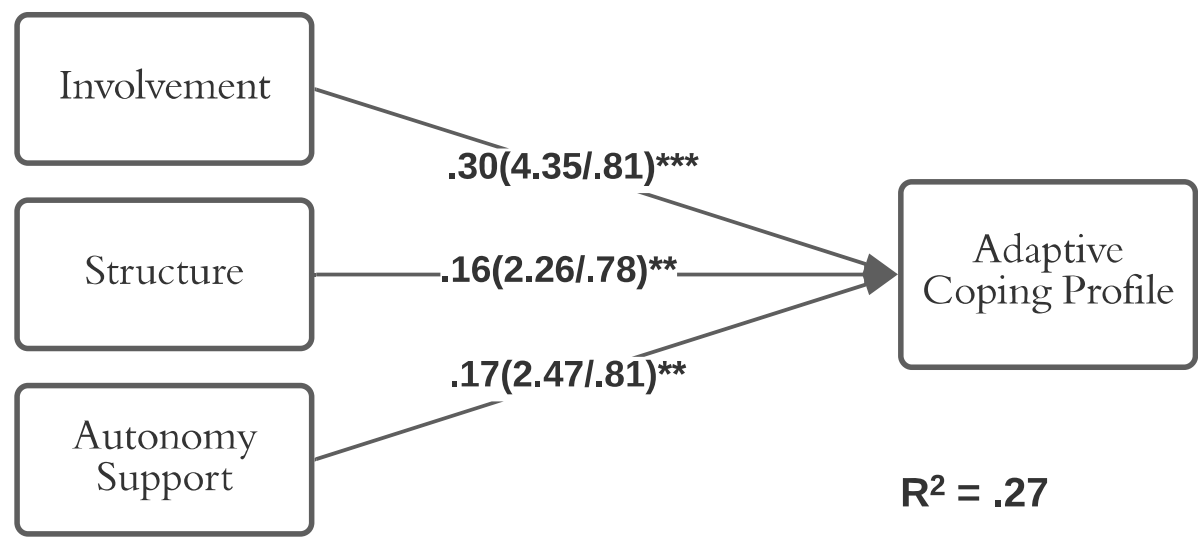

Note. Standardized coefficient (unstandardized/standard error) ${ }^{*} p<.05, * * p<.01, * * * p<.001, \mathrm{~ns}=$ non-significant

Second, to examine whether the lack of support for the hypothesis was due to high correlations among predictors, three separate multiple regression equations were calculated where each motivational support in the fall was entered as a separate predictor of change in adaptive coping across the school year. Results indicated that involvement and structure were both individual predictors of increases in adaptive coping from fall to spring, involvement: $b=1.34, S E=.60, \beta=.09, p=.03$, structure: $b=1.18, S E=.56, \beta$ $=.08, p=.03$ (Table 5.9). Although autonomy support in the fall was a unique predictor of adaptive coping in spring, it did not predict changes in adaptive coping from fall to spring, even when examined individually, $b=.41, S E=.60, \beta=.03, p=.50$. This suggested that a second reason for the unexpected pattern of findings was the overlap 


\section{PARENTING AND ACADEMIC COPING}

among predictors, specifically, involvement and structure, since, despite the strong crosstime stabilities, each predicted change in adaptive coping profiles on its own.

Table 5.9

Regression Analyses Predicting Changes in Adaptive Coping Profiles from Individual Parenting Variables in Fall

\begin{tabular}{|c|c|c|c|c|}
\hline \multirow[b]{2}{*}{ Predictors in Fall } & \multicolumn{4}{|c|}{ Adaptive Coping Profile in Spring } \\
\hline & $\beta$ & $b$ & $S E$ & $t$ \\
\hline Involvement & .09 & 1.34 & .60 & $2.24 *$ \\
\hline Adaptive Coping Profile & .71 & .82 & .05 & $18.0^{* * *}$ \\
\hline$R^{2}$ & .59 & & & \\
\hline Structure & .08 & 1.18 & .56 & $2.12 *$ \\
\hline Adaptive Coping Profile & .73 & .84 & .04 & $19.55^{* * *}$ \\
\hline$R^{2}$ & .59 & & & \\
\hline Autonomy Support & .028 & 409 & .600 & .68 \\
\hline Adaptive Coping Profile & .747 & .862 & .045 & $18.99 * * *$ \\
\hline$R^{2}$ & .58 & & & \\
\hline
\end{tabular}

Altogether, this pattern of results suggested that these three parental motivational supports, especially parental involvement and structure, may be accounting for overlapping variance in changes in adaptive coping from fall to spring, rather than having unique effects, but that generally all three were uniquely associated with higher levels of adaptive coping. Additionally, it suggested that parenting high on involvement and structure could individually lead to increases in children's adaptive coping profiles across the school year, but that high cross-time stabilities in adaptive coping profiles may have made it difficult to see unique effects of parenting variables on changes in coping when all were entered into a model simultaneously. 


\section{PARENTING AND ACADEMIC COPING}

Research question 1.a.2. Multiple regression was used to investigate whether initial levels of parental motivational supports in the fall predicted changes in each individual adaptive way of coping (i.e., strategizing, help-seeking, comfort-seeking, selfencouragement, and commitment) across the school year. As with the adaptive coping profile, all five individual ways of adaptive coping were positively correlated with all three motivational supports (Table 5.8). However, unlike the adaptive profile, parental involvement in the fall significantly and uniquely predicted increases in three individual ways of coping, namely, strategizing, comfort-seeking, and commitment, across the school year, despite relatively high cross-time stabilities in those ways of coping (ranging from .44 to .54$)$. At the same time, parental structure in the fall significantly and uniquely predicted increases in help-seeking from fall to spring (Table 5.10), despite its high crosstime stability $(r=.63)$. Self-encouragement was the only way of coping for which changes were not uniquely predicted by any parental supports. Autonomy support in the fall was not a significant unique predictor of changes in any of the five adaptive ways of coping across the school year. 


\section{PARENTING AND ACADEMIC COPING}

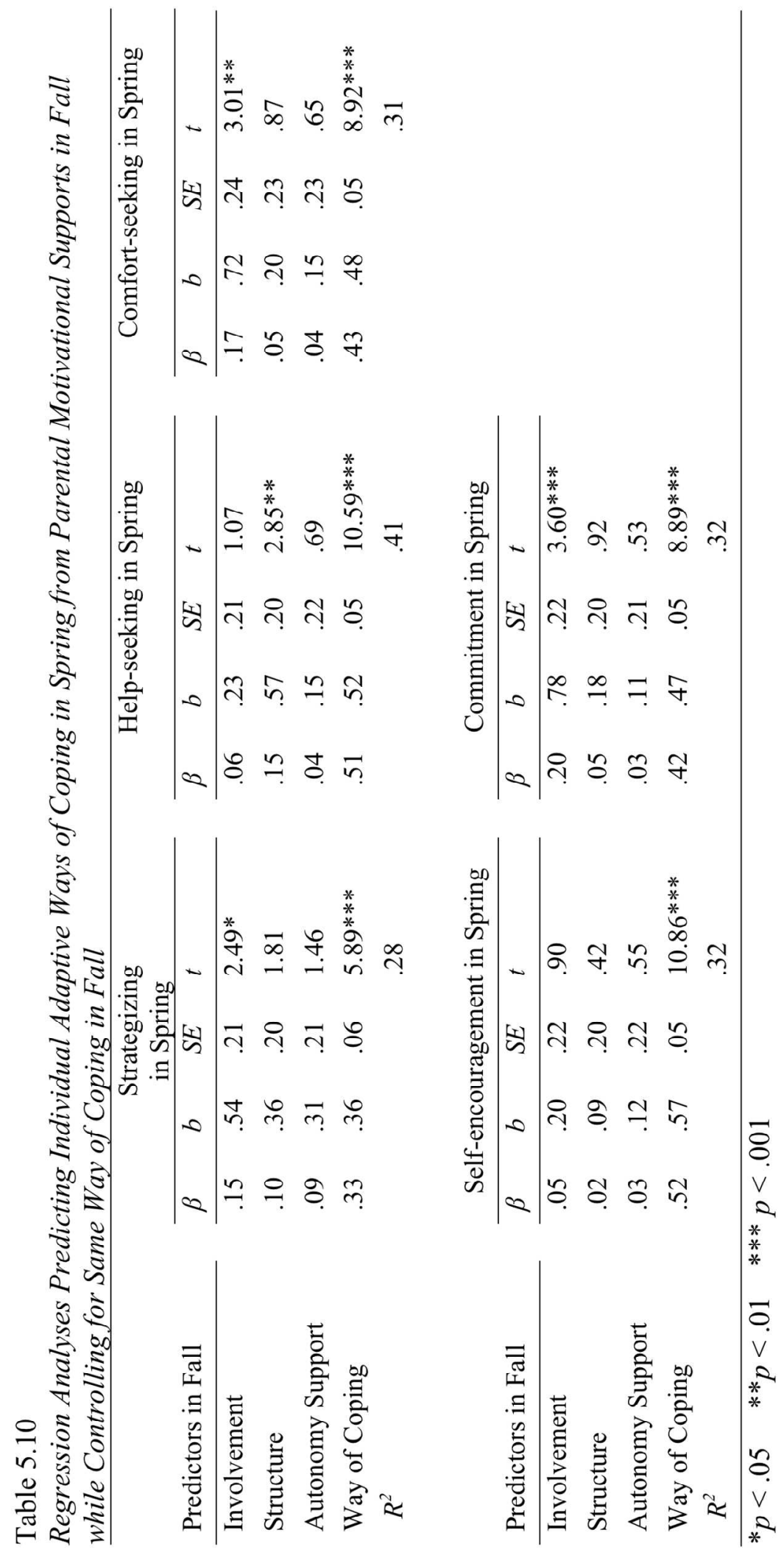




\section{PARENTING AND ACADEMIC COPING}

Because the full hypothesis, positing that all three parenting supports would uniquely predict change in all individual adaptive ways of coping, was not supported, further analyses were conducted. First, to investigate whether unexpected findings were due to high cross-time stabilities in some ways of coping, unique effects of parenting supports in the fall on all individual ways of adaptive coping in the spring were examined without controlling for level of coping in the fall (Table 5.11). Results indicated patterns of unique effects that differed by individual way of coping. All three aspects of parenting in the fall all uniquely predicted strategizing and help seeking in the spring, whereas comfort-seeking was uniquely predicted only by involvement and structure, selfencouragement only by involvement and autonomy support, and commitment only by involvement. 


\section{PARENTING AND ACADEMIC COPING}

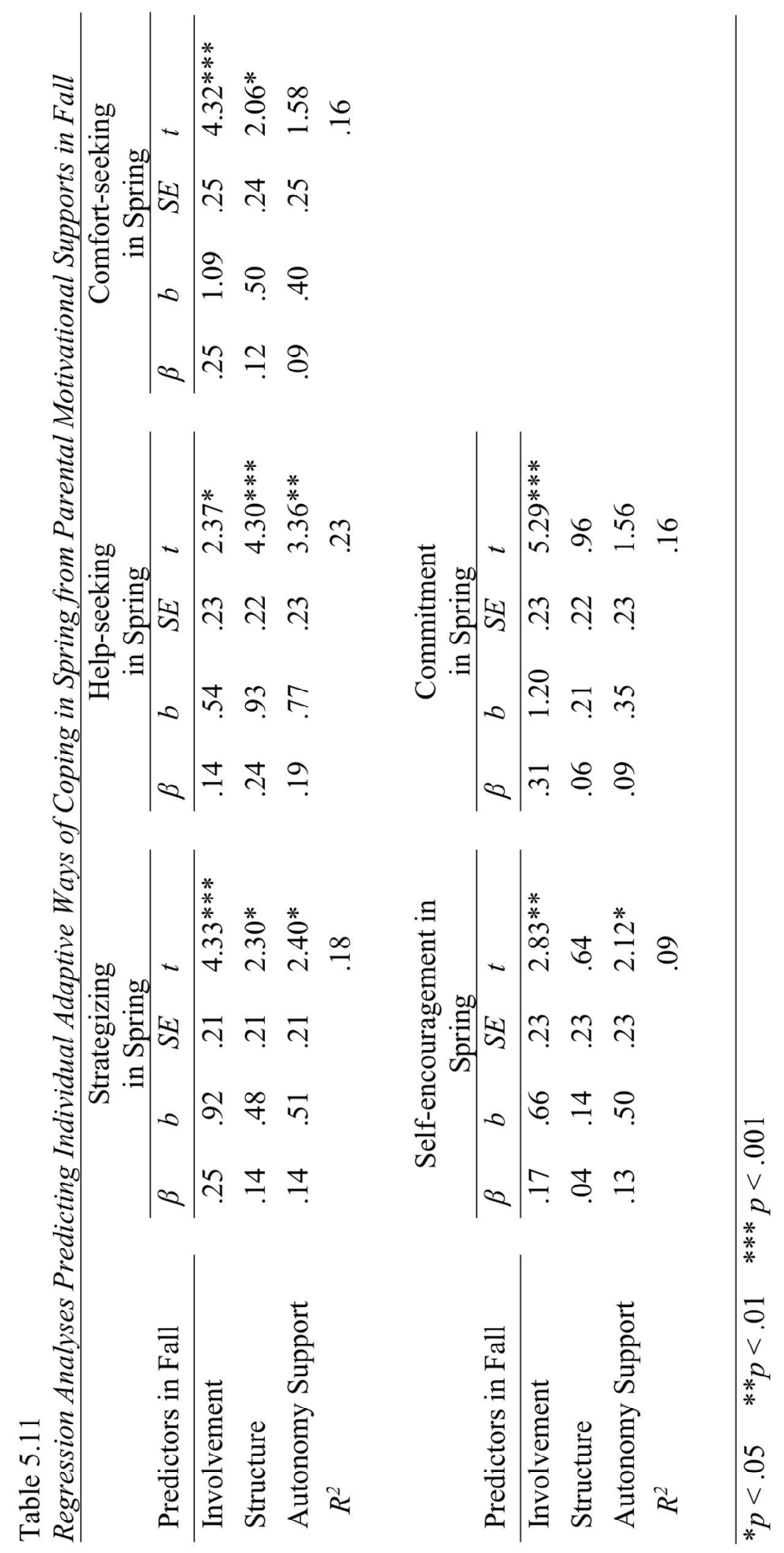




\section{PARENTING AND ACADEMIC COPING}

Second, to examine whether high correlations between parenting supports explained non-significant findings, parenting dimensions in the fall were investigated as individual predictors of changes in each way of adaptive coping across the school year. Results presented in Table 5.12 indicated that all parenting variables individually predicted increases in all individual adaptive ways of coping from fall to spring, with the exception of self-encouragement. For self-encouragement, much like when all parenting variables were entered simultaneously, none individually predicted changes in this way of coping. 


\section{PARENTING AND ACADEMIC COPING}

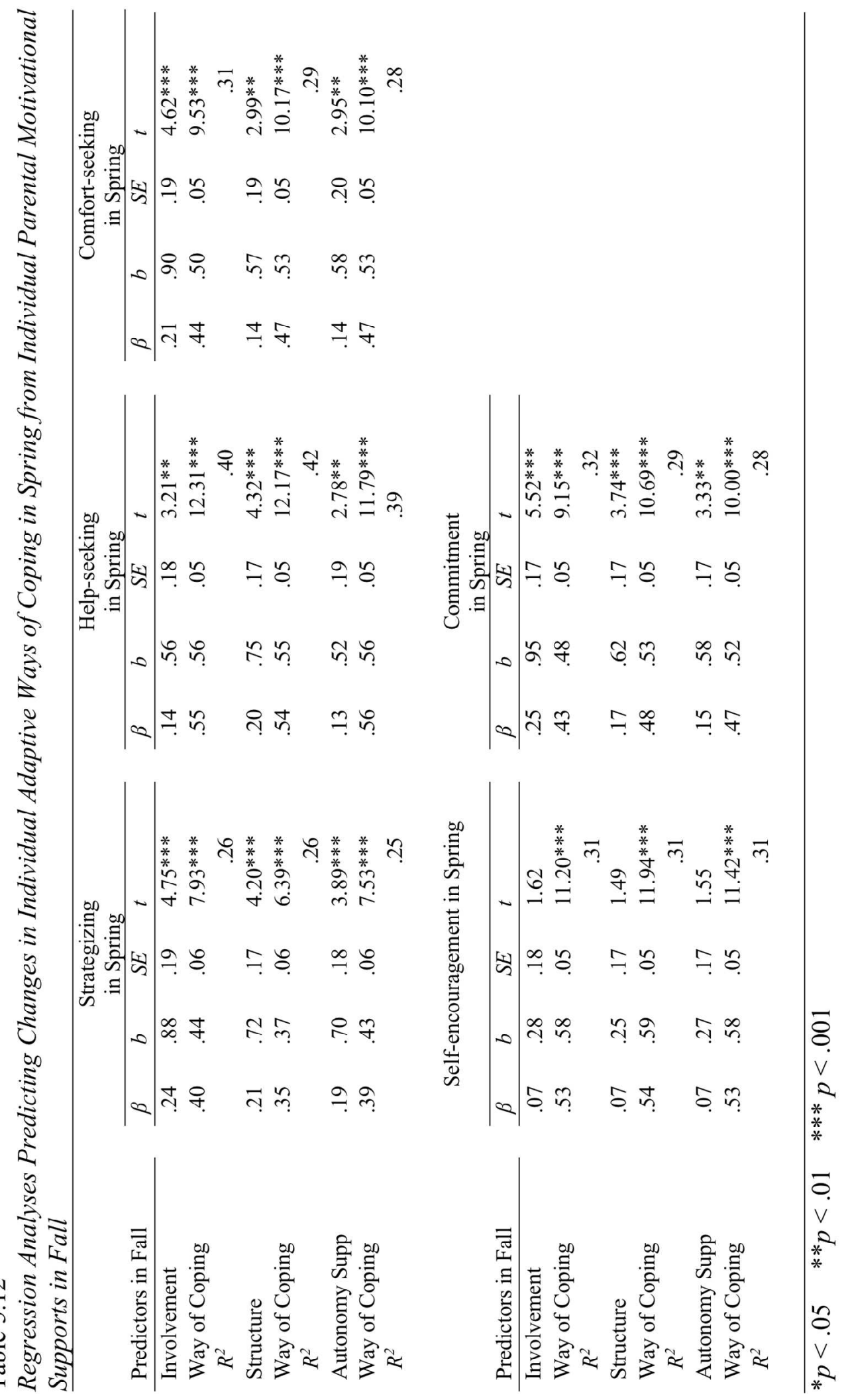




\section{PARENTING AND ACADEMIC COPING}

Ultimately, when examining results from adaptive coping profiles and individual adaptive ways of coping together, it appeared that both high cross-time stabilities (especially of the coping profile) and overlap among parenting dimensions may have made it difficult to detect the unique contributions of all three dimensions to changes in adaptive coping across the school year. When autoregressions were excluded, all three dimensions made unique contributions to strategizing, help-seeking, and the adaptive profiles in the spring. And, importantly, when each motivational support was considered individually, all three predicted increases in all ways of adaptive coping (besides selfencouragement), even though autonomy support was unable to predict changes in the adaptive profile even on its own.

\section{Research question 1b. Do higher initial levels of parental motivational}

\section{support in the fall predict decreases in children's maladaptive coping strategies}

\section{from fall to spring?}

Research question 1.b.1. Initial levels of parental motivational support in the fall were expected to lead to decreases in profiles of maladaptive coping from fall to spring. Multiple regression was used to investigate this hypothesis, with parental involvement, structure, and autonomy support in the fall predicting maladaptive coping profiles in the spring while controlling for maladaptive coping in the fall. Because these analyses were

all conducted using coping allocation scores which are calculated as a proportion of total coping (Vitaliano et al., 1987), results for maladaptive coping were the same as for adaptive coping with all coefficients reversed. Therefore, results indicated that the hypothesis was not supported: No parenting variables significantly predicted changes in 


\section{PARENTING AND ACADEMIC COPING}

maladaptive coping across the school year (Figure 5.3), and the further analyses

conducted found that all three parenting variables significantly and negatively predicted maladaptive coping in the spring (Figure 5.4), and involvement and structure each individually predicted decreases in maladaptive coping from fall to spring (Table 5.13). Again, as with adaptive coping these results suggested that high cross-time stabilities in coping profiles made it difficult for parenting dimensions to account for a significant amount of variance in maladaptive coping, but that when the effects of high cross-time stabilities and multicollinearity between dimensions was removed, all three supports accounted for a significant amount of variance in maladaptive coping in the spring, and that involvement and structure could individually predict change across the school year.

Figure 5.3

Parenting Support Variables in the Fall Predicting Spring Maladaptive Coping While Controlling for Fall Maladaptive Coping

$$
\text { Fall Spring }
$$

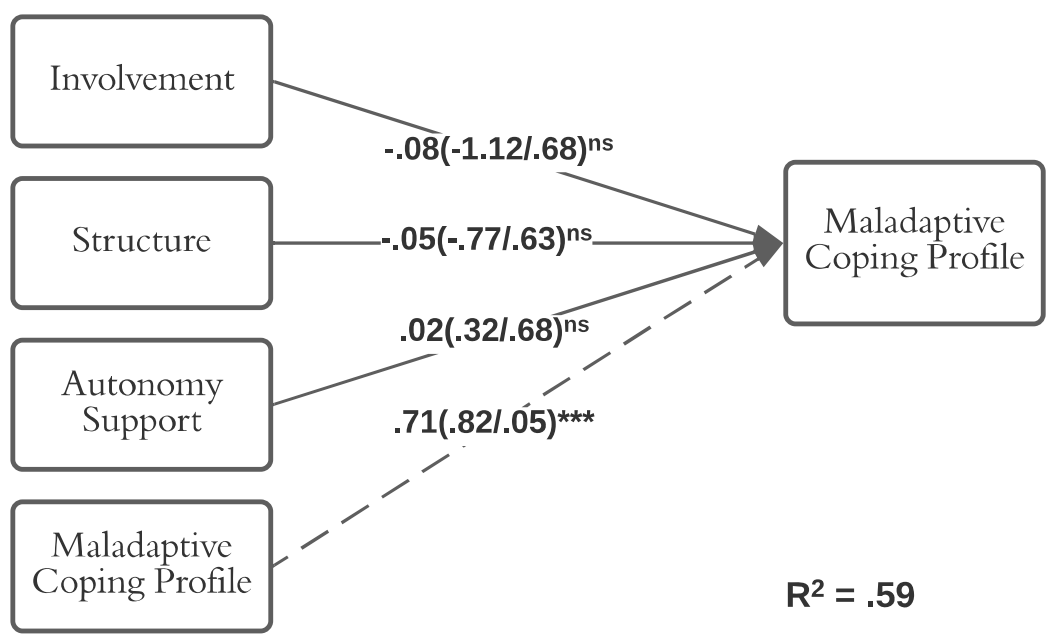

Note. Standardized coefficient(unstandardized coefficient/standard error)

$* p<.05 \quad * * p<.01 \quad * * * p<.001, \mathrm{~ns}=$ non-significant 


\section{PARENTING AND ACADEMIC COPING}

Figure 5.4

Parental Provision of Motivational Support in the Fall Predicting Maladaptive Coping in the Spring

Fall

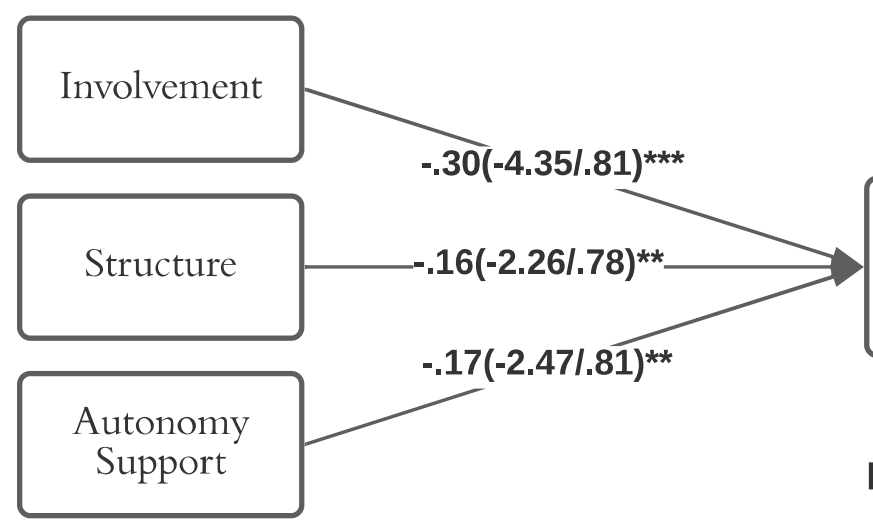

Spring

Maladaptive

Coping Profile

Note. Standardized coefficient(unstandardized coefficient/standard error)

$* p<.05 \quad * * p<.01 \quad * * * p<.001$

Table 5.13

Regression Analyses Predicting Changes in Maladaptive Coping Profiles in the Spring from Individual Parenting Variables in the Fall

\begin{tabular}{|c|c|c|c|c|}
\hline \multirow[b]{2}{*}{ Predictors in Fall } & \multicolumn{4}{|c|}{ Maladaptive Coping Profile in Spring } \\
\hline & $\beta$ & $b$ & $S E$ & $t$ \\
\hline Involvement & -.09 & -1.34 & .60 & $-2.24 *$ \\
\hline $\begin{array}{l}\text { Maladaptive Coping Profile } \\
R^{2}\end{array}$ & .71 & .82 & .05 & $\begin{array}{r}18.00 * * * \\
.55\end{array}$ \\
\hline Structure & -.08 & -1.18 & .56 & $-2.12 *$ \\
\hline $\begin{array}{l}\text { Maladaptive Coping Profile } \\
R^{2}\end{array}$ & .73 & .84 & .04 & $\begin{array}{r}19.55 * * * \\
.5 s\end{array}$ \\
\hline Autonomy Support & -.03 & -.41 & .60 & -.68 \\
\hline $\begin{array}{l}\text { Maladaptive Coping Profile } \\
R^{2}\end{array}$ & .75 & .86 & .05 & $\begin{array}{r}18.99^{* * *} \\
.58\end{array}$ \\
\hline
\end{tabular}




\section{PARENTING AND ACADEMIC COPING}

Research Question 1.b.2. Initial levels of parental involvement, structure, and autonomy support at the beginning of the year were also anticipated to lead to decreases in each individual way of maladaptive coping (i.e., confusion, escape, concealment, selfpity, rumination, and projection) from fall to spring. To test this hypothesis, multiple regression was used to predict each individual way of maladaptive coping in the spring from all three parenting dimensions in the fall while controlling for that same way of coping in the fall. Results indicated that involvement and structure uniquely and significantly predicted decreases in confusion from fall to spring, involvement uniquely and significantly predicted decreases in concealment and projection, and structure uniquely and significantly predicted decreases in self-pity (Table 5.14). No parenting supports significantly predicted changes in escape or rumination, and parental autonomy support did not uniquely predict changes in any individual maladaptive way of coping. 


\section{PARENTING AND ACADEMIC COPING}

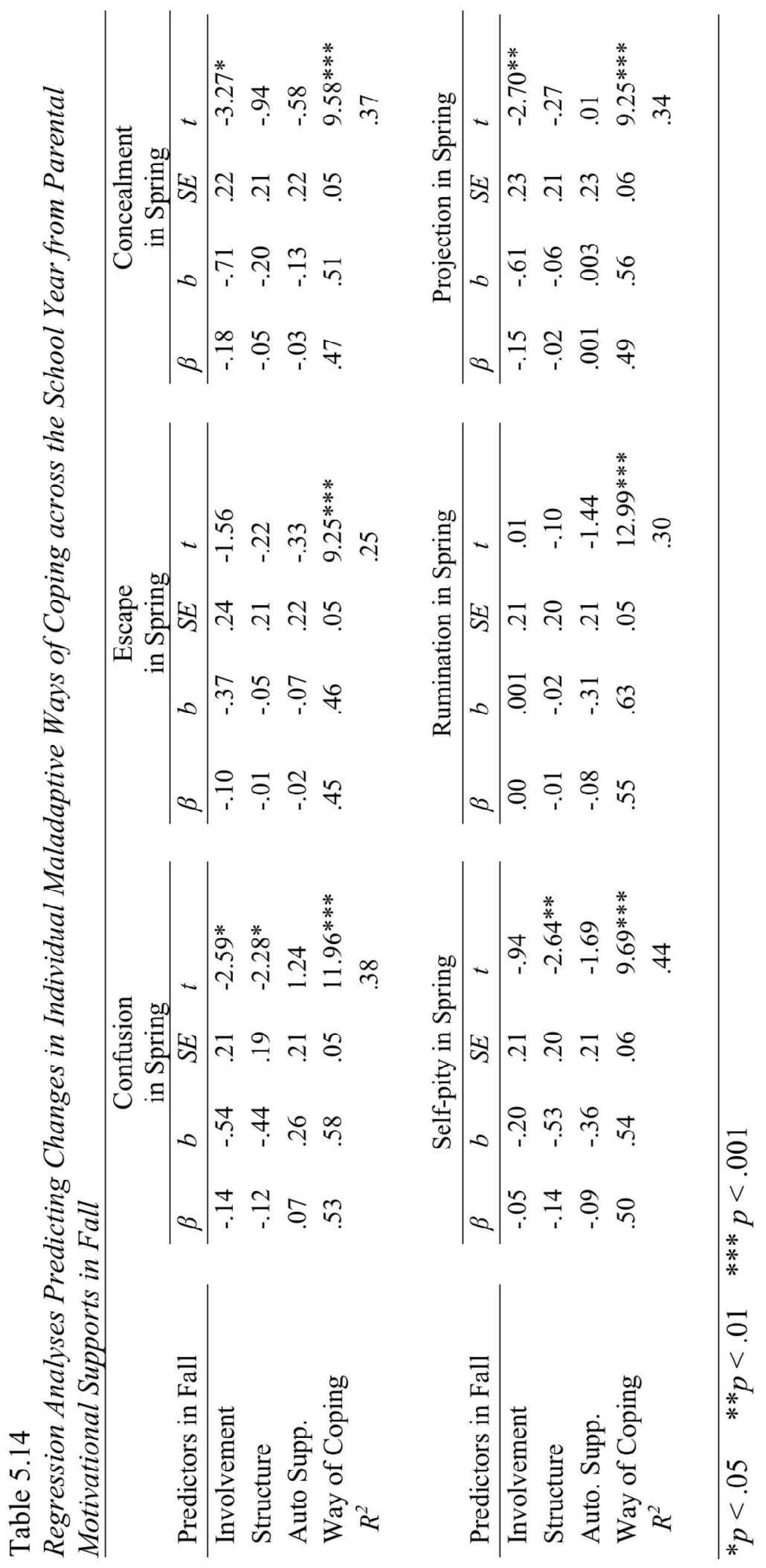




\section{PARENTING AND ACADEMIC COPING}

In order to investigate whether high cross-time stabilities in individual ways of coping may have resulted in the full hypothesis not being supported, unique effects from all parenting dimension in the fall to each individual maladaptive way of coping in the spring were examined (see Table 5.15). When the autoregressive path from each way of coping in the fall was removed, all three dimensions were unique predictors of concealment and self-pity, while involvement in the fall was the only unique predictor of three other ways, specifically, confusion, escape, and projection in the spring. Only rumination was not significantly and uniquely predicted by any of the parental motivational supports. 


\section{PARENTING AND ACADEMIC COPING}

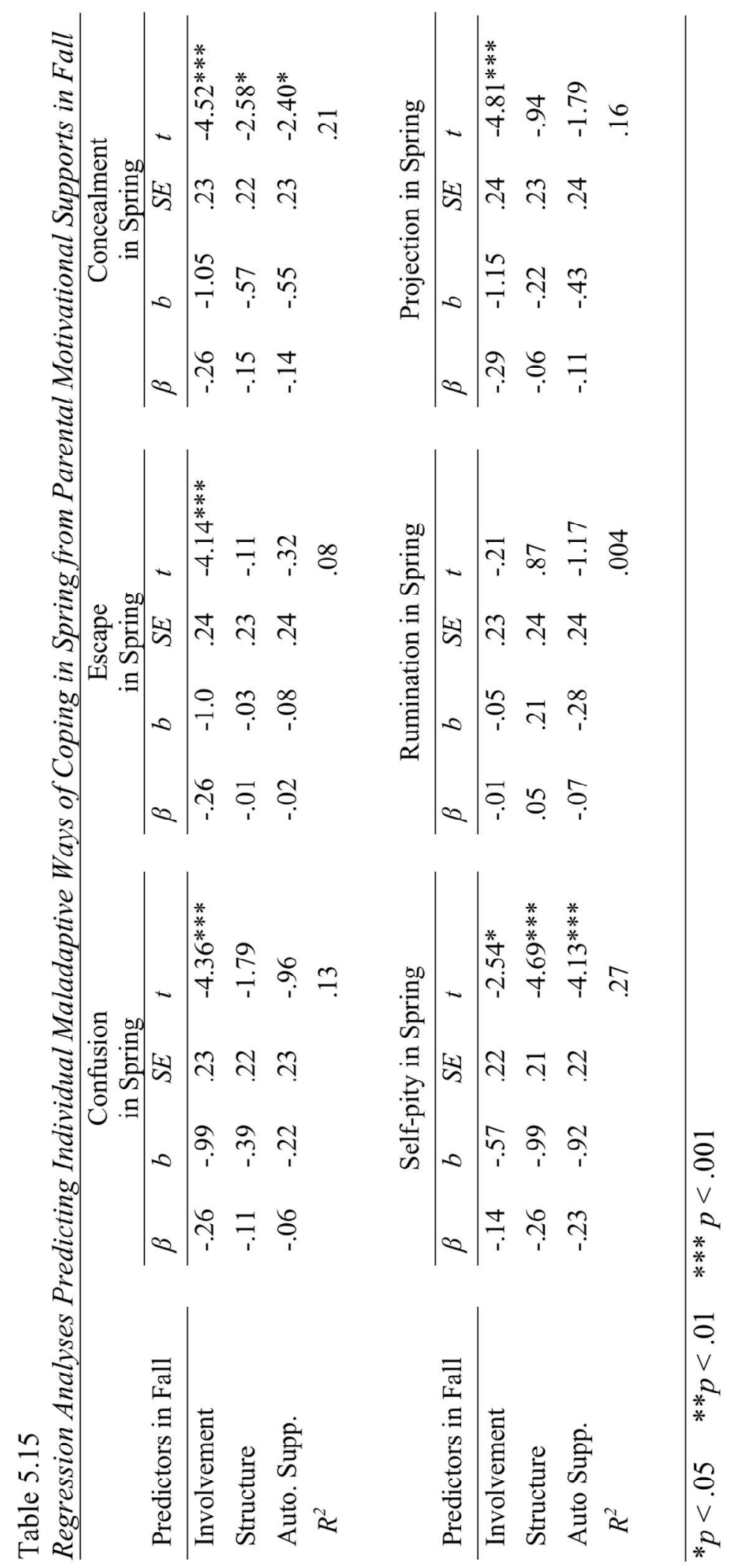




\section{PARENTING AND ACADEMIC COPING}

Additionally, to examine whether lack of support for the full hypothesis was due to overlap among parenting dimensions, all three parenting variables were investigated as individual predictors of changes in each way of maladaptive coping across the school year (see Table 5.16). Results indicated that all three individually predicted decreases in concealment and self-pity from fall to spring, while involvement and structure both individually predicted decreases in confusion, involvement individually predicted decreases in escape and projection, and only autonomy support predicted decreases in rumination. 


\section{PARENTING AND ACADEMIC COPING}

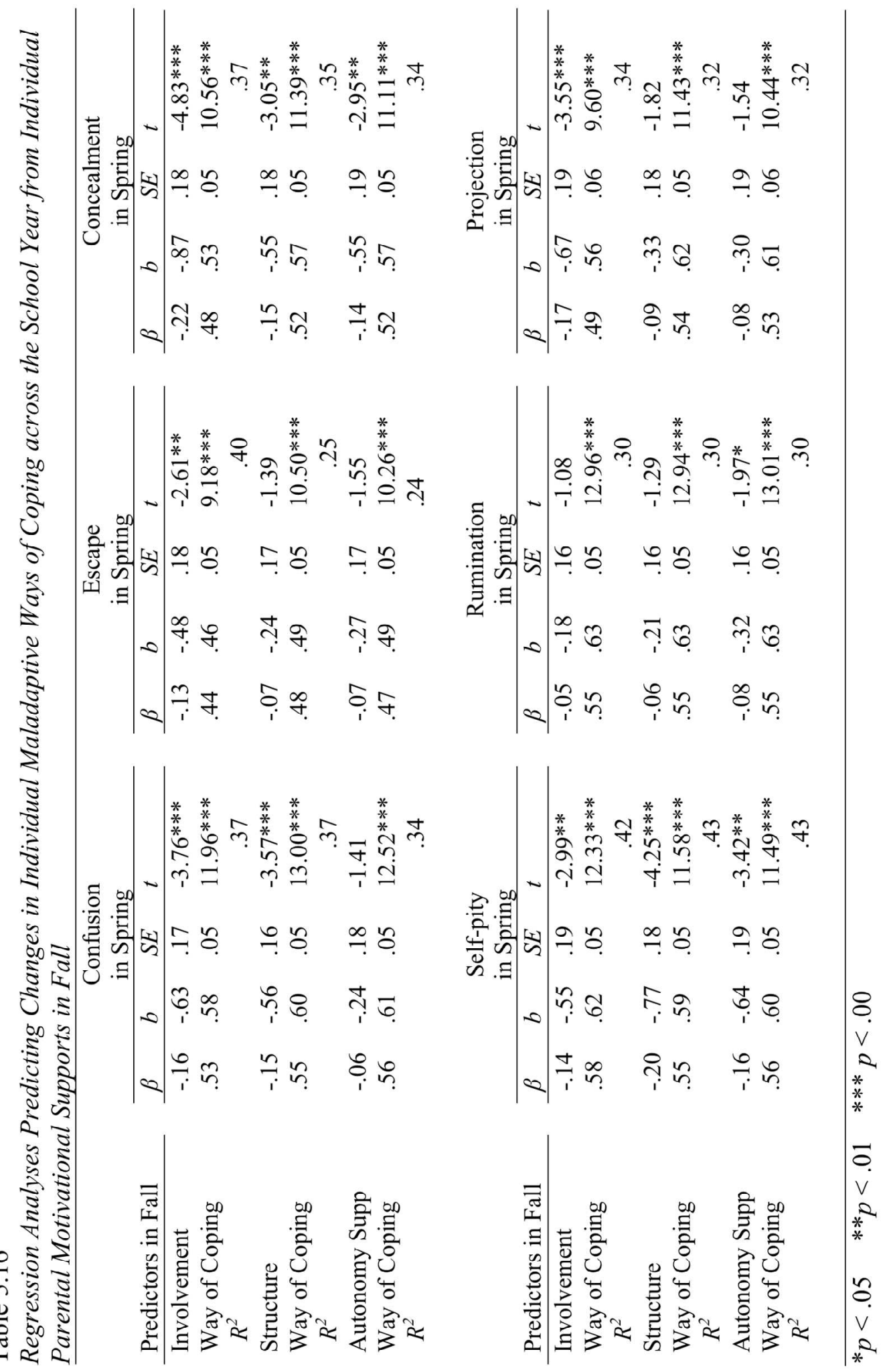




\section{PARENTING AND ACADEMIC COPING}

Overall, when combining the results for each individual way of maladaptive coping with those involving a maladaptive profile, both sets of findings suggested that the high cross-time stabilities of all outcome variables as well as correlations between parenting dimensions made it more difficult to uniquely and significantly predict changes over time. Concealment and self-pity were the only two individual maladaptive ways of coping that were both uniquely predicted by all three parenting dimensions when the autoregressive path was removed, and for whom all three parenting dimensions individually predicted changes across the school year. For almost all other ways of maladaptive coping (specifically, confusion, escape, and projection), parental involvement was the primary predictor and autonomy support was unable to account for a significant amount of variance even whether considered as an individual predictor of changes or with the autoregression removed. The notable exception to this was decreases in rumination from fall to spring, which were only significantly predicted by autonomy support on its own. Ultimately, taken altogether, these results suggested that both covariation among key variables (i.e., cross-time stabilities and construct overlap), and distinctions between coping constructs created different patterns of results.

\section{Research Question 2. Feedback Effects from Children's Initial Coping to Changes in Parenting across the Year}

Research question 2a. Do initial levels of adaptive coping in the fall predict changes in parental motivational support from fall to spring? 


\section{PARENTING AND ACADEMIC COPING}

Research question 2a1. Initially higher levels of profiles of adaptive coping in the fall were expected to lead to increases in involvement, structure, and autonomy support across the school year. Consistent with this hypothesis, correlations between adaptive coping profiles in the fall and parenting variables in the spring were all positive (see Table 5.17). Multiple regression was used to investigate whether a student's adaptive coping profile in the fall predicted each individual parenting motivational support in the spring while controlling for the initial level of that same parenting dimension in the fall. Results indicated that an adaptive coping profile predicted significant increases in involvement, structure, and autonomy support across the school year (see Table 5.18).

Table 5.17

Correlations between Fall Academic Coping and Spring Parenting Variables

\begin{tabular}{lccc}
\hline \multicolumn{1}{c}{ Coping in Fall } & \multicolumn{3}{c}{ Parenting in Spring } \\
\cline { 2 - 4 } & Involvement & Structure & Autonomy Support \\
\hline Adaptive Coping & & & \\
Strategizing & .465 & .343 & .372 \\
Help-seeking & .420 & .412 & .434 \\
Comfort-seeking & .396 & .336 & .329 \\
Self-encouragement & .369 & .261 & .310 \\
Commitment & .361 & .214 & .285 \\
Adaptive Profile & .560 & .440 & .484 \\
Maladaptive Coping & & & \\
Confusion & -.369 & -.265 & -.315 \\
Escape & -.367 & -.203 & -.201 \\
Concealment & -.450 & -.373 & -.372 \\
Self-pity & -.420 & -.434 & -.471 \\
Rumination & $.060^{\mathrm{ns}}$ & $.039^{\mathrm{ns}}$ & $.040^{\text {ns }}$ \\
Projection & -.449 & -.330 & -.406 \\
Maladaptive Profile & -.560 & -.440 & -.484 \\
\hline
\end{tabular}

Note. $N=1,020$

All correlations are significant at $p<.001$ unless noted $n s$ (non-significant). 


\section{PARENTING AND ACADEMIC COPING}

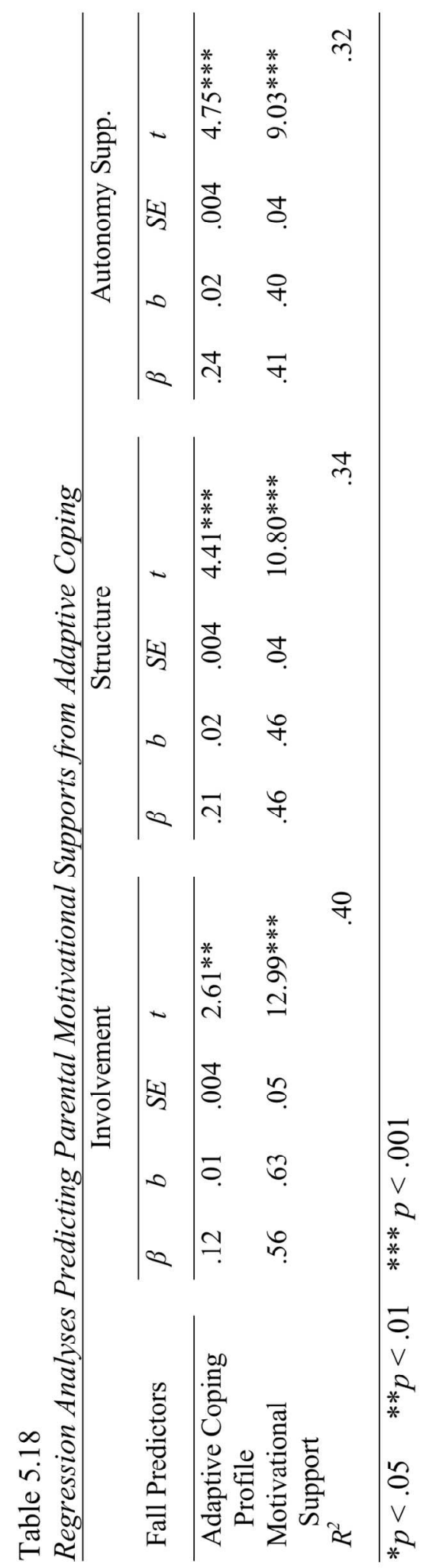




\section{PARENTING AND ACADEMIC COPING}

Research question 2a2. Initially higher levels of individual adaptive ways of coping, namely, strategizing, help-seeking, comfort-seeking, self-encouragement, and commitment, in the fall were also anticipated to uniquely predict increases in involvement, structure, and autonomy support from fall to spring. As presented in Table 5.17, correlations between adaptive ways of coping in the fall and parenting dimensions in the spring were positive, with the lowest association being that between commitment in the fall and structure in the spring $(r=.214)$. Multiple regression was used to examine whether all five individual ways of adaptive coping in the fall were significant, unique predictors of each individual parenting dimension in the spring while controlling for level of that same dimension in the fall. Results indicated that no adaptive ways of coping predicted changes in involvement from fall to spring, but strategizing and selfencouragement predicted increases in structure, and comfort-seeking and commitment both predicted increases in autonomy support (see Table 5.19). 


\section{PARENTING AND ACADEMIC COPING}

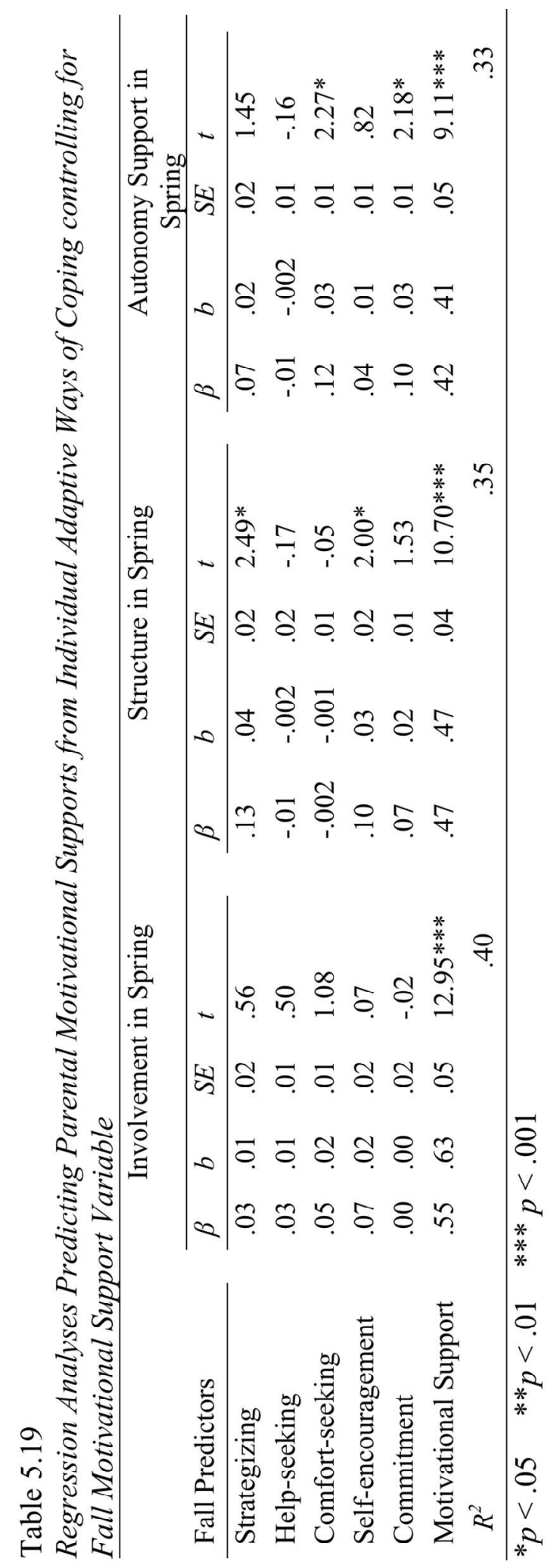




\section{PARENTING AND ACADEMIC COPING}

To investigate possible explanations for why the full hypothesis, that all five ways of coping would uniquely predict increases in all three parenting dimensions, was not supported, additional regression equations were calculated. First, unique effects of the five ways of coping in the fall as predictors of parenting dimensions in the spring were computed with the autoregressive path from the same dimension in the fall removed (see Table 5.20). Once initial levels of the parenting variable were no longer controlled for, four of the five adaptive ways of coping, namely, strategizing, help-seeking, comfortseeking, and self-encouragement became unique, significant predictors of involvement in the spring, although commitment was not. Structure was uniquely predicted by strategizing and help-seeking, and autonomy support by strategizing, help-seeking, comfort-seeking, and commitment. 


\section{PARENTING AND ACADEMIC COPING}

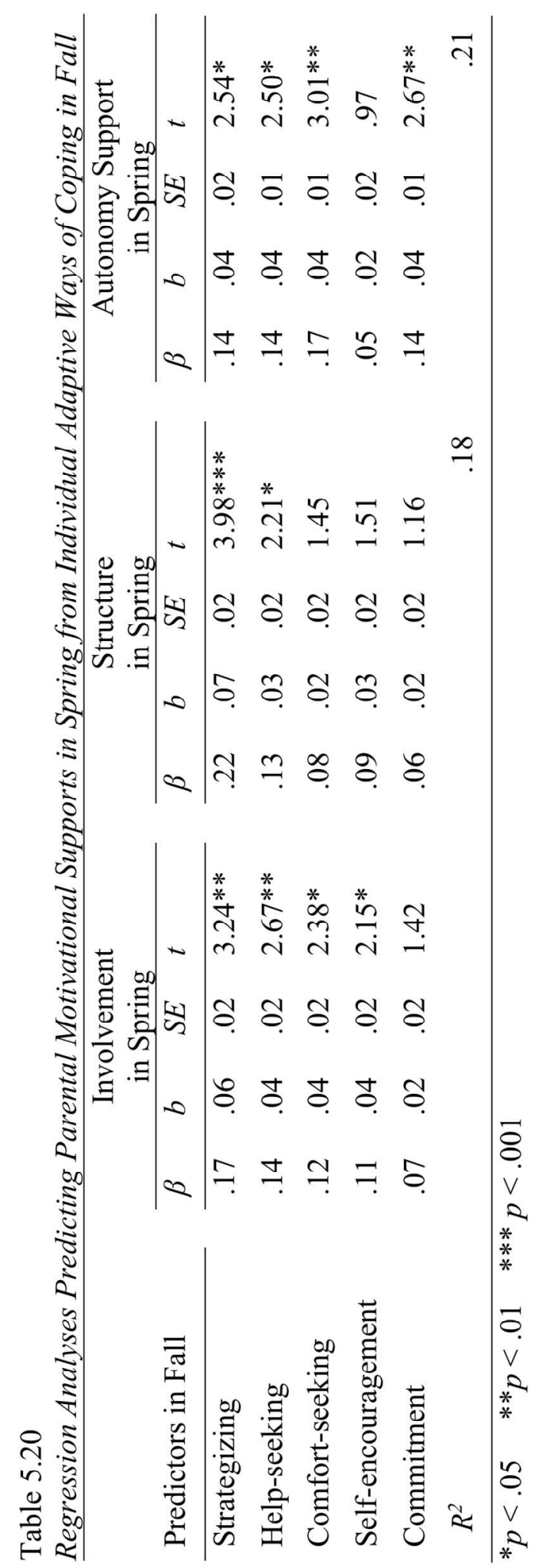




\section{PARENTING AND ACADEMIC COPING}

Second, multiple regression was used to investigate whether each way of adaptive coping individually predicted changes over time in involvement, structure, and autonomy support, without including all other ways as predictors (see Table 5.21). Increases in involvement were individually, significantly predicted only by self-encouragement, while increases in structure were predicted by four of the five adaptive ways of coping, namely, strategizing, help-seeking, self-encouragement, and commitment, and increases in autonomy support were predicted by all adaptive ways of coping. 


\section{PARENTING AND ACADEMIC COPING}

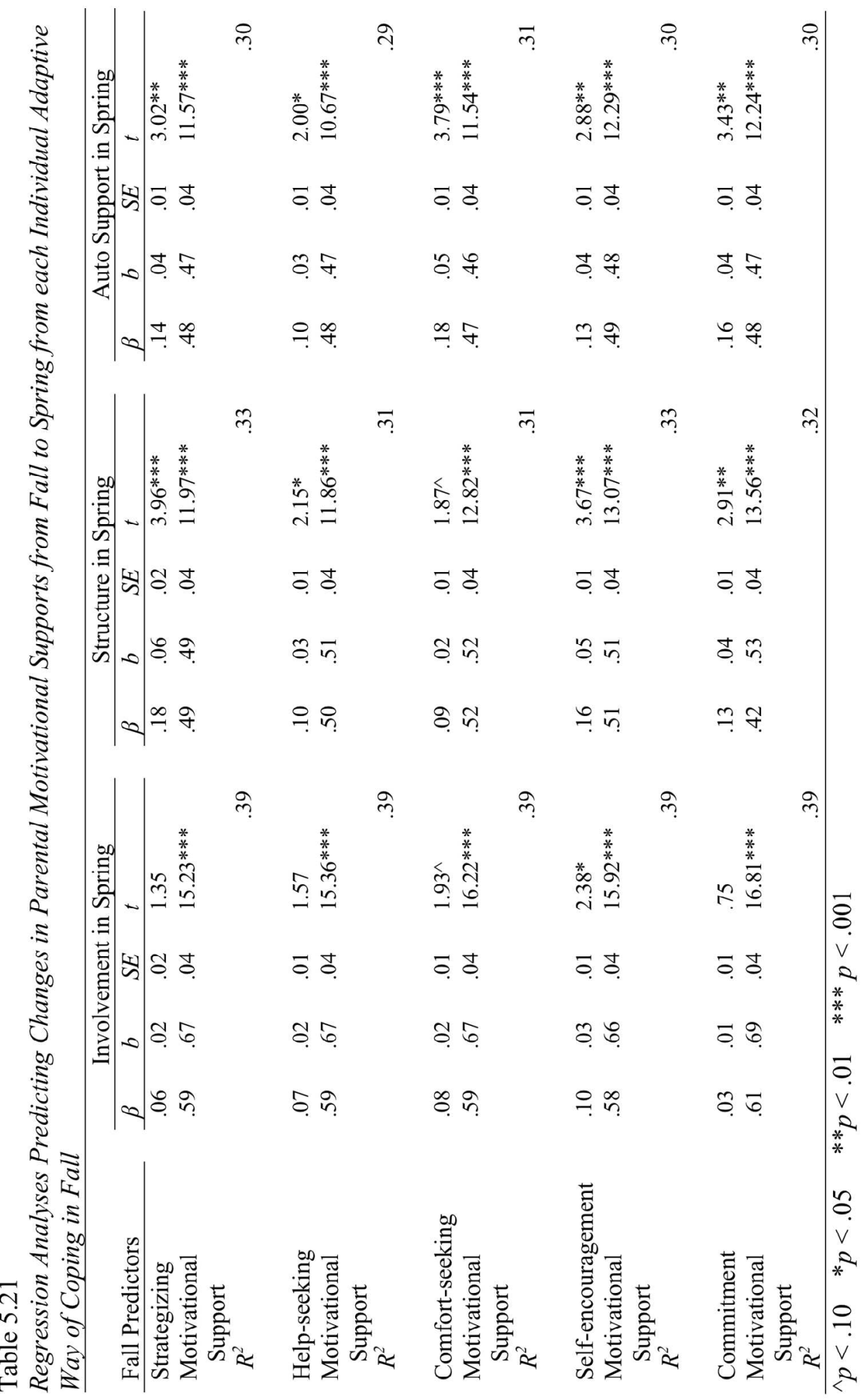




\section{PARENTING AND ACADEMIC COPING}

Overall these patterns of results indicate that high cross-time stabilities for involvement $(r=.606)$ may have made prediction of changes in that specific parenting dimension more difficult, especially when all five ways of coping were included in the model. Support for this contention is provided by the standardized regression coefficient in which involvement was predicted by the adaptive coping profile, which was only about half that of structure or autonomy support, indicating that when the adaptive profile was separated into all five ways, they were trying to account for a much smaller proportion of variance in involvement than that for the other parenting dimensions. It is also supported by the results presented in Table 5.20: Once the autoregressive path from a parenting variable in the fall was removed from the regression equation, most ways of coping uniquely predicted involvement in the spring. Additionally, almost all adaptive ways of coping predicted increases in structure and autonomy individually, suggesting that their relatively lower cross-time stabilities may have made it easier for these ways of coping to account for a significant amount of variance when the autoregressive path was included in the equation.

Research question 2b. Do initially higher levels of maladaptive coping in the fall lead to decreases in parental motivational support from fall to spring?

Research question 2.b.1. Higher initial levels of profiles of maladaptive coping in the fall were expected to lead to decreases in involvement, structure, and autonomy support across the school year. As expected, a maladaptive coping profile in the spring was negatively correlated with all parenting dimensions (see Table 5.17). Multiple 


\section{PARENTING AND ACADEMIC COPING}

regression was used to examine whether profiles of maladaptive coping in the fall predicted all three parenting variables individually in the spring while controlling for that same parenting dimension in the fall. Again, because the present study utilized coping allocation scores, all results using maladaptive coping to predict parenting dimensions were the same as those in research question 2al with adaptive coping predicting parenting, but with the signs of the coefficients reversed. Therefore, results indicated that maladaptive profiles in the fall significantly predicted decreases in involvement, structure, and autonomy support across the school year (see Table 5.22). 


\section{PARENTING AND ACADEMIC COPING}

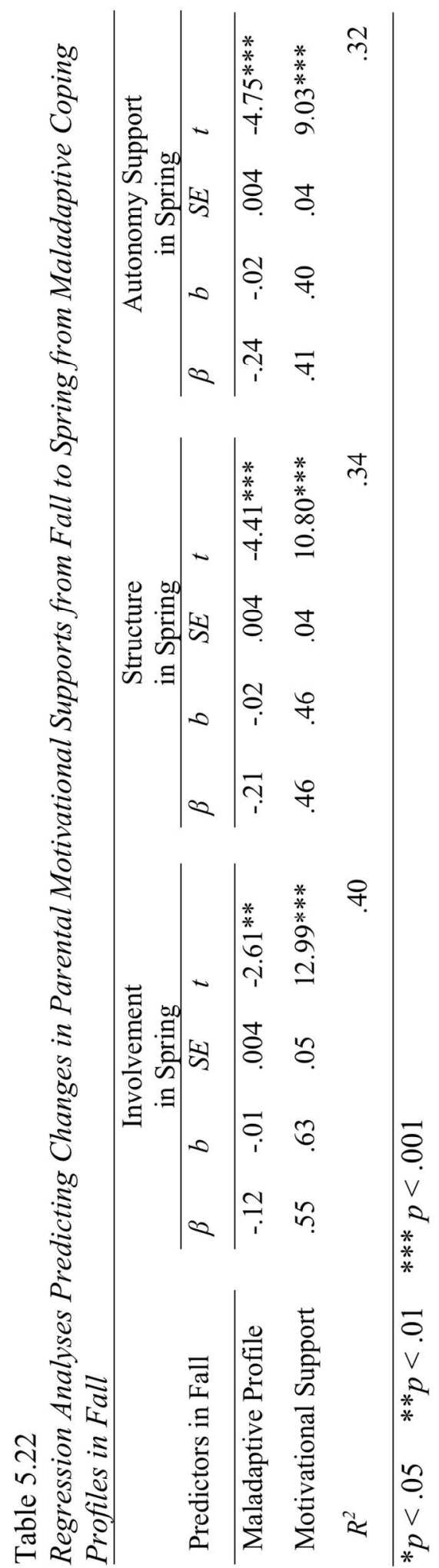




\section{PARENTING AND ACADEMIC COPING}

Research question 2 b2. Higher initial levels of individual maladaptive ways of coping, namely, confusion, escape, concealment, self-pity, rumination, and projection, in the fall are expected to uniquely predict decreases in all parental motivational supports from fall to spring. In general, all individual ways of maladaptive coping in the fall were negatively correlated with parenting dimensions in the spring, with the exception of rumination, which was not significantly correlated with any of the motivational supports. To investigate this hypothesis, multiple regression was used with all six ways of maladaptive coping in the fall predicting all three parenting dimensions in the spring individually while controlling for initial level of that same dimension in the fall. Results indicated that projection uniquely predicted decreases in involvement, structure, and autonomy support, while the only other maladaptive way of coping that made a unique contribution to any dimension was confusion, which uniquely predicted decreases in autonomy support (see Table 5.23). 


\section{PARENTING AND ACADEMIC COPING}

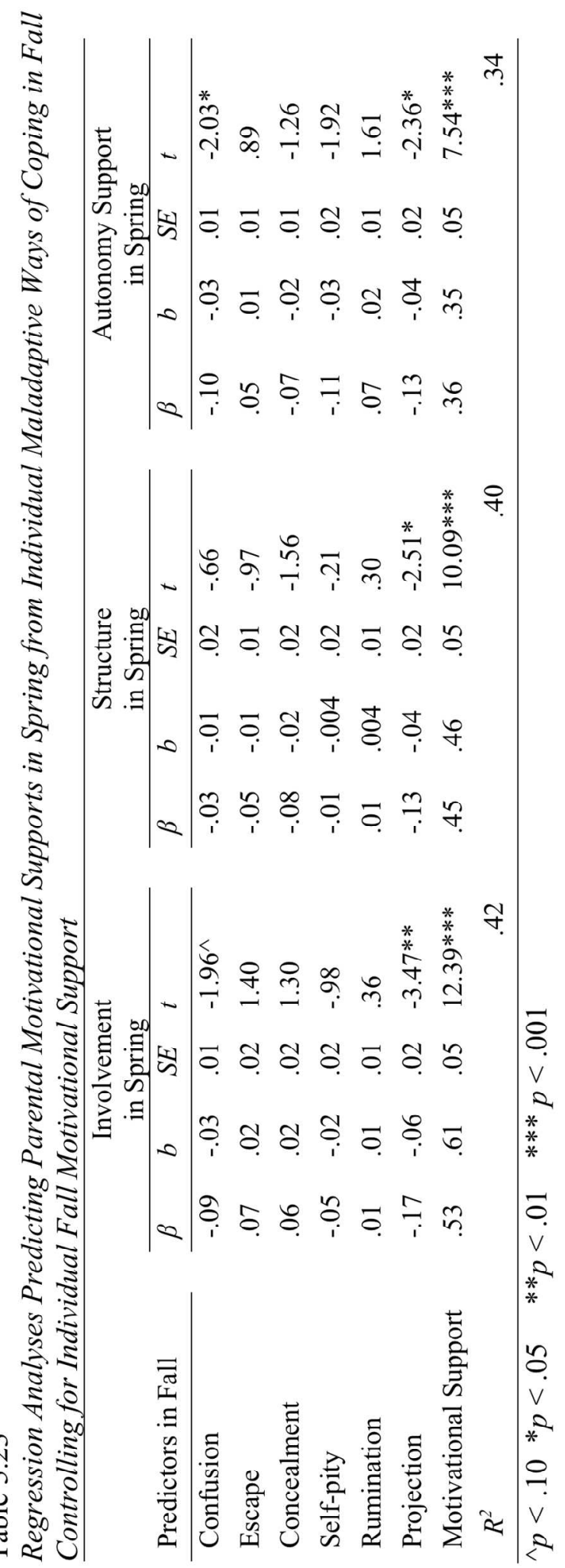




\section{PARENTING AND ACADEMIC COPING}

Because the full hypothesis, that all six ways would uniquely predict changes in all three parenting dimensions across the school year, was not supported, two additional sets of analyses were conducted to further examine the relationship between these constructs. First, individual ways of coping in the fall were investigated as unique predictors of parenting constructs in the spring without the autoregressive path from parenting in the fall. Results indicated that projection was again a significant unique predictor of involvement, structure, and autonomy support, but that with the autoregressive removed, three additional ways of coping made unique contributions to parenting dimensions in the spring. Like projection, self-pity uniquely and significantly predicted all three dimensions (see Table 5.24); confusion uniquely predicted involvement and autonomy support while concealment uniquely predicted structure and autonomy support. 


\section{PARENTING AND ACADEMIC COPING}

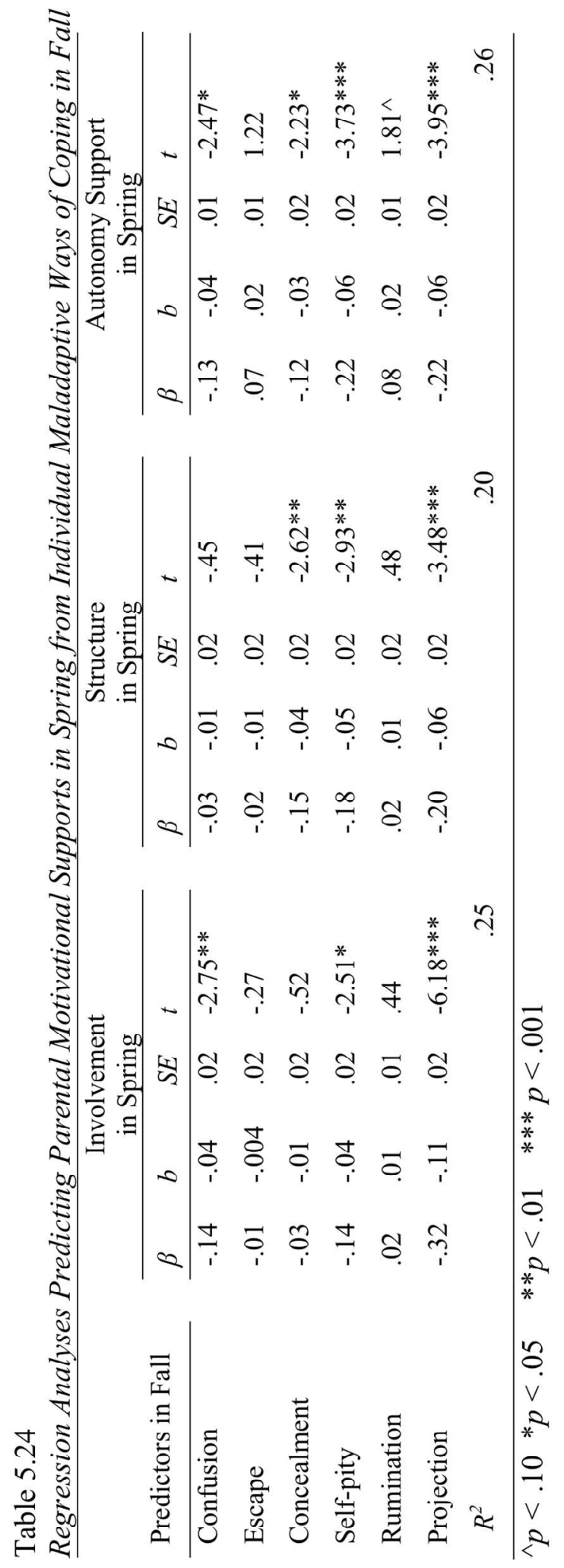




\section{PARENTING AND ACADEMIC COPING}

Second, all ways of coping were looked at as individual predictors of change over time in each parental motivational support. For most ways of coping, once all other ways were removed from the regression equation, they became significant predictors of decreases in all three dimensions across the school year (see Table 5.25). The exceptions to this were escape, concealment, and rumination. Escape only significantly predicted decreases in structure, while concealment significantly predicted decreases in structure and autonomy support. Consistent with both correlations and previous analyses, rumination did not predict changes in any parental motivational support. 


\section{PARENTING AND ACADEMIC COPING}

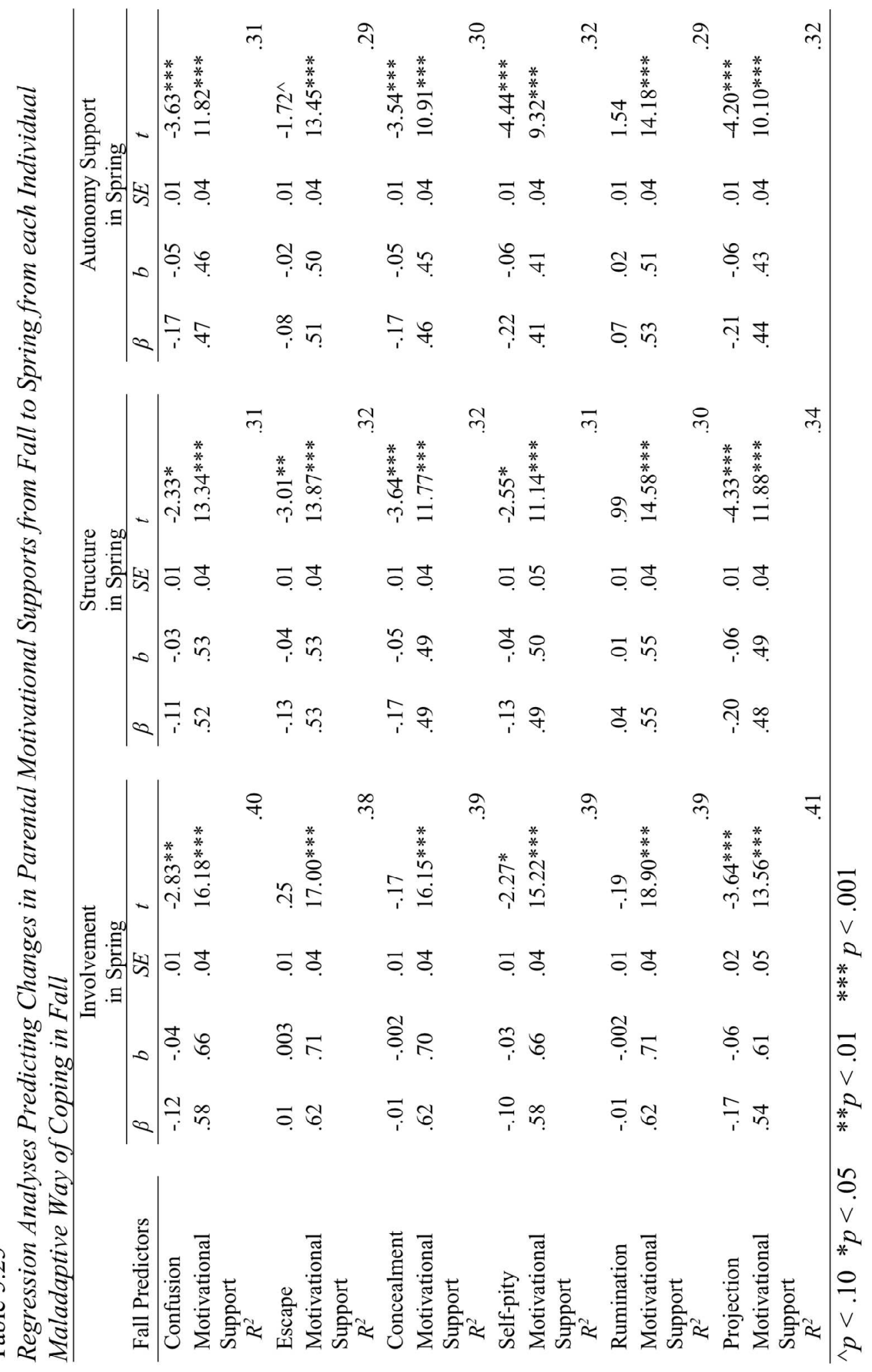




\section{PARENTING AND ACADEMIC COPING}

Altogether, these results suggest that, unlike results for research question 2a2, high cross-time stabilities in involvement were not making predicting changes from individual ways of coping more difficult. Instead, projection was such a powerful predictor of decreases in all three parenting dimensions that no other individual maladaptive way could account for a significant amount of variance. Support for this conclusion can be found in the results presented in Table 5.25: Once all individual ways of coping were separated from one another, all (with the exception of rumination) predicted decreases in one or more parenting motivational supports. Results in Table 5.24 also support these conclusions, though less obviously. Additionally, once the autoregressive path from each parenting dimension in the fall was removed, other ways of coping were able to account for more variance in the outcome: Two maladaptive ways joined projection in uniquely and negatively predicting each parental dimension, suggesting that as in previous analyses, high cross-time stabilities were making it difficult to discern unique predictors of change. But ultimately, projection remained the strongest predictor of involvement and structure, with the highest standardized coefficient, and shared that status with self-pity when predicting autonomy support.

\section{Research Questions 3. Children's Self-system Processes as Mediators of the Effects of Parental Motivational Supports on Changes in Children's Academic Coping}

To investigate children's self-system process and catastrophizing appraisals as possible mediators of the effects of parental motivational supports on changes in children's self-system processes, a traditional four step process was used as laid out by 


\section{PARENTING AND ACADEMIC COPING}

Baron and Kenny (1986; see Figure 5.5). First, the direct, or $c$, path between the predictors (involvement, structure, and autonomy support in the fall) and the outcome (changes in academic coping from fall to spring) was examined using multiple regression. If these coefficients were significant, then the second step was carried out, examining the $a$ path, or a regression equation where the parental motivational supports in the fall predicted the mediator variable in the spring (children's SSPs or catastrophizing variable). If this path was also significant, the $b$ path from the mediator variable to the outcome (changes in academic coping) was investigated. Finally, and of most interest, a multiple regression equation examining all antecedent variables, the mediator, and the outcome in the fall, was used to predict the outcome in the spring (path $\left.c^{\prime}\right)$. If the coefficients from the antecedents to the outcome were no longer significant, then full mediation was supported, but if they were smaller than those in the $c$ path but still significant, partial mediation was supported instead. Sobel's product of coefficients (1982) was used to calculate the indirect path from the antecedents(s) to the outcome through the mediator. This method computes this indirect effect by multiplying the unstandardized coefficients from the $a$ and $b$ paths together. To determine whether the resulting coefficient is statistically significant, a standard error is calculated. The present study utilized a Monte Carlo method within the Rmediation package in R (Tofighi \& MacKinnon, 2011) to estimate these errors and determine confidence limits. A confidence limit that did not contain zero indicated that the associated indirect effect was significant. 


\section{PARENTING AND ACADEMIC COPING}

Because this four-step method was used to examine evidence for mediation, the final step was tested only for those antecedents, outcomes, and mediators that showed significant findings for all three previous steps. Specifically, the first step in all models, testing direct paths or path $c$, were tested in research questions $1 \mathrm{a} 1$ and $1 \mathrm{~b} 1$, which identified dimensions of parenting that uniquely predicted changes in adaptive and maladaptive ways of coping from fall to spring. Because, for example, the direct paths between parental motivational supports and changes in adaptive and maladaptive coping profiles did not reach significance, further mediational steps were not completed for research questions $3 \mathrm{a} 1$ and $3 \mathrm{~b} 1$. 


\section{PARENTING AND ACADEMIC COPING}

Figure 5.5

Children's Self-system Processes and Catastrophizing Appraisals as Mediators of Parental Motivational Supports and Academic Coping

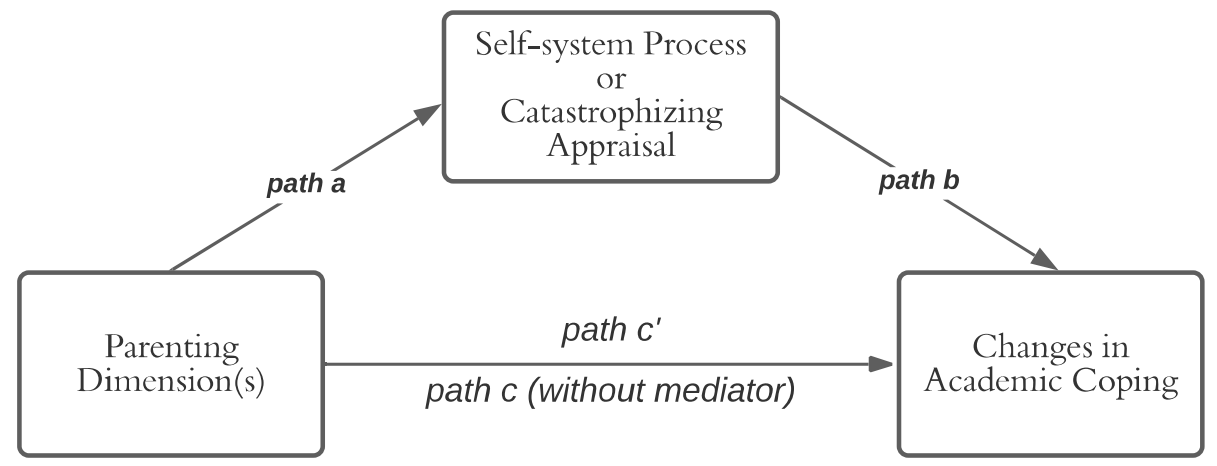

Research question 3a. Children's Self-system Processes as Mediators of the Effects of Parental Motivational Supports on Changes in Children's A Coping

Research question 3a1. It was expected that the effects of initial levels of parental motivational support in the fall on changes in adaptive coping profiles from fall to spring would be mediated by children's self-system processes of relatedness, competence, and autonomy in the spring. But, as demonstrated in the non-significant findings of research question 1a1, namely that neither involvement, structure, nor autonomy support uniquely predicted changes in adaptive profiles, the first step of the Baron and Kenny approach to mediation was not fulfilled, meaning that further steps were not conducted.

Research question 3a2. It was also anticipated that children's self-system processes would mediate the impact of initial parent support on changes in each individual adaptive way of coping across the school year. To test this hypothesis, the four-step process described previously was repeated with each individual adaptive way of coping as the outcome variable. 


\section{PARENTING AND ACADEMIC COPING}

Direct effects of antecedent to outcome (path c). Because direct effects from only one parental motivational support were found for each way of coping (see research question 1a2), only this significant unique predictor was retained for each mediational model. The exception to this was self-encouragement: It had no significant unique parental predictors, and so was not examined further. Results for this first step, or path $c$, are presented in Tables 5.27-5.30 and confirm those found in research question 1a2: That involvement was a significant unique predictor of increases in strategizing, comfortseeking, and commitment across the school year, and that structure was for changes in help-seeking.

Path from antecedent to mediator (path a). Because only one predictor was retained for each mediation, the $a$ path, or path from the antecedent to the mediator, was examined through the correlations presented in Table 5.26. Overall, they suggest generally positive associations between parenting and coping variables and children's self-system processes. Correlations were all significant and moderate to large, except for those between parenting variables and autonomy $(r=.11-.16)$, which were noticeably smaller than those with relatedness and competence. But, as expected, all three parenting dimensions in the fall had a significant and positive association with all three potential mediators in the spring, providing a significant and positive $a$ path for all subsequent analyses. 


\section{PARENTING AND ACADEMIC COPING}

Table 5.26

Correlations between Parenting in the Fall, Self-systems in the Spring, and Adaptive Coping in the Spring

\begin{tabular}{lccc}
\hline \multirow{2}{*}{ Variable } & \multicolumn{3}{c}{ Potential Mediator in Spring } \\
\cline { 2 - 4 } & Relatedness & Competence & Autonomy \\
\hline Parenting in Fall & .52 & .38 & .16 \\
Involvement & .41 & .37 & .11 \\
Structure & .39 & .37 & .16 \\
Autonomy Support & & & \\
Adaptive Coping in Spring & .46 & .52 & .34 \\
Strategizing & .47 & .44 & .35 \\
Help-seeking & .46 & .35 & .32 \\
Comfort-seeking & .39 & .38 & .33 \\
Self-encouragement & .44 & .43 & .38 \\
Commitment & & & \\
\hline Note. All correlations are significant $p<.001$ unless marked $n s$ (non-significant).
\end{tabular}

Path from mediator to outcome (path $b$ ). The third step in this method was to examine whether the proposed mediator, children's self-system process of relatedness, competence, or autonomy in the spring, significantly predicted changes in each individual way of coping across the school year. Multiple regression was used to investigate this path, and results indicated that all potential mediators significantly predicted increases in each adaptive way of coping (see Tables 5.27 - 5.30). Correlations presented in Table 5.26 also supported this hypothesized relationship with moderate to strong associations between each SSP and each adaptive way of coping. Because all included direct pathways from parental dimensions to changes in coping were also significant for paths $a$ and $b$, tests of the final step and indirect effects were presented separately for each way of coping. 


\section{PARENTING AND ACADEMIC COPING}

Strategizing. The pathway from parental involvement in the fall to increases in children's strategizing was expected to be mediated by children's self-system process of relatedness, competence, or autonomy. When examining the fourth step in Baron and Kenny's mediational method, where the antecedent and mediator were simultaneously added to the equation predicting the outcome, results indicated that, for all three selfsystem processes, the coefficient for involvement was reduced once the self-system process was added to the regression equation (see Table 5.27). This indicated that all three self-systems partially mediated the predictive relationship between involvement and increases in strategizing. The test of the indirect effect suggested that the pathway from involvement to increases in strategizing through either relatedness, competence, or autonomy was significant. 


\section{PARENTING AND ACADEMIC COPING}

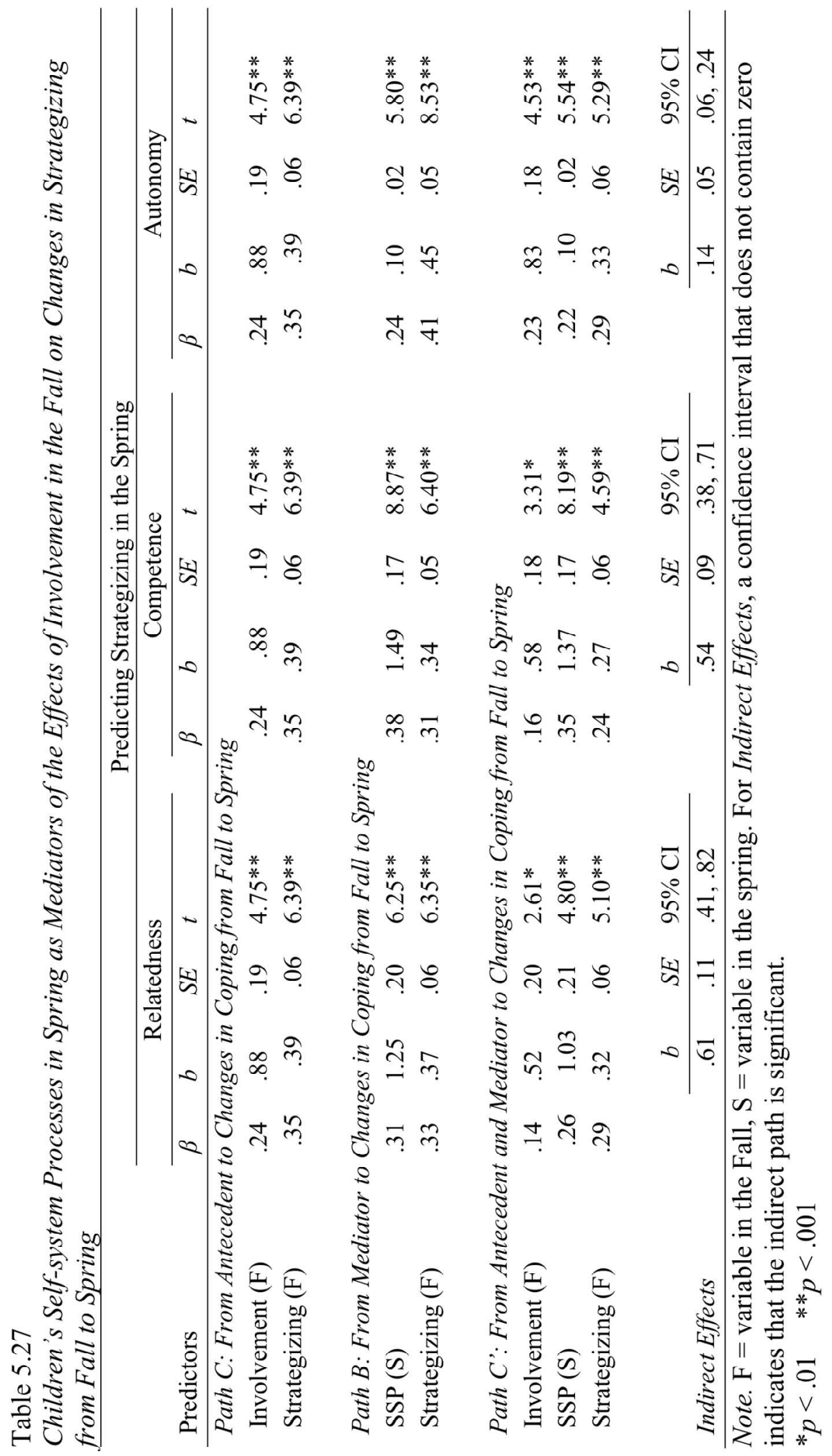




\section{PARENTING AND ACADEMIC COPING}

Help-seeking. A differentiated pattern of results was found for help-seeking, which was the only adaptive way of coping where structure was the significant unique predictor of increases over the school year. When either relatedness or competence were added as predictors, the coefficient for structure was reduced but still significant, suggesting that the relationship between parental structure and increases in help-seeking were partially mediated by both children's sense of relatedness and perceived competence (see Table 5.28). This was also supported by a significant indirect effect from structure to help-seeking through either SSP. The exception to this pattern of results was when autonomy was the proposed mediator. When autonomy was added as a predictor in the fourth step, the coefficient for structure remained roughly the same, suggesting that while autonomy was a significant contributor to increases in help-seeking, it was not a mediator between structure and this particular way of coping. 
PARENTING AND ACADEMIC COPING

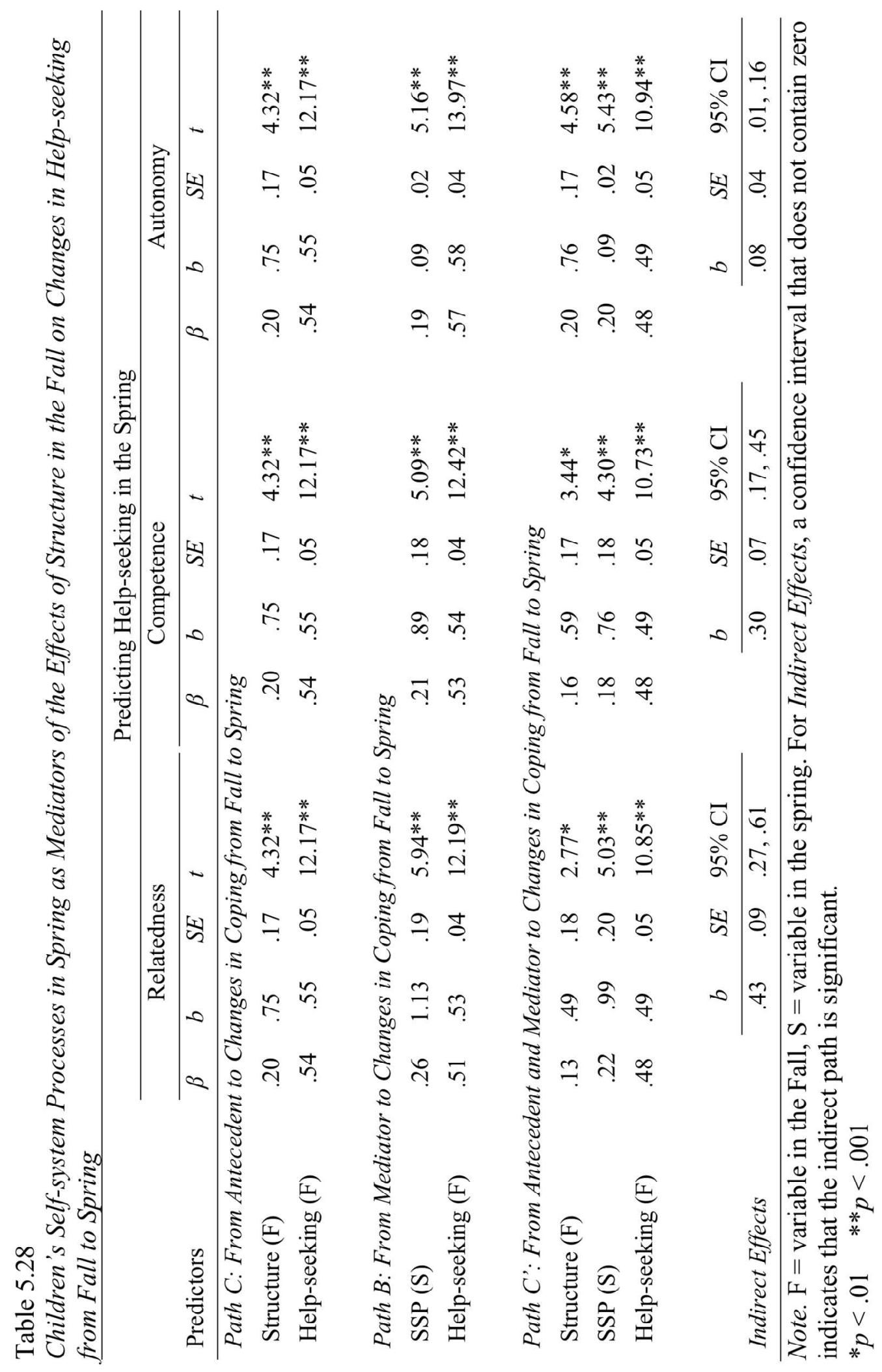




\section{PARENTING AND ACADEMIC COPING}

Comfort-seeking. Another distinct pattern of results was uncovered for comfortseeking. When children's sense of relatedness was added as a predictor, involvement was no longer a significant predictor of increases in comfort-seeking, suggesting that it fully mediated this relationship between parenting and changes in coping (see Table 5.29). Additionally, results indicated that the mediation had a significant indirect effect. When competence or autonomy were added to the regression equation for the fourth and final step, the coefficient for involvement was smaller but remained significant, suggesting the predictive relationship between involvement and increases in comfort-seeking was partially mediated. Further evidence for this mediation was provided by a significant indirect effect. 


\section{PARENTING AND ACADEMIC COPING}

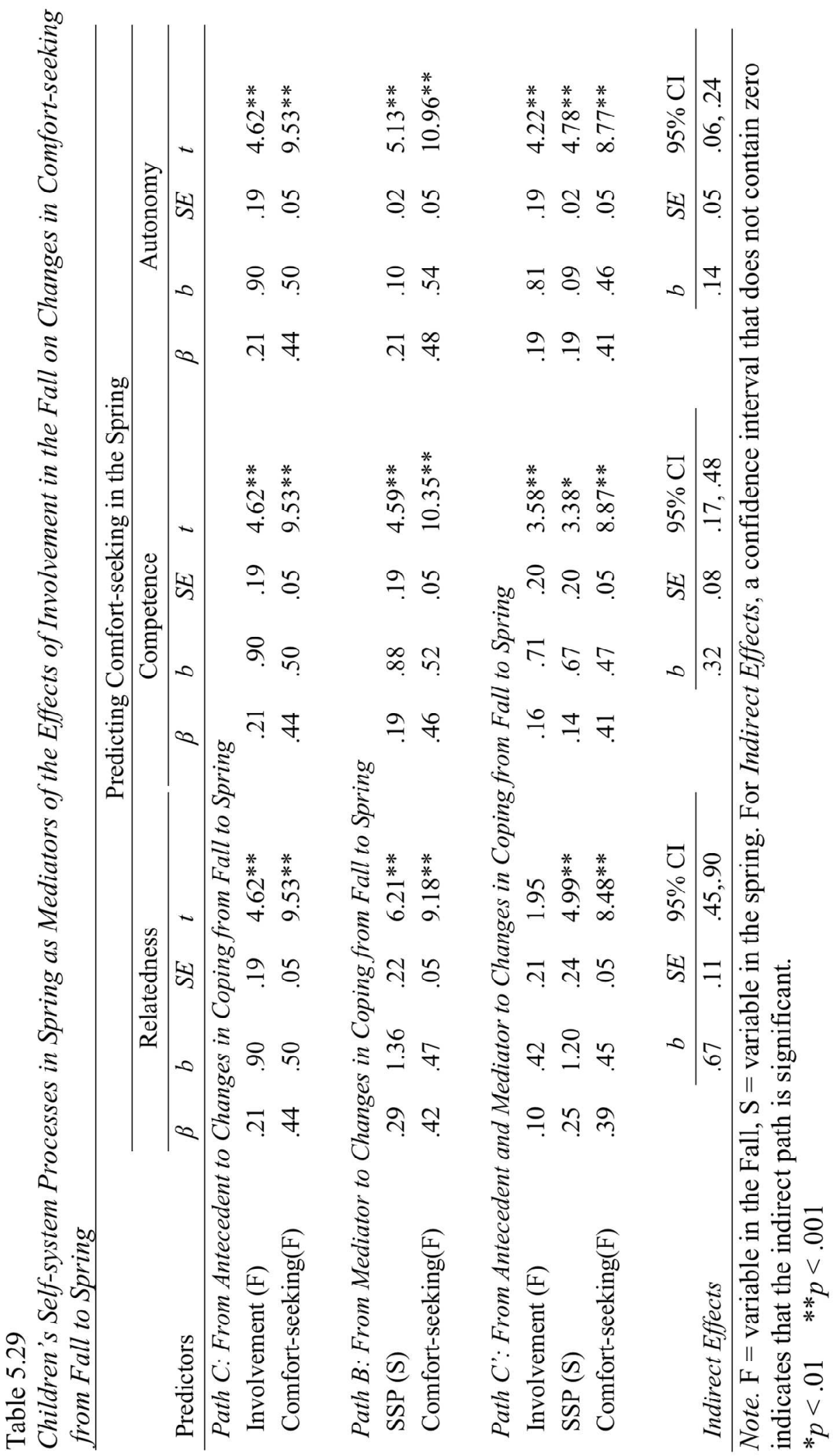




\section{PARENTING AND ACADEMIC COPING}

Commitment. Mediational results for commitment were the same as those found for strategizing, with all three self-system processes partially mediating the pathway between parental involvement and increases in children's use of commitment (see Table 5.30). Evidence for partial mediation was provided from smaller, but still significant, coefficients for involvement when either relatedness, competence, or autonomy were added to the regression equation, and significant indirect effects for the pathway from involvement to increases in commitment through any of the three SSPs. 


\section{PARENTING AND ACADEMIC COPING}

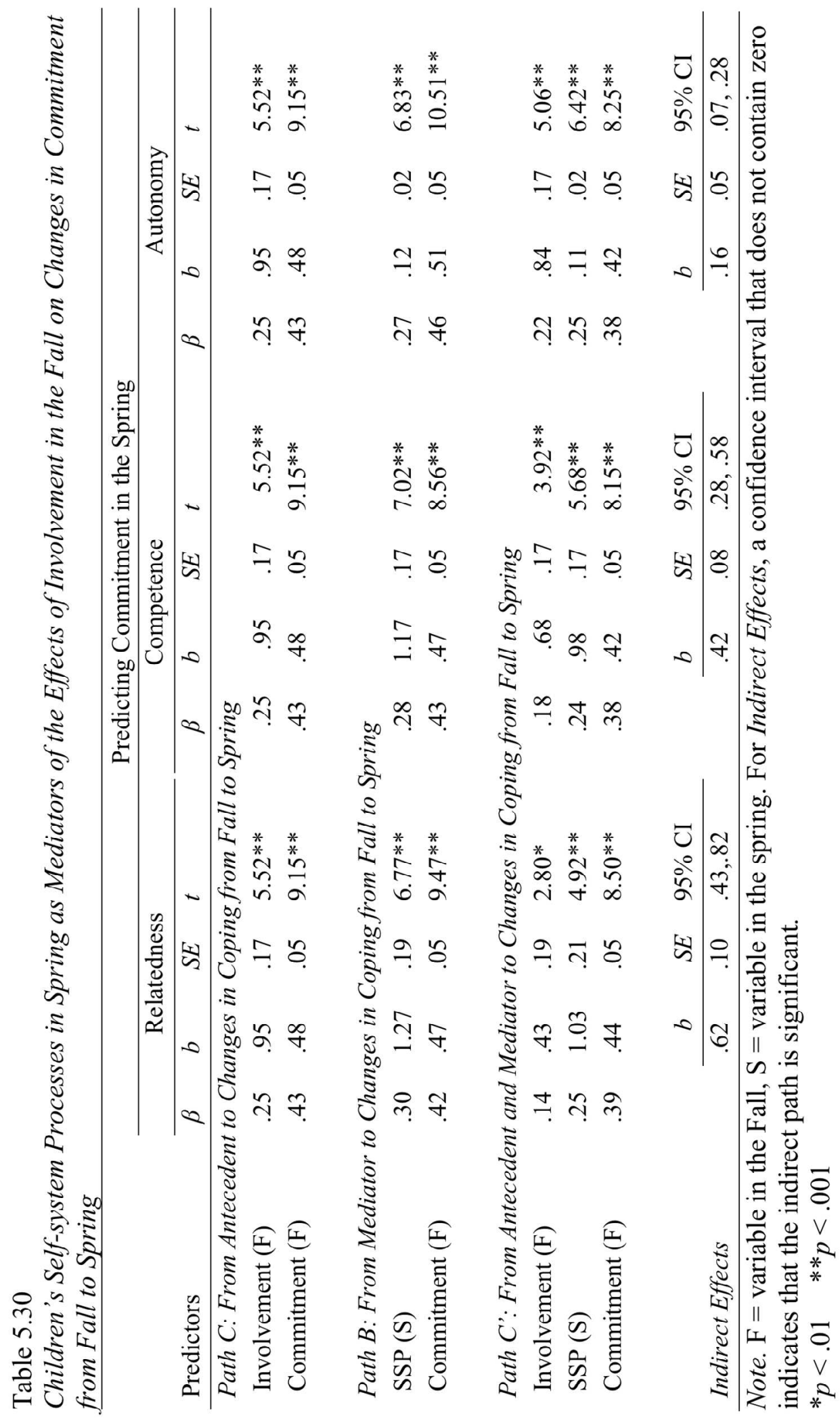




\section{PARENTING AND ACADEMIC COPING}

Consistent with the present hypothesis, all three mediators partially mediated the connection between parenting and increases in individual ways of academic coping when examining strategizing and commitment as the outcome variable. These self-system processes were also all mediators for comfort-seeking, however, relatedness fully mediated while competence and autonomy did so only partially. The only unexpected findings were found for help-seeking: While relatedness and competence were partial mediators, autonomy remained instead a significant contributor over and above that of structure, as previously suggested by lower zero-order correlations. Due to a lack of significant unique parental direct effects, self-encouragement was not included as an outcome variable for these mediational analyses. However, altogether these results suggested that, in general, all three of children's self-system processes mediated the effects of parental motivational supports on student's use of individual adaptive ways of coping.

Research question 3b. Children's Catastrophizing Appraisals as Mediators of the Effects of Parental Motivational Supports on Changes in Children's

\section{Maladaptive Coping}

Research question 3b1. Children's catastrophizing appraisals of relatedness, competence, and autonomy in the spring were also expected to mediate the connection between initial levels of parental motivational support in the fall and changes in maladaptive coping profiles from fall to spring. As explained previously, if the results from any one of the four steps was not significant, no further analyses were conducted. Therefore, because no significant direct effects were uncovered from any parenting 


\section{PARENTING AND ACADEMIC COPING}

dimensions to maladaptive coping profiles (see research question 1b1), no evidence was found to support this hypothesis.

Research question 3b2. All three catastrophizing appraisals were also expected to be processes through which initial levels of parental motivational supports lead to changes in individual maladaptive ways of coping. To test these mediational hypotheses, the four-step Baron and Kenny method and Sobel's product of coefficients method of calculating the indirect effect were used.

Direct effects of antecedent to outcome (path c). As in research question 3a2, the only parenting dimensions that were retained for mediational analyses were those that significantly and uniquely predicted changes in individual maladaptive ways of coping. This meant that for most maladaptive ways of coping only one or two dimensions remained as an antecedent. More specifically, involvement and structure each uniquely predicted decreases in confusion, while only involvement predicted decreases in concealment and projection, and only structure decreases in self-pity (see Tables 5.32 5.35). Changes in escape and rumination were not uniquely and significantly predicted by any of the parenting dimensions when they were all included as independent variables, and therefore further mediational analyses were not conducted for either of these ways of coping.

Path from antecedent to mediator (path a). As presented for research question $3 \mathrm{a} 2$, for most maladaptive ways of coping, path $a$ was examined using the correlations presented in Table 5.31 because only one antecedent and one mediator were retained. All correlations between parenting variables in the fall and children's catastrophizing 


\section{PARENTING AND ACADEMIC COPING}

appraisals in the spring were negative and moderate to large in magnitude (see Table 5.31). The only additional test needed was the examination of path $a$ for confusion, which had two antecedents, involvement and structure. As shown in Table 5.32, both of these parenting dimensions uniquely predicted all three potential mediators in spring. Hence, for all analyses, path $a$, that from the antecedent to the proposed mediator, was significant, fulfilling the requirements for step two.

Path from mediator to outcome (path b). Tests of step three, examining pathways from the mediator to changes in the outcome variable, were also significant for all proposed analyses. All three catastrophizing appraisals significantly predicted increases in all individual maladaptive ways of coping across the school year (see Tables 5.32 5.35). These results were consistent with the correlations presented in Table 5.31 that suggested an overall strong positive association between all three catastrophizing appraisals and most maladaptive ways of coping. This association was especially strong for all catastrophizing variables with confusion and self-pity. Exceptions to this pattern of strong correlations were found for escape and catastrophizing of competence and rumination and catastrophizing of relatedness which had lower but still positive correlations. 


\section{PARENTING AND ACADEMIC COPING}

Table 5.31

Correlations between Parenting in the Fall, Catastrophizing in the Spring, and Maladaptive Coping in the Spring

\begin{tabular}{lccc}
\hline & \multicolumn{3}{c}{ Potential Mediator in Spring } \\
\cline { 2 - 4 } \multicolumn{1}{c}{ Variable } & $\begin{array}{c}\text { Catastrophizing } \\
\text { of Relatedness }\end{array}$ & $\begin{array}{c}\text { Catastrophizing } \\
\text { of Competence }\end{array}$ & $\begin{array}{c}\text { Catastrophizing } \\
\text { of Autonomy }\end{array}$ \\
\hline $\begin{array}{l}\text { Parenting in Fall } \\
\text { Involvement }\end{array}$ & -.31 & -.24 & -.29 \\
Structure & -.38 & -.32 & -.34 \\
Autonomy Support & -.40 & -.33 & -.39 \\
Maladaptive Coping in Spring & & & .58 \\
Confusion & .56 & .61 & .20 \\
Escape & .23 & .12 & .45 \\
Concealment & .49 & .42 & .66 \\
Self-pity & .64 & .68 & .28 \\
Rumination & .20 & .35 & .39 \\
Projection & .39 & .31 & \\
\hline
\end{tabular}

Note. All correlations are significant $p<.001$ unless marked $n s$ (non-significant).

Confusion. Patterns of mediators were slightly different for the two parenting

dimensions that were significant unique predictors of decreases in confusion from fall to spring. For involvement, results presented in Table 5.32 demonstrated a reduced coefficient for involvement once catastrophizing of relatedness was added to the regression equation, as well as a significant indirect effect from involvement to decreases in confusion through this catastrophizing appraisal. This suggested that this appraisal partially mediated the connection between involvement and decreases in confusion (when controlling for structure). When catastrophizing of competence and autonomy were added as mediators, the coefficient for involvement remained roughly the same, suggesting that neither mediated this connection, and instead were both significant contributors to increases in confusion over and above the effect of parental involvement. 


\section{PARENTING AND ACADEMIC COPING}

In contrast, when all three mediators of structure were added, the coefficient for structure was no longer a significant unique predictor of changes in confusion. This, and a significant indirect effect, suggested that children's catastrophizing appraisals fully mediated the pathway from structure to decreases in confusion. 


\section{PARENTING AND ACADEMIC COPING}

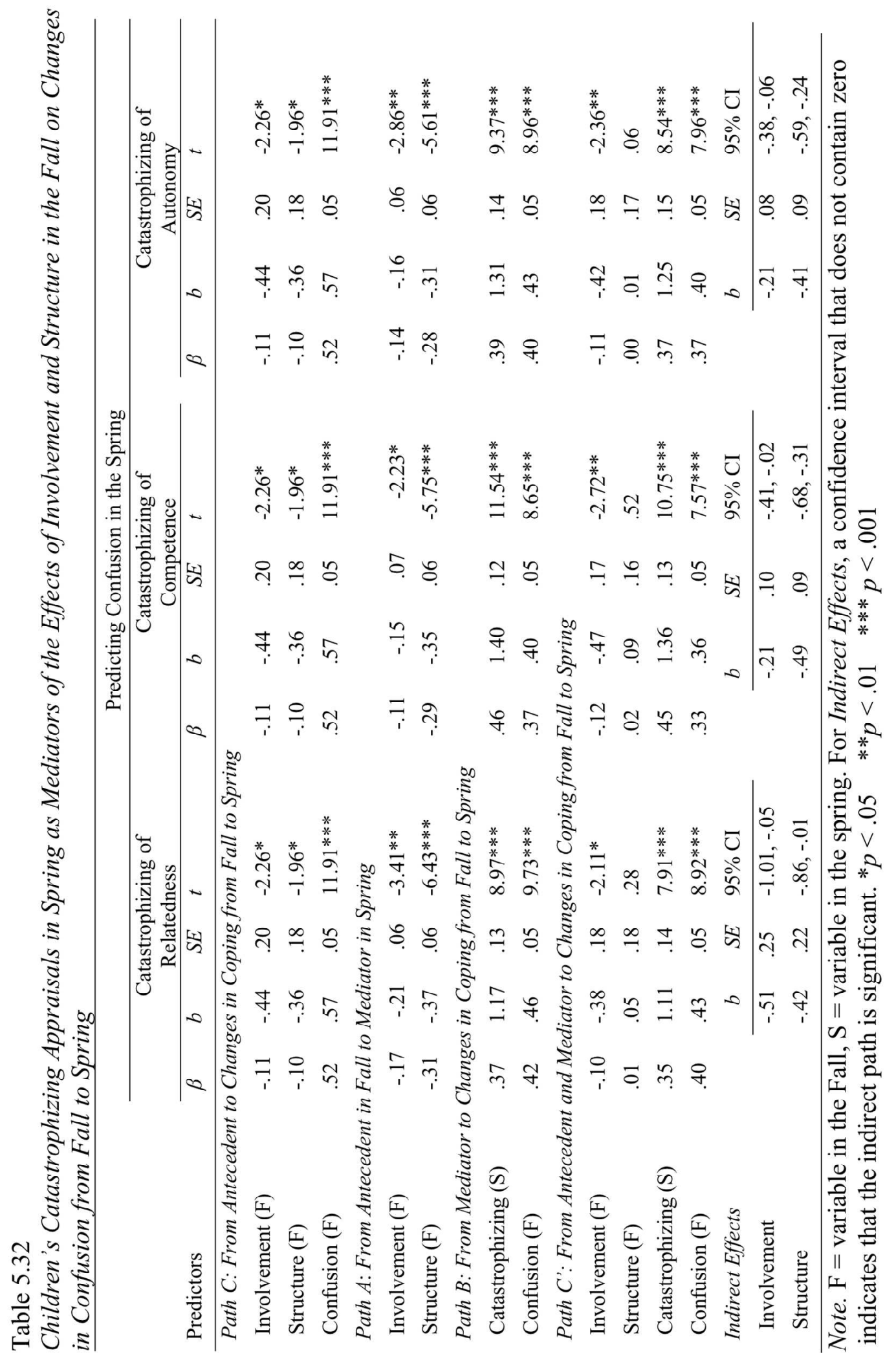




\section{PARENTING AND ACADEMIC COPING}

Concealment. Results for concealment indicated that when each proposed mediator was added to the regression equation, the coefficient for involvement remained significant but was reduced in magnitude, suggesting that each catastrophizing appraisal was partially mediating the connection between involvement and decreases in concealment (see Table 5.33). A significant indirect effect for each mediation provided further evidence for the hypothesis that the effect of involvement on changes in concealment may be through its negative association with catastrophizing of relatedness, competence, and autonomy. 


\section{PARENTING AND ACADEMIC COPING}

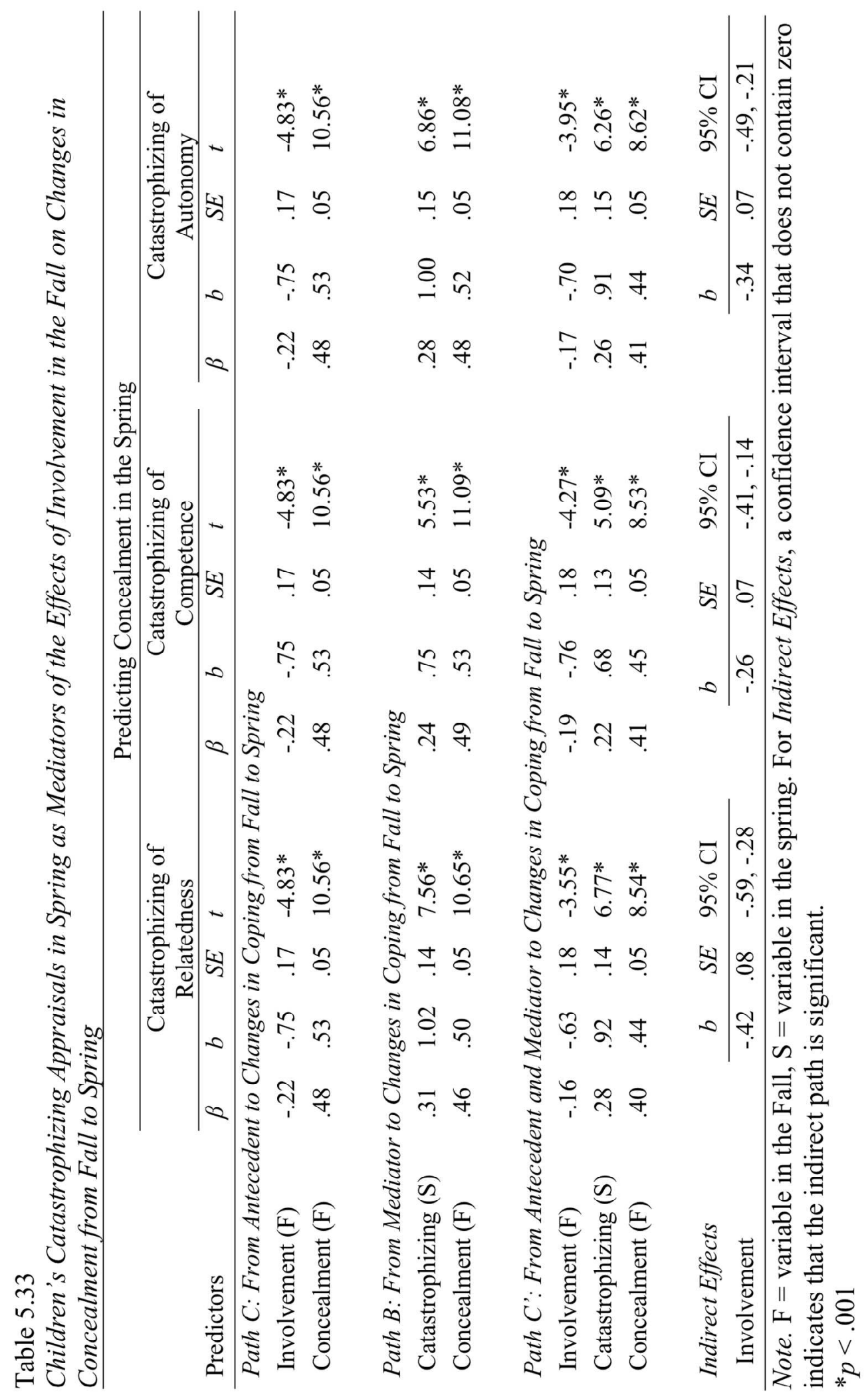




\section{PARENTING AND ACADEMIC COPING}

Self-pity. Results for self-pity mirrored those for concealment, with all three catastrophizing variables partially mediating the pathway from structure to decreases in self-pity, as demonstrated by both a reduced but significant coefficient for structure once the proposed mediator was added to the equation, as well as a significant indirect effect for the pathway from structure to decreases in self-pity through children's catastrophizing appraisals (see Table 5.34). 
PARENTING AND ACADEMIC COPING

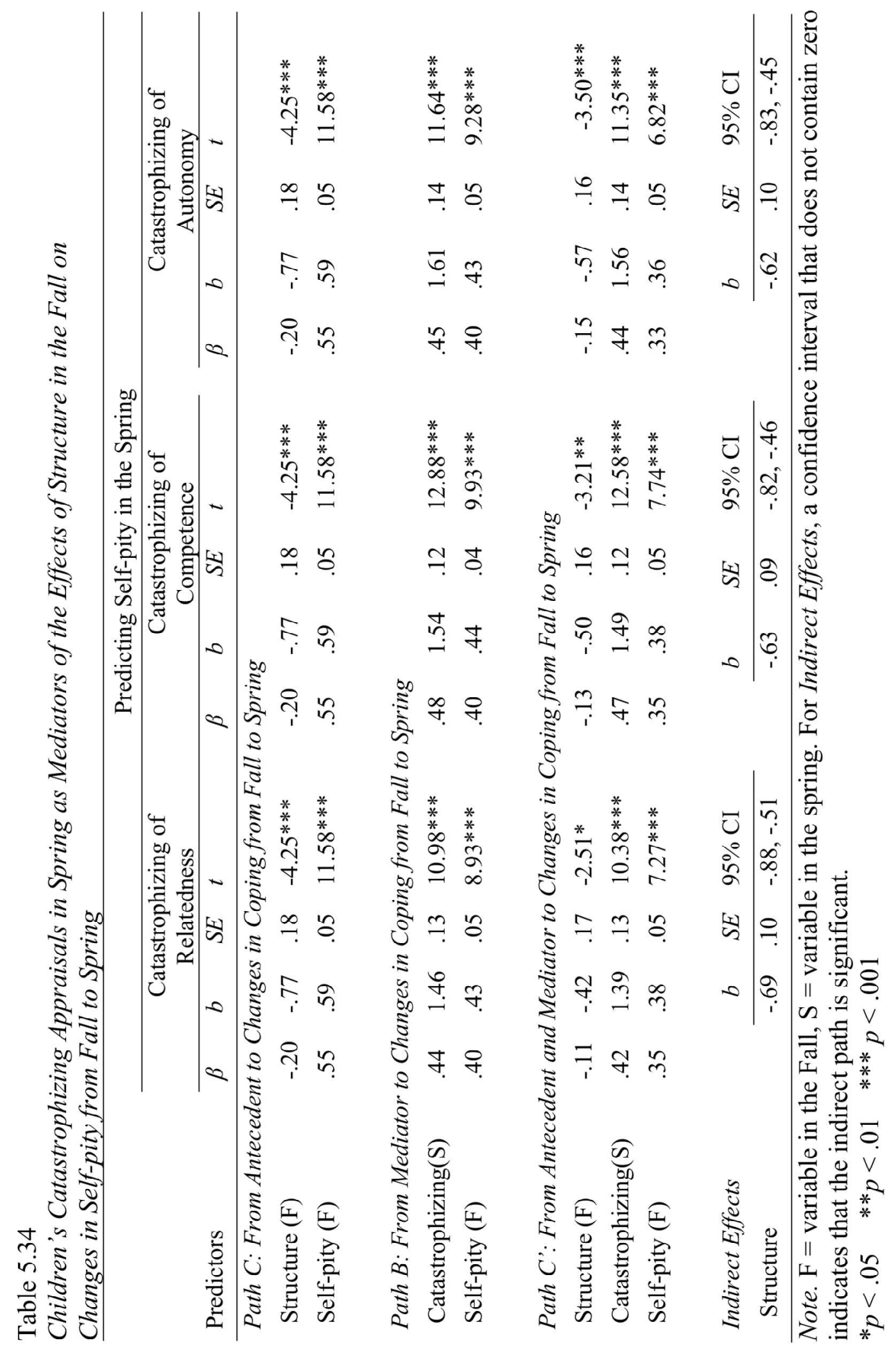




\section{PARENTING AND ACADEMIC COPING}

Projection. Results for projection were consistent with those found for both concealment and self-pity, with all three catastrophizing appraisals partially mediating the relationship between parental involvement and decreases in projection across the school year. As with previous analyses, this was demonstrated through a reduced but significant coefficient for parental involvement once children's appraisals were added as predictors, as well as a significant indirect effect (see Table 5.35). 
PARENTING AND ACADEMIC COPING

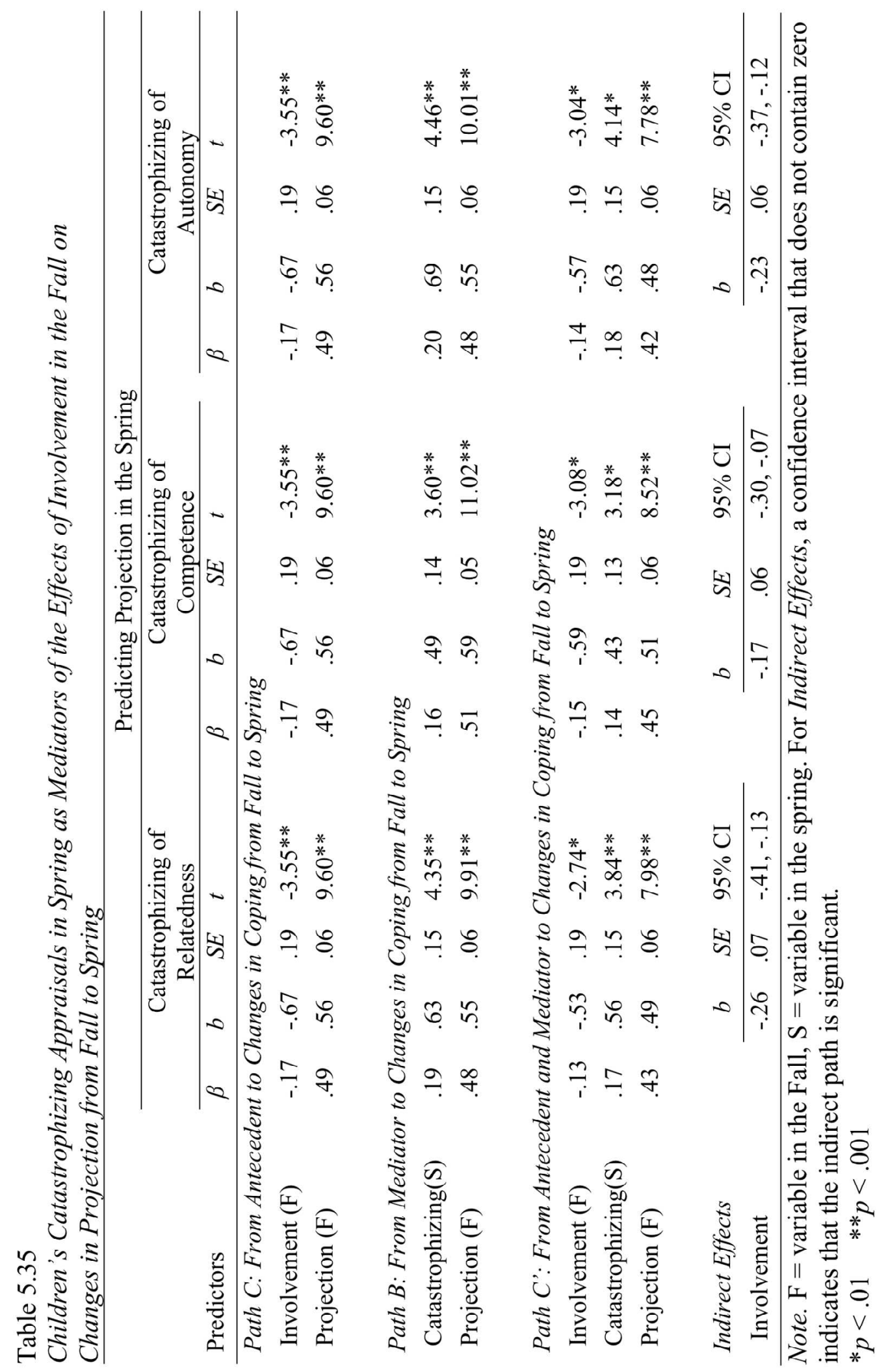




\section{PARENTING AND ACADEMIC COPING}

When examining children's catastrophizing appraisals as possible pathways through which parents influenced children's use of individual ways of maladaptive coping, three major differences in results were uncovered that generally followed the possible combinations of antecedents that were investigated. First, when both involvement and structure were retained, the connection between structure and confusion was fully mediated by all three catastrophizing appraisals, while only catastrophizing of relatedness partially mediated that between involvement and confusion. Second, for concealment and projection, only parental involvement was retained, and all three appraisals partially mediated this connection. Third, the relationship between only structure and changes in self-pity was also partially mediated by all three appraisals. No parenting dimensions were significant unique predictors of escape and rumination, and therefore no further mediational analyses were conducted for these individual ways. Overall, these results suggested that children's catastrophizing appraisals were one likely mechanism through which parents' offerings of motivational supports impacted changes in their use of maladaptive ways of coping. 


\section{PARENTING AND ACADEMIC COPING}

\section{Chapter VI: Discussion}

The present study was designed to answer three overarching research questions regarding the connection between parents' provision of three motivational supports and the ways their children handle the everyday academic stressors they encounter at school. These questions aimed to begin to describe the dynamic system of this interpersonal relationship, by both disentangling the direction of effects between parental support and children's academic coping and exploring possible mechanisms through which parents impact children's use of these strategies.

Previous research has been limited in all of these areas, due to a reliance upon cross-sectional data collected at one time-point, and a lack of focus on possible feedback effects from children's coping to parenting behaviors. This study therefore represented a starting place for further exploration of conceptualizations of parenting and academic coping as a dynamic system where both social partners are mutually influencing each other. This work also aimed to parse possible pathways through which parents are exerting their effects, providing a greater understanding of how parents impact children's ability to handle the stressful academic tasks they encounter. A more complex understanding of these mechanisms could provide the larger field with a foundation for supporting high-quality parenting and developing more effective interventions for both parents and students.

\section{Summary of Study Findings}

Study analyses were organized around three specific research questions. Research question one examined the hypothesis that initial levels of parental motivational supports 


\section{PARENTING AND ACADEMIC COPING}

would lead to changes in children's academic coping across the school year. Results for this question and its four sub-questions (focusing on adaptive profiles, individual adaptive ways of coping, maladaptive profiles, and individual maladaptive ways of coping) are summarized in Table 6.1. Although, contrary to predictions, no parenting dimensions were significant unique predictors of changes in either adaptive or maladaptive coping profiles, the examination of individual ways of coping revealed partial support for the hypothesis. Involvement consistently predicted increases in most individual adaptive ways of coping (specifically, strategizing, comfort-seeking, commitment) and decreases in most individual maladaptive ways (specifically, confusion, concealment, and projection). Structure uniquely predicted increases in only one adaptive way, help-seeking, and decreases in two maladaptive ways, confusion and self-pity. Autonomy support did not uniquely predict changes in any individual ways of coping.

Because the full hypothesis (i.e., that all three parental provisions would make unique contributions to changes in all ways of coping) was not supported for any of the four sub-questions within research question one, follow up analyses were conducted both to explore possible explanations for non-significant results and to further describe the relationship between parenting and coping variables. More specifically, without followup analyses, one potential interpretation of these findings would be that multiple dimensions of parenting do not play a role in the development of children's coping. Therefore, in order to see whether covariation among key variables (i.e., cross-time stabilities and overlap among parenting constructs) made it more difficult to discern 


\section{PARENTING AND ACADEMIC COPING}

unique predictors of changes in coping, follow-up analyses examined (1) unique effects of fall parenting dimensions on coping variables in the spring with coping autoregressions removed, and (2) individual effects of parenting dimensions on changes in coping for each parenting dimension separately. As a whole, follow-ups indicated that both these factors were in play for most ways of coping.

Four general patterns of results were uncovered. First, for both profiles and five ways of coping (strategizing, help-seeking, comfort-seeking, concealment, and self-pity), when either the autoregressive path was removed or predictors were separated, all (or almost all) parenting dimensions significantly predicted the outcome, suggesting high cross-time stabilities and overlap among parenting dimensions were making predicting change over time especially difficult. However, other ways of coping, specifically projection and confusion, did not follow this pattern, instead retaining their significant predictor(s) even when the autoregressive path was removed or the predictors were separated, providing evidence that these parenting dimensions actually were the only important predictors for these particular ways of coping. Third, two ways of coping (selfencouragement and commitment) lay somewhere in between these two patterns, with follow-up analyses allowing some additional dimensions of parenting to significantly predict the outcome or changes in the outcome, but not all. Fourth, for two ways of coping (escape and rumination), almost no parenting dimensions had a significant effect, whether initial coping was no longer controlled for or parental dimensions were separated. Because study hypotheses primarily concerned changes in academic coping across the school year, results of follow up analyses that included changes were of special 


\section{PARENTING AND ACADEMIC COPING}

interest. Overall, when parenting dimensions were separated into individual predictors of changes in coping over time, 29 out of $39(74 \%)$ of possible results were significant, suggesting that multiple dimensions of parenting may be contributing to increases in adaptive ways of coping and profiles and decreases in maladaptive coping over the school year.

Ultimately, results from the primary analyses suggest that a parenting context characterized by warmth and involvement, and for specific ways of coping (i.e., helpseeking and self-pity) has attuned limits and scaffolds, can, over and above the effects of the other two dimensions, lead children to utilize more adaptive coping strategies, and rely less upon maladaptive ways. However, generally high stability in children's coping across the school year and possible interdependence or overlap among parenting dimensions may make discerning these impacts more difficult. The relationship among involvement, structure, and autonomy support, the strengths and limitations of parental motivational support as a multidimensional construct, as well as its implications for future research will be discussed further in later sections. 


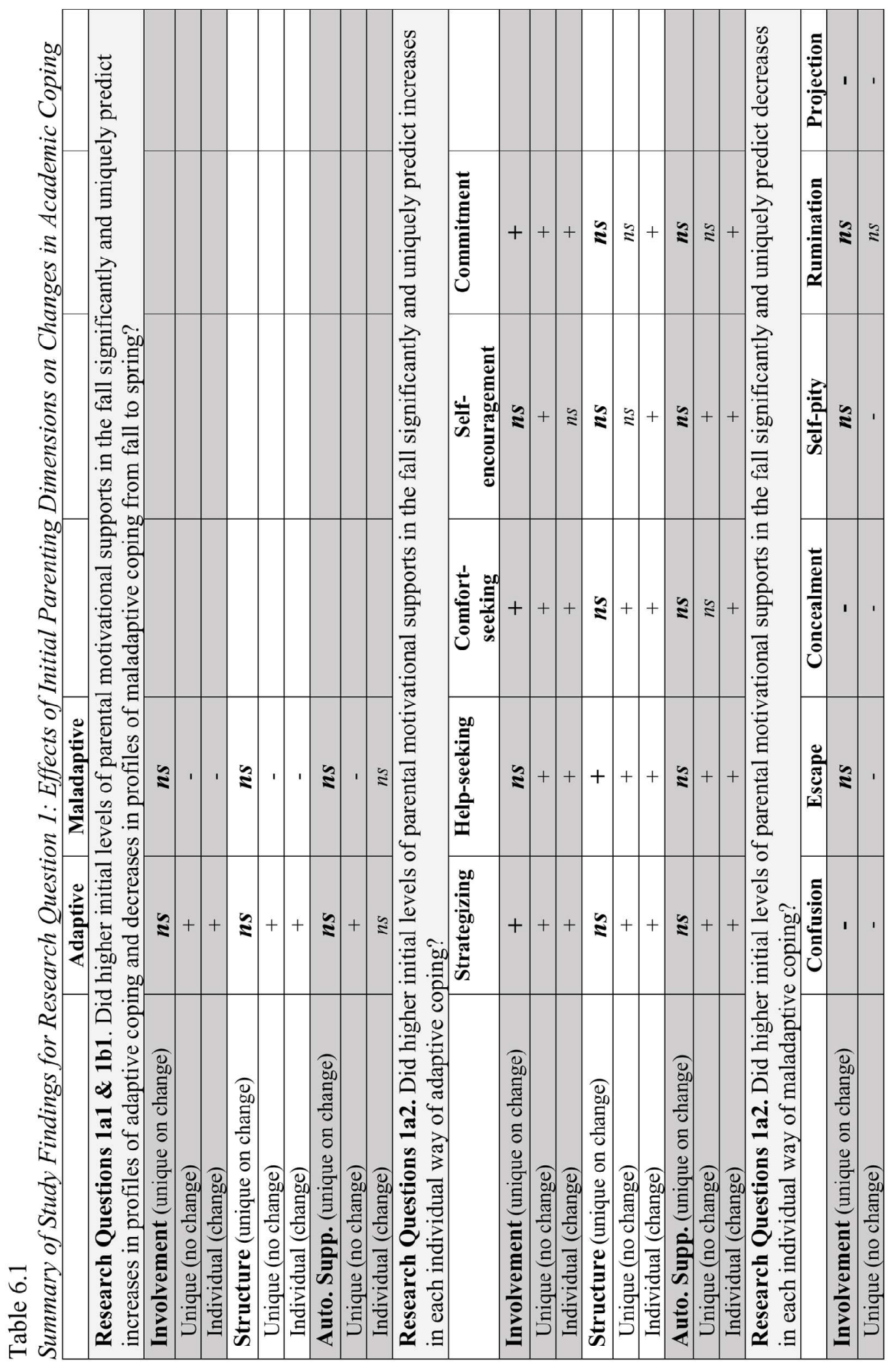




\section{PARENTING AND ACADEMIC COPING}

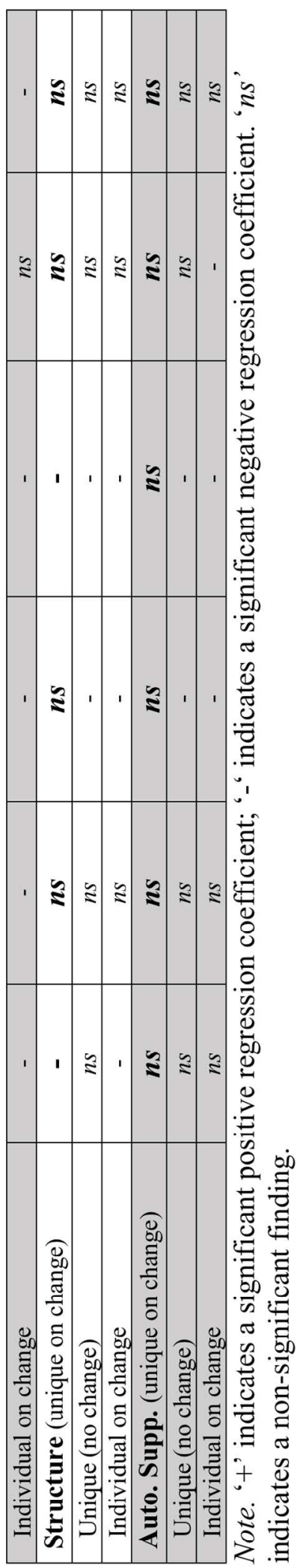




\section{PARENTING AND ACADEMIC COPING}

Feedback effects from coping to parenting. The second research question examined possible feedback effects from initial levels of academic coping to changes in parents' offering of motivational supports over the school year, and consistent with hypotheses, children who initially showed higher levels of adaptive coping experienced their parents as providing greater warmth and involvement, higher levels of structure and scaffolding, and more support for their perspective and preferences as the school year progressed (see Table 6.2). However, when looking at unique effects of individual ways of coping, a more differentiated pattern emerged, suggesting that the aforementioned connection between coping profiles and changes in parenting may be due to the use of particular ways of coping and not others. Specifically, out of all ways, only projection uniquely predicted decreases in all three dimensions of parenting across the school year, while two additional ways of coping (strategizing and self-encouragement) uniquely predicted changes in structure, and three additional ways (comfort-seeking, commitment, and confusion) changes in autonomy support. 


\section{PARENTING AND ACADEMIC COPING}

Table 6.2

Summary of Findings for Research Question 2: Feedback Effects from Children's Academic Coping to Changes in Parental Motivational Supports

\begin{tabular}{|c|c|c|c|}
\hline & Involvement & Structure & Autonomy Support \\
\hline \multicolumn{4}{|c|}{$\begin{array}{l}\text { Research Questions } 2 \text { a1 \& 2b1. Did initially higher levels of profiles of adaptive coping or } \\
\text { maladaptive coping in the fall significantly predict increases in involvement, structure, and } \\
\text { autonomy support across the school year? }\end{array}$} \\
\hline Adaptive Profile (unique on change) & + & + & + \\
\hline $\begin{array}{l}\text { Maladaptive Profile (unique on } \\
\text { change) }\end{array}$ & - & - & - \\
\hline \multicolumn{4}{|c|}{$\begin{array}{l}\text { Research Question } \mathbf{2 a 2} \boldsymbol{\&} \mathbf{2 b 2} \text {. Did initially higher levels of individual ways of adaptive and } \\
\text { maladaptive coping in the fall significantly predict changes in parental motivational supports across the } \\
\text { school year? }\end{array}$} \\
\hline Strategizing (unique on change) & $n s$ & + & $n s$ \\
\hline Unique effects (no change) & + & + & + \\
\hline Individual effects (change) & $n s$ & + & + \\
\hline Help-seeking (unique on change) & $n s$ & $n s$ & $n s$ \\
\hline Unique effects (no change) & + & + & + \\
\hline Individual effects (change) & $n s$ & $n s$ & + \\
\hline Comfort-seeking (unique on change) & $n s$ & $n s$ & + \\
\hline Unique effects (no change) & + & $n s$ & + \\
\hline Individual effects (change) & $n s$ & + & + \\
\hline $\begin{array}{l}\text { Self-encouragement (unique on } \\
\text { change) }\end{array}$ & $n s$ & + & $n s$ \\
\hline Unique effects (no change) & + & $n s$ & $n s$ \\
\hline Individual effects (change) & + & + & + \\
\hline Commitment (unique on change) & $n s$ & $n s$ & + \\
\hline Unique effects (no change) & $n s$ & $n s$ & + \\
\hline Individual effects (change) & $n s$ & + & + \\
\hline Confusion (unique on change) & $n s$ & $n s$ & - \\
\hline Unique effects (no change) & - & $n s$ & - \\
\hline Individual effects (change) & - & - & - \\
\hline Escape (unique on change) & $n s$ & $n s$ & $n s$ \\
\hline Unique effects (no change) & $n s$ & $n s$ & $n s$ \\
\hline Individual effects (change) & $n s$ & - & $n s$ \\
\hline Concealment (unique on change) & $n s$ & $n s$ & $n s$ \\
\hline Unique effects (no change) & $n s$ & - & - \\
\hline Individual effects (change) & $n s$ & - & - \\
\hline Self-pity (unique on change) & $n s$ & $n s$ & $n s$ \\
\hline Unique effects (no change) & - & - & - \\
\hline Individual effects (change) & - & - & - \\
\hline Rumination (unique on change) & $n s$ & $n s$ & $n s$ \\
\hline Unique effects (no change) & $n s$ & $n s$ & $n s$ \\
\hline Individual effects (change) & $n s$ & $n s$ & $n s$ \\
\hline Projection (unique on change) & - & - & - \\
\hline Unique effects (no change) & - & - & - \\
\hline Individual effects (change) & - & - & - \\
\hline
\end{tabular}

Note. '+' indicates a significant positive regression coefficient; '-' indicates a significant negative regression coefficient. ' $n s$ ' indicates no significant finding 


\section{PARENTING AND ACADEMIC COPING}

Again, because only partial support was found for these hypotheses (i.e., that all 11 ways of coping would uniquely predict changes in all three parenting dimensions), follow up analyses were conducted to examine possible explanations for non-significant results and to further explore the dynamic connection between academic coping and subsequent parental motivational supports. In follow-up analyses investigating unique effects from coping in the fall on parenting in the spring (with the autoregressions for parenting removed), parenting dimensions were significantly predicted by more individual ways of coping, but not by all. Involvement in the spring was uniquely predicted by seven of the 11 ways of coping, while structure was predicted uniquely by five, and autonomy support by eight. Because the theoretical framework for the current study focused on causal influences, emphasis was given to follow up analyses that included change over time, which are more consistent with feedback effects. When individual ways of coping were examined as separate predictors of changes in parenting over time, four ways of coping (self-encouragement, confusion, self-pity, and projection) significantly predicted changes in involvement, while all ways except help-seeking and rumination predicted changes in structure, and all except escape and rumination predicted changes in autonomy support.

Altogether, these results suggest that children who globally rely on more adaptive ways of coping experience their parents as providing more subsequent motivational supports, and those who instead rely on more maladaptive ways might experience the opposite, but that some individual ways might be having a disproportionate impact on these feedback effects when compared with others. For example, children who reported a 


\section{PARENTING AND ACADEMIC COPING}

more maladaptive coping profile seemed to experience greater losses in parental support - parents were increasingly less likely to be involved, provide needed instrumental resources, or take their child's perspective. At the same time, some individual ways of maladaptive coping, such as projection, may be more likely to have this effect. Children who coped by blaming other people for their problems experienced their parents as subsequently reducing their provision of all motivational supports. In contrast, other more internal maladaptive ways (i.e., escape or rumination), seemed to have little to no effect on changes in parental motivational support. As a whole, these results provide additional support for a multidimensional conceptualization of children's coping, demonstrating a differentiated pattern of unique feedback effects for individual ways.

Additionally, when comparing the results for $R Q 2$ with those uncovered for $R Q 1$, very different patterns of effects were uncovered for each parenting dimension. For example, while involvement showed the strongest and most common unique feedforward effects when predicting changes in coping whereas autonomy support had very little effect on coping at all (except when examined individually), the impact of children's coping on involvement was the weakest feedback effect, predicted by only projection, while changes in autonomy support were uniquely predicted by four individual ways. These differing results both support the use of multiple dimensions to measure highquality parenting and suggest distinct dynamic relationships between these dimensions and coping, as discussed in subsequent sections.

\section{Mediators between parental motivational support and academic coping.}

Research question three concerned children's self-system processes or catastrophizing 


\section{PARENTING AND ACADEMIC COPING}

appraisals as possible mediators between the direct effect of parental motivational supports and children's academic coping (see Figures 6.1 and 6.2). Because no direct effects on changes in adaptive or maladaptive profiles were uncovered when examining research questions $1 \mathrm{a} 1$ and 1a2, these analyses focused only on changes in individual ways of coping. Parental antecedent variables were only included if they were significant unique predictors of changes in individual coping, therefore involvement was retained as an antecedent variable for most ways (namely, strategizing, comfort-seeking, commitment, confusion, concealment, and projection), structure was retained only for help-seeking, confusion, and self-pity, and autonomy support was not included at all. In general, both types of proposed mediators partially mediated the relationship between parenting and changes in coping, specifically for strategizing, commitment, concealment, self-pity, and projection. Exceptions to this pattern were found for three ways of coping, namely, help-seeking, comfort-seeking, and confusion. Specifically, autonomy was not a mediator of the relationship between structure and help-seeking but instead an independent contributor to increases across the school year. Relatedness fully mediated the connection between involvement and comfort-seeking. And confusion, which was the only way of coping that included two unique parenting predictors, showed slightly different patterns of effects for the two dimensions. The relationship between structure and decreases in confusion (while controlling for involvement) was fully mediated by all three catastrophizing appraisals. In contrast, the direct effect of involvement on decreases in confusion was only partially mediated by catastrophizing of relatedness, but not by 


\section{PARENTING AND ACADEMIC COPING}

catastrophizing of competence and autonomy which were instead independent contributors to increases in confusion across the school year. 


\section{PARENTING AND ACADEMIC COPING}

Figure 6.1

Summary of Findings for Research Question 3a: Children's Self-system Processes Tested Individually as Mediators of Parental Motivational Supports and Adaptive Coping
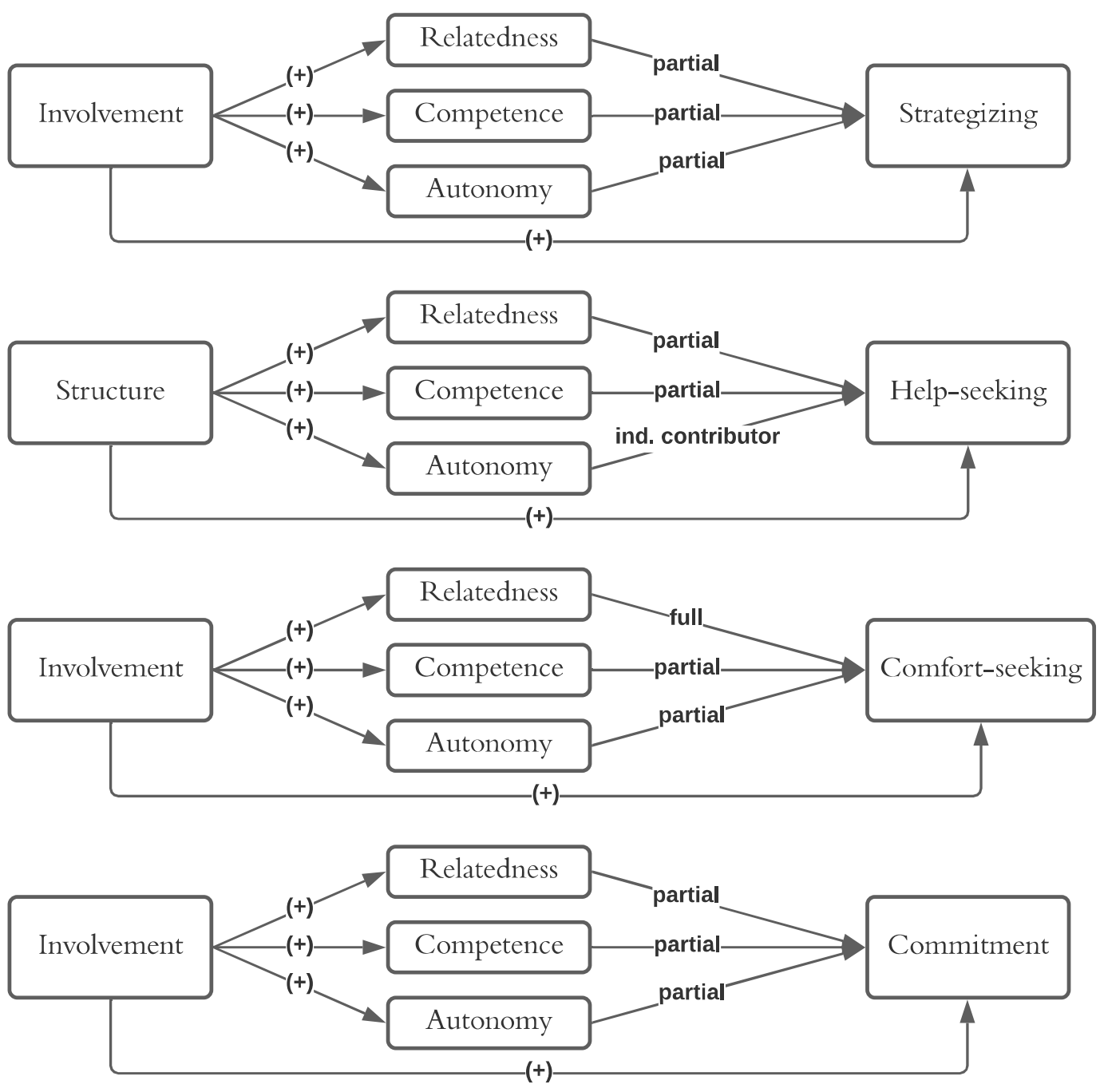

Note. Each self-system was tested individually as a mediator. '+' indicates a significant positive regression coefficient; '-" indicates a significant negative regression coefficient. 'Partial' indicates partial mediation; 'full' indicates full mediation, and 'ind. contributor' indicates variable was a significant predictor but not a mediator. 


\section{PARENTING AND ACADEMIC COPING}

Figure 6.2

Summary of Results for Research Question 3b: Children's Catastrophizing Appraisals as Tested Individually as Mediators of Parental Motivational Supports and Maladaptive Coping
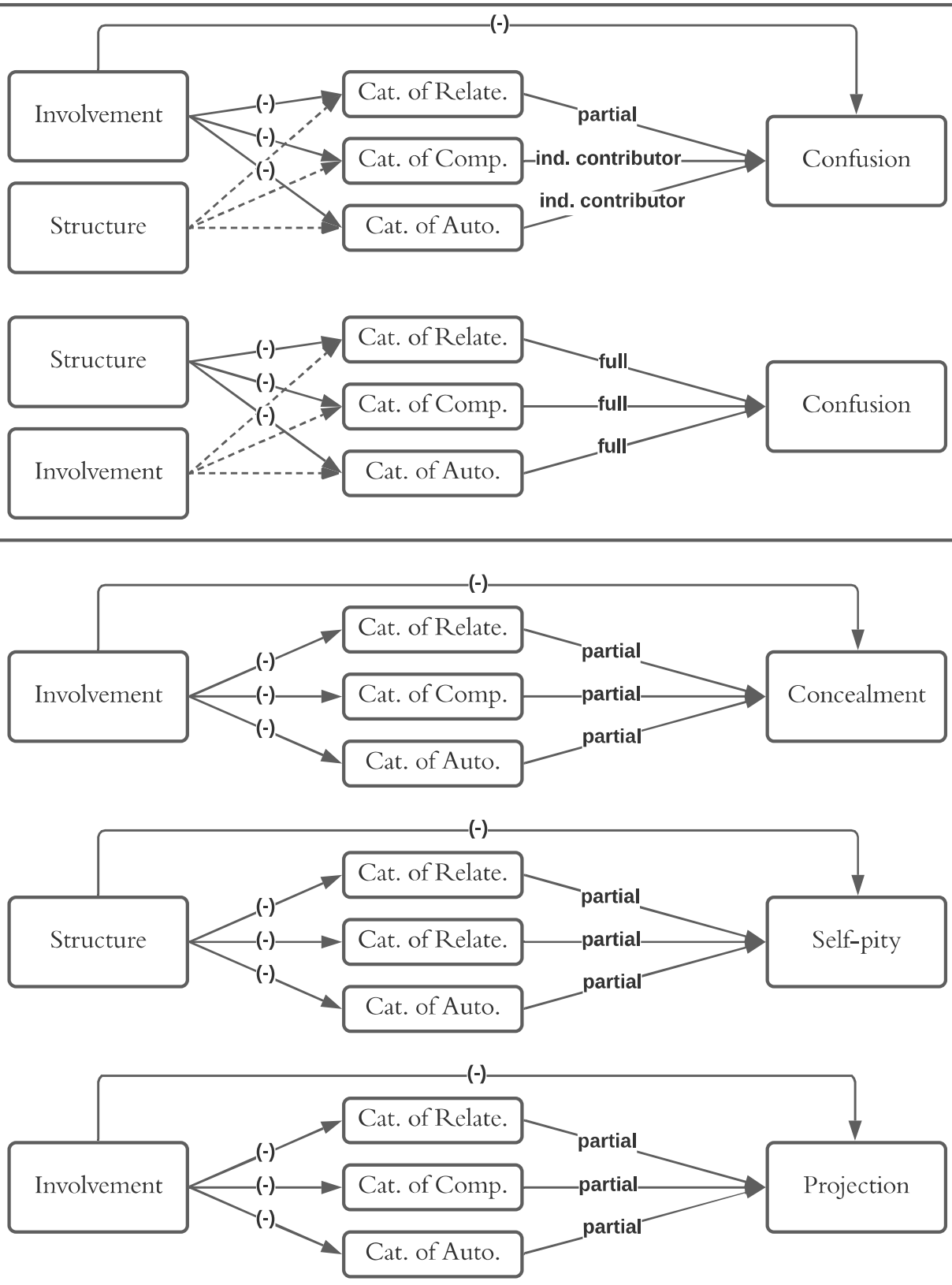

Note. Each self-system was tested individually as a mediator. ' + ' indicates a significant positive regression coefficient; '-' indicates a significant negative regression coefficient. 'Partial' indicates partial mediation; 'full' indicates full mediation, and 'ind. contributor' 


\section{PARENTING AND ACADEMIC COPING}

indicates variable was a significant predictor but not a mediator. Confusion is presented twice because the first indirect path is for involvement and the second for structure.

Conclusion. Ultimately, the present study found very different levels of support for each research question and its sub-questions. For research question one, no evidence was found that any dimensions of parenting made unique a contribution to changes in either adaptive or maladaptive profiles of academic coping. However, some evidence was found suggesting that specific parenting dimensions serve as unique predictors of changes in most individual adaptive and maladaptive ways (with the exception of selfencouragement, escape, and rumination). Feedback effects proposed in research question two were fully supported when adaptive or maladaptive profiles were used to predict changes in each parenting dimension, but when individual ways were tested as sets, only some uniquely predicted increases or decreases in parenting from fall to spring. Specifically, only one way of coping (projection) uniquely predicted changes in all three, while multiple other specific adaptive and maladaptive ways were able to uniquely predict changes in structure and autonomy support. Finally, mediational hypotheses proposed in research question three were generally supported, besides those positing mediations between parenting and coping profiles, which could not be tested because no direct effects were found. This suggested that self-system processes and catastrophizing appraisals were mechanisms through which parenting had its impact on the use of individual ways of coping. Specific exceptions to this were found only for autonomy, which was instead an independent contributor to help-seeking; and catastrophizing of competence and of autonomy which were independent contributors to confusion. 


\section{PARENTING AND ACADEMIC COPING}

Altogether, the results of these three research questions suggest a bidirectional, dynamic relationship between parenting supports and children's academic coping, wherein parents are having their impact on subsequent coping through their influence on children's appraisals (both self-system processes and catastrophizing). However, some findings present a more differentiated picture than that put forth by study hypotheses. Parental involvement appeared to play the most important role in feedforward effects, uniquely predicting changes in multiple ways of adaptive and maladaptive coping, while projection was the way of coping that most consistently participated in feedback effects, uniquely predicting decreases in all three parenting dimensions. These specific variations, their implications for future work, and possible applications within the context of school and home will be discussed further in subsequent sections.

\section{Strengths and Limitations}

Strengths. The conclusions drawn from these results add to the larger field of academic coping, more specifically expanding our understanding of the dynamic system that may exist between how parents support their child's motivation and children's action regulation under stress. The dearth of research concerning parents' impact on a repertoire of children's academic coping represents a gap in the field that the current study aimed to begin to fill. The explication of this relationship is especially important now as we slowly emerge out of the COVID-19 pandemic and resume in person learning after an extended period of learning at home. Although this may have been a limited event, it is a stark example of how much of children's academic experience is shaped by what occurs outside of school. 


\section{PARENTING AND ACADEMIC COPING}

Deepening our understanding of how parents change in response to children's coping behaviors, emotions and actions meaningfully contributes to the field through its application to effective interventions, parent education, and how we conceive of parenting. It is only possible to give adults a full picture about how they should parent by acknowledging that they are never acting in a vacuum, but instead within a dynamic history that begins the moment they bring their child into the family. Children bring their own temperaments, personalities, and inherent needs to their personal relationships, and it should be no surprise that this also shapes parents' behaviors, emotions, actions, and supports. Directly looking at these feedback effects not only adds new information to the academic coping literature, but also serves as additional empirical evidence of the bidirectional nature of the parent-child dyad, hopefully encouraging further study of these types of processes in the future.

Another strength of the present study is its contributions to our understanding of exactly how parents are having an influence, as results suggest that this may not always be directly through assistance with academic tasks, but instead through the history of interactions that are building children's internal representations of the world. Children appear to be taking the resources and liabilities gathered from their home environment with them to school, indirectly shaping their ability to function and achieve.

The present study addressed these aims through multiple methodological and theoretical strengths in addition to its larger contributions to the field. First, the study sample was comprised of a whole population: The entire school district in a ruralsuburban community in upstate New York. Second, the use of short-term longitudinal 


\section{PARENTING AND ACADEMIC COPING}

data enabled feedforward and feedback effects to be examined. Third, the application of a theoretical framework based in SDT and the inclusion of mediators suggested by the same motivational framework provided an overarching structure for novel findings within a much larger body of work.

Limitations. Although the current study contributes novel findings to our larger understanding of the connection between parenting and children's academic coping, there are a number of limitations based on the study design and sample that constrain the breadth and generalizability of the conclusions that can be drawn. First, the sample is fairly homogenous, in terms of SEs and ethnicity, and therefore not representative of the general United States population. This impacts the generalizability of this study's findings, making them applicable to only a subset of the population. Even though support was found for most hypotheses, further research is required to examine whether these results are similar across different sub-populations. To conduct this work, however, it will be important to reconsider many aspects of the study. For example, it may be that these academic coping measures do not fully capture the diversity of coping actions in other racialized or lower SES groups (e.g., Gaylord-Harden et al., 2013) and therefore additional measurement construction and validation may be needed. Other social partners (i.e., siblings, relatives, family friends, community members) may also be making meaningful contributions in terms of these motivational resources, so their purposeful inclusion in future work may also provide more complete and complex findings. Furthermore, researchers examining autonomy support have uncovered multiple subdimensions within this construct (i.e., perspective-taking and choice) that may have 


\section{PARENTING AND ACADEMIC COPING}

differential levels of importance depending on the collectivist or individualist nature of the larger cultural context, supporting the universality of this dimension but emphasizing its possible unique manifestation depending on cultural differences (Marbell $\square$ Pierre et al., 2019).

Second, all variables in this study were self-reported and reflected student perceptions rather than objective conditions. While children's perceptions are of interest in the present study, it does limit some of the conclusions that can be drawn from results. For example, it does not definitively test whether parenting itself is shaping coping, only that children's perceptions of their parents are. This is still of interest to the research at hand but may not be as useful for designing interventions or offering advice to struggling parents. To increase the present research's suitability for real-world applications, children's self-reports should be supplemented with teacher, parent, and peer or sibling reports, or combined with real-time observations.

Third, the larger dataset from which the current study was drawn was collected over a four-year period in the early 1990 s, meaning that the historical conditions within which families are raising children and said children are going to school have shifted and changed in the intervening years, and some of these changes may have had an impact on the role of parenting in the development of children's academic coping. There are many differences between students during that historical period and students today, and some may lead to different dynamics than the ones found here. For example, elementary and middle grade students today have lived through multiple transformational events that could have increased their overall stress: a global pandemic, worldwide protests for racial 


\section{PARENTING AND ACADEMIC COPING}

justice, and economic upheaval. Repeating these proposed analyses with more recent datasets or new collections would help confirm and expand upon these results through the inclusion of students who have lived through possibly more stressful historical periods.

Fourth, although this work helps to explicate the direction of possible effects by utilizing data collected at two time points, the addition of further time points during the school year would allow for a more differentiated understanding of possible mediational processes. The present study investigated a mediational model where both mediator and outcome occurred at the same time point, with predictors at time 1 . This model could draw stronger causal conclusions if three time points were used. Moreover, adding more densely spaced data collection points might better capture the hypothesized dynamic social interactions between parents and children, because the effects of these proximal processes may, on the one hand, be more immediate and, on the other, show longer more differentiated trajectories. The implications of this type of analysis will be discussed further in subsequent sections.

\section{Implications and Future Directions}

Findings from this study have implications for our conceptualizations of parenting, children's coping, and the parent-child relationship itself. This suggests that additional research can supplement these results in multiple ways, through the addition of alternative research perspectives, the use of different methodologies, and the improvement of construct measurement properties. All of these implications and their possibilities for future research will be discussed in subsequent sections. 


\section{PARENTING AND ACADEMIC COPING}

Parental dimensions. A primary aim of the present study was to examine how parents can best support the development of their children's ability to handle the difficulties they encounter every day in school. While it was hypothesized that all three parenting motivational supports (i.e., involvement, structure, and autonomy support) would make unique contributions to changes in children's coping across the school year, results presented a different picture, where parental involvement was the primary contributor to coping trajectories, with some contributions from structure, and little to none from autonomy support. On the one hand, this suggests that involvement may be the most important aspect of parental motivational supports, but, as will be discussed later, it is less clear that involvement is the only relevant support.

Role of parental involvement. Previous research is consistent with interpretations of study findings that suggest involvement may be the most impactful element in academic coping. Research focusing on attachment and social support show that parenting dimensions akin to involvement are strong predictors of other aspects of academic functioning, including achievement, motivation, and engagement (Barger et al., 2019; Boonk et al., 2018; Fan \& Chen, 2001; Grolnick, 2016). Involvement was also the predictor or antecedent most commonly included in research focused explicitly on parenting and academic coping, and showed the strongest positive correlations with adaptive ways and negative correlations with maladaptive ways, emphasizing its centrality to researchers' conceptions of high-quality parenting (Deci et al., 1992; Raftery-Helmer \& Grolnick, 2016, 2018). But all studies focused on involvement and academic coping to date have been cross-sectional, hence the present study's use of two 


\section{PARENTING AND ACADEMIC COPING}

timepoints provided stronger support for this conceptualization of involvement: It was not only associated with higher mean levels of adaptive coping and lower of maladaptive at both time points, but also predicted increases in individual adaptive ways of coping and decreases in maladaptive ways. Even further, this study tells a more detailed story concerning the mechanisms underlying this connection between involvement and coping, specifically that parenting characterized by love, affection, and warmth can shape children's perceptions about how connected they feel to themselves, others, and the world around them, their sense of mastery, and feelings of self-determination, which in turn influence the ways of coping they are likely to turn to when dealing with difficult academic tasks (see Figure 6.1 for a summary of mediational results). For example, a parent who is aware of their child's homework responsibilities and visibly enjoys talking with them about school, may build up in the child a greater feeling of connection and belonging to those around them through the construction of a mental model of the world as an affectionate, involved, loving place. These feelings of relatedness may then lead the child to strategize more effectively, to commit to challenging tasks, and to seek out others for emotional support (i.e., comfort-seeking) when they run into trouble. Involvement also protected children from reliance on some maladaptive ways of coping by leading to lower levels of catastrophizing appraisals, suggesting that it not only promotes adaptive processes and coping, but also may buffer against some maladaptive tendencies.

Role of parental structure. In addition to extending our understanding of the relationship between parental involvement and coping, study findings also suggested that structure had a role to play, uniquely predicting increases in self-encouragement and 


\section{PARENTING AND ACADEMIC COPING}

decreases in confusion and self-pity. Although this effect obtained for fewer individual ways of coping than that of involvement, these unique effects suggest that parental structure may also play a role in shaping the development of children's coping. Much less research has focused on structure as an element of parenting that impacts children's academic functioning and achievement, but the small body of work that does exist suggests that it is a complex, multidimensional construct that goes beyond "strictness" or "rule-setting." Instead, reviews of the literature on structure more generally suggest that it may be comprised of six components: 1) clear rules and expectations, 2) a contingent environment, 3) constructive feedback, 4) facilitation of meeting expectations, 5) giving reasons behind rules, and 6) parental leadership (Farkas \& Grolnick, 2010). This conceptualization of structure has been demonstrated to be a unique contributor to children's academic and motivational outcomes, implying that involvement is not the only influential aspect of high-quality parenting (Farkas \& Grolnick, 2010; Grolnick et al., 2014; Skinner et al., 2005).

Meditational results with structure as an antecedent provide a more detailed understanding of how structure is impacting certain individual ways of coping. Providing instrumental support, scaffolding difficult tasks, and having clear and comprehensible expectations for children bolsters children's sense of belonging, feelings of competence, perceived autonomy, and reduces children's reliance upon catastrophizing appraisals, in turn leading to increases in help-seeking and decreases in confusion and self-pity. For instance, a parent who is actively supporting their child's completion of their homework by creating a dedicated space and providing them with helpful strategies for learning may 


\section{PARENTING AND ACADEMIC COPING}

reduce that child's inclination to appraise stressful situations as threatening to their sense of competence, leading to a reduction in their confusion surrounding their homework and in their whining or complaining about the situation (i.e., self-pity).

Role of parental autonomy support. While results for structure provide support for the assertion that parental dimensions other than involvement provide valuable coping resources over and above the other dimensions of parenting, results for autonomy support indicate the opposite. Autonomy support did not uniquely predict changes in either profiles or individual ways of coping. Conceptually, autonomy support is an essential element of high-quality, motivationally supportive parenting because empathizing with children, genuinely respecting their thoughts, feelings, and preferences, taking their perspective, and allowing them an appropriate role in family decision-making promotes autonomous motivation, internalization of family values, and psychological well-being (Assor, 2012). The larger literature supports this conceptualization: Recent reviews show that children whose parents are more autonomy supportive also show higher levels of positive academic functioning (Vasquez et al., 2016). Three previous studies examining parenting and academic coping included autonomy support as a dimension of parental support, and found some support for its impact on lower levels of rumination and projection (Deci et al., 1992; Raftery-Helmer \& Grolnick, 2016, 2018). Although main study findings did not provide evidence for unique contributions of autonomy support to changes in coping, descriptive and follow-up analyses did show clear connections between this dimension of parenting and children's academic coping. Correlations between autonomy support and all coping variables were strong, with adaptive profiles 


\section{PARENTING AND ACADEMIC COPING}

and ways associated positively and maladaptive negatively. On its own autonomy support was also able to predict changes in all adaptive and a handful of maladaptive ways of coping suggesting it can be a resource for children when they are stressed. But even separately, it did not predict changes in three maladaptive ways (i.e., confusion, escape, and projection) suggesting that for these particular ways, autonomy support may not make a material impact on their future use. It is possible that parenting that is characterized as supportive of children's autonomy, encouraging children to make informed choices and respecting their opinions and preferences, does not reduce their reliance, for example, on confusion, a way of coping that might benefit more from scaffolding and instrumental support. Hence, it may be inappropriate to conclude that autonomy support is entirely unimportant to children's coping, but instead that it has the potential to facilitate the development of adaptive strategies of coping, while not always buffering children's use of less constructive ways.

Distinguishing among parental dimensions. A central question raised by study findings is whether these parenting dimensions are distinguishable from one another in their effects on the development of coping. Although previous confirmatory structural analyses have shown that these dimensions can be distinguished (Skinner et al., 2005), psychometric and descriptive information suggested measurement problems in the present study: All three parenting dimensions had low to moderate internal consistencies, with autonomy support in the fall having the lowest $(\mathrm{a}=.48)$ and involvement in the spring the highest $(\mathrm{a}=.76)$. Moreover, correlations between autonomy support and both involvement and structure at both time points were higher than its internal reliabilities-- 


\section{PARENTING AND ACADEMIC COPING}

further indicating significant overlap among these dimensions. Altogether, these measurement properties suggest that study findings, especially for autonomy support, could be a result of poor reliability and construct overlap.

Results from this study, taken together, provided a relatively complex answer to the question of whether parenting dimensions should be examined individually or combined in future studies. On the one hand, findings from research question one indicated that these three dimensions seem to be accounting for overlapping variance in changes in children's coping, and therefore may not be distinguishable in their effects.

On the other hand, when the autocorrelations for coping were removed, and the effects of all three dimensions of parenting in fall were examined as predictors of children's coping in spring, a different picture emerged. For profiles and many ways of coping, all three dimensions were able to uniquely predict the outcome in the spring. Although changes in coping were the primary focus of this study, these follow-up analyses did imply that parenting dimensions were not redundant.

Findings from the other two research questions also supply some evidence about whether parenting should be studied as a multidimensional construct, but again evidence was complex. While feedback effects do not provide insight into how parents are impacting coping, they do supply some evidence suggesting that the kinds of coping that predict changes in parenting differ across the three dimensions of parenting. Projection and coping profiles were the only coping outcomes that had identical patterns of results for all three dimensions. All other ways had distinct patterns of effects on each individual aspect of parenting, revealing that these are not merely different labels for one 


\section{PARENTING AND ACADEMIC COPING}

overarching construct (i.e., high-quality parenting). In the same vein, mediational results appeared to tell an identical story for each dimension examined (i.e., involvement and structure), but upon closer inspection, when both involvement and structure were included as antecedents of changes in confusion coping, differences between the two in terms of their mediators were uncovered. Specifically, catastrophizing of relatedness was the only partial mediator of involvement, while catastrophizing of relatedness, competence, and autonomy all fully mediated the effects of parental structure on changes in confusion coping. These results demonstrate how different conclusions could be drawn between dimensions that appeared to heavily overlap.

To address concerns about multiple dimensions of parenting, future work could focus on improving measurement properties of the current instrument or, longer-term, on fine tuning conceptualization of these dimensions in relation to coping per se. Short-term, future analyses with this same measure could be conducted with an eye toward maximizing the separation among dimensions (e.g., by deleting overlapping items or conducting exploratory factor analysis using orthogonal rotation). As next steps, individual items could also be sharpened, and new items could be added until measures reach acceptable levels of reliability. Longer term, more careful theoretical reconsideration of dimensions may be warranted, thinking especially about their individual and differential connections to coping and its development.

Eventually, the preponderance of evidence could lead to the conclusion that these dimensions are not distinguishable, at least with respect to their effects of the development of coping. However, it would be important not to jump to this conclusion 


\section{PARENTING AND ACADEMIC COPING}

too quickly. For example, when considering children's experience of these parenting dimensions, it is possible that they are three aspects of the same proximal processes, and therefore all integral to optimal expression of the other. An instance of this might be seen when parents provide structure without involvement or autonomy support, and children interpret these actions as coercive. Or parents provide autonomy support but when this is not accompanied by involvement or structure, children might interpret this as neglectful. From this perspective, it might be more useful to consider dimensions as part of higherorder parenting styles (e.g., authoritative parenting). Specific high/low combinations of these dimensions may map onto traditional conceptions of parenting styles (Baumrind, 1971; Maccoby \& Martin, 1983; Skinner et al., 2005). Therefore future research might include a more pattern-centered approach to parenting, that is, for example, high on involvement but low on structure and autonomy support compared with those that are high on all three. Compared to a variable-centered approach, a focus on parenting styles would not require dimensions to compete with each other as unique predictors of variance in coping (or changes in coping). It may be that these combinations, and not any one dimension on its own, have the biggest impact on the development of coping.

Summary. The present study raised two major questions regarding parenting and its connection to coping. The first was whether involvement was the most important dimension to changes in children's coping. Study results suggested that it was the most impactful for feedforward effects, but that for feedback effects, autonomy support was instead the most impacted by children's coping. This illustrates how involvement provides a strong benefit for children, but that parents offer (or fail to offer) this resource 


\section{PARENTING AND ACADEMIC COPING}

regardless of their child's use of individual ways of coping (except in the case of projection). Autonomy support may instead be deployed at different levels depending on specific coping actions but does not make as much of a material impact on changes in these individual ways. Structure occupied a middle ground, being able to both shape changes in some individual ways and have changes in it shaped by others. This implies that involvement may be the most crucial dimension but that all have a role to play within the dynamic system, especially when examining both directions of effects. The second question raised was whether a multidimensional conception of parenting that includes all three dimensions is useful to coping studies and whether future studies should only focus on involvement if it is the most important of the three. Study results provided a clearer answer here, demonstrating distinguishable results for each dimension, with structure predicting changes in some individual ways, and changes in all three predicted by both profiles and uniquely by different combinations of individual ways. But future work can further explicate the differences between these dimensions through improvement of the measure and alternative approaches that allow for them to work together (i.e., patterncentered analyses) rather than compete for variance in the coping outcome.

Academic coping. Previous research has found that children's coping can shape academic achievement and functioning outcomes, demonstrating its importance to children's performance and well-being at school (e.g., Skinner \& Saxton, 2019). These findings emphasize how essential it is to have a clear and comprehensive conception of coping when including it as a study variable. Results from the present study raise questions concerning what conceptualization of coping is most useful when investigating 


\section{PARENTING AND ACADEMIC COPING}

its connection with parenting and whether there are alternative research designs and methods that might provide a deeper and richer picture of this relationship. These questions will be discussed further in the following sections.

Profiles and individual ways. Findings from this study were helpful in evaluating and critiquing the conceptualization and measure of academic coping used in the present investigation and could be used to formulate suggestions for improvements and future studies.

As explained in more detail in previous chapters, the current study utilized a strong theoretical framework based in SDT as an organizing structure for conceptions of academic coping in order to counteract the murkiness in the larger field, based on disagreements about the core categories, comprehensiveness, and distinguishability of individual families and ways of coping. The current conception of coping consisted of 11 individual ways, five of which are adaptive and six maladaptive (Skinner \& Wellborn, 1994, 1997). The present study not only included these individual ways, but also included adaptive and maladaptive profiles made up of each student's proportional use of all adaptive ways or all maladaptive ways. This conceptualization of coping had numerous advantages not often seen in the broader literature: Clearly delineated categories, multiple adaptive and maladaptive ways, a comprehensive range of possible ways, and theory driven guidance on what constitutes adaptive or maladaptive coping.

In addition to the confusion surrounding the core categories of coping, the larger literature often narrows its target constructs, by focusing on either coping profiles alone or on a single individual way (i.e., strategizing or help-seeking). The current study 


\section{PARENTING AND ACADEMIC COPING}

specifically attempted to expand upon our knowledge around coping by utilizing both profiles and all 11 ways of coping suggested by SDT. There are possible benefits and drawbacks to looking at coping either way. Focusing on profiles provides general information about the repertoire of strategies children are using to handle stressors more globally, while measuring individual ways provides more detailed information about exactly how children are coping with difficulty. But the use of both profiles and 11 individual ways of coping adds complexity to the study of coping, and this added complexity may not be justified. For example, it is possible that this preponderance of variables does not provide unique information when compared to those found from only profiles or some individual ways. It is also possible that reducing all 11 ways to merely two overarching profiles provides no valuable information because it eliminates possible differences between the parental resources offered to children using different individual ways. Therefore it is important to address whether this conception of coping is useful when examining the dynamics of parent-child interactions or if a simpler alternative framing would suffice. Study results suggested three possible options: Using only coping profiles, instead using only individual ways, or eliminating certain individual ways. These three possibilities and their relative merits will be discussed next.

First, study results provided some evidence that effects followed a pattern of more global coping profiles rather than highly differentiated results for individual ways. This was mainly demonstrated through mediational results that indicated little difference between individual adaptive and maladaptive ways, with the relationship between either involvement or structure and increases in adaptive coping ways mediated primarily by 


\section{PARENTING AND ACADEMIC COPING}

children's self-system processes, while that between parenting and decreases in maladaptive coping was mostly mediated by children's catastrophizing appraisals. But, when examining research questions one, results were dramatically different between profiles and individual ways, with parental variables unable to uniquely predict changes in profiles, but able to predict some changes in individual ways. Research question two also had differentiated patterns for profiles and ways: Profiles predicted changes in parental motivational supports, while only some (and in the case of involvement, only projection) individual ways were able to uniquely predict changes in parenting.

The second way one could interpret these findings is to conclude that if results are so differentiated between individual ways, relying upon profiles will merely wash out compelling results. Evidence for this conclusion is strongest when considering feedback effects from children's coping to changes in their involvement. Although maladaptive coping predicted decreases in involvement, when individual maladaptive ways were instead investigated as unique predictors of changes, only projection was able to uniquely predict decreases in this dimension. This suggests that the maladaptive ways driving the effect of a maladaptive profile is not them all together, but instead primarily the negative effect of projection. Alternatively, when examining the same research question but instead looking at only adaptive coping, an adaptive profile was able to predict increases in involvement, but no single adaptive way could uniquely predict changes. Altogether, this combination of findings suggests that both profiles and individual ways can contribute useful information to our understanding of these dynamics. 


\section{PARENTING AND ACADEMIC COPING}

Finally, study findings could also be interpreted as suggesting that some ways of coping are not as relevant to interpersonal contexts and therefore could be eliminated or combined with other ways in future studies. More specifically, escape and rumination had very few significant results as either outcomes or predictors, and were removed from mediational analyses because no parenting dimensions uniquely predicted changes in either variable. Correlations between rumination specifically were non-significant with many other maladaptive ways, and even showed negative associations with escape and projection. While one interpretation of these results could be to conclude that rumination is not truly a maladaptive way, it is also possible that it, and escape, are instead more internal ways of coping that are less visible to social partners. Even further, these ways may also lead to positive behavioral outcomes because they may spur further effort on difficult tasks (i.e., rumination), or allow for task-caused distress to dissipate (i.e., mental escape). Methodologically, it is also possible that these construct items are not fully tapping the concept of "rumination" or "escape," and therefore not capturing their more maladaptive elements. The addition of rumination items that incorporate the negative affect typically included in this construct (Nolen-Hoeksema et al., 2008) or the addition of escape items that include physical escape (e.g., giving up) might sharpen and strengthen the participation of these ways of coping. For these reasons, both conceptual and methodological, it appears inappropriate to abandon these categories, but instead to further investigate their nuances as well as possibly improve their measures.

Other research and theoretical frameworks have also suggested that some adaptive ways of coping can be combined. For example, researchers have pointed out that 


\section{PARENTING AND ACADEMIC COPING}

strategizing and help-seeking, which consist of problem-solving on your own or going to others for similar strategies, are essentially similar types of coping and therefore should be combined into an adaptive construct such as "active" coping (e.g., Zimmer-Gembeck \& Locke, 2007). The present study did not provide evidence to support such aggregation. Instead findings indicated differentiated patterns between these two ways when examining feedforward effects, feedback effects, and mediational results. More specifically, only involvement uniquely predicted increases in strategizing while structure was the only unique predictor of help-seeking; and strategizing uniquely predicted increases in structure, while help-seeking did not predict changes in any parenting variable. Mediational results also differed slightly, with the previously established connection between involvement and strategizing being partially mediated by all three self-system processes, but only relatedness and competence able to mediate the connection between structure and help-seeking while autonomy remained an independent contributor. Hence, at least when examining academic coping in connection with appraisals and interpersonal relationships, it makes more sense to consider strategizing and help-seeking as distinguishable means for dealing with academic demands.

While the current study presents some findings that support these alternative conceptions of academic coping, altogether it makes a stronger argument for conceptualizations that include all 11 ways and profiles. Previous measurement studies provide strong evidence that 11 individual ways make up children's adaptive and maladaptive academic coping (Gonçalves et al., 2019; Skinner et al., 2013), and generally 


\section{PARENTING AND ACADEMIC COPING}

study findings provide further evidence of the value in looking at coping in this way, especially when considering the dynamics of the parent child relationship.

Configurations of children's academic coping. Overall, the present study took a variable-centered approach to examining the dynamics of parenting and children's coping. As demonstrated in the previous section, this provided information regarding how these interactions over time may have differed for each individual way of coping. But it provided less information about how this system might function differently for children who display different coping "styles," that is, specific combinations of high/low levels of individual ways. Future work could examine this possibility through the use of a pattern- or person-centered approach that focused on these different coping configurations and how parents might shape them over time. In some ways, the current study did use one of these possible combinations to represent children's coping: Adaptive and maladaptive coping profiles represent children who are either high vs. low on all adaptive or high vs. low on all maladaptive ways. Although the inclusion of this specific combination did provide more global information about both how parents shape these overall "good news" or "bad news" profiles of coping and how these profiles might shape subsequent parenting, it did not capture the coping repertoires of other children whose adaptive or maladaptive profiles are somewhere in the middle, and therefore might consist of other high/low combinations of individual ways.

Rather than assuming a standard coping profile, person-centered analyses allow researchers to conceptually and empirically identify subgroups of children whose coping repertoires show similar patterns. Conceptually, one could imagine that these 


\section{PARENTING AND ACADEMIC COPING}

configurations might consist of different groupings of ways of coping that utilize similar processes, such as children who are high on internal maladaptive ways (i.e., rumination, escape, and concealment) but low on external ones (i.e., projection). Children who instead are high on projection could also be high on self-pity, lamenting their situation that they believe was caused by others, but low on all other maladaptive and adaptive ways. It is also possible that weak results for rumination could be explained by a specific configuration of coping that is high on rumination: These children could also be high on other adaptive ways because their obsession with their failings may also result in their continuing to work on the task.

A further question suggested by these possible configurations is whether they themselves are beneficial or harmful to academic functioning and achievement outcomes. Future work could investigate whether members of subgroups showing different coping configurations also differ in their engagement, disaffection, motivation, and achievement to begin to more fully understand how children's coping repertoires may be shaping their educational outcomes. Additionally, it is worth investigating whether these groups differ in the mean levels of parenting they are receiving. For example, using the motivational model of coping as a theoretical framework, children whose coping profile consists of both high rumination and high adaptive ways might be experiencing their parents as generally involved and providing structure, but lower in their autonomy support. This example also suggests that it may be worthwhile to examine the connection between patterns of parenting and these coping configurations. For example, parenting that is characterized as low on involvement and autonomy support but high on structure might 


\section{PARENTING AND ACADEMIC COPING}

be associated with greater odds of having a coping repertoire that relies upon projection and self-pity as primary ways of reacting to academic problems. Even further, these parenting patterns may influence whether children are able to transition between coping configurations over time. Future work could address this possibility through the use of latent transition analysis, explicitly examining how social partners shape the stability (or systematic change) in students' membership in these configurations during childhood and adolescence. For example, it may be likely that as students make the transition to middle school, they are more likely to transition from an adaptive to a maladaptive configuration of coping (e.g., Skinner \& Saxton, 2020). But perhaps children with highly supportive parents are less likely to make this normative transition and so maintain a more adaptive coping repertoire.

Parenting and coping as proximal processes. One of the primary purposes of the present study was to begin building an area of research concerning the dynamic system between parenting and children's academic coping and its underlying processes, where very little previous work had been conducted. Therefore, these results represent the very beginning of an exploration of academic coping and its dynamic interaction with parenting. More specifically, this study's use of two timepoints enabled the examination of change over time and explicated differences between feedforward and feedback effects. However, these effects only implied the existence of proximal processes, but did not examine them explicitly. Though this still represents meaningful contributions to our understanding of coping and parenting across the school year, future research can more directly target these issues. Most importantly, it can scrutinize parent-child interactions at 


\section{PARENTING AND ACADEMIC COPING}

the level at which coping and parenting actually occur, which can be characterized as more episodic, changing with the task at hand. Therefore, future research should focus on parenting and academic coping using intensive continuous real-time observational methods that could capture these episodic, proximal processes. The theoretical framework underlying the current study provides a lot of information about core components of such a program of research. It suggests coding categories for both parent actions (i.e., involvement, structure, and autonomy support and/or their subcomponents) and child coping (i.e., the 11 categories of coping). Further, it outlines hypotheses depicting how these sequences may be unfolding, positing that specific parenting supports (e.g., involvement) lead children to develop internal working models about themselves and the world around them (e.g., relatedness) that then suggest specific coping actions when they experience academic stress (e.g., comfort-seeking and selfencouragement). To also capture children's theorized appraisals and self-systems, daily diaries and time series analyses could be used to supplement observational data.

Empirical research using real-time continuous coding of intensive observations and time-series analysis could examine whether these theorized sequences are occurring in the manner described and might provide some evidence of possible causal connections between these variables. More specifically, these methodologies might demonstrate how coping shifts after parents intervene, for instance, a parent might notice a child's confusion concerning a difficult math problem, and then offer instrumental support in the form of specific math strategies, leading the child to seek the parent out for further strategies when working on another difficult problem. These types of interactions may be 


\section{PARENTING AND ACADEMIC COPING}

common in this hypothetical household, and therefore might result in an amplifying pattern over time where the child relies less upon confusion in the face of difficult math problems and instead is able to problem-solve on their own because of increased parental structure. Hence, conducting research using intensive observational methods would expand upon the results suggested by the present study, allowing for the gathering of coping data at the level of the proximal process. Further implications for viewing the parent-child relationship as a dynamic system constructed out of these proximal processes will be discussed next.

Dynamic system. A primary goal of the present study was to begin to describe the connection between parents' offering of motivational resources and children's coping responses to academic difficulty as a dynamic system partially constructed out of a history of proximal processes between parent and child. Previous research concerning this specific interpersonal relationship has focused almost exclusively on the effects of only parents on children, ignoring the well-established theoretical conception of social interactions as fundamentally transactional processes where social partners mutually influence one another cyclically over time (Bronfenbrenner \& Morris, 1998; Sameroff, 2010). While it may be conceptually clearer that the social partner with more power and control in the relationship may have a more substantial impact on the other, parents are rarely parenting in a vacuum, but instead responding to their child's behavior and needs, as well as the constraints and affordances provided to them by their own larger contextual conditions. 


\section{PARENTING AND ACADEMIC COPING}

Preliminary evidence from the present study supports the conceptualization of this relationship as comprised of both feedforward and feedback effects. Specifically, unique direct effects from parental involvement, structure, and autonomy support on increases in specific individual adaptive ways of coping and decreases in certain maladaptive ways, provided evidence for feedforward effects. Hypothesized feedback effects were supported by impacts of both coping profiles and some individual ways on changes in parenting dimensions. Overall, this provides some initial evidence that together both parenting and children's coping may create a virtuous or viscous cycle over time. For example, based on results from both $R Q 1$ and $R Q 2$, parenting that is characterized by warm interactions with their child may result in that child then independently problem-solving any difficulties they encounter in their schoolwork (i.e., strategizing) later in the year. That child's increased use of strategizing may then send a signal to the parent to provide greater scaffolding and instrumental support, which in turn may lead the child to seek those resources out when they run into trouble (i.e., help-seeking; for a review of similar findings, see Tables 6.1 and 6.2). A similar pattern based on study findings could also be constructed that implies a viscous cycle, where parenting characterized as less loving and involved leads children to blame others for their academic difficulty, which in turn leads parents to become even less involved in their children's academic lives, provide less assistance, and become more coercive, possibly using punishments or threats to get the child to continue working on a task.

Probing these cycles through the use of two timepoints reveals a system that is not stable, but instead amplifying the effects of positive or negative interactions over time. 


\section{PARENTING AND ACADEMIC COPING}

This is consistent with previous research into the effects of children's oppositional behavior on parents that demonstrated that the dynamic system created from both children's defiant outbursts and increased coercive parenting heightened both social partner's negative behaviors over time (Patterson, 1982). When applied to academic coping and results from the present study, one could imagine a similar amplifying effect between parenting low on all three motivational supports and children's reliance upon blaming others when faced with a difficult task. Alternatively, when this dynamic system is running smoothly, with parents providing attuned motivational resources and children relying more upon adaptive rather than maladaptive coping, these constructive interactions may result in an increasingly positive relationship over time. Furthermore, the ample resources provided for both partners may also result in both children and parents being able to "bounce-back" from negative reactions or experiences more easily, because these experiences are overall less threatening to their fundamental needs.

Though this relationship was implied by the combination of results from research questions one and two, further research could more explicitly test whether these dynamic coping episodes build upon one another over time. Empirically investigating the amplifying effects of these encounters may be especially relevant as families deal with the ramifications of learning at home for over a year during the COVID-19 pandemic. Though many children are now able to return to in-person learning, shifting the learning environment to primarily in the home created a high-pressure situation for many families that may have also magnified negative or positive interactions. Having a more solid 


\section{PARENTING AND ACADEMIC COPING}

understanding of exactly how this dynamic system is both constructed and changes may help ensure that we can better support families in the future.

Though altogether this evidence hints at a parent-child dyad that consists of bidirectional influence, it does not directly methodologically address the question of bidirectionality itself, nor does it focus on the proximal processes, instead looking more at overall trajectories over the school year. While the cumulative effects of these social transactions over time is of interest to the current work, at present it can only be assumed that parent-child interactions are the engine behind increases or decreases that may occur. An explicit examination of these interactions that relies upon a different type of data and analysis would therefore be necessary to begin to explicate a bidirectional relationship and further parse what is exactly happening at the level of the proximal process.

As explained previously, to accomplish this goal, future research might focus on collecting observational data that directly examines parent-child interactions when working on challenging academic material in real, continuous time, using time-series analyses methods to examine possible causal and bidirectional effects. Continuing this collection over a longer period, possibly two years or more, would allow for an investigation into how these proximal processes influence mean levels of coping and therefore shape coping trajectories over time. Focusing study on developmental windows where stressful transitions may be occurring, such as that from elementary to middle school, second to third grade, or pre-school to kindergarten, may also help determine how child-parent transactions are impacted by larger contextual forces that increase normative levels of stress. Furthermore, even if data is instead collected at fewer discrete time- 


\section{PARENTING AND ACADEMIC COPING}

points and is therefore non-continuous, the use of other analysis techniques, such as cross-lagged panel or developmental cascade models using three or more time points, may provide stronger support for a bidirectional relationship between these social partners than the present study.

\section{Implications for Practice}

Study findings also have concrete applied implications for parents and caregivers, interventionists, policymakers, and educators. These results can help parents support their children's learning under stress, help interventionists determine the most effective levers of change, inform impactful local and nationwide policies to support families, and communicate to school administrators and teachers how the school environment is spilling over into the home. The following section will further explicate these implications and provide suggestions for additional avenues for research that might help optimize outcomes for families.

Advice to parents. Because this study specifically concerned the connection between parenting and children's ability to handle academic stressors, findings provide tangible advice to parents who would like to improve this relationship. First, study results bolster the idea that the task of supporting children's coping is highly complex, requiring parents to provide multiple types of supports simultaneously, while being careful not to undermine one specific dimension by focusing too exclusively on another. For example, a parent who is attempting to assist with their child's homework by providing strong instrumental support runs the risk of becoming too coercive if they do not also support their children's autonomy at the same time. Therefore, parents could keep in mind that 


\section{PARENTING AND ACADEMIC COPING}

while it is important for their child's coping to try to be involved, provide structure, and be autonomy supportive, it may be difficult to maintain a balance between all three from moment-to-moment.

Second, results from feedback effects suggest that it is important that parents understand that children's coping may be communicating information about what their child might need from them in terms of these motivational supports. These results also generally indicate that typically, dynamics are amplifying: Parents are likely to respond positively when their children are coping adaptively but might withdraw resources when children are instead coping maladaptively, even though these may be the moments when resources are needed most. This suggests that it might be advantageous for parents to take a brief pause when noticing their child's coping behaviors, emotions, and actions to consider what this is telling them about their child's needs in that moment. Additionally, these feedback effects may help parents to better understand their own maladaptive parenting actions. While children should not bear any responsibility for their parents' lack of provision of motivational supports, the knowledge that some of the adults' specific reactions may be a result of their "knee-jerk" response to their child's behavior, may make it easier for parents to reconsider this reaction in the future, especially with the assistance of effective supports and interventions.

Third, mediational results signal the importance of informing parents about how their actions in the moment are impacting their children long-term. Through their provision of motivational supports, parents are not only building children's capacity to handle academic stressors (i.e., coping) but are also shaping their academic identity. 


\section{PARENTING AND ACADEMIC COPING}

Mediational results suggest that this is occurring through parents' effects on children's self-system processes or internal working models. The conception of proximal processes between parents and children building over time into larger coping trajectories tentatively suggested by the feedforward and feedback results of this study imply that these interactions may be cumulative over time, emphasizing their importance to children's later academic coping outcomes. But the cumulative nature of these transactions should also give parents some "breathing room": A "bad" interaction, as long as it is not indicative of a larger vicious cycle, will not spoil a relationship built of largely constructive proximal processes.

These three pieces of advice may seem to suggest that once parents are informed about what is necessary to improve their facilitations of their child's coping, they should be able to carry out these challenging tasks on their own. However, it is important to note that, while the information gleaned from this study may be helpful in understanding what parents can do to support children, findings provide no information regarding how to help parents accomplish the above stated goals. For this work, additional theories and research are needed.

Supporting parents to support children's coping. To investigate what parents might need to optimally support their children's coping, future research could shift from a focus on children to one that puts parenting first, explicitly investigating parents not just as contextual factors for children but as individuals who need resources and support for adaptive functioning in their own right. Using this perspective, researchers could then investigate what specific contextual variables provide support for high-quality parenting, 


\section{PARENTING AND ACADEMIC COPING}

how parenting develops, and how to optimize this development. Then, from this body of knowledge, effective interventions could be designed and tested that support parents and families holistically, helping to provide them with the resources necessary to balance all three parenting dimensions, interpret their child's maladaptive coping as a request for additional resources, and consider the long-term effects of their in-the-moment parenting. Currently, the default for many parenting interventions is to merely provide parents with information about how they can improve. While this information could be an important first step, it ignores what self-determination theory tells us about parents-- they are individuals with fundamental needs that their contexts may alternatively foster or thwart. SDT outlines a set of processes that may underlie parent's inability to provide needed motivational supports to their children: Parents' own lack of support for their fundamental human need for relatedness, competence, and autonomy. Hence, research investigating the antecedents of motivationally supportive parenting would help interventionists include support for these needs in their programs. Even further, the stress from a lack of these resources may be necessitating coping by parents as well, so a model of parenting as coping could also assist in the creation of more holistic interventions.

Mediators of feedback effects. A focus on parenting as an outcome suggests that there are additional underlying processes through which both larger contextual antecedents and feedback effects are shaping changes in parents' offerings of motivational supports. Results from $R Q 3$ generally supported the hypothesis that children's self-system processes and catastrophizing appraisals were underlying mechanisms through which parental motivational supports impacted changes in coping 


\section{PARENTING AND ACADEMIC COPING}

across the school year. Though this conclusion is a substantial contribution to our understanding of how parents may shape children's coping, it does not address possible processes through which feedback effects from children's coping are shaping changes in parental involvement, structure, and autonomy support.

Future work could investigate potential mediators between children's coping and changes in parenting. One possible mediator could be parents' appraisals of their children's coping, especially how they are perceiving and interpreting the use of maladaptive ways. If parents view maladaptive coping as a "bad" behavior rather than a less constructive request for additional support, they may withdraw resources at a time when those resources are even more essential. For example, parents whose child is blaming them for their difficulty with homework might interpret that projection as defiance and respond to it with more coercive parenting. On the other hand, another parent might interpret that same way of coping as a symptom of the child being under stress and respond with more autonomy support, asking the child if they would like to take a break or work on another aspect of the task. This also suggests that these appraisal processes may be an effective lever of intervention, where parents could be taught how to recognize maladaptive coping as signaling a need for additional involvement, structure, or autonomy support.

Self-determination theory also suggests that these appraisals might shape parents' own self-system processes of relatedness, competence, and autonomy. These are likely processes underlying this connection because parents may experience their children's coping and their own appraisals of this coping as alternatively bolstering or threatening 


\section{PARENTING AND ACADEMIC COPING}

their perceptions regarding these three dimensions. For example, children who seek their parents out for emotional support when they run into trouble may send a message to parents that they are competent parents who have a strong social bond with their families, which then leads them to be more involved in their children's academic life in the future. In contrast, when children cope maladaptively, parents may begin to feel coerced or helpless.

Another important focus of future research would be the study of how larger contextual factors may be influencing parenting through their impact on these selfsystems, because it is unlikely that adults internal working models regarding relatedness, competence, and autonomy in parenting are only built out of interactions within the parent-child dyad. Instead, individuals exist within a complex system built from many differing contextual levels, all of which may be having differing impacts on their selfsystems. For example, a supportive co-parent or grandparent who believes in them may be very helpful in bolstering a parent's feelings of competence or relatedness when parents' or children's coping takes a maladaptive turn. The impacts of these higher-order contexts and their implications for social policy and interventions will be discussed in the next section.

Higher-order contexts of parenting. Parents are not the only social partners influencing the dynamic processes discussed within this study. Co-parents, siblings, extended family, friends, and community members are also engaged in proximal processes with the child and parent that may shape the dyadic relationship. But while the examination of the impacts of other individuals is a natural extension of current study 


\section{PARENTING AND ACADEMIC COPING}

findings, there are other higher-order contexts within which parent and child are situated that are not addressed. It may be that to truly optimize outcomes for these two social partners, interventions might be most impactful at the level of these macrosystems. Specifically, this study does not contend that if parents are merely "better" (i.e., high on involvement, structure, and autonomy support) then children will be more constructive copers, and therefore experience all the positive academic achievement and functioning outcomes suggested by the broader literature (e.g., Skinner \& Saxton, 2019). Instead, it aims to inform more effective social policy and intervention through its description of this dynamic system and its underlying processes.

In the United States, a lack of material supports for caregivers makes parenting especially difficult, further complicating the dynamic system described in earlier sections. A lack of paid family leave, affordable childcare, and social support depletes resources that might be needed within the parent child relationship for both individuals to function optimally. But this lack of support is qualitatively different for families who belong to historically and currently marginalized groups. Families who are experiencing poverty or who belong to racialized groups that are structurally and explicitly discriminated against may experience high levels of chronic "everyday" stressors that require daily coping on the part of both parent and child (Evans, 2004; Trent et al., 2019). For example, parents who are working multiple jobs or families who are experiencing food insecurity must spend extra cognitive energy trying to manage these concerns (Mani et al., 2013), while families who experience structural and overt racism must contend with daily stressful 


\section{PARENTING AND ACADEMIC COPING}

racist aggressions and microaggressions at school, work, and healthcare settings throughout their lives (Jones et al., 2020).

Often, membership in multiple marginalized groups may overlap and intersect, compounding the effects of these hardships (Crenshaw, 2005). The aggregate of these stressors over time has been shown to negatively impact health outcomes, showcasing one aspect of how a lifetime of higher stress levels can accumulate (Fiscella \& Williams, 2004; Trent et al., 2019). This larger stress load also taxes available resources that might otherwise be deployed to handle academic difficulty or assist in learning activities. Asset based frameworks suggest that communities experiencing these higher stress loads have developed culturally specific coping strategies to manage them (Garcia Coll et al., 1996; Gaylord $\square$ Harden et al., 2012; Hope \& Spencer, 2017; Yosso, 2006), but society still has an obligation to improve contextual conditions and should work to remove these stressors and add back resources to counteract previous inequities and improve well-being. While communities can be resilient to negative structural conditions, improving these conditions could support parents in a myriad of ways, one of which is in their facilitation of children's academic coping.

Further research should focus on these higher-order systems and their effects on parenting and family functioning. A natural example could be an investigation into the impacts of CARE act and American Rescue Plan act direct payments, or the pre-payment of an increased child tax credit, on everyday family processes and stress-levels. Theoretically, these nation-wide assistances could be shaping parents' provision of motivational resources because they are supporting parents' own self-system processes 


\section{PARENTING AND ACADEMIC COPING}

and fundamental needs. For example, a parent who must work multiple jobs may not be able to be involved in their child's schoolwork, but the addition of an extra 300 dollars a month (the amount paid per child 6 and older; American Rescue Act, 2021) may enable that parent to reduce their working hours and spend more time with their family.

While this type of evaluative, evidence-based work may be essential to specifically determining the most effective large-scale interventions and policy changes for families, describing and explaining the full breadth of parenting and caregiving experiences within all of these high-order contexts may require work done within alternative paradigms and epistemologies. Specifically, qualitative interviews or observations may be most appropriate when trying to faithfully represent the lived experiences of parents and children coping with hostile or non-supportive contexts. Gathering this type of data may also enable the depiction of a more holistic view of parenting and coping, avoiding a piecemeal approach that focuses interventions on only individual measured variables without a consideration of how multiple identities and contexts may intersect to create complex systems. These methodologies may also allow for greater community engagement in research practices and an elevation of participant voices.

Implications for educators. Although the present study was not focused specifically on academic coping within the school context itself, the health of the mesosystem created by the interaction between school and home is of direct interest to this study and to other researchers focused on family processes and academic coping. Coping itself often occurs within the school, but around third grade when homework is 


\section{PARENTING AND ACADEMIC COPING}

beginning to be assigned, coping actions shift to the home even if the task originates at school. This represents a "spillover" effect from school to home where mesosystem conditions shape family processes. But another type of spillover effect is also occurring: The dynamic system between parenting and children's coping also has implications for subsequent coping at school. Therefore, study findings have direct implications for educators as well.

Present study findings indicate that how children are interacting with their schoolwork and homework may partially shape family dynamics. Schools have a certain amount of control over the amount of stress families are experiencing through their impact on children's experiences at school and their decision to send additional work home. Therefore, educators should seriously consider whether the benefits of homework outweigh possible harms. Stressful, difficult homework can be disruptive at home (Dudley-Marling, 2000; Kohn, 2006), and in response many school districts have either banned it outright, or refused to grade it (Hobbs, 2018). If homework continues to be seen as an essential element of elementary and middle grade education, other options for facilitating its completion should be considered. One possible way to relieve some of the pressure put on already stressed families could be the expansion of after school programs that provide tutoring and homework assistance. Staff within these programs could also be trained to recognize maladaptive coping and be given strategies to help foster adaptive ones, such as how to motivationally support students through the provision of involvement, structure, and autonomy support. 


\section{PARENTING AND ACADEMIC COPING}

Schools are also a place where unrelated adults might provide these motivational resources to students who may be lacking them at home. As mentioned in the previous section, parents may not have the available resources to be involved, structured, and autonomy supportive parents due to poor structural conditions. Teachers or other community members may be able to provide these supports to children, positively shaping their later coping ability. But, like parents, teachers and school administrators are also individuals who have their own fundamental needs that must be supported by their contexts, and therefore shifting the burden to them will only be feasible if larger structural inadequacies and resources are addressed first.

\section{Conclusion}

In sum, the present study attempted to expand upon a relatively small body of knowledge regarding the interaction between parenting and academic coping, and the processes underlying this interaction. Even further, it aimed to look at this specific connection from a perspective that has rarely been explored: that of a dynamic system comprised of both feedforward and feedback effects. Although support was found for many study hypotheses, some unexpected findings, methodological concerns, and unexplored areas indicate that much more work could be conducted in the future to build up a robust area of research that could inform efficacious social policy and interventions for families and educators. 


\section{PARENTING AND ACADEMIC COPING}

\section{References}

Ainsworth, M. S. (1979). Infant-mother attachment. American Psychologist, 34(10), 932-937. https://doi.org/10.1037/0003-066X.34.10.932

Altermatt, E. R. (2007). Coping with academic failure: Gender differences in students' self-reported interactions with family members and friends. The Journal of Early Adolescence, 27(4), 479-508. https://doi.org/10.1177/0272431607302938

Amemiya, J., \& Wang, M.-T. (2018). African American adolescents' gender and perceived school climate moderate how academic coping relates to achievement. Journal of School Psychology, 69, 127-142. https://doi.org/10.1016/j.jsp.2018.05.001

Anderman, E. M., \& Mueller, C. E. (2010). Middle school transitions and adolescent development. In Handbook of Research on Schools, Schooling and Human Development (pp. 198-215).

Anderson, K. E., Lytton, H., \& Romney, D. M. (1986). Mothers' interactions with normal and conduct-disordered boys: Who affects whom? Developmental Psychology, 22(5), 604-609. https://doi.org/10.1037/0012-1649.22.5.604

Arsenio, W. F., \& Loria, S. (2014). Coping with negative emotions: Connections with adolescents' academic performance and stress. The Journal of Genetic Psychology: Research and Theory on Human Development, 175(1), 76-90. https://doi.org/10.1080/00221325.2013.806293

Assor, A. (2012). Allowing choice and nurturing an inner compass: Educational practices supporting students' need for autonomy. In S. L. Christenson, A. L. Reschly, \& C. 


\section{PARENTING AND ACADEMIC COPING}

Wylie (Eds.), Handbook of Research on Student Engagement (pp. 421-439). Springer US. https://doi.org/10.1007/978-1-4614-2018-7_20

Assor, A., \& Tal, K. (2012). When parents' affection depends on child's achievement: Parental conditional positive regard, self-aggrandizement, shame and coping in adolescents. Journal of Adolescence, 35(2), 249-260. https://doi.org/10.1016/j.adolescence.2011.10.004

Bandura, A. (1997). Self-efficacy: The exercise of control. W H Freeman/Times Books/ Henry Holt \& Co.

Barger, M. M., Kim, E. M., Kuncel, N. R., \& Pomerantz, E. M. (2019). The relation between parents' involvement in children's schooling and children's adjustment: A meta-analysis. Psychological Bulletin, 145(9), 855-890. https://doi.org/10.1037/bul0000201

Baron, R. M., \& Kenny, D. A. (1986). The moderator-mediator variable distinction in social psychological research: Conceptual, strategic, and statistical considerations. Journal of Personality and Social Psychology, 51(6), 1173-1182. https://doi.org/10.1037/0022-3514.51.6.1173

Baumrind, D. (1971). Current patterns of parental authority. Developmental Psychology, 4(1, Pt.2), 1-103. https://doi.org/10.1037/h0030372

Bell, R. Q. (1964). The effect on the family of a limitation in coping ability in the child: A research approach and a finding. Merrill-Palmer Quarterly of Behavior and Development, 10(2), 129-142. 


\section{PARENTING AND ACADEMIC COPING}

Bell, R. Q. (1968). A reinterpretation of the direction of effects in studies of socialization. Psychological Review, 75(2), 81-95. https://doi.org/10.1037/h0025583

Bell, R. Q. (1979). Parent, child, and reciprocal influences. American Psychologist, 34(10), 821-826. https://doi.org/10.1037/0003-066X.34.10.821

Ben-Eliyahu, A., \& Kaplan, A. (2015). Growth curve modeling analysis of social and academic coping during elementary school. Journal of Applied Developmental Psychology, 41, 99-109. https://doi.org/10.1016/j.appdev.2015.09.001

Bishop, D. I., Hansen, A. M., Keil, A. J., \& Phoenix, I. V. (2019). Parental attachment and adjustment to college: The mediating role of avoidant coping. Journal of Genetic Psychology, 180(1), 31-44.

https://doi.org/10.1080/00221325.2019.1577797

Boon, H. J. (2011). School moves, coping, and achievement: Models of possible interactions. The Journal of Educational Research, 104(1), 54-70. https://doi.org/10.1080/00220670903567372

Boon, H. J. (2014). Parenting, coping and motivation of Australian at-risk adolescents. In M. T. Garrett (Ed.), Youth and adversity: Psychology and influences of child and adolescent resilience and coping (pp. 1-26). Nova Biomedical Books.

Boonk, L., Gijselaers, H. J. M., Ritzen, H., \& Brand-Gruwel, S. (2018). A review of the relationship between parental involvement indicators and academic achievement. Educational Research Review, 24, 10-30. https://doi.org/10.1016/j.edurev.2018.02.001 


\section{PARENTING AND ACADEMIC COPING}

Bronfenbrenner, U., \& Morris, P. A. (1998). The ecology of developmental processes. In W. Damon \& R. M. Lerner (Eds.), Handbook of child psychology: Theoretical models of human development (Volume 1, 5th ed.) (pp. 993-1028). John Wiley \& Sons Inc.

Brunk, M. A., \& Henggeler, S. W. (1984). Child influences on adult controls: An experimental investigation. Developmental Psychology, 20(6), 1074-1081. https://doi.org/10.1037/0012-1649.20.6.1074

Carver, C. S., Scheier, M. F., \& Weintraub, J. K. (1989). Assessing coping strategies: A theoretically based approach. Journal of Personality and Social Psychology, 56(2), 267-283. https://doi.org/10.1037/0022-3514.56.2.267

Causey, D. L., \& Dubow, E. F. (1992). Development of a self-report coping measure for elementary school children. Journal of Clinical Child Psychology, 21(1), 47-59. https://doi.org/10.1207/s15374424jccp2101_8

Causey, D. L., \& Dubow, E. F. (1993). Negotiating the transition to junior high school: The contributions of coping strategies and perceptions of the school environment. Prevention in Human Services, 10(2), 59-81. https://doi.org/10.1300/J293v10n02_05

Cohen, J., Cohen, P., West, S. G., \& Aiken, L. S. (2013). Applied Multiple Regression/Correlation Analysis for the Behavioral Sciences. Routledge.

Compas, B. E., Connor-Smith, J. K., Saltzman, H., Thomsen, A. H., \& Wadsworth, M. E. (2001). Coping with stress during childhood and adolescence: Problems, progress, 


\section{PARENTING AND ACADEMIC COPING}

and potential in theory and research. Psychological Bulletin, 127(1), 87-127. https://doi.org/10.1037/0033-2909.127.1.87

Connell, J. P., \& Ilardi, B. C. (1987). Self-system concomitants of discrepancies between children's and teachers' evaluations of academic competence. Child Development, 58(5), 1297-1307. https://doi.org/10.2307/1130622

Connell, J. P., \& Wellborn, J. G. (1991). Competence, autonomy, and relatedness: A motivational analysis of self-system processes. In M. R. Gunnar \& L. A. Sroufe (Eds.), Self processes and development (pp. 43-77). Lawrence Erlbaum Associates, Inc.

Connor-Smith, J. K., Compas, B. E., Wadsworth, M. E., Thomsen, A. H., \& Saltzman, H. (2000). Responses to stress in adolescence: Measurement of coping and involuntary stress responses. Journal of Consulting and Clinical Psychology, 68(6), 976-992. https://doi.org/10.1037/0022-006X.68.6.976

Crenshaw, K. (2005). Mapping the margins: Intersectionality, identity politics, and violence against women of color. In Violence against women: Classic papers (pp. 282-313). Pearson Education New Zealand.

Deci, E. L., Hodges, R., Pierson, L. H., \& Tomassone, J. (1992). Autonomy and competence as motivational factors in students with learning disabilities and emotional handicaps. Journal of Learning Disabilities, 25(7), 457-471. https://doi.org/10.1177/002221949202500706

Deci, E. L., \& Ryan, R. M. (1985). Intrinsic motivation and self-determination in human behavior. Plenum. 


\section{PARENTING AND ACADEMIC COPING}

Dempster, A. P., Laird, N. M., \& Rubin, D. B. (1977). Maximum likelihood from incomplete data via the EM algorithm. Journal of the Royal Statistical Society: Series B (Methodological), 39(1), 1-22. https://doi.org/10.1111/j.25176161.1977.tb01600.x

Dudley-Marling, C. (2000). A family affair: When school troubles come home. Heinemann.

Duineveld, J. J., Parker, P. D., Ryan, R. M., Ciarrochi, J., \& Salmela-Aro, K. (2017). The link between perceived maternal and paternal autonomy support and adolescent well-being across three major educational transitions. Developmental Psychology, 53(10), 1978-1994. https://doi.org/10.1037/dev0000364

Eccles, J. S., \& Roeser, R. W. (2009). Schools, academic motivation, and stageenvironment fit. In R. M. Lerner \& L. Steinberg (Eds.), Handbook of adolescent psychology: Individual bases of adolescent development (Vol. 1, 3rd ed.) (pp. 404-434). John Wiley \& Sons Inc. https://doi.org/10.1002/9780470479193.adlpsy001013

Elliot, A. J., \& Dweck, C. S. (2005). Competence and motivation: Competence as the core of achievement motivation. In A. J. Elliot \& C. S. Dweck (Eds.), Handbook of competence and motivation (pp. 3-12). Guilford Publications.

Eppelmann, L., Parzer, P., Lenzen, C., Bürger, A., Haffner, J., Resch, F., \& Kaess, M. (2016). Stress, coping and emotional and behavioral problems among German high school students. Mental Health and Prevention, 4(2), 81-87. https://doi.org/10.1016/j.mhp.2016.03.002 


\section{PARENTING AND ACADEMIC COPING}

Evans, G. W. (2004). The environment of childhood poverty. American Psychologist, 59(2), 77-92. http://dx.doi.org.proxy.lib.pdx.edu/10.1037/0003-066X.59.2.77

Fan, X., \& Chen, M. (2001). Parental involvement and students' academic achievement: A meta-analysis. Educational Psychology Review, 13(1), 1-22. https://doi.org/10.1023/A:1009048817385

Farkas, M. S., \& Grolnick, W. S. (2010). Examining the components and concomitants of parental structure in the academic domain. Motivation and Emotion, 34(3), 266279. https://doi.org/10.1007/s11031-010-9176-7

Fiscella, K., \& Williams, D. R. (2004). Health disparities based on socioeconomic inequities: Implications for urban health care. Academic Medicine, 79(12), 11391147

Friedel, J. M., Cortina, K. S., Turner, J. C., \& Midgley, C. (2007). Achievement goals, efficacy beliefs and coping strategies in mathematics: The roles of perceived parent and teacher goal emphases. Contemporary Educational Psychology, 32(3), 434-458. https://doi.org/10.1016/j.cedpsych.2006.10.009

Frydenberg, E. (2017). Coping and the challenge of resilience. Palgrave Macmillan.

Furrer, C., \& Skinner, E. (2003). Sense of relatedness as a factor in children's academic engagement and performance. Journal of Educational Psychology, 95(1), 148162. https://doi.org/10.1037/0022-0663.95.1.148

Garcia Coll, C., Lamberty, G., Jenkins, R., McAdoo, H. P., Crnic, K., Wasik, B. H., \& Garcia, H. V. (1996). An integrative model for the study of developmental 


\section{PARENTING AND ACADEMIC COPING}

competencies in minority children. Child Development, 67(5), 1891-1914. https://doi.org/10.2307/1131600

Gaylord $\square$ Harden, N. K., Burrow, A. L., \& Cunningham, J. A. (2012). A cultural-asset framework for investigating successful adaptation to stress in African American youth. Child Development Perspectives, 6(3), 264-271. https://doi.org/10.1111/j.1750-8606.2012.00236.x

Gaylord-Harden, N. K., Elmore, C. A., \& Montes de Oca, J. (2013). Maternal parenting behaviors and child coping in African American families. Journal of Family Psychology, 27(4), 607-617. https://doi.org/10.1037/a0033414

Gonçalves, T., Lemos, M. S., \& Canário, C. (2019). Adaptation and validation of a measure of students' adaptive and maladaptive ways of coping with Academic problems. Journal of Psychoeducational Assessment, 37(6), 782-796. https://doi.org/10.1177/0734282918799389

Grolnick, W. S. (2016). Parental involvement and children's academic motivation and achievement. In W. C. Liu, J. C. K. Wang, \& R. M. Ryan (Eds.), Building Autonomous Learners: Perspectives from Research and Practice using SelfDetermination Theory (pp. 169-183). Springer. https://doi.org/10.1007/978-981287-630-0_9

Grolnick, W. S., Friendly, R. W., \& Bellas, V. M. (2009). Parenting and children's motivation at school. In K. R. Wenzel \& A. Wigfield (Eds.), Handbook of motivation at school (pp. 279-300). Routledge/Taylor \& Francis Group. 


\section{PARENTING AND ACADEMIC COPING}

Grolnick, W. S., Raftery-Helmer, J. N., Marbell, K. N., Flamm, E. S., Cardemil, E. V., \& Sanchez, M. (2014). Parental provision of structure: Implementation and correlates in three domains. Merrill-Palmer Quarterly, 60(3), 355-384. https://doi.org/10.13110/merrpalmquar1982.60.3.0355

Guo, X. (2019). Coping as a mediator between parental attachment and resilience: An examination of differential effects between Chinese adolescents from single parent families versus those from intact families. Psychological Reports, 122(2), 506-524. https://doi.org/10.1177/0033294118765418

Hébert, M., Daspe, M.-È., \& Cyr, M. (2018). An analysis of avoidant and approach coping as mediators of the relationship between paternal and maternal attachment security and outcomes in child victims of sexual abuse. Psychological Trauma: Theory, Research, Practice, and Policy, 10(4), 402-410. https://doi.org/10.1037/tra0000321

Hobbs, T. (2018, December 12). Down With Homework, Say U.S. School DistrictsWSJ. https://www.wsj.com/articles/no-homework-its-the-new-thing-in-u-sschools-11544610600

Hope, E. C., \& Spencer, M. B. (2017). Civic engagement as an adaptive coping response to conditions of inequality: An application of Phenomenological Variant of Ecological Systems Theory (PVEST). In N. J. Cabrera \& B. Leyendecker (Eds.), Handbook on Positive Development of Minority Children and Youth (pp. 421435). Springer International Publishing. https://doi.org/10.1007/978-3-319-43645$6 \_25$ 


\section{PARENTING AND ACADEMIC COPING}

Jones, S. C. T., Anderson, R. E., Gaskin-Wasson, A. L., Sawyer, B. A., Applewhite, K., \& Metzger, I. W. (2020). From "crib to coffin": Navigating coping from racismrelated stress throughout the lifespan of Black Americans. American Journal of Orthopsychiatry, 90(2), 267-282.

http://dx.doi.org.proxy.lib.pdx.edu/10.1037/ort0000430

Kahraman, N., \& Sungur, S. (2013). Antecedents and consequences of middle school students' achievement goals in science. Asia-Pacific Education Researcher (Springer Science \& Business Media B.V.), 22(1), 45-60. https://doi.org/10.1007/s40299-012-0024-2

Kaplan, A., \& Midgley, C. (1999). The relationship between perceptions of the classroom goal structure and early adolescents' affect in school: The mediating role of coping strategies. Learning and Individual Differences, 11(2), 187-212. https://doi.org/10.1016/S1041-6080(00)80005-9

Karabenick, S. A., \& Knapp, J. R. (1991). Relationship of academic help seeking to the use of learning strategies and other instrumental achievement behavior in college students. Journal of Educational Psychology, 83(2), 221-230.

https://doi.org/10.1037/0022-0663.83.2.221

Knee, C. R., \& Zuckerman, M. (1998). A nondefensive personality: Autonomy and control as moderators of defensive coping and self-handicapping. Journal of Research in Personality, 32(2), 115-130. https://doi.org/10.1006/jrpe.1997.2207

Kohn, A. (2006). The homework myth: Why our kids get too much of a bad thing. Hachette Books. 


\section{PARENTING AND ACADEMIC COPING}

Lau, S., \& Nie, Y. (2008). Interplay between personal goals and classroom goal structures in predicting student outcomes: A multilevel analysis of person-context interactions. Journal of Educational Psychology, 100(1), 15-29.

https://doi.org/10.1037/0022-0663.100.1.15

Lazarus, R. S., \& Folkman, S. (1984). Stress, appraisal, and coping. Springer Publishing Company.

Leung, G. S. M., \& He, X. (2010). Resourcefulness: A protective factor buffer against the academic stress of school-aged children. Educational Psychology, 30(4), 395410.

Levine, S. L., Holding, A. C., Milyavskaya, M., Powers, T. A., \& Koestner, R. (2020). Collaborative autonomy: The dynamic relations between personal goal autonomy and perceived autonomy support in emerging adulthood results in positive affect and goal progress. Motivation Science. https://doi.org/10.1037/mot0000209

Lewis, R., \& Frydenberg, E. (2002). Concomitants of failure to cope: What we should teach adolescents about coping. British Journal of Educational Psychology, 72(3), 419-431. https://doi.org/10.1348/000709902320634483

Maccoby, E. E., \& Martin, J. A. (1983). Socialization in the context of the family: Parentchild interaction. In P. H. Mussen (Ed.), Handbook of child psychology (Vol. 4, pp. 1-101). Wiley.

Mani, A., Mullainathan, S., Shafir, E., \& Zhao, J. (2013). Poverty impedes cognitive function. Science, 341(6149), 976-980. 


\section{PARENTING AND ACADEMIC COPING}

Mantzicopoulos, P. (1997). How do children cope with school failure? A study of social/emotional factors related to children's coping strategies. Psychology in the Schools, 34(3), 229-237. https://doi.org/10.1002/(SICI)1520-6807(199707)34:3

Marbell $\square$ Pierre, K. N., Grolnick, W. S., Stewart, A. L., \& Raftery $\square$ Helmer, J. N. (2019). Parental autonomy support in two cultures: The moderating effects of adolescents' self-construals. Child Development, 90(3), 825-845. https://doi.org/10.1111/cdev.12947

Martin, A. J. (2013). Academic buoyancy and academic resilience: Exploring 'everyday' and 'classic' resilience in the face of academic adversity. School Psychology International, 34(5), 488-500. https://doi.org/10.1177/0143034312472759

Nolen-Hoeksema, S., Wisco, B. E., \& Lyubomirsky, S. (2008). Rethinking rumination. Perspectives on Psychological Science, 3(5), 400-424. https://doi.org/10.1111/j.1745-6924.2008.00088.x

Osofsky, J. D., \& O’Connell, E. J. (1972). Parent-child interaction: Daughters' effects upon mothers' and fathers' behaviors. Developmental Psychology, 7(2), 157-168. https://doi.org/10.1037/h0033016

Patrick, B. C., Stockbridge, S., Roosa, H. V., \& Edelson, J. S. (2019). Self-silencing in school: Failures in student autonomy and teacher-student relatedness. Social Psychology of Education, 22(4), 943-967. https://doi.org/10.1007/s11218-01909511-8

Patterson, G. R. (1982). Coercive family process. Castalia Press. 


\section{PARENTING AND ACADEMIC COPING}

Power, T. G. (2004). Stress and coping in childhood: The parents' role. Parenting, 4(4), 271-317. https://doi.org/10.1207/s15327922par0404_1

Putwain, D. W., Connors, L., Symes, W., \& Douglas-Osborn, E. (2012). Is academic buoyancy anything more than adaptive coping? Anxiety, Stress, \& Coping, 25(3), 349-358. https://doi.org/10.1080/10615806.2011.582459

Putwain, D. W., Daly, A. L., Chamberlain, S., \& Sadreddini, S. (2016). "Sink or swim": Buoyancy and coping in the cognitive test anxiety—Academic performance relationship. Educational Psychology, 36(10), 1807-1825. https://doi.org/10.1080/01443410.2015.1066493

Raftery, J. N., Grolnick, W. S., \& Flamm, E. S. (2012). Families as facilitators of student engagement: Toward a home-school partnership model. In S. L. Christenson, A. L. Reschly, \& C. Wylie (Eds.), Handbook of research on student engagement (pp. 343-364). Springer Science + Business Media. https://doi.org/10.1007/978-14614-2018-7_16

Raftery-Helmer, J. N., \& Grolnick, W. S. (2016). Children's coping with academic failure: Relations with contextual and motivational resources supporting competence. The Journal of Early Adolescence, 36(8), 1017-1041. https://doi.org/10.1177/0272431615594459

Raftery-Helmer, J. N., \& Grolnick, W. S. (2018). Parent and teacher effects on academic coping and classroom engagement: Testing a motivational model. Motivation and Emotion, 42(5), 638-652. https://doi.org/10.1007/s11031-018-9676-4 


\section{PARENTING AND ACADEMIC COPING}

Reschly, A. L., Huebner, E. S., Appleton, J. J., \& Antaramian, S. (2008). Engagement as flourishing: The contribution of positive emotions and coping to adolescents' engagement at school and with learning. Psychology in the Schools, 45(5), 419 431. https://doi.org/10.1002/pits.20306

Rijavec, M., \& Brdar, I. (1997). Coping with school failure: Development of the school failure coping scale. European Journal of Psychology of Education, 12(1), 37-49. https://doi.org/10.1007/BF03172868

Ryan, R. M., \& Connell, J. P. (1989). Perceived locus of causality and internalization: Examining reasons for acting in two domains. Journal of Personality and Social Psychology, 57(5), 749-761. https://doi.org/10.1037/0022-3514.57.5.749

Ryan, R. M., \& Deci, E. L. (2017). Self-determination theory: Basic psychological needs in motivation, development, and wellness. The Guilford Press. https://doi.org/10.1521/978.14625/28806

Sameroff, A. (2010). A unified theory of development: A dialectic integration of nature and nurture. Child Development, 81(1), 6-22. https://doi.org/10.1111/j.14678624.2009.01378.x

Seiffge-Krenke, I. (1995). Stress, coping, and relationships in adolescence. Lawrence Erlbaum Associates, Inc.

Shih, S.-S. (2015a). An examination of academic coping among Taiwanese adolescents. The Journal of Educational Research, 108(3), 175-185. https://doi.org/10.1080/00220671.2013.867473 


\section{PARENTING AND ACADEMIC COPING}

Shih, S.-S. (2015b). The relationships among Taiwanese adolescents' perceived classroom environment, academic coping, and burnout. School Psychology Quarterly, 30(2), 307-320. https://doi.org/10.1037/spq0000093

Simmons, R. G., \& Blyth, D. A. (1987). Moving into adolescence: The impact of pubertal change and school context. Aldine de Gruyter.

Skinner, E. A. (1995). Perceived control, motivation, \& coping. Sage Publications.

Skinner, E. A., \& Edge, K. (2002). Parenting, motivation, and the development of children's coping. In L. J. Crockett (Ed.), Agency, motivation, and the life course (pp. 77-143). University of Nebraska Press.

Skinner, E. A., Edge, K., Altman, J., \& Sherwood, H. (2003). Searching for the structure of coping: A review and critique of category systems for classifying ways of coping. Psychological Bulletin, 129(2), 216-269. https://doi.org/10.1037/00332909.129.2.216

Skinner, E. A., Johnson, S., \& Snyder, T. (2005). Six dimensions of parenting: A motivational model. Parenting: Science and Practice, 5(2), 175-235. https://doi.org/10.1207/s15327922par0502_3

Skinner, E. A., Kindermann, T., \& Mashburn, A. (2019). Lifespan developmental systems: Meta-theory, methodology and the study of applied problems. Routledge.

Skinner, E. A., \& Pitzer, J. R. (2012). Developmental dynamics of student engagement, coping, and everyday resilience. In S. L. Christenson, A. L. Reschly, \& C. Wylie 


\section{PARENTING AND ACADEMIC COPING}

(Eds.), Handbook of Research on Student Engagement (pp. 21-44). Springer US. https://doi.org/10.1007/978-1-4614-2018-7_2

Skinner, E. A., Pitzer, J. R., \& Steele, J. S. (2016). Can student engagement serve as a motivational resource for academic coping, persistence, and learning during late elementary and early middle school? Developmental Psychology, 52(12), 20992117. https://doi.org/10.1037/dev0000232

Skinner, E. A., Pitzer, J., \& Steele, J. (2013). Coping as part of motivational resilience in school: A multidimensional measure of families, allocations, and profiles of academic coping. Educational and Psychological Measurement, 73(5), 803-835. https://doi.org/10.1177/0013164413485241

Skinner, E. A., \& Saxton, E. A. (2019). The development of academic coping in children and youth: A comprehensive review and critique. Developmental Review, 53. https://doi.org/10.1016/j.dr.2019.100870

Skinner, E. A., \& Saxton, E. A. (2020). The development of academic coping across late elementary and early middle school: Do patterns differ for students with differing motivational resources? International Journal of Behavioral Development, 44(4), 339-353. https://doi.org/10.1177/0165025419896423

Skinner, E. A., \& Wellborn, J. G. (1994). Coping during childhood and adolescence: A motivational perspective. In D. L. Featherman, R. M. Lerner, \& M. Perlmutter (Eds.), Life-span development and behavior, Vol. 12 (pp. 91-133). Lawrence Erlbaum Associates, Inc. 


\section{PARENTING AND ACADEMIC COPING}

Skinner, E. A., \& Wellborn, J. G. (1997). Children's coping in the academic domain. In S. A. Wolchik \& I. N. Sandler (Eds.), Handbook of children's coping: Linking theory and intervention (pp. 387-422). Plenum Press. https://doi.org/10.1007/9781-4757-2677-0_14

Skinner, E. A., \& Zimmer-Gembeck, M. J. (2016). The development of coping: Stress, neurophysiology, social relationships, and resilience during childhood and adolescence. Springer International Publishing AG. https://doi.org/10.1007/978-3$319-41740-0$

Skinner, E. A., Zimmer-Gembeck, M. J., \& Connell, J. P. (1998). Individual differences and the development of perceived control. Monographs of the Society for Research in Child Development, 63(2-3). https://doi.org/10.2307/1166220

Sobel, M. E. (1982). Asymptotic confidence intervals for indirect effects in structural equation models. Sociological Methodology, 13, 290-312.

Soenens, B., Luyckx, K., Vansteenkiste, M., Luyten, P., Duriez, B., \& Goossens, L. (2008). Maladaptive perfectionism as an intervening variable between psychological control and adolescent depressive symptoms: A three-wave longitudinal study. Journal of Family Psychology, 22(3), 465-474. https://doi.org/10.1037/0893-3200.22.3.465

Suldo, S. M., Dedrick, R. F., Shaunessy-Dedrick, E., Fefer, S. A., \& Ferron, J. (2015). Development and initial validation of the Coping with Academic Demands Scale: How students in accelerated high school curricula cope with school-related 


\section{PARENTING AND ACADEMIC COPING}

stressors. Journal of Psychoeducational Assessment, 33(4), 357-374.

https://doi.org/10.1177/0734282914552165

Suldo, S. M., Shaunessy-Dedrick, E., Ferron, J., \& Dedrick, R. F. (2018). Predictors of success among high school students in advanced placement and International Baccalaureate programs. Gifted Child Quarterly, 62(4), 350-373. https://doi.org/10.1177/0016986218758443

Tero, P. F., \& Connell, J. P. (1984, April). When children think they've failed: An academic coping inventory. [Paper]. American Educational Research Association, New Orleans, LA.

Tofighi, D., \& MacKinnon, D. P. (2011). RMediation: An R package for mediation analysis confidence intervals. Behavior Research Methods, 43(3), 692-700. https://doi.org/10.3758/s13428-011-0076-x

Trent, M., Dooley, D. G., Dougé, J., Health, S. on A., Pediatrics, C. on C., \& Adolescence, C. O. (2019). The impact of racism on child and adolescent health. Pediatrics, 144(2). https://doi.org/10.1542/peds.2019-1765

Urdan, T., \& Kaplan, A. (2020). The origins, evolution, and future directions of achievement goal theory. Contemporary Educational Psychology, 61, 101862. https://doi.org/10.1016/j.cedpsych.2020.101862

Vansteenkiste, M., Soenens, B., Van Petegem, S., \& Duriez, B. (2014). Longitudinal associations between adolescent perceived degree and style of parental prohibition and internalization and defiance. Developmental Psychology, 50(1), 229-236. https://doi.org/10.1037/a0032972 


\section{PARENTING AND ACADEMIC COPING}

Vasquez, A. C., Patall, E. A., Fong, C. J., Corrigan, A. S., \& Pine, L. (2016). Parent autonomy support, academic achievement, and psychosocial functioning: A metaanalysis of research. Educational Psychology Review, 28(3), 605-644. https://doi.org/10.1007/s10648-015-9329-z

Vierhaus, M., Lohaus, A., \& Wild, E. (2016). The development of achievement emotions and coping/emotion regulation from primary to secondary school. Learning and Instruction, 42, 12-21. https://doi.org/10.1016/j.learninstruc.2015.11.002

Vitaliano, P. P., Maiuro, R. D., Russo, J., \& Becker, J. (1987). Raw versus relative scores in the assessment of coping strategies. Journal of Behavioral Medicine, 10(1), 118. https://doi.org/10.1007/BF00845124

White, R. W. (1959). Motivation reconsidered: The concept of competence. Psychological Review, 66(5), 297-333. https://doi.org/10.1037/h0040934

Wigfield, A., Eccles, J. S., Fredricks, J. A., Simpkins, S., Roeser, R. W., \& Schiefele, U. (2015). Development of achievement motivation and engagement. In M. E. Lamb \& R. M. Lerner (Eds.), Handbook of child psychology and developmental science: Socioemotional processes (Vol. 3, 7th ed.) (pp. 657-700). John Wiley \& Sons Inc. https://doi.org/10.1002/9781118963418.childpsy316

Wolchik, S. A., \& Sandler, I. N. (Eds.). (1997). Handbook of children's coping: Linking theory and intervention. Plenum Press. https://doi.org/10.1007/978-1-4757-26770 


\section{PARENTING AND ACADEMIC COPING}

Xu, J., Du, J., Wu, S., Ripple, H., \& Cosgriff, A. (2018). Reciprocal effects among parental homework support, effort, and achievement? An empirical investigation. Frontiers in Psychology, 9. https://doi.org/10.3389/fpsyg.2018.02334

Yosso, T. J. (2006). Whose culture has capital? A critical race theory discussion of community cultural wealth. In Critical Race Theory in Education. Routledge.

Zimmer-Gembeck, M. J., \& Locke, E. M. (2007). The socialization of adolescent coping behaviours: Relationships with families and teachers. Journal of Adolescence, 30(1), 1-16. https://doi.org/10.1016/j.adolescence.2005.03.001

Zimmer-Gembeck, M. J., \& Skinner, E. A. (2011). Review: The development of coping across childhood and adolescence: An integrative review and critique of research. International Journal of Behavioral Development, 35(1), 1-17. https://doi.org/10.1177/0165025410384923

Zimmer-Gembeck, M. J., Webb, H. J., Pepping, C. A., Swan, K., Merlo, O., Skinner, E. A., Avdagic, E., \& Dunbar, M. (2017). Review: Is parent-child attachment a correlate of children's emotion regulation and coping? International Journal of Behavioral Development, 41(1), 74-93. https://doi.org/10.1177/0165025415618276 
Appendix: Measures

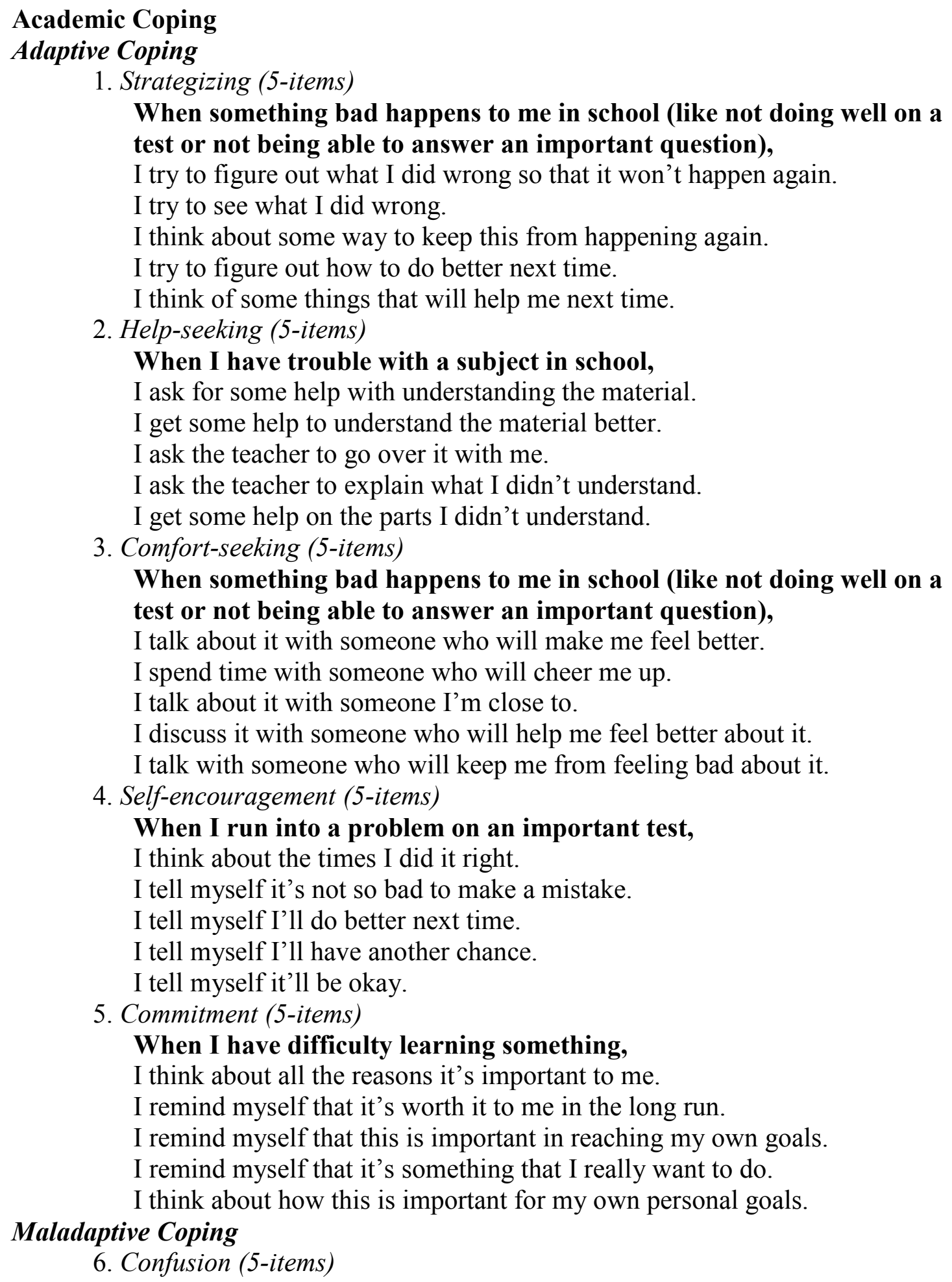

When something bad happens to me in school (like not doing well on a test or not being able to answer an important question),

I try to figure out what I did wrong so that it won't happen again.

I try to see what I did wrong.

I think about some way to keep this from happening again.

I try to figure out how to do better next time.

I think of some things that will help me next time.

2. Help-seeking (5-items)

When I have trouble with a subject in school,

I ask for some help with understanding the material.

I get some help to understand the material better.

I ask the teacher to go over it with me.

I ask the teacher to explain what I didn't understand.

I get some help on the parts I didn't understand.

3. Comfort-seeking (5-items)

When something bad happens to me in school (like not doing well on a test or not being able to answer an important question),

I talk about it with someone who will make me feel better.

I spend time with someone who will cheer me up.

I talk about it with someone I'm close to.

I discuss it with someone who will help me feel better about it.

I talk with someone who will keep me from feeling bad about it.

4. Self-encouragement (5-items)

When I run into a problem on an important test,

I think about the times I did it right.

I tell myself it's not so bad to make a mistake.

I tell myself I'll do better next time.

I tell myself I'll have another chance.

I tell myself it'll be okay.

5. Commitment (5-items)

When I have difficulty learning something,

I think about all the reasons it's important to me.

I remind myself that it's worth it to me in the long run.

I remind myself that this is important in reaching my own goals.

I remind myself that it's something that I really want to do.

I think about how this is important for my own personal goals.

Maladaptive Coping

6. Confusion (5-items) 


\section{PARENTING AND ACADEMIC COPING}

When I run into a problem on an important test,

I'm not sure what to do next.

I can't remember what to do.

My mind goes blank.

I get all confused.

It's difficult for me to think.

7. Escape (5-items)

When something bad happens to me in school (like not doing well on a test or not being able to answer an important question),

I quit thinking about it.

I tell myself it's not such a big deal.

I tell myself it didn't matter.

I say it wasn't important.

I say I didn't care about it.

8. Concealment (5-items)

When something bad happens to me in school (like not doing well on a test or not being able to answer an important question),

I try to keep people from finding out.

I make sure nobody finds out.

I try to hide it.

I don't tell anyone about it.

I don't let anybody know about it.

9. Self-pity (5-items)

When something bad happens to me in school (like not doing well on a test or not being able to answer an important question),

I think about all the times this happens to me.

I say "This always happens to me."

I ask myself "Why is this always happening to me?"

I say "Here we go again.",

I can't believe this is always happening to me.

10. Rumination (5-items)

When something bad happens to me in school (like not doing well on a test or not being able to answer an important question),

I just can't stop thinking about it.

I keep thinking about it over and over.

I think about it all the time.

I'm always thinking about it afterwards.

I can't get it out of my head.

11. Projection (5-items)

When I run into a problem on an important test, I say it was the teacher's fault.

I say the teacher didn't tell us the right thing to study.

I say the teacher isn't fair. 


\section{PARENTING AND ACADEMIC COPING}

I say the test was too hard.

I say the test was not fair.

\section{Involvement (5-items)}

My parents know a lot about what is important to me in school.

My parents talk with me about schoolwork.

My parents enjoy hearing about my day.

My parents think that what I have to say about school is important.

My parents don't seem to have enough time for me. (-)

\section{Structure (6-items)}

A lot of times I don't know what my parents want me to do. (-)

When my parents punish me, they don't explain why. (-)

I can count on my parents when I have problems in school.

When things go wrong in school, I can depend on my parents.

I can't always depend on my parents when things get hard in school. (-)

I can't count on my parents for help with my schoolwork. (-)

\section{Autonomy Support (4-items)}

When my parents find out I did something at school they don't like, they listen to me before they decide what they are going to do.

My parents listen to me when I have something to say about school.

When it comes to school, my parents try to control everything I do. (-)

When decisions are made about my schoolwork, my parents usually don't ask me what I think. (-)

\section{Relatedness (20-items)}

Emotional Security with Mother, Father, Teacher, Classmates, Friends

When I'm with my , I feel accepted.

When I'm with my ___ I feel like someone special.

When I'm with my __ I I feel ignored. (-)

When I'm with my ___ I feel unimportant. (-)

\section{Competence (6-items)}

If I decide to learn something hard, I can.

I can do well in school if I want to.

I can get good grades in school.

I can't get good grades no matter what I do. (-)

I can't stop myself from doing poorly in school. (-)

I can't do well in school, even if I want to. (-)

\section{Autonomy (17-items)}

External Regulation 


\section{PARENTING AND ACADEMIC COPING}

Why do I do my homework? Because I'll get in trouble if I don't.

Why do I work on my classwork? So that the teacher won't yell at me.

Why do I work on my classwork? Because that's the rule.

Why do I work on my classwork? Because the teacher says we have to.

\section{Introjected Regulation}

Why do I do my homework? Because I'll feel bad about myself if I don't do it.

Why do I work on my classwork? Because I'll be ashamed of myself if it doesn't get done.

Why do I try to do well in school? Because I'll feel really bad about myself if I don't do well.

Why do I try to do well in school? Because I feel guilty when I don't do as well as I should.

\section{Identified Regulation}

Why do I do my homework? Because I want to understand the subject.

Why do I do my classwork? Because I want to learn new things.

Why do I work on my classwork? Because I think classwork is important for my learning.

Why do I try to do well in school? Because I enjoy doing schoolwork well.

Why do I try to do well in school? Because doing well in school is important to me.

\section{Intrinsic Regulation}

Why do I do my homework? Because it's fun.

Why do I do my homework? Because I enjoy doing my homework.

Why do I work on my classwork? Because it's fun.

Why do I work on my classwork? Because I enjoy doing my classwork.

\section{Catastrophizing of Relatedness (9-items)}

When something bad happens to me in school (like not doing well on a test or not being able to answer an important question in class),

I feel like nobody will have anything to do with me.

I feel like nobody will like me.

I feel like nobody will care about me.

I feel like no one will like me as much.

I feel like I let everybody down.

I feel like I disappointed everybody.

I feel like I didn't come through for people.

I feel like I failed everybody.

I feel worthless.

\section{Catastrophizing of Competence (9-items)}

When something bad happens to me in school (like not doing well on a test or not being able to answer an important question in class),

I worry that I will miss other problems too. 


\section{PARENTING AND ACADEMIC COPING}

I worry about what will happen next time.

I worry that I won't do well on anything.

I worry that I'll never learn how to do it.

I feel totally stupid.

I feel like the dumbest person in the world.

I feel like an idiot.

I feel totally incompetent.

I feel really dumb.

\section{Catastrophizing of Autonomy (9-items)}

When I have trouble with a subject in school,

It's never the same for me again.

I'm never as interested in that subject.

I don't care as much about the subject anymore.

It really spoils the subject for me.

When something bad happens to me in school (like not doing well on a test or not being able to answer an important question),

I feel like I should never have let this happen.

I feel like it's all my fault.

I feel like I'm a bad person.

I feel like I'm to blame.

I feel like yelling at myself. 